\title{
SHIPBOARD SCIENTISTS' HANDBOOK
}

\author{
OCEAN DRILLING PROGRAM
}

TEXAS A\&M UNIVERSITY

TECHNICAL NOTE 3 (REVISED)

MARCH 1990

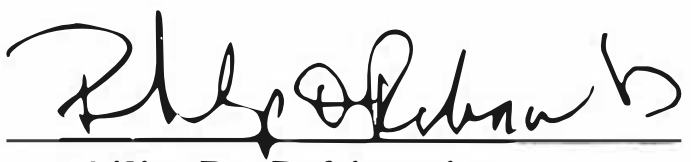

Philip D. Rabinowitz

Director
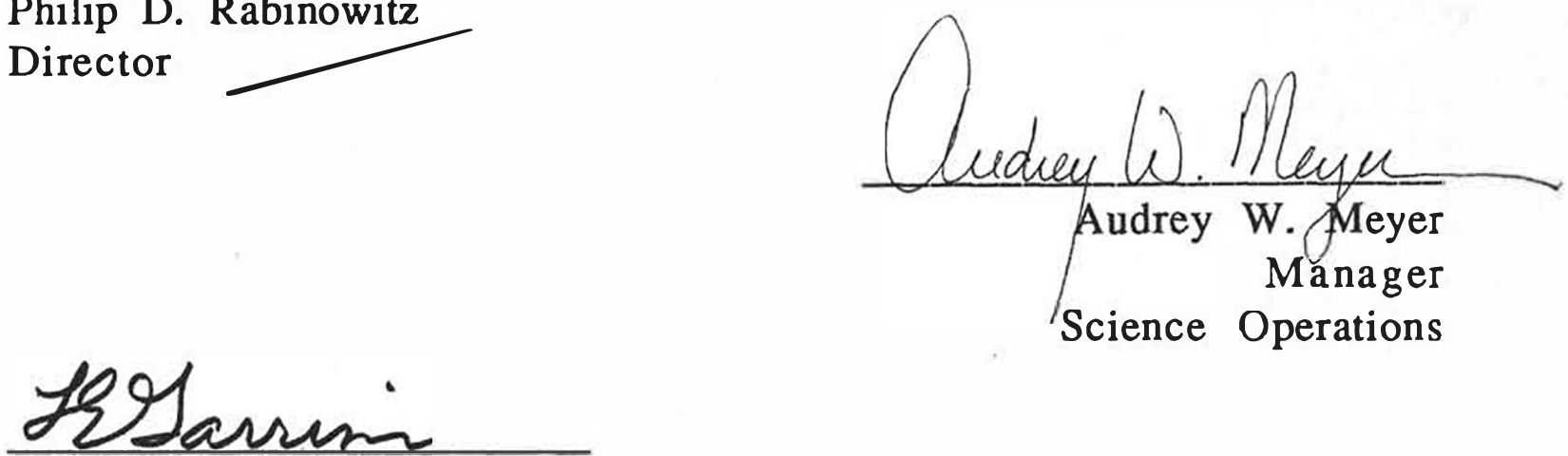

Louis E. Garrison

Deputy Director 
Material in this publication may be copied without restraint for library, abstract service, educational or personal research purposed; however, republication of any portion requires the written consent of the Director, Ocean Drilling Program, Texas A\&M University Research Park, 1000 Discovery Drive, College Station, Texas, 77845-9547, as well as appropriate acknowledgement of this source.

Technical Note 3

Third Printing 1990

Distribution

Copies of this publication may be obtained from the Director, Ocean Drilling Program, Texas A \& M University Research Park, 1000 Discovery Drive, College Station, Texas 77845-9547. In some cases, orders for copies may require a payment for postage and handling.

\section{DISCLAIMER}

This publication was prepared by the Ocean Drilling Program, Texas A \& M University, as an account of work performed under the international Ocean Drilling Program, which is managed by Joint Oceanographic Institutions, Inc., under contract with the National Science Foundation. Funding for the program is provided by the following agencies:

Canada/Australian Consortium for the Ocean Drilling Program

Deutsche Forschungsgemeinschaft (Federal Republic of Germany)

Institut Francais de Recherche pour l'Exploitation de la Mer (France)

Ocean Research Institute of the University of Tokyo (Japan)

National Science Foundation (United States)

Natural Environment Research Council (United Kingdom)

European Science Foundation Consortium for the Ocean Drilling Program (Belgium, Denmark, Finland, Iceland, Italy, Greece, the Netherlands, Norway, Spain, Sweden, Switzerland, and Turkey)

Any opinions, findings, and conclusions or recommendations expressed in this publication are those of the author(s) and do not necessarily reflect the views of the National Science Foundation, the participating agencies, Joint Oceanographic Institutions, Inc., Texas A \& M University, or Texas A \& M Research Foundation. 


\section{SHIPBOARD SCIENTISTS' HANDBOOK}

\section{TABLE OF CONTENTS}

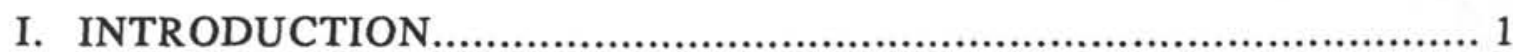

II. OCEAN DRILLING PROGRAM ORGANIZATION..................................... 2

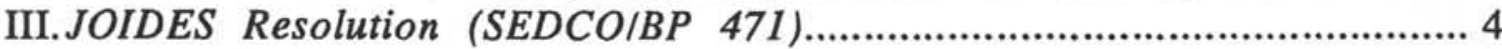

A. Description of the Vessel................................................................. 4

B. Dynamic Positioning....................................................................... 5

C. Office and Laboratory Facilities........................................................ 5

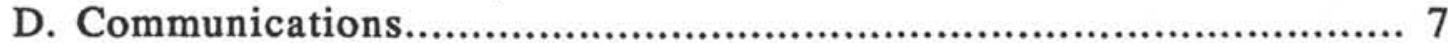

1. Introduction......................................................................... 7

2. Ship-to-Shore Communications.................................................... 7

3. Shore-to-Ship Communications..................................................... 9

4. Personal Communications........................................................ 9

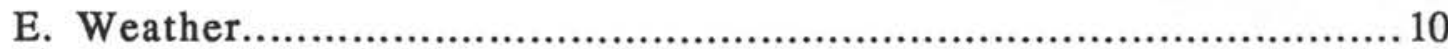

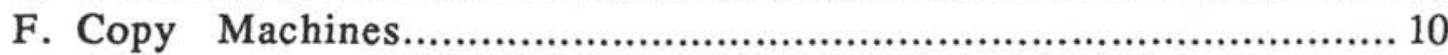

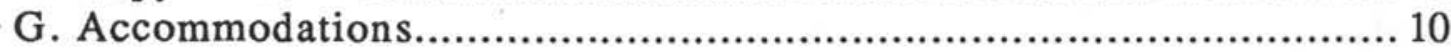

1. Quarters and Laundry Facilities.................................................... 11

2. Meal Facilities and Hours......................................................... 11

3. Gymnasium..........................................................................11

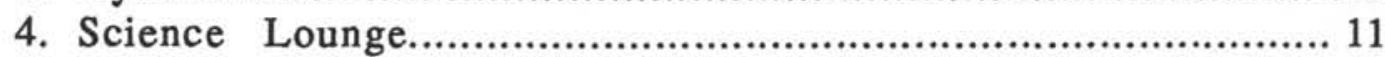

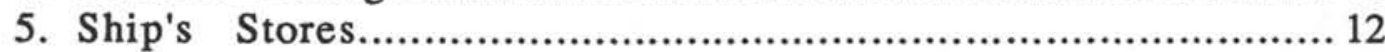

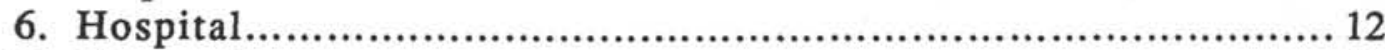

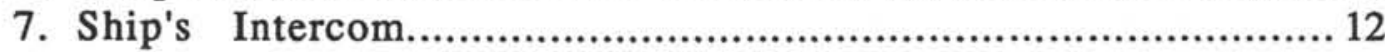

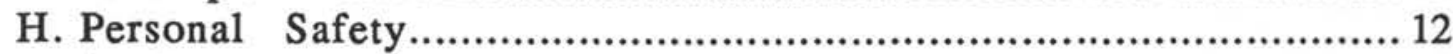

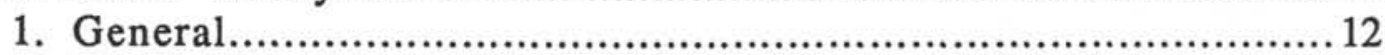

2. Emergencies and Weekly Drills.................................................. 13

3. Compassionate Emergencies.................................................... 15

IV.SHIPBOARD PERSONNEL AND RESPONSIBILITIES............................ 15

A. ODP Engineering and Drilling Operations Personnel.................................. 15

1. Operations Superintendent........................................................ 15

2. Special Tools Engineer................................................................ 17

B. ODP Technical Personnel..............................................................17

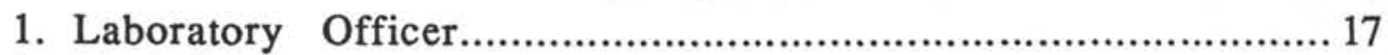

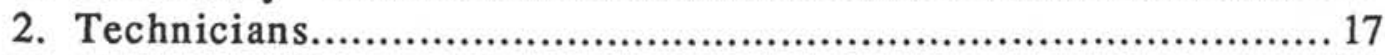

3. Computer System Manager.......................................................17

4. Curatorial Representative.......................................................... 18

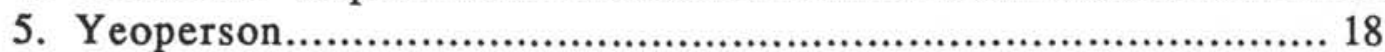

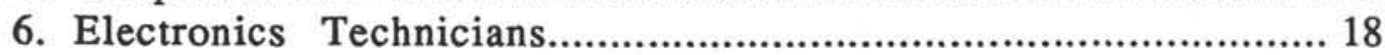

C. Shipboard Science Party............................................................... 18

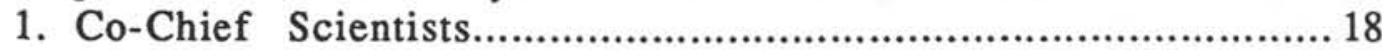

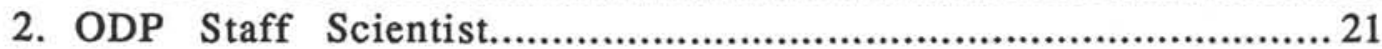

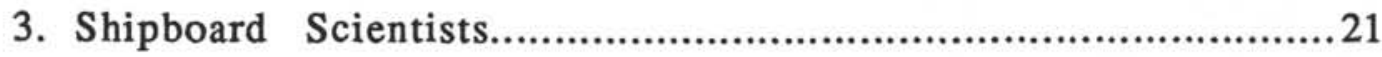




\section{TABLE OF CONTENTS - CONTINUED}

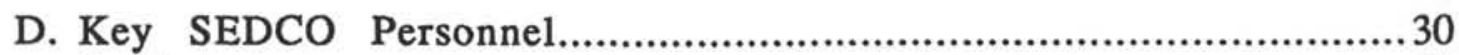

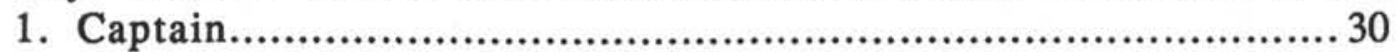

2. Drilling Superintendent............................................................30

3. Electrical Supervisor.................................................................30

V. DRILLING/CORING EQUIPMENT AND PROCEDURES........................... 30

A. General Procedures................................................................. 30

B. Drilling Depth Measurements............................................................. 32

C. Logging Depth Measurements........................................................ 34

D. Coring and Drilling Equipment and Usage..............................................34

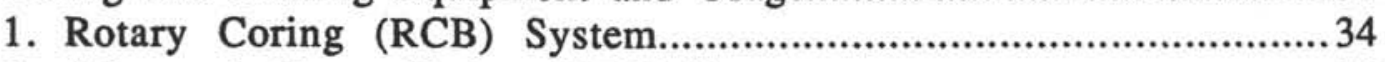

2. Advanced Piston Coring (APC) System............................................ 36

3. Extended Core Barrel (XCB) .........................................................37

4. Motor-Driven Core Barrel (MDCB) ................................................. 37

5. Diamond Coring System (DCS) ................................................... 38

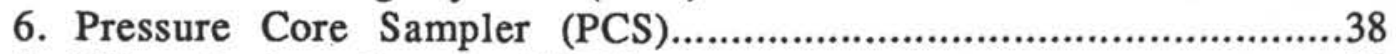

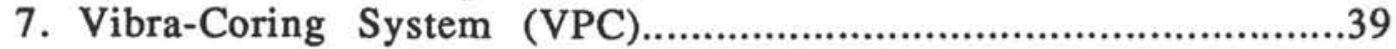

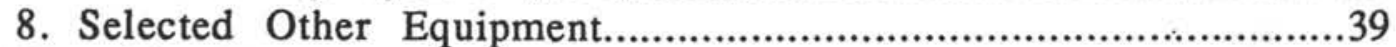

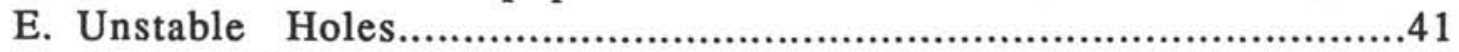

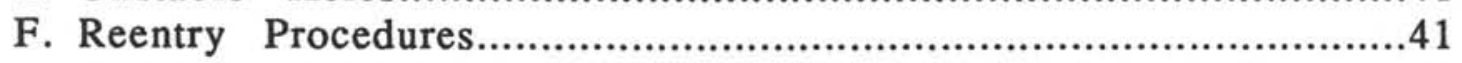

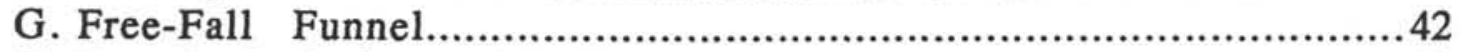

H. Bare-Rock Coring and Drilling Systems...............................................42

1. Hard-Rock Guide Base and Deployment System.................................44

2. Positive-Displacement Drilling and Coring Motors.................................44

3. Television System..................................................................46

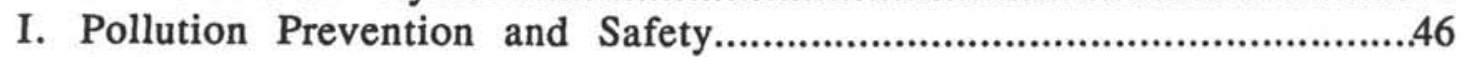

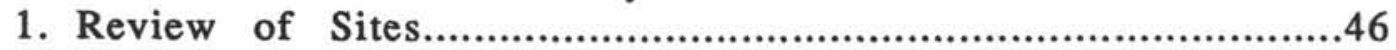

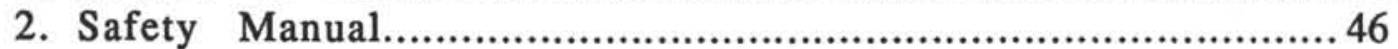

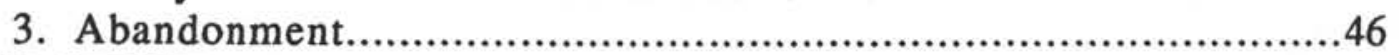

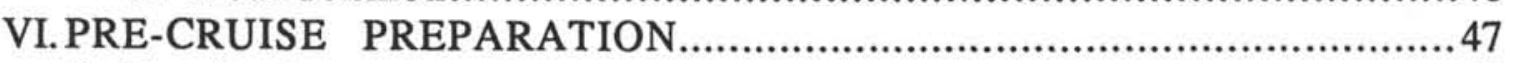

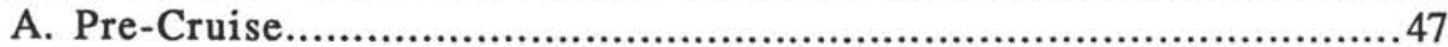

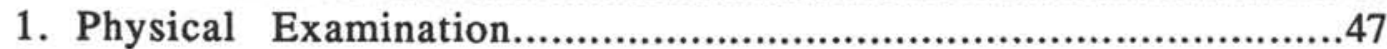

2. Travel Arrangements..................................................................47

3. Personal Clothing and Equipment..................................................47

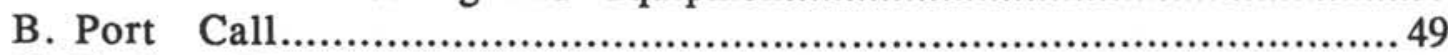

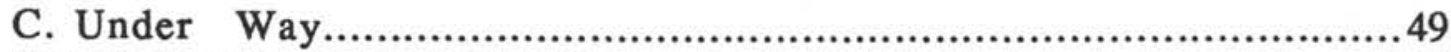

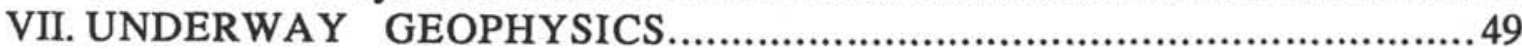

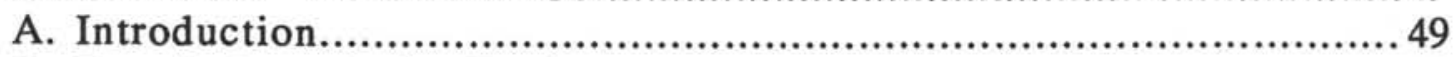

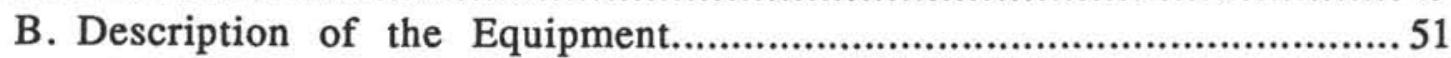

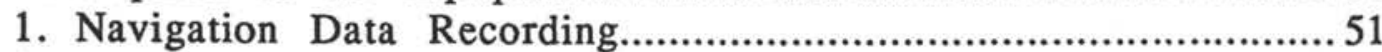

2. Bathymetric Data Recording........................................................

3. Magnetics Data Recording.........................................................52

4. Single-Channel Seismic System....................................................... 52 


\section{TABLE OF CONTENTS - CONTINUED}

C. Underway Geophysics Procedures.................................................... 53

1. Data Collection Policy................................................................53

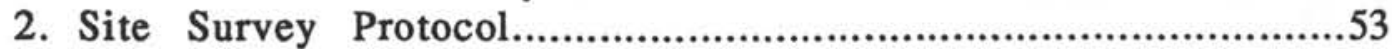

3. Seismic Line Acquisition and Processing..........................................54

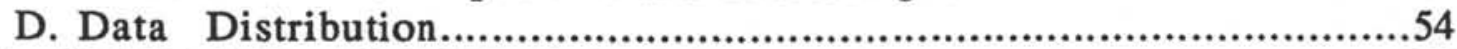

VIII. SHIPBOARD SCIENTIFIC PROCEDURES........................................... 55

A. Numbering of Sites, Holes, Cores, and Samples...................................... 55

B. Conventions (and Exceptions).........................................................55

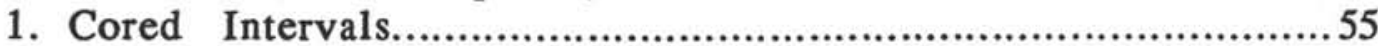

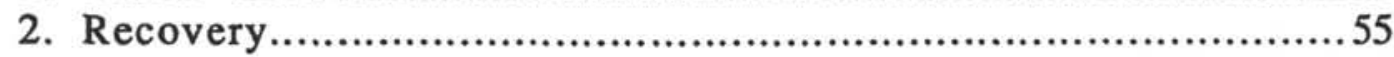

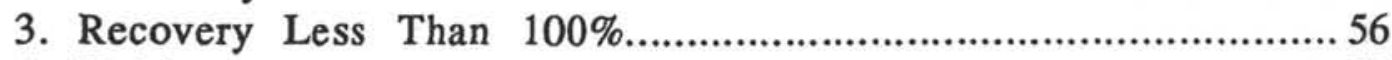

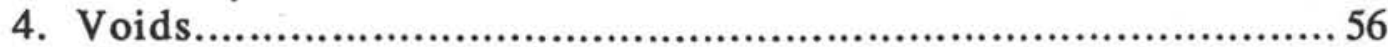

5. Special Cases - Core Handling....................................................58

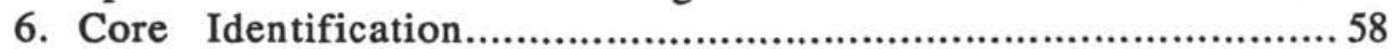

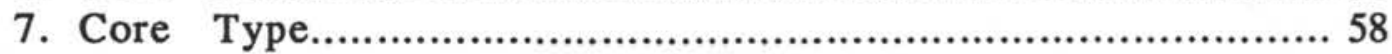

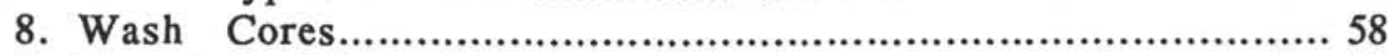

9. Downhole Water Samples......................................................... 58

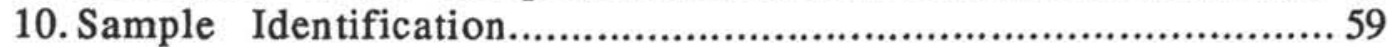

11. Sample Sub-bottom Depth.........................................................59

C. Core Laboratory Procedures - Sediments and Sedimentary Rocks.....................60

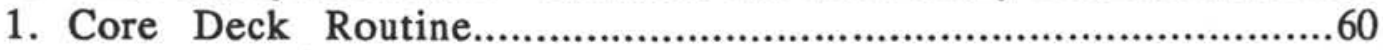

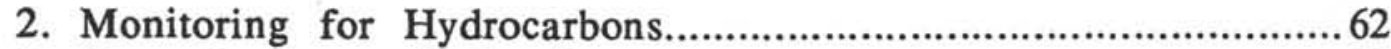

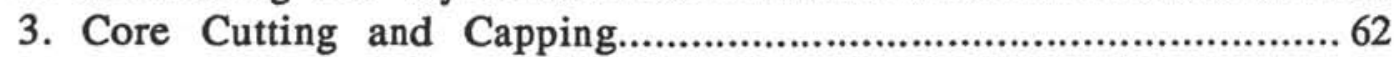

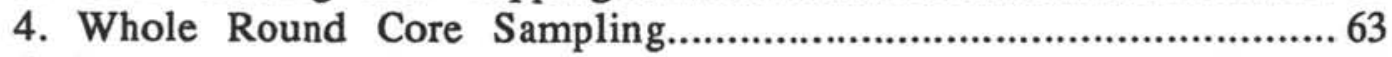

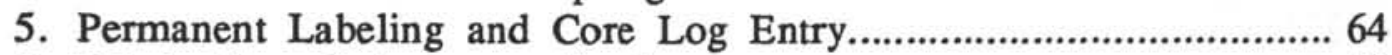

6. Whole-Core Laboratory Analyses................................................... 64

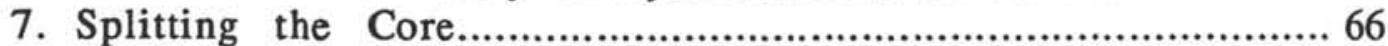

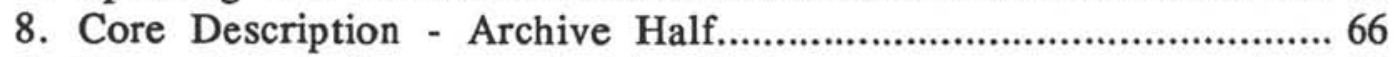

9. Magnetics Analyses on Archive Halves...........................................67

10. Core Sampling - Working Half.................................................... 67

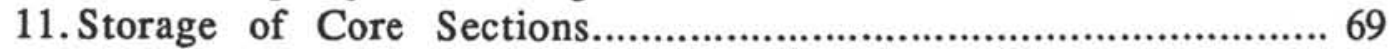

D. Core Laboratory Procedures - Igneous and Metamorphic Rocks.................... 69

1. First Arrival of a Core on Deck................................................... 69

2. Core Entry Lab Procedure ......................................................... 69

3. Placing of Spacers, Numbering, and Splitting..................................... 70

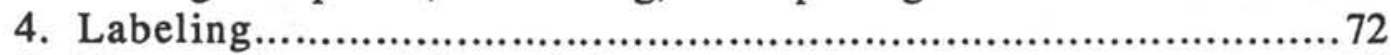

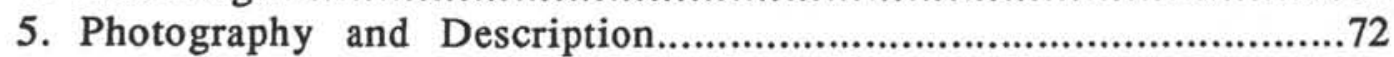

6. Preliminary Shipboard Sampling....................................................72

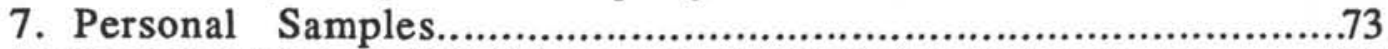

IX.SCIENTIFIC LABORATORY AND DATA COLLECTION FACILITIES..............74

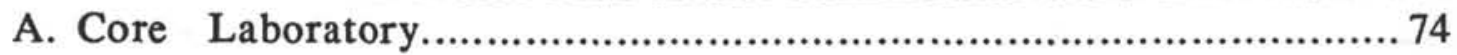




\section{TABLE OF CONTENTS - CONTINUED}

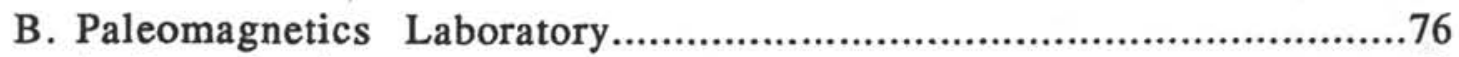

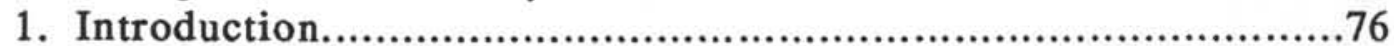

2. Paleomagnetics Sampling........................................................77

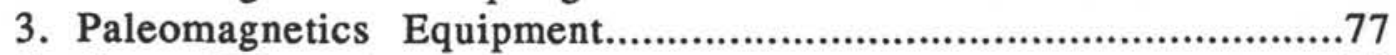

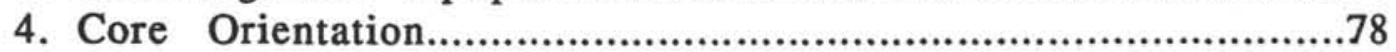

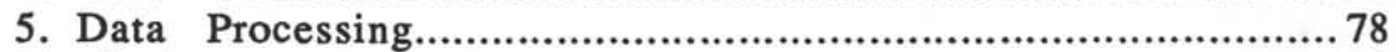

C. Physical Properties Laboratory......................................................... 78

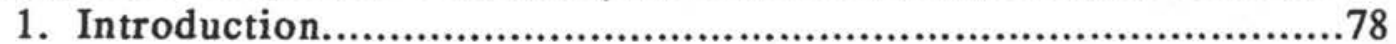

2. Sampling for Physical Properties................................................... 78

3. Whole Core Section Analyses...................................................... 79

4. Whole Round Samples for Consolidation/Triaxial Testing........................ 79

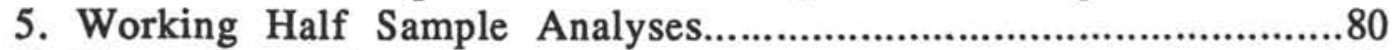

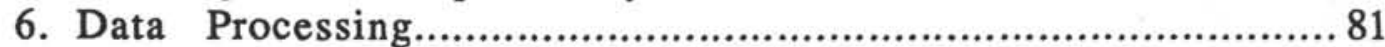

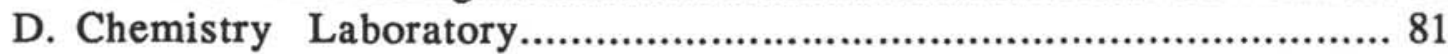

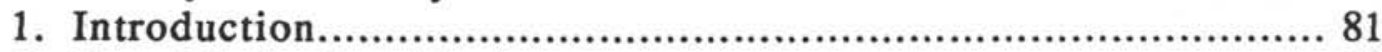

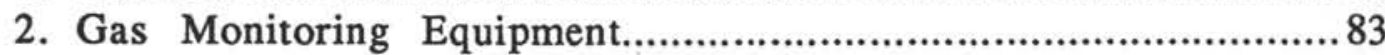

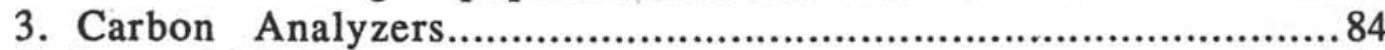

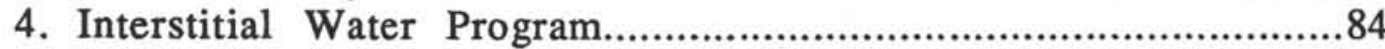

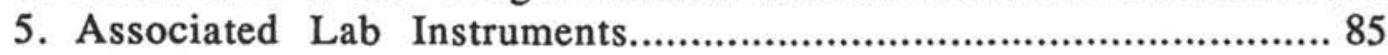

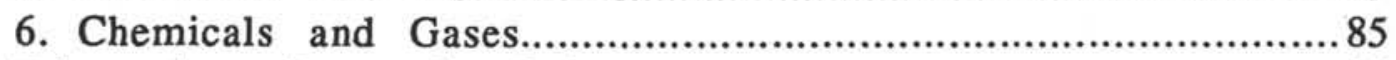

E. Paleontology Preparation Laboratory................................................... 85

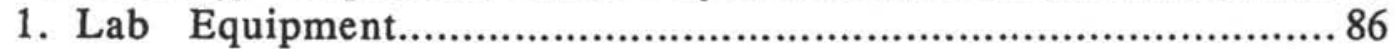

2. Chemicals, Mounting Media, Stains and Dyes........................................86

F. Microscope Laboratory.............................................................. 86

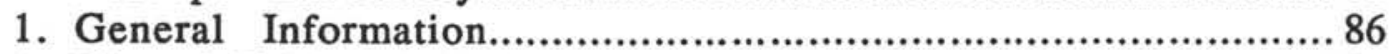

2. List of Shipboard Optical Equipment................................................. 87

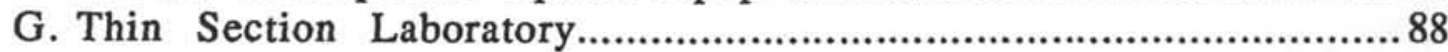

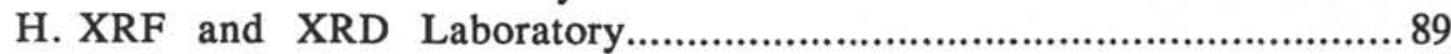

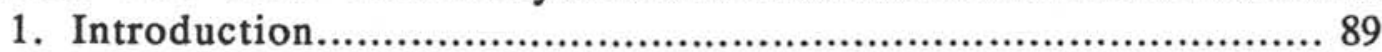

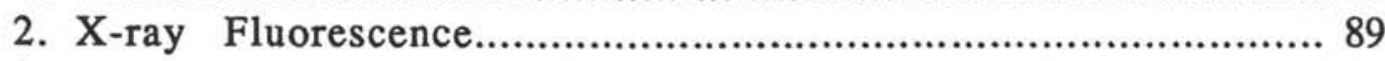

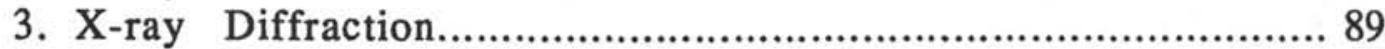

4. Sample Preparation Equipment and Supplies...................................... 89

I. Shipboard Computer System............................................................. 90

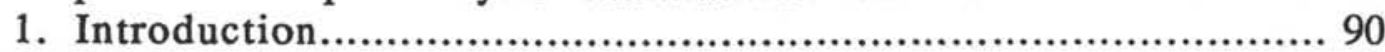

2. Shipboard System Description.................................................... 92

3. Shipboard Documentation........................................................ 94

4. Shipboard Computer System Policies and Procedures.............................94

5. Shipboard System Daily Routines.................................................... 94

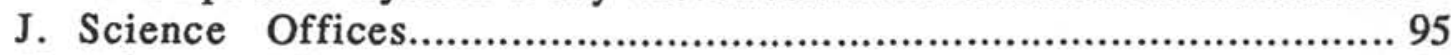

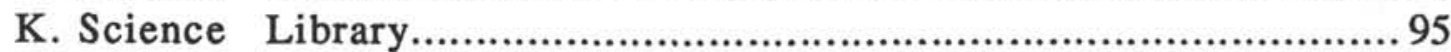

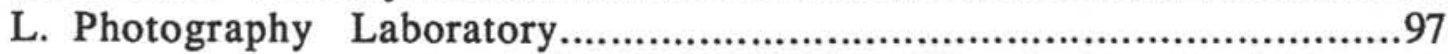

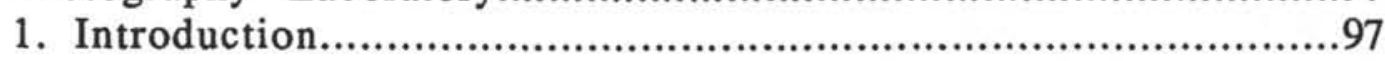


2. Labs and Equipment.............................................................97

3. Policies and Procedures..........................................................97

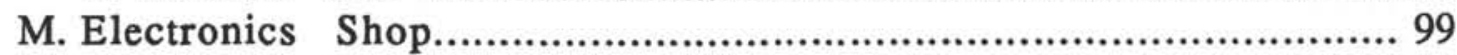

N. Second Look Lab...................................................................... 99

O. Downhole Measurements Laboratory.................................................... 101

1. LDGO Wireline Logging Program................................................... 101

2. ODP Downhole Tools............................................................... 105

X. SHIPBOARD SCIENTIFIC DATA AND REPORTS.................................... 107

A. Data Collection Aboard Ship......................................................... 108

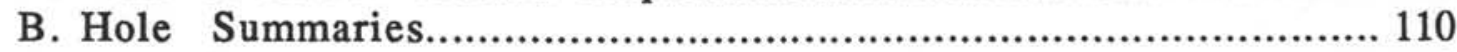

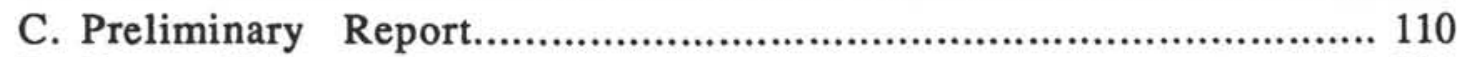

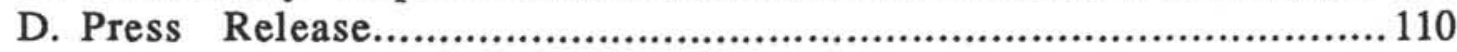

E. Geotimes and Nature Articles....................................................... 110

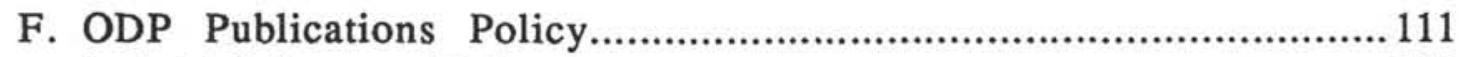

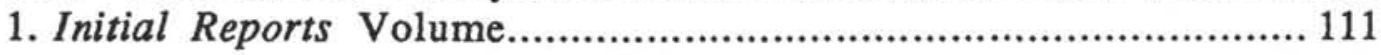

2. Scientific Results Volume............................................................. 111

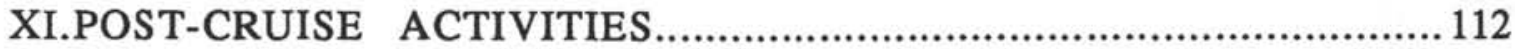

A. Post-Cruise Meetings............................................................ 112

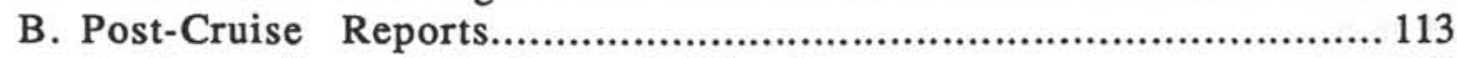

1. Proceedings of the Ocean Drilling Program.......................................113

2. General Geological Articles......................................................... 114

APPENDIX A. SAMPLE DISTRIBUTION POLICY .................................. 115

1. Distribution of Samples for Research Leading to

Contributions to ODP Reports...................................................... 115

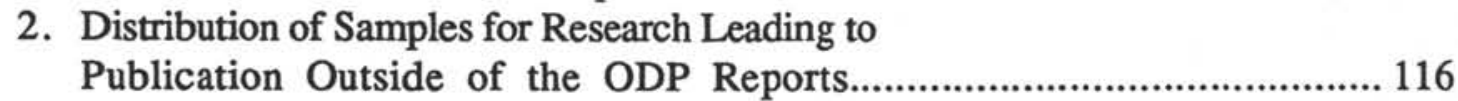

3. Distribution of Samples to Paleontological Reference Centers....................... 118

4. Distribution of Samples for Educational Purposes.................................... 120

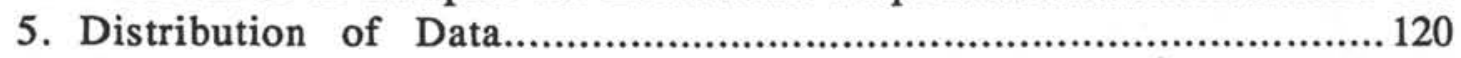

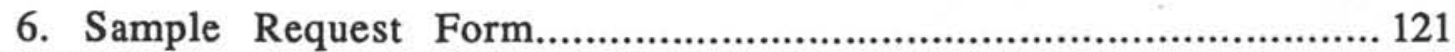

APPENDIX B. SEDIMENT/SEDIMENTARY ROCK CLASSIFICATION............125

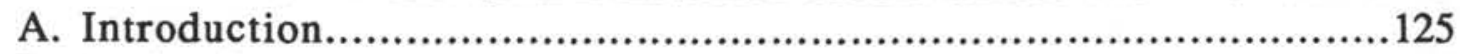

B. Basic Sediment Types..............................................................126

C. Classification of Granular Sediments.................................................126

D. Classification of Chemical Sediments............................................... 135

E. Examples of Granular-Sediment Classification..................................... 137

APPENDIX C. IGNEOUS/METAMORPHIC ROCK CLASSIFICATION........... 141

A. Introduction and Checklists......................................................... 141

B. Instructions for Thin Section Description Form..................................... 146

C. Lithologic Units - Basalts................................................................... 146

D. Terminology and Definitions......................................................... 148

APPENDIX D. STONE SOUP: COMMON ODP ABBREVIATIONS................... 154 


\section{LIST OF ILLUSTRATIONS}

1. SEDCO/BP 471 (JOIDES Resolution) ……............................................ 3

2. Diagram of JOIDES Resolution's laboratory and library decks............................ 6

3. ODP shipboard organization chart showing direct and working relationships among ODP and SEDCO personnel.............................................................16

4. Coring systems used in shipboard drilling operations......................................... 35

5. Dynamic positioning system and reentry--JOIDES Resolution ............................ 43

6. Hard-rock guidebase with reentry cone and casing.......................................... 45

7. Schematic layout of the underway geophysics laboratory...................................50

8. Diagram of procedures for numbering core sections.........................................57

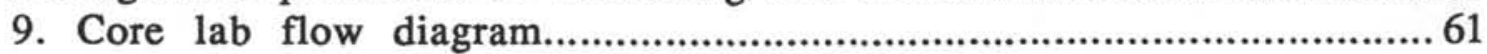

10. Numbering system for hard-rock pieces.......................................................71

11. Layout of core lab, paleomagnetics lab, and physical properties lab.................... 75

12. Layout of chemistry, XRF/XRD, thin section, SEM, and paleontology labs...........82

13. Layout of computer rooms, science lounge, and offices...................................91

14. Layout of shipboard science library........................................................... 96

15. Layout of photography laboratory and electronics shop....................................98

16. Layout of second look lab and refrigerated core storage areas............................100

17. Downhole measurements laboratory............................................................102

\section{APPENDIX FIGURES}

B-1. Diagram showing classes of granular sediment.........................................127

T-1. Outline of granular-sediment classification scheme...................................... 129

T-2. Udden-Wentworth grain-size scale for siliciclastic sediments..........................131

B-2. Ternary diagram showing principal names for siliciclastic sediments................. 132

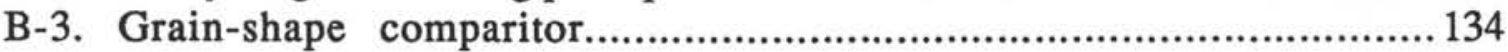

C-1. Example of completed Ig/Met VCD form..................................................142

C-2. Example of completed Ig/Met VCD form................................................ 144

C-3. Example of completed thin section description form................................... 147 


\section{INTRODUCTION}

This manual is the result of combined efforts over many years to develop a comprehensive look at the Ocean Drilling Program's shipboard scientific and operational procedures. Rather than being an overview or brief introduction to daily life aboard ship, it incorporates detailed descriptions of shipboard laboratories, core handling procedures, and drilling operations in non-technical language. The first two sections of this handbook set the international framework within which the Ocean Drilling Program functions. Chapter III contains a close look at shipboard facilities. Chapter IV describes the responsibilities of shipboard personnel, including shipboard scientists, technicians, and ship's crew. Chapter $\mathrm{V}$ offers an introduction to common drilling and coring techniques and equipment. Chapter VI takes a brief look at pre-cruise preparation for shipboard scientists. Chapters VII and VIII describe underway geophysics and general scientific procedures, organized chronologically from pre-site to post-site activities. Chapter VIII is further divided into conventions for sediments/sedimentary rocks and conventions for igneous and metamorphic rocks. Chapter IX details laboratory and data collection facilities. Chapter X discusses what data are collected and how they are reported. Chapter XI looks at postcruise meetings and publications.

Four appendixes complete the handbook. First is the ODP Sample Distribution Policy and sample request form for shipboard participants. The second contains the formal ODP sediment classification scheme. The third contains the igneous and metamorphic classification scheme. The fourth, "Stone Soup," contains abbreviations commonly used at ODP.

Other written materials available from ODP take a broader, less specific look at ODP (for example, public information brochures and Technical Note \#11: "Introduction to the Ocean Drilling Program) or a considerably more detailed approach (for example, a booklet on the shipboard computer system, and technical notes for sedimentologists and paleontologists). Further information may be obtained from the Manager of Science Operations, Ocean Drilling Program, Texas A\&M University Research Park, 1000 Discovery Drive, College Station, Texas 77845-9547 U.S.A.

The Ocean Drilling Program (ODP) is an international partnership of scientists and governments that have joined together to explore the structure and history of the earth beneath the ocean basins. The central purpose of ODP is to provide core samples and downhole measurements from beneath the oceans' floors, and facilities to study those samples. The United States, Federal Republic of Germany, France, Canada/ Australia Consortium for the Ocean Drilling Program, Japan, United Kingdom, and the European Science Foundation Consortium for the Ocean Drilling Program (composed of Belgium, Denmark, Finland, Iceland, Italy, Greece, the Netherlands, Norway, Spain, Sweden, Switzerland and Turkey) are working together to organize scientific study of the sediments and rocks that fill and underlie the ocean basins. The data generated will lead to a better understanding of the processes of plate tectonics, of the earth's crustal structure and composition, of conditions in ancient oceans, and of changes in climate through time, and in turn to a fuller comprehension of the evolution of our planet. 
A predecessor to ODP, the Deep Sea Drilling Project (DSDP), was established in 1966 at Scripps Institution of Oceanography to acquire deep sea cores on a routine basis for scientific study. Utilizing D/V Glomar Challenger, scientists were able to obtain more than 60 miles of core from over 1000 holes at 624 sites around the world. Techniques were developed for computer-controlled dynamic positioning, which stabilizes the ship over a borehole in mid-ocean, and for reentry systems that allow drill bits to be changed and then re-inserted into the drill hole.

As Science Operator for the Ocean Drilling Program, Texas A\&M University has leased the drill ship SEDCOIBP 471, also known as JOIDES Resolution (Fig. 1), to conduct the next phase of the ocean exploration begun aboard Glomar Challenger. JOIDES Resolution offers such capabilities as (1) a 30,000 ft ( $9150 \mathrm{~m}$ ) drill string, (2) a stable drilling platform, (3) large enclosed storage areas for drill pipe and casing, (4) a draw works with $31,000 \mathrm{ft}(9450 \mathrm{~m})$ of wireline, (5) berths for 51 scientific and technical personnel, (6) 12,000 sq ft (1080 sq m) of lab and office space, and (7) a strengthened hull for drilling in high-latitude waters. Based on advice from Joint Oceanographic Institutions, Inc. (JOI), Joint Oceanographic Institutions for Deep Earth Sampling (JOIDES) panel members, and other members of the scientific community, JOIDES Resolution's shipboard laboratories have been equipped with state-of-the-art scientific equipment (described in Section IX).

During each cruise, specific scientific objectives are pursued by the personnel on board. The complement of approximately 25 scientists works on routine core studies in addition to performing special sampling and analytical projects within their own fields. About 20 technicians and other ODP personnel provide technical support for shipboard data collection and operational procedures, and assist in upgrading and maintaining the shipboard labs and scientific equipment. The complement of logging personnel maintains and runs downhole tools under the direction of the LDGO Borehole Research Group. The ship's crew of 52 consists of those engaged in the drilling operations and those who run and service the ship.

\section{OCEAN DRILLING PROGRAM ORGANIZATION}

The National Science Foundation (NSF), a U.S. government agency, has chosen the Joint Oceanographic Institutions, Inc. (JOI) to act as manager of ODP. JOI is a consortium of ten major U.S. oceanographic institutions, which provides management support to scientific research programs of international stature. The ten institutions involved are the University of California at San Diego, Columbia University, University of Hawaii, University of Miami, Oregon State University, University of Rhode Island, Texas A\&M University, University of Texas at Austin, University of Washington, and Woods Hole Oceanographic Institution.

JOI is advised in the overall objectives of ODP by the Joint Oceanographic Institutions for Deep Earth Sampling (JOIDES), an international group of scientists, which provides planning and program advice regarding science goals and objectives, facilities, scientific personnel, and operating procedures. The primary governing arm of the 


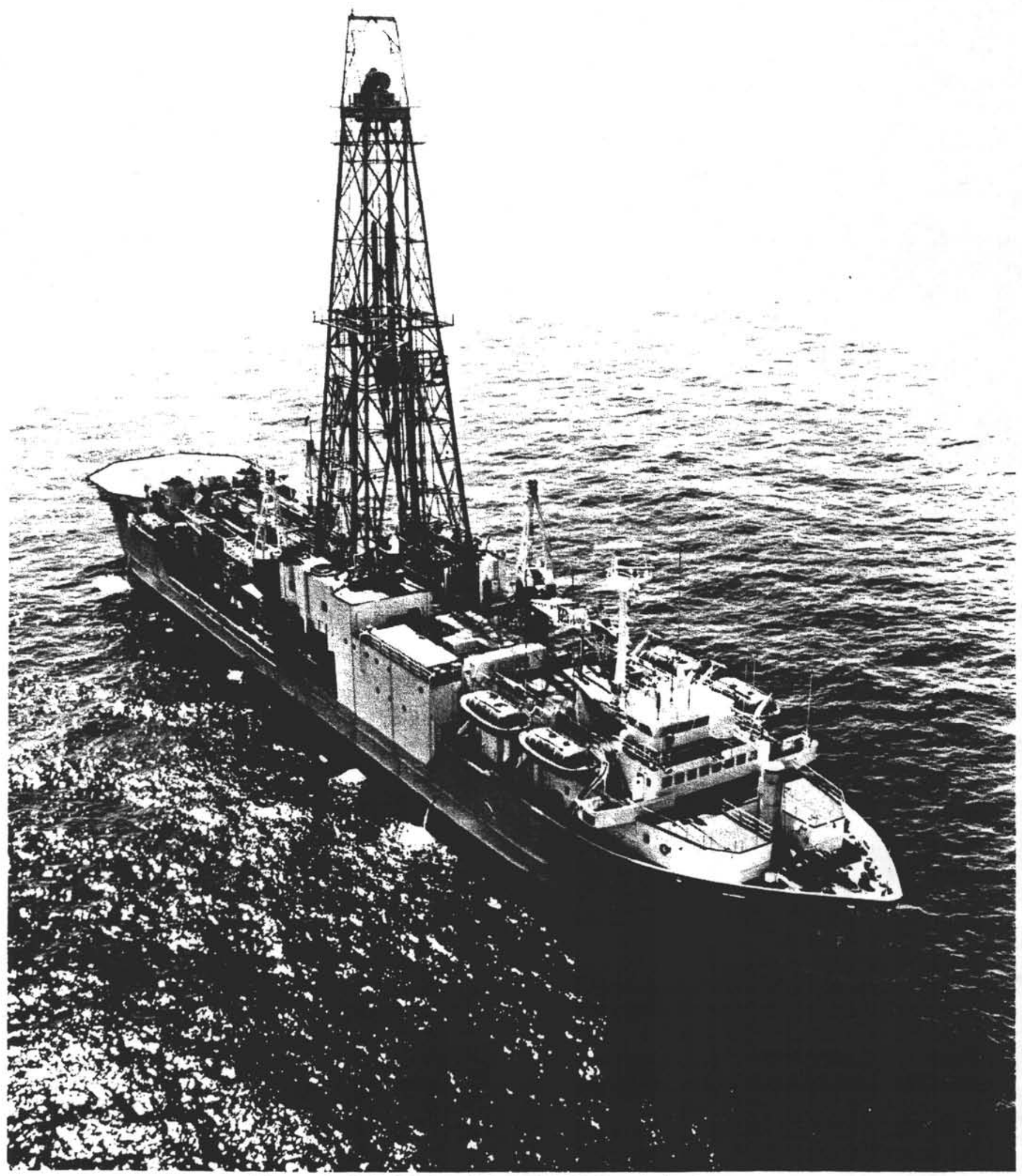

Figure 1. SEDCO/BP 471 (JOIDES Resolution) . 
JOIDES organization is the Executive Committee (EXCOM). The Planning Committee (PCOM) evaluates advice from the science advisory structure, prioritizes scientific objectives, and formulates drilling programs, forwarding recommendations on scientific objectives and drilling plans to EXCOM for final approval. The science advisory structure is headed by PCOM and consists of four thematic panels (Lithosphere, Ocean History, Sedimentary and Geochemical Processes, and Tectonics panels), five service panels (Downhole Measurements, Information Handling, Pollution Prevention and Safety, Site Survey, and Shipboard Measurements panels), a Technology and Engineering Development Committee, and short-lived detailed planning groups that are created as needed to assist in translating broad thematic programs into concrete drilling plans.

The operation of the drillship, which includes planning and implementation of cruises, is managed from ODP facilities at Texas A\&M University (ODP/TAMU) in College Station, Texas. This facility also serves as a repository for cores from the Pacific and Indian Oceans. As science operator, TAMU is responsible for (1) implementing science planning and operations, (2) guiding engineering development and improvement of drilling technology, (3) selecting scientists for the shipboard scientific parties, (4) designing, furnishing, and maintaining shipboard and shore-based laboratories necessary to meet the needs of the shipboard scientific staff, (5) curating and distributing all core samples and data, (6) publishing scientific results, and (7) providing public information about ODP.

The East Coast Repository, a repository facility located at Lamont-Doherty Geological Observatory (LDGO), stores ODP and DSDP cores from the Atlantic, Antarctic, Mediterranean, and Caribbean. ODP cores from the Pacific and Indian oceans and the Red Sea are housed at TAMU in the Gulf Coast Repository. DSDP cores from the Pacific and Indian oceans and the Red Sea are stored in the West Coast Repository at Scripps Institution of Oceanography. ODP/TAMU is curator of all cores in the three repository facilities.

The LDGO Borehole Research Group (BRG) manages wireline logging operations for obtaining electronic measurements in ODP drill holes.

The ODP Site Survey Data Bank is located at LDGO. It has served the JOIDES community since 1975 by archiving and distributing site survey and other geophysical data to various panels and individuals associated with scientific ocean drilling.

Underseas Drilling., Inc./SEDCO, Inc. (UDI/SEDCO), owned by Schlumberger, was contracted to supply a drill ship to carry out the drilling program at sea. The registered ship name is SEDCOIBP 471; she is jointly owned by SEDCO, Inc., and British Petroleum. The ship's crew and drilling team are employees of SEDCO, Inc.

\section{JOIDES Resolution (SEDCO/BP 471)}

\section{A. Description of the Vessel}

The vessel used in the Ocean Drilling Program, known as JOIDES Resolution, is a dynamically positioned drill ship with a length of $470 \mathrm{ft}(143 \mathrm{~m})$, beam of $70 \mathrm{ft}(21$ $\mathrm{m})$, and draft of $27.6 \mathrm{ft}(8.4 \mathrm{~m})$. The displacement of the ship is 16,596 long tons. She is a 
completely self-sustained unit carrying sufficient fuel, water, and stores to enable her to remain working at sea for 70 days without replenishing. Emergency reserves for an additional 35 days are carried on board. On site, she can suspend as much as $30,000 \mathrm{ft}$ $(9150 \mathrm{~m})$ of drill pipe and maintain her position in up to $27,000 \mathrm{ft}(8200 \mathrm{~m})$ of water. The drill ship is capable of operating in air temperatures of $-18^{\circ} \mathrm{C}$ to $43^{\circ} \mathrm{C}$ and sea temperatures of $-2^{\circ} \mathrm{C}$ to $27^{\circ} \mathrm{C}$. Her hull is ice strengthened for navigation in medium ice conditions.

JOIDES Resolution is of the flush deck type with a forecastle (fo'c'sle) and poop deck (Fig. 2). A 22-ft (7-m) diameter well, the moonpool, is located on centerline amidships to provide an area for running drilling equipment to the seafloor. Thruster wells are located on centerline forward, on the forward port side, and on the aft starboard side of the vessel, as well as in the ship's skeg. The drilling and thruster wells are free-flooding. Crew accommodations and navigation facilities are located forward; electrical generation, propulsion machinery, and a heliport are located aft. Subdivision of the hull is provided by nine major transverse bulkheads, two longitudinal wing bulkheads, and an inner bottom.

Drilling, propulsion, and positioning equipment is diesel-electric powered. Twin propellers give her an average cruising speed of 11 knots. Special features of her design particularly valuable for deep-ocean drilling include dynamic positioning equipment with a computerized control system and satellite navigation equipment.

\section{B. Dynamic Positioning}

JOIDES Resolution's dynamic positioning system employs an acoustic referencing device to maintain the ship over a specific location while drilling in water depths of up to $27,000 \mathrm{ft}(8200 \mathrm{~m})$. The positioning system uses ten retractable thrusters occupying forward, port, and starboard wells and two fixed thrusters in the skeg, each capable of $22,600 \mathrm{lb}(100,525$ newtons $)$ of thrust. When operating in conjunction with the ship's main screws, the thrusters enable her to move in any direction. Four hydrophones are mounted within the hull and continually receive signals transmitted from a sonar beacon placed on the ocean floor. The signals are fed into a computer that calculates the position of the ship relative to the beacon as based on the delay times of the arriving signals. The computer automatically controls the thrusters and main propulsion unit to maintain the ship's heading and location over the hole. The dynamic positioning system has both computerized and manual controls. Under normal operating conditions, the system can safely maintain the drill ship at a desired surface location within $1 \%$ of water depth.

\section{Office and Laboratory Facilities}

Laboratory and data collection facilities are housed in a separate structure installed aft of the main superstructure and forward of the rig floor. The "lab stack" contains seven levels: four above deck and three below deck in the casing hold (Fig. 2). The topmost level is the downhole measurements laboratory. The next level down, the bridge deck, contains the core entry and core splitting areas of the core lab as well as the sedimentology, magnetics, and physical properties labs. Below is the fo'c'sle deck with chemistry, X-ray diffraction/fluorescence, thin section, paleontology preparation, and microscope 
Figure 2. Diagram of JOIDES Resolution's laboratory and library decks.
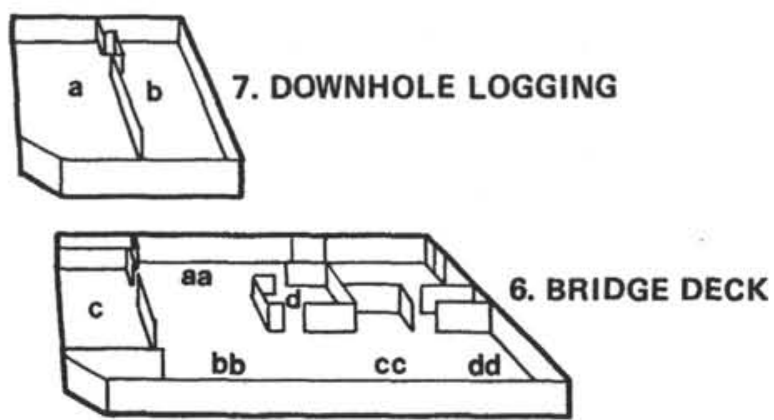

a

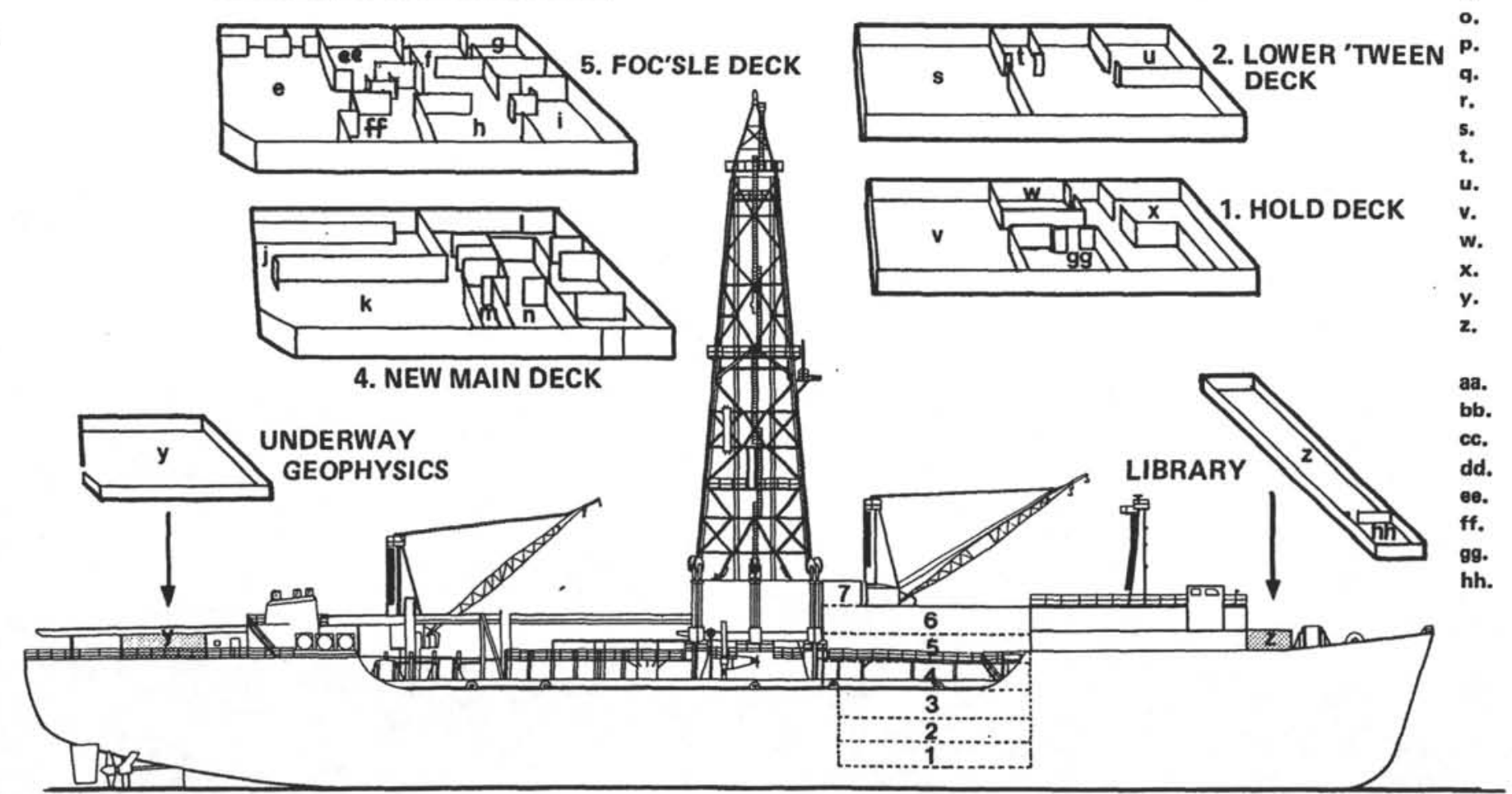

Downhole Instruments, Logging Downhole Instruments, Logging Magnetics Lab

Core Splitting Lab

Chemistry Lab

XRD/XRF

Thin Section

Paleo Stations

Paleo Prep Lab

Computer Machine Room and Office

Science Lounge

Computer User Area

Curatorial Representatives Office

Yeoperson's Office

Electronic Shop

Photo Darkroom

Photo Finish Room

Fan Room

Core Storage Reefer

(Cold Storage) Chemical Refrigerated Storage

2nd Look Lab

Core Storage Reefer

Freezer

Storage

U/W Geophysics

Library

Physical Properties Lab

Sampling

Core Description

Core Photography

XRD/XRF Lab

SEM/Petrology Stations

Elevator Control Room

Conference Room 
laboratories. The new main deck houses shipboard computer facilities, the science lounge, the Yeoperson's office, and the Curatorial Representative's office.

Below deck are three more laboratory levels. On the upper 'tween deck are the electronics shop, the photography lab, and a storage area for lab supplies. The lower 'tween deck has the second look lab, refrigerated core storage, and more storage for lab supplies. The hold deck has more refrigerated core storage and lab supplies storage.

An elevator connects all levels of the laboratory structure and is used primarily for transportation of cores and supplies.

The science library is located forward on the fo'c'sle deck of the ship's superstructure. The Operations Superintendent, the Laboratory Officer and Technicians, and the Co-Chief Scientists and Staff Scientist have offices on the ship's bridge deck.

All living spaces, offices, and laboratory facilities on the ship are heated, air conditioned, and acoustically insulated. Hot and cold potable water, nonpotable circulation water, salt water, and cooling water are available as required. Power throughout the laboratory stack is either $120 \mathrm{~V}$ or $208 \mathrm{~V}$, 3-phase, 60 cycle. Circuits are available in each lab for both ship's power and regulated power. Regulated power by definition is not uninterruptible power but power in which the output voltage is kept within certain limits and voltage spikes are truncated.

\section{Communications}

\section{Introduction}

This section outlines communications procedures between JOIDES Resolution and ODP Headquarters at Texas A\&M University. These procedures are designed to ensure that ship-to-shore and shore-to-ship messages are sent and received promptly and with minimal confusion. Telephone, facsimile transmission (FAX), telex, electronic mail, "ham patch," and continuous wave (CW) radio facilities aboard JOIDES Resolution permit daily contact with ODP. Most official ODP messages are sent via BLAST satellite, telex, or FAX.

\section{Ship-to-Shore, ODP-Related-Business Communications}

All business messages must be approved by the Operations Superintendent, who ultimately is responsible for all ODP communications that leave the vessel. Reports concerning the technical staff and equipment must also be approved by the Laboratory Officer. Messages concerning science operations or scientific results from the cruise must also be approved by a Co-Chief Scientist or the Staff Scientist. The following business messages are sent routinely from the ship:

\section{a. Daily Operations Reports}

Operations reports containing critical information regarding the ship's location, operational activities, and scientific progress are sent each day to ODP/TAMU. These reports are written by the Operations Superintendent. The shipboard System Manager files a daily computer operations report with the Operations Superintendent, and the Staff Scientist provides a brief report describing the age and lithologies of core material recovered during each 24-hour period. 


\section{b. Operational Hole Summary}

Operational Hole Summaries are compiled by the Operations Superintendent after terminating a hole, or weekly if drilling on one hole continues for more than seven days.

\section{c. Scientific Site Summary}

The Co-Chief Scientists complete and transmit to ODP/TAMU a Site Summary at the end of each site. Interim weekly reports are sent also, if drilling at the same site continues for more than seven days. The site summary contains site identification number, latitude and longitude, water depth, depths of penetration at the hole(s) drilled, and a brief text detailing the lithology and ages of the materials recovered and other preliminary scientific results.

\section{d. Personnel List}

Shortly after the ship leaves port the Yeoperson sends to ODP/TAMU a list of all scientific and technical crew members.

\section{e. Logging Reports}

The shipboard Logging Scientist and the LDGO Logging Scientist are responsible for a weekly logging report and a report of logging results after a hole has been logged. The report is sent to the LDGO Borehole Research Group with a copy to ODP/TAMU. f. Press Release

A press release is written by the Co-Chiefs and transmitted to ODP/TAMU before the end of the leg. This press release states the important results of the leg in layman's language. Examples of previous press releases are available aboard ship.

Copies of all non-confidential ship-to-shore communications are distributed within ODP to the Director, the Deputy Director, the Administrator, all ODP managers, the Gulf, East, and West Coast Core Repositories, and the addressee. Copies sent to the core repositories are for the information of ODP employees only and are not made available to the public. Copies of all incoming messages from JOIDES Resolution not marked confidential are also posted at ODP/TAMU. Official messages sent in confidence are given by the telex operator directly to the addressee and copies are given only to the ODP Director and Deputy Director.

The only ship-to-shore messages distributed outside ODP are the scientific site summaries, the press release, and the daily operations report. The operations report is telecopied to the JOI office, as required by contract. In addition, a brief weekly summary of drilling and science operations, compiled at ODP/TAMU from the daily operations reports, is made available to the JOIDES institutions via OCEANET and BITNET.

Site summaries are edited by the ODP Manager of Science Operations as necessary and are distributed to members of the JOIDES Planning Committee and Executive Committee, JOIDES panel chairmen, foreign ODP Offices, the JOI Office, the NSF Office, and ODP/TAMU, including the core repositories. The press release is edited by the Public Information Officer, approved by the Director, and is distributed to electronic and print media, colleges and universities, earth scientists, and interested individuals world-wide. 
Site summaries can be sent from ODP headquarters to an address of each shipboard participant's choosing. For this service, a "Site Summary Request Form" is mailed to each shipboard scientific participant prior to the cruise, and must be returned to ODP at that time.

\section{Shore-to-Ship, ODP-Related-Business Communications}

All messages to the ship originating from ODP are approved by the sender's department manager. Messages originating from individuals and institutions outside ODP/TAMU are approved by the Manager of Science Operations.

Copies of all non-confidential messages sent from ODP/TAMU to the ship are given to the Operations Superintendent, the Laboratory Officer, and the addressee. In addition a copy is posted outside the Yeoperson's office in the science lounge area, and a copy is kept on file. Messages to members of the scientific party will be placed in their assigned mailboxes. Messages regarding specific laboratory equipment or procedures should be addressed to both the Laboratory Officer and the Technician assigned to that laboratory.

All confidential messages sent to the ship are given to the Operations Superintendent, who hand delivers them to the addressee.

\section{Personal Communications}

Communicating with family or with colleagues at a home institution during the cruise may be accomplished by a number of methods, depending on the nature and urgency of the message. Cruise or scientific results are not to be discussed in any personal communications.

Collect or credit card personal telephone calls can be made from the ship via MARISAT, at a cost of approximately $\$ 10$ per minute. This method can be used for business or commercial matters. Direct voice communication for personal messages is sometimes available to the United States by "ham" amateur radio. Contact is made with a stateside "ham" operator who then phones the onshore party collect. The charge for the phone call varies depending on the distance from the onshore "ham" operator to the onshore party. Please note: regulations governing "ham" calls state that conversations must be entirely of a personal nature; no business or commercial matters (including personal finances) may be discussed.

If it becomes necessary for someone ashore to contact shipboard personnel for critical personal reasons, ODP will relay messages to the ship as part of daily communications. Science Operations provides emergency-contact information to members of the scientific party about a month prior to the cruise. This "emergency communications memorandum" is meant to be left "at home." It explains procedures to be followed in the event of a situation necessitating emergency contact with a member of the shipboard party. It should be noted that it is the policy of the Ocean Drilling Program not to interrupt or alter the course of a cruise for the purpose of evacuating an ODP employee or a cruise participant in the event of a personal emergency on shore.

Non-ODP-related written personal communications ("Pmail") to and from the ship are sent from ODP once a week (on Sunday). Typed personal letters for shipboard 
participants, received during the preceding week by ODP/TAMU Science Operations, are retyped into computer files and sent to the ship by BLAST satellite transmission. At the same time, computer-written letters from shipboard participants are BLASTed to ODP/TAMU, where they are printed out and mailed. The cost to shipboard participants depends upon procedures used in transmission, but is usually less than $\$ 5$ per page. This charge covers only the cost of transmitting the correspondence; costs associated with computerizing correspondence to the ship and mailing correspondence coming from the ship are borne by ODP/TAMU. Interested shipboard participants may send and receive mail in this manner, but costs for all sent and received Pmail must be paid in U.S. dollars before the end of the cruise. Details about Pmail communications are sent to cruise participants by the Manager of Science Operations prior to the cruise. Further information concerning Pmail may be requested from the Communications Officer, ODP Science Operations, 1000 Discovery Drive, College Station, Texas 77845-9547 U.S.A.

Written correspondence to members of the ODP shipboard scientific parties (including PMail correspondence arrives too late for transmission) is delivered at the port call at the end of the cruise. Since it is hand-carried, port-call mail is limited to letters. Mail to shipboard party members must reach ODP no later than one week prior to the ship's date of arrival in port. Mail intended for port call should be addressed in care of the Logistics and Technical Support Office, Ocean Drilling Program, 1000 Discovery Drive, College Station, Texas 77845-9547 U.S.A.

Rarely, there are rendezvous at sea during which mail intended for port call can be delivered prior to the end of the cruise. In these cases a mailbag is generally also carried off the ship by the transfer vessel; the sender must provide stamps or funds for postage (U.S. postage stamps are available at cost from the Yeoperson; the Yeoperson can answer questions on posting mail to other countries).

\section{E. Weather}

ODP staffs a Weather Observer on some cruises, who works primarily with an Alden APTS3B Ground Weather Satellite Receiving Station located in the ship's dynamic positioning room. SEDCO maintains additional weather equipment.

\section{F. Copy Machines}

Two photocopiers are available aboard ship. Because of limited supplies, personal copying must be kept to a minimum. The ODP Electronics Technicians make all repairs to these machines except for replacement or unjamming of paper (Technicians handle this kind of problem).

\section{G. Accommodations}

The comforts of home and then some are provided by the Captain and crew of JOIDES Resolution to make the stay of ODP scientists and technicians as pleasant as possible. 


\section{Quarters and Laundry Facilities}

A variety of 2- and 4-man cabins with corresponding lavatory and shower facilities are provided for shipboard scientists and technicians. Of the 51 berths assigned to scientific and technical personnel, 32 are in 4-man rooms. Room assignments are posted by the Laboratory Officer upon arrival at the ship. The rooms are heated/airconditioned, and are cleaned by the ship's stewards. JOIDES Resolution has an excellent fresh-water storage system that allows all personnel to shower daily. Fresh towels and bed linens are provided regularly. Personal decorations may be added to the rooms but must be removed at the end of the cruise; rooms are not to be permanently modified in any way.

The ship provides free laundry service. Soiled clothes placed in the bags provided are to be left in front of the cabin doors. Laundry is picked up daily and returned the same day. Since it takes equal time to launder a small amount as a large amount of clothes, it is requested that laundry be accumulated for a few days before sending it out to be washed.

Note that because of this laundry service, it is not necessary to bring many changes of sea clothes, which is a convenience in reducing the amount of luggage. However, each person must take into account the anticipated weather based on season and geography of the cruise, and bring appropriate clothing and footwear. Steel-toed safety shoes are required on the rig floor (Co-Chief Scientists please note). Footwear worn outside on catwalks, deck, or rig floor is not to be worn in accommodations areas; it is important to bring a pair of "indoor shoes" or slippers.

\section{Meal Facilities and Hours}

Meal hours are:

5:00 a.m. to 7:00 a.m. Breakfast

11:00 a.m. to 1:00 p.m. Lunch

5:00 p.m. to 7:00 p.m. Supper

11:00 p.m. to 1:00 a.m. Snacks and Grill

The mess hall is on the ship's upper 'tween deck. It is open throughout the day and night, except for one hour after each meal to allow time for cleaning and set-up. Meals are served cafeteria style. The capacity of the mess hall is 40 persons, with no predetermined seating arrangement. It is expected that everyone wear clean clothes to meals, with the exception of on-duty drilling crew members.

\section{Gymnasium}

Exercise equipment is available in one of the storage holds. There are two adjustable tension exercise bicycles, a flywheel-resistance rowing machine, and a threestation weight machine with a bench press, upper and lower pulleys, leg extension/leg curl bench, and abdominal board. The gym has an audio-video system (with aerobics videotapes!) and a ping-pong table.

\section{Science Lounge}

The science lounge contains audio-video equipment in designated viewing and listening-reading areas. There are two viewing areas with a variety of video formats: SonyBeta and Zenith-VHS VCRs (compatible with SEDCO's system) and a Pioneer laser disk player, 25-in. and 19-in. color monitors and a 50-in. movie screen, and a 16-mm movie 
projector. Videotapes are provided by SEDCO. A Commodore 64 computer system offers an assortment of video games. Slide projectors, an overhead projector, and a screen are also available. A Casio electronic keyboard is kept in the science lounge. It has headphones, so a keyboardist can enjoy making music without disturbing others. A selection of paperbacks and magazines is kept in the lounge for leisure reading; more are located in the science library.

\section{Ship's Stores}

A ship's store operated by the SEDCO crew sells miscellaneous personal supplies and toiletries. A store run by ODP sells ODP/TAMU t-shirts and sweatshirts, Resolution baseball caps, small cloth ODP patches, ODP coffee mugs, and Resolution note cards and color postcards. ODP items may also be purchased by visitors to ODP/TAMU, through the Office of Logistics and Technical Support.

All shipboard purchases must be paid for in U.S. dollars (cash).

\section{Hospital}

The ship's hospital is located on the fo'c'sle deck just inside the starboard door. The hospital is staffed by a certified medical doctor (MD), whose regular office hours are posted at the beginning of each cruise. The doctor is on call 24 hours a day.

The hospital has six beds and its own lavatory and shower facilities. It has an X-ray machine, defibrillator, and artificial respirator apparatus in addition to medicines, bandages, and other first-aid supplies.

Shipboard participants requiring special or prescription drugs must bring an ample two-month supply for their use. No prescriptions can be refilled on board, and only small quantities of over-the-counter drugs are maintained.

Note: Shipboard participants who have experienced motion sickness, or have reason to believe it may be a problem, are advised to discuss precautionary measures with their doctor, for example during the required pre-cruise physical examination. Medications are available to prevent seasickness, but are less helpful after symptoms have begun. Also, it is advisable to notify the ship's doctor as soon as possible at the beginning of the cruise that seasickness may be a concern.

\section{Ship's Intercom}

There are telephones in every lab, with an intercom system near each phone. One person can call another by paging over the intercom system and then conversing by phone. There are dedicated voice-powered phone lines from the bridge to the engine room and rig floor for use by the ship's crew.

\section{H. Personal Safety}

\section{General}

In the interest of preventing accidents, it is requested that while on site all persons not directly connected with drilling operations stay off the rig 
floor. For those who are not familiar with the machinery and its operation or who do not take proper precaution, crossing the rig floor while pipe operations are in progress can be extremely hazardous. The driller and his team are operating equipment that handles loads of over 300 tons under dynamic conditions and that is unforgiving of error. The driller is responsible for the safety of everyone on the rig floor; a lapse in concentration on the driller's part could easily result in a serious or fatal accident to a visitor or crew member. It could also cause a "wreck" with disastrous consequences to the equipment, drill string, or even the voyage. The following guidelines must be observed:

a. Wear a hard hat outside the deck house and lab stack areas, and wear safety shoes on the rig floor and around machinery or moving loads.

b. Avoid the drill floor during pipe handling operations unless you have specific business there, and then walk around behind the drawworks as an alternative to crossing the drill floor. Don't visit with or otherwise distract the driller while he is operating machinery.

c. Don't ever walk between the iron roughneck or the dual elevator system and the centerwell; and don't walk on the piperacker catwalk unless you have a real need to do so and are fully aware of the current operational situation.

d. Be constantly alert for men working aloft in the derrick and for crane loads being swung overhead, and DON'T stand underneath!

e. Don't use the rig floor as a route of convenience to the underway geophysics or logging winch areas.

Personnel may go aloft in the derrick after getting permission from the SEDCO tool pusher on duty and notifying the Operations Superintendent, and only when the ship is under way. Hard hats must be worn by all ODP and SEDCO personnel when outside on catwalks, rig floor, or aft decks (on the way to the helipad or underway geophysics lab, for example).

Use of alcoholic beverages or controlled substances is forbidden. In 1988 the U.S. government enacted the Drug-Free Workplace Act, which contains a requirement for federal contractors and grant recipients to maintain drug-free workplaces by adhering to certain requirements. The act specifically prohibits the "unlawful manufacture, distribution, dispensation, possession, or use of a controlled substance" in the workplace. Failure to comply with this law may result in loss of government funding. Accordingly, ODP relies upon the integrity, professional attitude, and good judgment of all cruise participants to refrain from engaging in these types of activities.

Smoking is permitted only in non-dangerous areas and is never allowed where "No Smoking" signs are posted. Smoking is permitted in the living quarters.

Firearms or other weapons cannot be transported or possessed.

\section{Emergencies and Weekly Drills}

The scientific work of JOIDES Resolution takes her to areas where immediate assistance is unavailable. Thus, it is necessary to rely upon the knowledge and experience of the ship's crew to avoid potentially dangerous situations. This is done in a systematic way developed through the practice of weekly drills. These drills are required by law, and the ship takes pride in the serious manner in which they are organized and executed. 
Station bills of lifeboat assignments and emergency signals are posted in passageways and personnel stations. This information must be thoroughly and carefully read; the Chief Mate or Captain can answer any questions. Personnel not directly involved in dealing with an emergency are to report to their assigned stations immediately upon hearing an alarm. This facilitates assignment of additional help or directing of abandon-ship procedures. Depending on the severity of an emergency, the Captain may call upon any or all hands aboard for assistance; therefore, everyone must be ready to respond to any order the Captain or ship's officers may issue in a drill or real emergency.

There are different emergency alarms to signify unsafe conditions aboard ship:

a. General Emergencies: For a general emergency, such as a fire or collision, the general alarm and ship's whistle sound for a least 10 seconds and instructions describing the type of emergency and location are given over the public address system. b. Abandon Ship: For abandon ship circumstances, 6 short blasts followed by one long blast are given on the alarm and whistle. One short blast means to lower boats; two short blasts means to stop lowering boats. Accompanying commands and instructions to abandon ship are given over the public address system.

c. Man Overboard: If a person falls overboard, an alarm is given by hailing "Man Overboard" and notifying the mate on duty. Three long blasts on the whistle may be given.

d. Return to Safe Conditions: When an emergency is over, the "All Clear" signal for dismissal is given by three short blasts of the whistle and general alarm.

Fire drills, man overboard drills, and abandon ship drills are held at least once weekly; attendance is mandatory. Helicopter emergency drills are held less frequently. Procedures and details connected with these drills are explained at the first drill, held a few hours out of port.

JOIDES Resolution is equipped with 4 motor-propelled, self-contained, totally enclosed lifeboats, each with a capacity of 65 persons. The boats contain oxygen breathing systems to be used when operating in a fire area. There is also a complete exterior water-spray system to prevent buildup of excessive interior temperatures. Lifeboats are located above the bridge deck, two each on port and starboard. They are launched and boarded from the fo'c'sle deck. In addition to the lifeboats, the ship has inflatable life rafts.

Life jackets are worn during every boat drill by all persons. Regulation-type life jackets are kept aboard for all personnel. They are stored in each cabin and near each lifeboat. Survival suits are also stored in each cabin and in the lab stack.

The shipboard computer facility is protected by a Halon fire extinguisher system, located in the Koomey room on the upper 'tween deck. This system protects the computer machine room, system manager's office, and computer user's area. Only the Captain may authorize manual activation of the Halon system in the event of a fire. A loud alarm sounds, and protected areas must be evacuated immediately and all doors tightly closed. Halon is non-toxic but it must be contained within the air-tight protected area in order to be effective. As in all emergency situations, the bridge must be notified FIRST.

One final word on emergencies: If you should discover a fire or a similar dangerous situation, do not try to combat it! The first and most important action to take is to 
notify the bridge immediately and stand by to aid or point out the area involved to the Emergency Squad as they arrive. If, in your judgment, you would be able to help by using an extinguisher on a fire at its inception, you may do so only after you notify the bridge. After the Emergency Squad has taken control, go to your assigned emergency station.

\section{Compassionate Emergencies}

It is the policy of the Ocean Drilling Program not to interrupt or alter the course of a cruise for the purpose of evacuating an ODP employee or a cruise participant in the event of a personal emergency on shore. Personal emergencies include but are not limited to a death in the family or the serious illness of a family member. Exceptions to this policy may be made at the discretion of the ODP Director or Deputy Director. An exception would be based in part on the location of the ship, availability of resources for evacuation, and nature of the emergency.

On rare occasions, it may be necessary for JOIDES Resolution to deviate from its planned scientific activities to transport scientific or SEDCO personnel to the nearest port. There are contractual ramifications to such a decision, and ODP requests that shipboard scientific personnel not offer advice or suggestions in these matters.

\section{SHIPBOARD PERSONNEL AND RESPONSIBILITIES}

\section{A. ODP Engineering and Drilling Operations Personnel}

\section{Operations Superintendent}

The Operations Superintendent represents ODP/TAMU on the vessel and is responsible for all matters affecting the technical and operational success of the expedition (Figure 3). He plans and directs the activities of shipboard UDI/SEDCO personnel through their designated supervisors, and is charged with the responsibility of ensuring that the best possible techniques, equipment, and work efforts are used to maximize scientific results with minimum risk of loss of equipment or personal safety.

The Operations Superintendent is the senior ODP representative aboard ship, and is responsible for the execution of the recommendations and procedures made by the JOIDES Safety Panel and approved by ODP. It is the Operations Superintendent's obligation, after consulting the $\mathrm{Co}-\mathrm{Chief}$ Scientists, to terminate drilling operations whenever necessary to prevent any possible release of hydrocarbons. Final authority to terminate drilling resides with the Operations Superintendent.

The Operations Superintendent represents ODP/TAMU in determining acceptable drilling conditions; in dealing with matters pertaining to discipline of the ship, drilling, and scientific crews; and in approving on-site changes in equipment or drilling and coring procedures. He is responsible for complete and accurate reports of drilling, coring, and ship operation/maintenance, and for transmission of this information ashore (daily operations reports; Section III.D). All outgoing messages originated by ODP scientific and technical personnel must be cleared by him, and all communications with SEDCO 


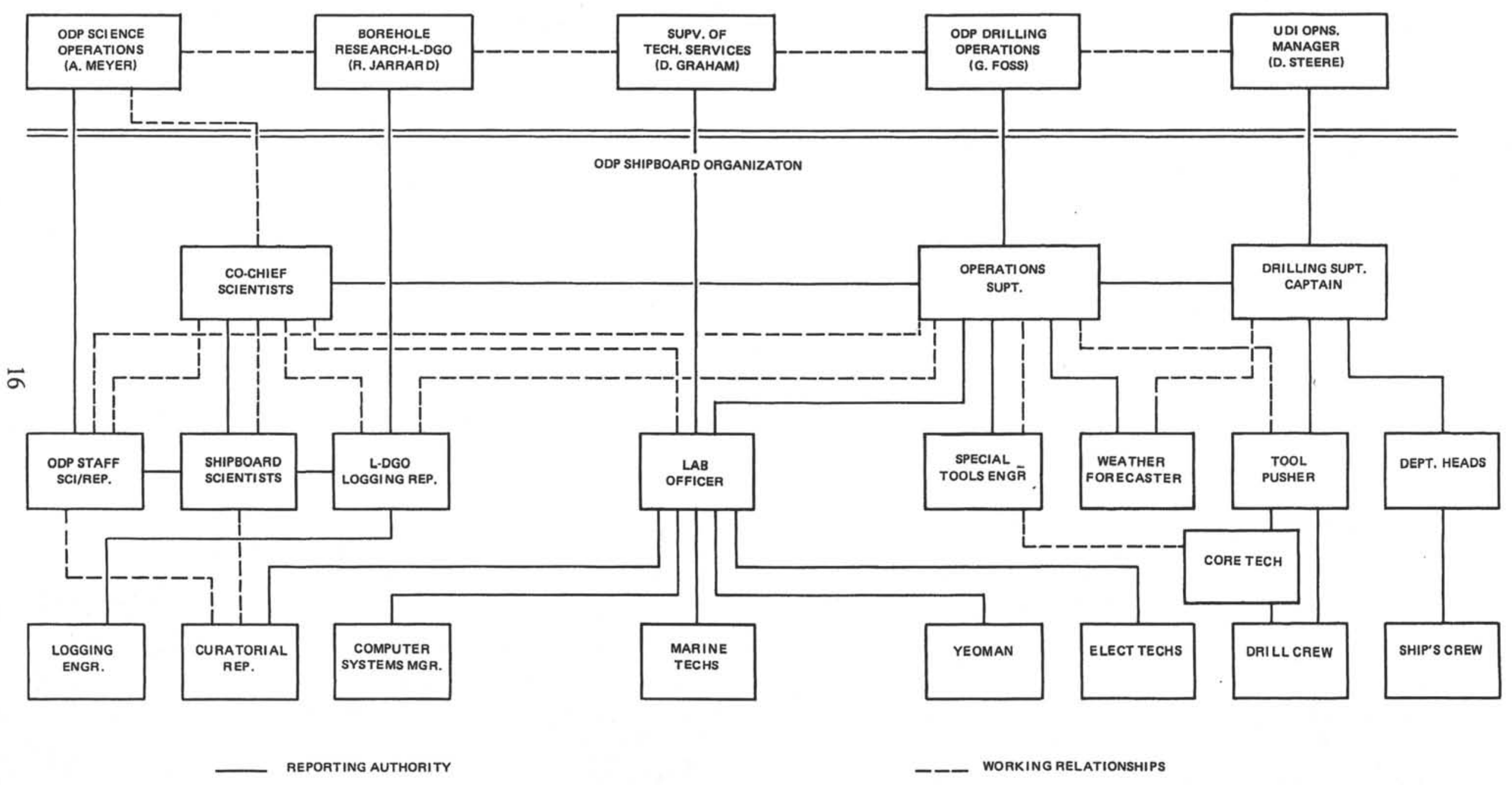

Figure 3. ODP shipboard organization chart showing direct and working relationships among ODP and SEDCO personnel. 
personnel regarding cruise operations or any other business matters must go through him. The Operations Superintendent also has direct supervision of the Special Tools Engineer.

\section{Special Tools Engineer}

On some cruises a Special Tools Engineer is aboard to supervise maintenance and deployment of special coring tools. The Engineer tests downhole tools under development, trains rig crews in the routine use of new tools, and assists in the deployment of rarely operated equipment.

\section{B. ODP Technical Personnel}

\section{Laboratory Officer}

While at sea, the Laboratory Officer reports to the Operations Superintendent (Figure 6) and is responsible to the Co-Chief Scientists for the direct supervision, performance, and safety of the ODP technical staff in the collection of core material and recording of data; and for the proper, efficient, and safe operation and maintenance of the ship's laboratories and related equipment. On most cruises, a member of the technical staff is designated Assistant Laboratory Officer, handling part of these responsibilities. The technical staff on board JOIDES Resolution usually consists of a Laboratory Officer, eight Technicians, one Photographer, one Yeoperson, two Chemists, three Electronics Technicians, one Computer System Manager, and one Curatorial Representative. In normal practice the Lab Officer directs these activities in a way consistent with the guidelines and overall priorities, policies, and assignments made by ODP.

The Lab Officer is responsible for all shipboard scientific equipment and supply items. All samples, data, and equipment, including necessary paper work, are prepared for shipment under his direction.

The Lab Officer works with UDI/SEDCO through the Operations Superintendent when his areas of responsibility involve ship's personnel, equipment, or operations.

\section{Technicians}

Under the supervision of the Lab Officer, the ODP Technicians are responsible for collection, recording, and preservation of core material and scientific data and for proper operation and maintenance of the ship's laboratories and related equipment. The majority of technicians are assigned core processing duties as their first priority; secondary priority activities associated with individual labs are accomplished on a time-available basis. The chemistry lab, photography lab, electronics lab, computer system, and curatorial responsibilities are provided with dedicated technical support. In consultation with the Lab Officer, the Co-Chief Scientists have some flexibility in assigning the limited technical support available as they see fit, in order to accomplish the specific scientific objectives of the cruise.

\section{Computer System Manager}

Under the supervision of the Lab Officer, the System Manager is responsible for the shipboard computer system, serving as the primary contact for shipboard users and as 
the final authority on system operation. The System Manager maintains the integrity of the hardware, software, and data, and allocates user accounts that provide access to the system. The System Manager reconfigures system hardware as new equipment arrives, installs software updates, and identifies and reports problems in system software to the shore-based Computer Services Group for action. Assisted by the Yeoperson, the System Manager acquaints shipboard scientists with operating procedures, software, and labspecific applications available for use during the cruise.

\section{Curatorial Representative}

The ODP Curatorial Representative is supervised by the Laboratory Officer while at sea, and represents the Curator and JOIDES/ODP sampling policies aboard the vessel. He assumes responsibility for the care and handling of cores and core samples as soon as the core liner is removed from the core barrel. Collecting samples is the responsibility of the entire shipboard scientific party under the supervision and assistance of the Curatorial Representative. The Curatorial Representative maintains records of all samples taken on board the vessel and ensures rigorous adherence to all provisions of JOIDES/ODP policies regarding core handling, sampling procedures, and sample distribution.

\section{Yeoperson}

The primary responsibility of the Yeoperson is to maintain complete, clear records of all data taken during the cruise. This includes collecting and filing copies of all data forms from all labs and work areas. The Yeoperson assists scientists in learning to use the shipboard computer system, and is available to type shipboard reports written by scientists as they complete shipboard studies at each site or to compile and edit reports scientists have entered in the computer themselves. The Yeoperson is also ship's Librarian, in charge of keeping the library books in reasonable order, cataloging and shelving new acquisitions, and inventorying all books before the end of each cruise.

\section{Electronics Technicians}

ODP staffs three Electronics Technicians (ETs) on each cruise. They are responsible for maintaining and repairing all shipboard ODP electrical equipment, including the VAX computer system, analytical laboratory equipment, copy machines, and some of the downhole tools.

\section{Shipboard Science Party}

\section{Co-Chief Scientists}

The Co-Chief Scientists are responsible for the scientific success of the entire expedition. At sea they are responsible for optimum use of the vessel's time, except as abridged by policies set by the ODP Program Plan (available from ODP/TAMU), safety considerations, and/or laws of the sea. The Co-Chief Scientists are charged with implementing the recommendations of the JOIDES Planning Committee for drilling, coring, and logging, after the recommendations have been reviewed operationally and approved by ODP management. 
The job of the Co-Chief Scientists begins some time (usually 10-12 months) prior to the cruise, when they are appointed by ODP. Pre-cruise responsibilities include these:

(1) They aid ODP staff in refining scientific objectives of the cruise, taking account of operational constraints, and ensure that the necessary geologic, geophysical, oceanographic, and meteorological data are assembled.

(2) They aid ODP Site Survey Databank personnel as necessary in preparation of the safety package for formal review by the JOIDES Pollution Prevention and Safety Panel.

(3) They review scientists' applications for participation on the cruise, and make recommendations to the ODP Manager of Science Operations for selection of participants.

(4) They participate in a Co-Chief Scientists' pre-cruise meeting in order to complete cruise planning and meet ODP personnel. This is scheduled about 4 months pre-cruise. (5) They prepare the cruise scientific prospectus for distribution to cruise participants and the JOIDES community about 3 months pre-cruise.

(6) They review requests for samples prior to the cruise, in preparation for compiling a preliminary sampling scheme at the beginning of the cruise.

The Co-Chief Scientists' duties at sea include the following:

(1) They direct and coordinate the shipboard science activities toward attaining the cruise objectives set by the JOIDES Planning Committee. They must maintain good order and adherence to safety regulations within the scientific staff. They are required to become familiar with ODP policies and procedures as outlined in this handbook. The Staff Scientist can advise on any points requiring clarification.

(2) They work closely with the Operations Superintendent to ensure best scientific returns from the coring and logging programs taking place on the rig floor. For decisions concerning logging and downhole experimentation, the Co-Chief Scientists rely upon advice from the JOIDES and LDGO Logging Scientists.

(3) They share responsibility with the Operations Superintendent for avoidance of any risk of encountering hydrocarbon accumulations. They must ensure that the Operations Superintendent is notified immediately if any petroleum stain, fluorescence, or readily discernible amounts of extractable hydrocarbons, petroleum odor, or natural gas are noted on or in any samples recovered, relying upon advice from shipboard organic geochemists and/or petroleum geologists. Although ODP management assures that all sites outlined in the cruise prospectus have been reviewed by the Safety Panel prior to cruise departure, the Co-Chief Scientists are responsible for ensuring that Safety Panel recommendations are followed during the cruise.

(4) They are responsible for seeing that the sample plan agreed to upon sailing is implemented and that all shipboard scientists assist in its completion.

(5) They act in close consultation with the Operations Superintendent, the scientific party, and ODP management to make any necessary changes to the order of site occupation, number of holes drilled at a site, or locations of the sites. As such changes can severely impact the ship's schedule, major changes in site occupation require the prior approval of ODP management, who consult with applicable JOIDES panels regarding safety considerations and compatibility with cruise and overall program 
objectives. Examples of major cruise changes that require prior ODP management approval include, but are not limited to, the following: (1) drilling secondary priority sites before completing primary cruise objectives, (2) moving site locations away from the specific areas approved by the JOIDES Pollution Prevention and Safety Panel, (3) identifying and drilling new sites for scientific objectives different from those in the cruise prospectus, (4) adoption of less than the minimum recommended logging program or changes in plans for downhole experimentation, and (5) adoption of a noncontinuous-coring program. As a general rule, when there is doubt as to the appropriate procedure in changing drilling plans, ODP management must be contacted.

(6) They must send ODP/TAMU a concise report of scientific results obtained at each site immediately after departing that site (Site Summaries; Section III.D). Weekly science progress summaries are also required in instances where sites are occupied for longer than several days. All reports of scientific results must be cleared by the ODP Operations Superintendent and forwarded through ODP management . The Co-Chief Scientists are responsible for assuring that this policy is strictly adhered to by other members of the shipboard scientific team.

(7) Co-Chief Scientists are responsible for determining when and what types of underway geophysical data to collect during transits. In practice, these decisions have generally been made well in advance, in consultation with ODP management at the precruise Co-Chief Scientists' meeting.

(8) Near the end of the cruise, they are responsible for reporting information generated during the leg by preparing, with the help of the shipboard scientific party, before the ship docks: the Hole Summaries, a Preliminary Report, a press release, and articles for Geotimes and Nature (for details, see Section IX).

(9) In addition to completing a Cruise Evaluation Form, each Co-Chief Scientist is asked to keep a log during the cruise containing notes on the performance of equipment and procedures and ODP and SEDCO personnel, as well as suggested modifications. These final informal cruise reports ensure that the ship and its laboratories maintain their state-of-the-art capabilities.

After the cruise ends, the Co-Chief Scientists are responsible for the following: (1) Coordinating post-cruise studies by shipboard and shore-based researchers so that their results can be reported in the ODP Proceedings volumes.

(2) Reviewing post-cruise sample requests from shipboard and shore-based scientists until the 1-year post-cruise moratorium has passed.

(3) Participating in post-cruise meetings (nominally 4-5 and 10-12 months post-cruise), during which chapters for the Initial Reports volume are completed, results of postcruise scientific research projects are discussed, and the table of contents for the Scientific Results volume is determined. They provide ODP with a list of qualified scientists from which ODP selects the external member of the Scientific Results editorial review board for that leg's volume.

(4) They serve on the editorial review board for the Scientific Results volume for their cruise (see Section XI.B). 


\section{ODP Staff Scientist}

A Staff Scientist is assigned to sail on each cruise; Staff Scientists sail at least once a year, and complete leg-specific pre-cruise and post-cruise duties in addition to their time at sea. Pre-cruise responsibilities include aiding in shipboard staffing, assisting with the completion of the Scientific Prospectus, reviewing sample requests with the Co-Chief Scientists and ODP Curator, and responding to questions from interested members of the community about the upcoming cruise.

In addition to functioning as a member of the shipboard scientific party in his field of scientific expertise, while aboard ship the Staff Scientist helps acquaint the other scientists with shipboard facilities and advises the scientific party on ODP procedures and policies regarding format and content of data forms and published materials.

After the cruise, the Staff Scientist serves as the scientific focal point at ODP for all postcruise activities, organizes post-cruise meetings of the shipboard scientists at ODP/TAMU to finalize the Initial Reports volume, discuss results of post-cruise scientific research, and develop a table of contents for the Scientific Results volume, and serves as a member of the editorial review board for review and revision of manuscripts submitted for the Scientific Results volume.

\section{Shipboard Scientists}

Shipboard scientists who sail on ODP cruises range in levels of expertise from graduate students well advanced in their doctoral research programs to senior research scientists with many years of research and teaching experience. Each scientist must be able to commit a considerable amount of time before and after the cruise in addition to the roughly twelve hours a day working aboard ship during the cruise.

Shipboard scientists collect, analyze, and compile data in a manner conformable with ODP standards and format. Specific shipboard duties are detailed below for sedimentologists, paleontologists, petrologists, paleomagnetists, physical properties specialists, organic and inorganic geochemists, logging scientists, and geophysicists.

During the cruise, shipboard scientists also pursue their own scientific interests in the form of pilot studies leading to formal papers submitted to the Scientific Results volume of the ODP Proceedings. Aboard ship, however, personal research is accomplished as time permits, and not at the expense of shipboard duties necessary to achieve leg objectives.

Shipboard scientists' duties prior to the cruise include:

(1) Completing a sample request form by two months pre-cruise, detailing the nature of the studies they wish to pursue post-cruise and the kinds of samples needed to complete these studies.

(2) Completing and returning required administrative forms before the cruise, relating

to proposed travel itinerary, pre-cruise physical examination, and shipboard communications.

(3) Reviewing the "Introduction to the Ocean Drilling Program" technical note and, if necessary, initiating planning for the cruise with respect to special experiments outside the scope of the routine shipboard program, especially as it affects logistics and technical support. 
Post-cruise duties common to all shipboard scientists include:

(1) Completing a "Cruise Evaluation Form" at the end of the cruise, and returning it to the ODP Science Operations office via the Staff Scientist or by mail.

(2) Analyzing their samples and data and reporting scientific results in a format and time frame appropriate for inclusion in the ODP database and for publication in the ODP Proceedings volumes, as detailed in the ODP Sample Distribution Policy.

(3) Reviewing the Hole Summary site reports written aboard ship and submitting corrections to the designated shipboard scientist before the initial post-cruise meeting (normally held 4-5 months post-cruise). Shipboard scientists designated to attend the initial post-cruise meeting are responsible for assembling all suggested corrections to the site reports and for making final revisions to these chapters.

(4) Attending the scientific post-cruise meeting (normally held 10-12 months postcruise), where results of post-cruise science are presented and discussed, and the table of contents for the Scientific Results volume of the ODP Proceedings is formalized.

(5) Submitting manuscripts for the Scientific Results volume of the $O D P$

Proceedings by 16-18 months post-cruise, and revising them based on peer review in a timely manner.

Below are listed the most important duties during the cruise for each major shipboard scientific position.

a. Sedimentologists

During the cruise, sedimentologists are responsible for:

(1) Collecting, analyzing, and compiling data in a manner conformable with ODP standards and format. Sedimentologists' primary shipboard responsibilities are to describe the lithology and stratigraphy of recovered sediments and sedimentary rocks and to provide a written interpretation of the geologic history of the drill site. (Further information is available in ODP Technical Note 8, "Handbook for Shipboard Sedimentologists.") Each sedimentologist is expected to become familiar with shipboard computer facilities and with lab-specific and generic (e.g., word-processing) software used in the core lab. Where data are collected on paper data forms, shipboard scientists are asked to complete hand-written forms accurately, completely, and legibly, so that these data can be entered correctly into ODP's computerized database after the cruise.

Data collected by the sedimentologists include:

i. Visual core descriptions (VCDs), which are detailed descriptions of each core section in the format of graphic representation of sedimentary features (color, structures, drilling disturbance) supplemented by written description. These core descriptions represent important prime data that are almost never refined post-cruise and to which all samples are related. This key shipboard activity must be completed carefully and recorded legibly.

ii. Smear slides, which are prepared by Sedimentologists and examined with petrographic microscopes. Sedimentologists estimate compositional and textural percentage data and enter the values into the computerized SLIDES database. Paper forms are also available for recording additional data (e.g., sketches).

iii. The sedimentologic portion of the "barrel sheets," which summarize data obtained by the entire shipboard party for each core. The sedimentologic portion 
includes graphic and written descriptions of core lithology, and a summary of smear-slide and thin-section data.

(2) Selecting samples for shipboard analyses (XRD, XRF, and carbonate content), thin sections, and close-up photographs, and, with the guidance of the Curatorial Representative, taking part in the routine shipboard sampling program for their own and others' post-cruise studies, as outlined in the cruise sample plan.

(3) Writing the "Lithostratigraphy" sections of the Hole Summaries, which present a description of recovered materials and an interpretation of the depositional and diagenetic history for each site. The Hole Summaries form the basis for the Initial Reports volume of the Proceedings of the Ocean Drilling Program.

(4) Assisting the Co-Chief Scientists in preparing articles for submission to Nature and Geotimes, and a press release for general distribution to news media immediately after the cruise.

(5) Compiling sedimentologic-related material for the "Explanatory Notes" chapter of the Initial Reports volume of the ODP Proceedings. This includes the standard sediment classification scheme and all modifications specific to the cruise, all drilling disturbance and sedimentary structures symbols used during the cruise, and any corehandling practices that differ from normal ODP practice.

b. Paleontologists

During the cruise, paleontologists are responsible for providing accurate biostratigraphic age information for recovered sediments and sedimentary rocks, and producing a general environmental interpretation based on paleontological evidence. The shipboard Paleontologists' first priority is to obtain ages from core-catcher samples as soon as possible after cores are recovered. Paleontologists may examine additional samples in order to provide as complete a biostratigraphic characterization of the cored section as possible within the time available, including recognition of zonal boundaries and hiatuses. (Further information is available in ODP Technical Note 12, "Handbook for Shipboard Paleontologists.")

Paleontologists collect, analyze, and compile data in a manner conformable with ODP standards and format. Each paleontologist is expected to become familiar with shipboard computer facilities and with the lab-specific and generic (e.g., wordprocessing) software used in the paleontology lab. Where data are collected on paper data forms, shipboard scientists are asked to complete all hand-written forms accurately, completely, and legibly, so that these data can be entered correctly into ODP's computerized database after the cruise. Their specific shipboard duties include: (1) Recording paleontologic data on paleontology/biostratigraphy data forms. On these forms Paleontologists note for each sample the abundance and preservation of their specialty group, nature of reworked fossils, general environmental interpretation, any special preparation techniques that might bias the representativeness of the sample examined, the abundance of biostratigraphic indicators, zonal assignment, and corresponding geological age. At the completion of each site, results are recorded on "barrel sheets," which summarize the most important data obtained by the entire shipboard party for each core; for paleontologists this includes zonation and age information. 
(2) Updating the shipboard computer core log and the white board in the core entry lab regularly with age "calls" (both the computer core log and the white board contain a running tally of the cores, time and depths of recovery, and other information of immediate and general interest).

(3) Selecting samples for shipboard biostratigraphic age dating and, with the guidance of the Curatorial Representative, taking part in the routine shipboard sampling program for their own and others' post-cruise studies, as outlined in the cruise sample plan.

(4) Writing reports for inclusion in the "Biostratigraphy" chapter of the Hole Summaries. These reports summarize the principal biostratigraphic findings at the site, and are written for non-specialists as well as other paleontologists.

(5) Collaborating with shipboard paleomagnetists in determining sedimentation rates at each site and writing the "Sedimentation Rates" chapter of the Hole Summaries.

(6) Compiling material for the "Explanatory Notes" chapter of the Initial Reports volume of the Proceedings of the Ocean Drilling Program. A discussion of biostratigraphic zonations, complete with a table of stratigraphic events, estimated age and references, taxonomic schemes (where appropriate to document), preparation techniques, microscope procedures, preservation/ abundance criteria, etc., should be included for each fossil group studied on the cruise.

(7) Assisting the Co-Chief Scientists in preparing articles for submission to Nature and Geotimes, and a press release for general distribution to news media immediately after the cruise.

c. Petrologists

During the cruise, petrologists are responsible for:

(1) Collecting, analyzing, and compiling data in a manner conformable with ODP standards and format. Petrologists' primary shipboard responsibilities involve hand specimen and thin section description and classification of all igneous and metamorphic rocks recovered on the cruise. Shipboard Petrologists should be experienced in one or more of the following aspects of the petrology of oceanic rocks: chemical petrology, lithology and volcanology, mineralogy and petrography, and alteration. Each petrologist is expected to become familiar with shipboard computer facilities and with the lab-specific and generic (e.g., word-processing) software used in the core and petrology labs. Where data are collected on paper data forms, shipboard scientists are asked to complete hand-written forms accurately, completely, and legibly, so that these data can be entered correctly into ODP's computerized database after the cruise. Shipboard petrologists produce detailed core descriptions of every piece of igneous or metamorphic rock recovered in coring operations. Core descriptions are entered into the HARVI (hard-rock visual core description) database. Hard-rock core descriptions represent important prime data that are almost never refined post-cruise and to which all samples are related. This key shipboard activity must be completed carefully. (2) Requesting thin sections for preparation by technicians, and subsequently describing each thin section during the cruise. Thin section descriptions are entered into the HRTHIN database; paper forms are also available for recording additional data (e.g., sketches). 
(3) Selecting hard-rock samples for shipboard analyses (e.g., XRF) and close-up photographs.

(4) Taking part in the routine shipboard sampling program for their own and others' post-cruise studies, as outlined in the cruise sample plan.

(5) Preparing "barrel sheets" for hard-rock cores, and adding information to barrel sheets for sediments or sedimentary rocks where igneous or metamorphic units are interbedded. Barrel sheets summarize data obtained by the entire shipboard party for each core.

(6). Writing a description and interpretation of the geologic history of each site for the "Igneous and Metamorphic Petrology" section of the Hole Summaries. The Hole Summaries form the basis for the Initial Reports volume of the Proceedings of the Ocean Drilling Program.

(7) Compiling material for the "Explanatory Notes" chapter of the Initial Reports volume of the ODP Proceedings. The igneous/metamorphic classification scheme and all modifications to it used during the cruise should be included.

(8) Assisting the Co-Chief Scientists in preparing articles for submission to Nature and Geotimes, and a press release for general distribution to news media immediately after the cruise.

\section{d. Paleomagnetists}

During the cruise, paleomagnetists are responsible for

(1) Collecting, analyzing, and compiling data in a manner conformable with ODP standards and format. The shipboard Paleomagnetists conduct or supervise all paleomagnetic measurements and the reduction of paleomagnetic data to intensities and direction of magnetization. Paleomagnetists are responsible for checking the performance and calibration of the shipboard paleomagnetic laboratory, assuring that it is maintained in good condition. They work with shipboard scientists and the drill crew to ensure that core material is not damaged (e.g., by heating or exposure to strong magnetic fields), and that core sections are not inverted. Each paleomagnetist is expected to become familiar with shipboard computer facilities and with the lab-specific and generic (e.g., word-processing) software used in the paleomagnetics lab. Specific duties include overseeing analyses of entire sections of core using the cryogenic magnetometer and overseeing routine magnetic susceptibility analyses run on whole APC cores. Magnetic susceptibility analyses are run in conjunction with other whole-core measurements on the multisensor track, and data are collected directly by computer. Data reduction and interpretation are responsibilities of the Paleomagnetists.

(2) Choosing samples for discrete shipboard paleomagnetic analyses.

(3) Taking part in the routine shipboard sampling program for their own and others' post-cruise studies, as outlined in the cruise sample plan.

(4) Adding paleomagnetics information to the "barrel sheets," which summarize data obtained by the entire shipboard party for each core.

(5) Writing the "Paleomagnetism" chapter for the Hole Summaries, and also taking part in writing the "Sedimentation Rates" chapter with the shipboard paleontologists. Hole Summaries form the basis for the Initial Reports volume of the Proceedings of the Ocean Drilling Program. 
(6) Compiling paleomagnetics-related material for the "Explanatory Notes" chapter of the Initial Reports volume of the ODP Proceedings.

(7) Assisting the Co-Chief Scientists in preparing articles for submission to Nature and Geotimes, and a press release for general distribution to news media immediately after the cruise.

e. Physical Properties Specialists

During the cruise, Physical Properties Specialists are responsible for:

(1) Collecting, analyzing, and compiling data in a manner conformable with ODP standards and format. The Physical Properties Specialists conduct or supervise the collection of all routine physical properties measurements on recovered materials. They share responsibility with other members of the scientific party for integrating their results with other shipboard measurements (e.g., correlating lab data with logging data). Physical Properties Specialists are responsible for checking the performance and calibration of shipboard physical properties laboratory equipment, assuring that it is maintained in good condition. Each Physical Properties Specialist is expected to become familiar with shipboard computer facilities and with the lab-specific and generic (e.g., word-processing) software used in the physical properties lab. Where data are collected on paper data forms, shipboard scientists are asked to complete hand-written forms accurately, completely, and legibly, so that these data can be entered correctly into ODP's computerized database after the cruise.

(2) Selecting core samples on which to determine index properties (water content, porosity, and bulk density), velocities, shear strength, and thermal conductivity; with the Sedimentologists, selecting samples for carbonate analysis.

(3) Taking part in the routine shipboard sampling program for their own and others' post-cruise studies, as outlined in the cruise sample plan.

(4) Overseeing routine measurements for $P$-wave and GRAPE made using the multisensor track on APC-cored whole-round core sections.

(5) Performing routine measurements including but not limited to thermal conductivity, velocity, and index properties.

(6) Adding physical properties data to the "barrel sheets," which summarize data obtained by the entire shipboard party for each core.

(7) Writing the "Physical Properties" chapter for the Hole Summaries, including comparison and correlation of sonic velocities, impedance, water content, porosity, etc., with lithologic units and acoustic stratigraphy. The Hole Summaries form the basis for the Initial Reports volume of the Proceedings of the Ocean Drilling Program.

(8) Compiling physical-properties-related material for the "Explanatory Notes" chapter of the Initial Reports volume of the ODP Proceedings.

(9) Assisting the Co-Chief Scientists in preparing articles for submission to Nature and Geotimes, and a press release for general distribution to news media immediately after the cruise.

\section{f. Organic Geochemists}

During the cruise, Organic Geochemists are responsible for collecting, analyzing, and compiling data in a manner conformable with ODP standards and format. (Further information is available in ODP technical notes numbers 6 and 7: 
"Organic Geochemistry aboard JOIDES Resolution--an Assay" and "Shipboard Organic Geochemistry on JOIDES Resolution.") Each Organic Geochemist is expected to become familiar with shipboard computer facilities and with the lab-specific and generic (e.g., word-processing) software used in the chemistry lab. Where data are collected on paper data forms, shipboard scientists are asked to complete hand-written forms accurately, completely, and legibly, so that these data can be entered correctly into ODP's computerized database after the cruise.

Shipboard Organic Geochemists are responsible primarily for advice as to when hydrocarbons in cores may constitute a safety or pollution hazard requiring abandonment of the drill site. To do this, they monitor cores for gas pockets, fluorescence, oil cysts, and odors or visual signs of hydrocarbons. Specific duties include:

(1) Performing organic-geochemical analyses in the shipboard chemistry lab, and overseeing analyses performed by the ODP Chemists staffing the lab.

(2) Taking part in the routine shipboard sampling program for their own and others' post-cruise studies, as outlined in the cruise sample plan.

(3) Coordinating their results with shipboard data (e.g., porosity, density, geologic age, acoustic reflectors, and thermal gradient), to assist in monitoring for drilling hazards.

(4) Adding organic-geochemical data to the "barrel sheets," which summarize data obtained by the entire shipboard party for each core.

(5) Writing the "Organic Geochemistry" chapter for the Hole Summaries. The Hole Summaries form the basis for the Initial Reports volume of the Proceedings of the Ocean Drilling Program.

(6) Compiling organic-geochemistry-related material for the "Explanatory Notes" chapter of the Initial Reports volume of the ODP Proceedings.

(7) Assisting the Co-Chief Scientists in preparing articles for submission to Nature and Geotimes, and a press release for general distribution to news media immediately after the cruise.

g. Inorganic Geochemists

During the cruise, Inorganic Geochemists are responsible for collecting, analyzing, and compiling data in a manner conformable with ODP standards and format. (Further information is available in ODP technical note number 5: "WaterChemistry Procedures aboard JOIDES Resolution--some Comments.") Each Inorganic Geochemist is expected to become familiar with shipboard computer facilities and with the lab-specific and generic (e.g., word-processing) software used in the chemistry lab. Where data are collected on paper data forms, shipboard scientists are asked to complete hand-written forms accurately, completely, and legibly, so that these data can be entered correctly into ODP's computerized database after the cruise.

Shipboard Inorganic Geochemists are primarily responsible for conducting carbonate and interstitial pore water analyses. A routine analytical program for inorganic geochemistry is carried out by both the shipboard Inorganic Geochemists and ODP Chemists, highly trained technicians assigned full-time to the shipboard chemistry lab. Specific duties include: 
(1) Performing inorganic-geochemical analyses in the shipboard chemistry lab, and overseeing analyses performed by the ODP Chemists staffing the lab.

(2) Selecting samples for shipboard analyses XRD, XRF, and carbonate content), made in cooperation with the Sedimentologists and Petrologists.

(3) Taking part in the routine shipboard sampling program for their own and others' post-cruise studies, as outlined in the cruise sample plan.

(4) Adding inorganic-geochemistry information to the "barrel sheets," which summarize data obtained by the entire shipboard party for each core.

(5) Writing up their results in an "Inorganic Geochemistry" chapter for inclusion in the Hole Summaries. The Hole Summaries form the basis for the Initial Reports volume of the Proceedings of the Ocean Drilling Program.

(6) Compiling inorganic-geochemistry-related material for the "Explanatory Notes" chapter of the Initial Reports volume of the ODP Proceedings.

(7) Assisting the Co-Chief Scientists in preparing articles for submission to Nature and Geotimes, and a press release for general distribution to news media immediately after the cruise.

\section{h. Geophysicists}

During the cruise, Geophysicists are responsible for collecting, analyzing, and compiling data in a manner conformable with ODP standards and format. Each Geophysicist is expected to become familiar with shipboard computer facilities and with the lab-specific and generic (e.g., word-processing) software used in the underway geophysics lab. Where data are collected on paper data forms, shipboard scientists are asked to complete hand-written forms accurately, completely, and legibly, so that these data can be entered correctly into ODP's computerized database after the cruise. Specific duties include:

(1) Assisting the $\mathrm{Co}-\mathrm{Chief}$ Scientists in accurately locating the drill sites detailed in the cruise Scientific Prospectus.

(2) Overseeing collection of bathymetric, navigational, seismic, and magnetic underway data and, as time allows, assisting in data collection in other laboratories.

(3) Taking part in the routine shipboard sampling program for their own and others' post-cruise studies, as outlined in the cruise sample plan.

(4) Processing seismic profiles for inclusion in the "Underway Geophysics" chapters of the Hole Summaries. The Hole Summaries form the basis for the Initial Reports volume of the Proceedings of the Ocean Drilling Program.

(5) Compiling underway-geophysics-related material for the "Explanatory Notes" chapter of the Initial Reports volume of the Proceedings of the Ocean Drilling Program. (6) Assisting the Co-Chief Scientists in preparing articles for submission to Nature and Geotimes, and a press release for general distribution to news media immediately after the cruise.

i. JOIDES Logging Scientists

The position of JOIDES Logging Scientist is open to scientists of any discipline (e.g., seismology, rock physics, stratigraphy, geochemistry), with or without previous logging experience, who have an interest in using continuously recorded borehole data to add to the scientific success of the expedition. The JOIDES Logging Scientist will 
receive pre-cruise training in ODP logging operations and log interpretation from the Borehole Research Group at LDGO.

During the cruise, Logging Scientists are responsible for collecting, analyzing, and compiling data in a manner conformable with ODP standards and format. Each Logging Scientist is expected to become familiar with shipboard computer facilities and with the lab-specific and generic (e.g., word-processing) software used in the downhole measurements lab. Where data are collected on paper data forms, shipboard scientists are asked to complete hand-written forms accurately, completely, and legibly, so that these data can be entered correctly into ODP's computerized database after the cruise.

JOIDES Logging Scientists advise the Co-Chief Scientists on the logging program for the cruise. They work closely with the LDGO Logging Scientist and the Schlumberger field engineer in the design, implementation, and subsequent interpretation of this program. Specific shipboard duties include:

(1) Assisting in the routine processing of all borehole logging data. During logging runs, assisting the LDGO Logging Scientist in monitoring operations, with primary responsibility for rapid distribution and explanation of logging data to the scientific party immediately after the data have been collected.

(2) With other shipboard scientists, integrating logging data with other scientific data (e.g., physical-properties data) collected on the cruise and, as time allows, assisting in data collection in other laboratories.

(3) Taking part in the routine shipboard sampling program for their own and others' post-cruise studies, as outlined in the cruise sample plan.

(4) Writing a "Downhole Measurements" chapter for the Hole Summaries for each logged site, with assistance from the LDGO Logging Scientist. Also, a brief operational report is written at the end of the leg. The Hole Summaries form the basis for the Initial Reports volume of the Proceedings of the Ocean Drilling Program.

(5) Compiling logging-related material for the "Explanatory Notes" chapter of the Initial Reports volume of the ODP Proceedings.

(6) Assisting the Co-Chief Scientists in preparing articles for submission to Nature and Geotimes, and a press release for general distribution to news media immediately after the cruise.

j. LDGO Logging Scientist

The LDGO Logging Scientist is the staff representative from the Borehole Research Group at Lamont-Doherty Geological Observatory (LDGO), and assists the Co-Chief Scientists and Logging Scientist in the design, implementation, and subsequent interpretation of the logging program on each leg. He is under the supervision of the Operations Superintendent. The LDGO Logging Scientist assists in the shipboard sampling program, taking samples for the shipboard and shore-based investigators. At the end of each site, where appropriate, the LDGO Logging Scientist assists the shipboard Logging Scientist in writing a "Downhole Measurements" chapter for the Hole Summaries. 


\section{Key SEDCO Personnel}

\section{Captain}

The Captain is responsible for the ultimate safety of the drill ship and its personnel. He has primary command whenever the drill ship is under way and while in port. While on site drilling, the Captain cedes primary operations responsibility to the Drilling Superintendent.

\section{Drilling Superintendent}

The Drilling Superintendent is responsible for safe conduct of drilling operations. While on site, he is the primary responsible party for UDI/SEDCO. Specific duties of the Drilling Superintendent include assuring that drilling operations are conducted in a safe, efficient manner, and advising the Operations Superintendent of unsafe operations or procedures that could compromise safety or drilling/coring operations.

\section{Electrical Supervisor}

The Electrical Supervisor is responsible for proper operation and maintenance of the Dynamic Positioning system and all SEDCO electronic/electrical apparatus. This includes advising the Drilling Superintendent of any Dynamic Positioning System status changes that could affect drilling operations or safety.

\section{DRILLING/CORING EQUIPMENT AND PROCEDURES}

\section{A. General Procedures}

Situated amidships is the Dreco derrick, reaching an elevation of $202 \mathrm{ft}(62 \mathrm{~m})$ above the water line, with a static load capacity of $1,200,000 \mathrm{lb}(500,000 \mathrm{~kg})$. At the base of the derrick is the $22-\mathrm{ft}(7-\mathrm{m})$ diameter moonpool, which contains a funnelshaped guide horn to restrain the drill string and prevent stress from accumulating at specific points as the ship moves. A Western Gear heave compensator of 800,000 $\mathrm{lb}(400,000-\mathrm{kg})$ capacity is integrated into the derrick's traveling block to decouple the vessel's vertical motion from the drill string.

As soon as the ship is under way, precision depth recorder, air gun and/or water gun seismic, and magnetometer profiling equipment is rigged and operated by ODP personnel as directed by the Lab Officer and the Co-Chief Scientists. In most areas, seismic profiles collected previously by other oceanographic vessels allow JOIDES Resolution to commence drilling operations immediately after running a profile over the proposed site to confirm location and bottom condition.

Before arriving at a site, operations and scientific personnel meet. At this pre-site meeting, the Co-Chief Scientists describe the site, their expectations regarding sediments and/or rocks, and what information they want to obtain from coring and logging. A preliminary drilling, coring, and logging plan is reviewed.

The final approach to the site is normally made with the vessel traveling at $\sim 6$ 
kt or less and with an acoustic positioning beacon ready for immediate deployment. The Co-Chief Scientists monitor profiling to determine the final drop point. As the vessel passes over the site, the beacon is dropped and allowed to free-fall to the seafloor. During the beacon's descent, the underway equipment is brought aboard and stowed, and the vessel turns back toward the drop point. The thrusters and positioning hydrophones are lowered to operating position as the ship returns slowly to the beacon drop point. The positioning system is locked onto the beacon signal and checked for reliable operation. A "final" high-quality satellite navigation fix assures the actual location of the site.

As stable positioning over the beacon is established, preparations are made for running the core barrel and bottom-hole assembly to the seafloor. The bottom-hole assembly (BHA) most commonly used consists of a 2-7/16-in. X 9-7/8-in. roller cone core bit, one 8-1/4-in. outside diameter (OD) outer core barrel, eight 8-1/4-in. OD X 30-ft drill collars, one 7-1/4-in. X 30-ft drill collar and three joints of 5-1/2-in. OD $30.3-\mathrm{lb}$ range 2 drill pipe. The BHA is attached to 5 -in. OD $19.5-\mathrm{lb}$ S- 135 drill pipe in 90-ft (27-m) three-joint stands. For hydraulic piston (APC) coring, a 3.80-in. X 11.44in. bit and special outer core barrel adapter subs are used. This configuration also permits deployment of the extended core barrel (XCB) system, usually used for coring beyond the maximum depth of the piston corer. Heavier BHA configurations may be used for coring hard rock or abbreviated assemblies may be run where only softer sediments are to be cored.

The drill string is run to within about $20 \mathrm{~m}$ of the seafloor as determined by the precision depth recorder (PDR) profile corrected for temperature and salinity of the water column as well as for seafloor slope. To assure the best available water depth information and to avoid the possibility of "running into" the ocean floor with the drill string, at least two independent readings of the PDR are made, one by the Operations Superintendent and one by another qualified person, usually the Lab Officer. The Operations Superintendent ensures that any discrepancies are worked out. This depth reading is later superseded by drill pipe measurement after the hole has been started (see Section V.B).

At this point the top drive (an electric motor that rotates the pipe) and swivel are picked up and attached to the traveling block/heave compensator. Drill pipe is added to the drill string as coring begins. Contact with the seafloor, often difficult to detect in soft sediments, is known as "spudding in." If a mud-line core is desired, the drill string is lowered until the bit starts to "take weight" or until it is believed that the inner core barrel contains sediments. The inner core barrel is retrieved by wireline and the core removed. For mud-line cores with the APC, the drill string is lowered until the bit is thought to be 3-7 $\mathrm{m}$ above the mudline, and a core is taken.

Drilling is accomplished by rotating the drill string with the Varco electric top drive system, capable of $41,000 \mathrm{ft}-\mathrm{lb}$ of torque, which is connected directly to the drill string through the pup joint, a short piece of pipe. This arrangement allows drilling down more than one joint of drill pipe at a time for increased efficiency.

Surface sea water is used for circulation around the drill bit. Water is pumped down the drill pipe, up the annulus and out the hole at the mud line to remove cuttings, 
cool the bit, and aid in hole stability. Circulation of seawater is maintained nearly constantly. At times, 20-50 bbl "spots" of drilling mud (fresh-water bentonite) are used to assist in hole cleaning, such as when shale, chert, or basalt chips are sloughing. The use of weighted material usually is restricted to abandonments, as barite $\left(\mathrm{BaSO}_{4}\right)$ can be carried only in limited quantities on the vessel. Occasionally, barite slugs may be used if pure gel is ineffective in cleaning or to "slug the pipe" against backflow. The hole may be filled with gel mud if required for certain types of open-hole logs.

After total depth has been reached, when the hole is to be logged, the bit is released on bottom, normally using a hydraulic disconnect (HBR). In some bits with wide throats a lockable flapper valve permits logging tools to pass through the bit throat, without bit release. Both methods leave the pipe "open-ended" with a minimum inside clearance of 3-15/16 in. The drill string is pulled up until its end is located at the base of the uppermost competent formation (usually $\sim 100 \mathrm{mbsf}$ ). A suite of electric wireline logs is then recorded (see Section IX.O). Holes deeper than 400 mbsf and all holes that penetrate into basement rocks are surveyed with a basic suite of open-hole logs.

When site operations are completed, the hole is abandoned in accordance with the JOIDES Pollution Prevention and Safety Panel's recommendations. When all equipment is secured on deck, the vessel moves on to the next site.

\section{B. Drilling Depth Measurements}

Sub-bottom depth measurements give rise to considerable confusion, frustration, and misinformation among ODP scientists and data-handling personnel. Users of ODP data are often not fully aware of the bases or uncertainties of the depth measurements with which they are working.

It is of primary importance that interested parties understand that, for all its advanced technology, ODP has no means of measuring directly the depth of the water or the hole. The best that can be done is to measure the length of the drill string suspended beneath the ship. The last point at which the drill pipe can be seen or marked as it is lowered is the top of the dual elevator stool (DES) on the rotary table, about $70 \mathrm{~cm}$ above the rig floor. For that reason, the DES is used as the official datum for all drill-string-related depth information. The permanent datum is, of course, mean sea level, and the correction to mean sea level from DES measurement is calculated for each site by the Operations Superintendent.

Convenience measurements, such as depth in meters below the rig floor (mbrf), below sea level (mbsl), below seafloor (mbsf), etc., are used by different special-interest groups on board. Such usage makes certain studies and correlations easier, but often causes confusion when attempts are made to correct back to official depths or to correlate with the depths of someone who has used a different convenience datum.

It should be noted that the PDR depth is used only as a preliminary guide for drilling personnel in running the proper length of drill string before the top drive is deployed and coring operations begin. Once a drill pipe measurement (DPM) is 
obtained for water depth, the PDR depth has no further value and is disregarded.

Drill pipe measurements used in reaching the ocean floor are obtained by rack measurements, using a steel tape, of each piece of pipe when new pipe is placed in service and on the first pipe trip of each cruise (or crew change). Depths of penetration are measured using drill string lengths added after spudding in.

Depth measurements based on a long string of suspended pipe are subject to numerous errors and inaccuraties, some of which are detailed below:

a. Pipe stretch: Probably the most significant error in normal ODP operations, pipe stretch increases with the length of the drill string as a result of increasing suspended weight. The cumulative effect of stretch during coring is minor except in very deep holes (e.g., $9.4 \mathrm{~m}$ of elongation for $\sim 4500 \mathrm{~m}$ of drill pipe).

b. Temperature: The drill string, deployed in a tropical ocean, undergoes length contraction of about $1 \mathrm{~m}$ per $4500 \mathrm{~m}$ of pipe as it is lowered into the colder waters at depth.

c. Positioning: Although the accuracy of JOIDES Resolution's automatic station keeping (ASK) system is a remarkable $1 \%$ of water depth, in $5000 \mathrm{~m}$ of water $50 \mathrm{~m}$ of lateral variation is possible. When the ship is not directly over the hole, more pipe is necessary to reach the bottom; the ratio of horizontal to vertical offset is difficult to calculate, because the weight of the unsupported pipe causes it to sag into a modified catenary. An error of several meters may exist at any time, and there is no way of confirming or measuring it.

d. Currents: The lateral forces imposed by subsurface or deep-running surface currents on the surface area of a long drill string may be considerable. Those forces can result in a bow or even an S-curve in the string, another departure from a straight line that defies measurement.

e. Tide: The effects of tidal variations in the open ocean are usually dismissed as insignificant. However, a tidal range of about $1.5 \mathrm{~m}$ was observed at DSDP Site 504 off Ecuador during Leg 111 when the drill string was immobilized in a reentry cone for an extended period.

f. Vessel heave: Vertical motion of the drill ship can reach 4-5 $m$ under severe sea/swell conditions, but normally is much less. In firm and hard formations, heave motion is taken up by the drill string heave compensator. In soft formations where low bit weights are used the bit may be alternately lifted off the bottom and pushed deep into the yielding sediment. This error is most significant in seafloor depth determination and in APC coring. "Extra" core may be recovered, or a short core may be obtained if the APC fires on an up-heave. Heave motion is the principal cause of frustrating discrepancies between depths of seafloor and correlative horizons in double-APC holes.

g. Change in draft: The distance from the top of the DES to the sea surface is approximately $11 \mathrm{~m}$, but varies with the draft of the vessel according to its loading and rates of fuel and water usage. The Operations Superintendent determines the height of the DES above sea level at the beginning of each site, using draft figures provided by the ship's officers. The change in draft over a 2-month leg is less than 1 meter, so corrections during occupancy of a given site normally would be insignificant. 


\section{Logging Depth Measurements}

Logging depth measurements aboard JOIDES Resolution are subject to most or all previously mentioned factors. In most cases, the water depth is much greater than hole depth, and the majority of depth error, systematic or otherwise, accumulates in the water column. Because ODP logs are intended to correlate with cores and drilling parameters that are based on drill-string measurements, and because total depth accuracy is not a primary consideration, a non-oilfield approach to depth measurements is taken. As the logging tool passes the end of the drill string, the logging engineer simply adjusts his depthometer to agree with the driller's pipe depth. The existing errors are therefore equalized, and logging depths should agree closely with drilling depths. In very deep holes, however, a differential stretch correction may be needed, as the pipe and logging cable have different stretch coefficients.

\section{Coring and Drilling Equipment and Usage}

\section{Rotary Coring System (RCB) - all sediment and rock types}

A modified Hycalog wireline core barrel is the primary coring tool for the Ocean Drilling Program (Fig. 4a). This design uses a drill collar as the outer core barrel. The collar is the same as those used in the BHA. The design places an inner barrel support bearing near the bit so that the core barrel can remain motionless relative to the incoming core while the bit and outer barrel rotate. Cores are cut by rotating and lowering the entire drill string. Cutters on the core bit and circulation of seawater remove rock or sediment ahead of the bit, but leave a central stub that becomes the core. The core passes through the open throat of the bit and into a plastic sleeve called the core liner, inside the inner core barrel. The inner barrel retains the core by means of core catchers at the bottom support. The core is retrieved through the drill pipe by means of a sand line. This system can be used in virtually any sediment or crustal material with only minor modifications in equipment and techniques. Standard cores recovered are up to $9.5 \mathrm{~m}$ long $(9.3 \mathrm{~m}$ core + $0.2 \mathrm{~m}$ core-catcher) and $\sim 66 \mathrm{~mm}$ in diameter (see discussion of core recovery, Section VIII.B.2).

Slushy unconsolidated formations are cored using a punch core procedure. The drill pipe is lowered evenly and steadily without rotation, holding as closely as possible to a constant bit weight. No fluid is pumped during this operation. The inner barrel fills in approximately six minutes. Faster lowering of the drill pipe results in poor recovery. To prevent the core sample from falling out of the barrel during retrieval, a "flapper" type core catcher or a dog-type catcher with sailcloth sock is used.

Formations that are dry and consolidated enough not to fall through the dog-type core catcher are cored with the bit turning slowly. The core is taken without fluid being pumped until the bit weight and torque increase to a point where it is necessary to pump fluid. At the instant circulation is "broken," the pumps are shut off; penetration instantly increases and the coring cycle is repeated. Constant circulation is used as soon as the sediment becomes firm enough to resist washing away at the minimum sustained pump rate. 


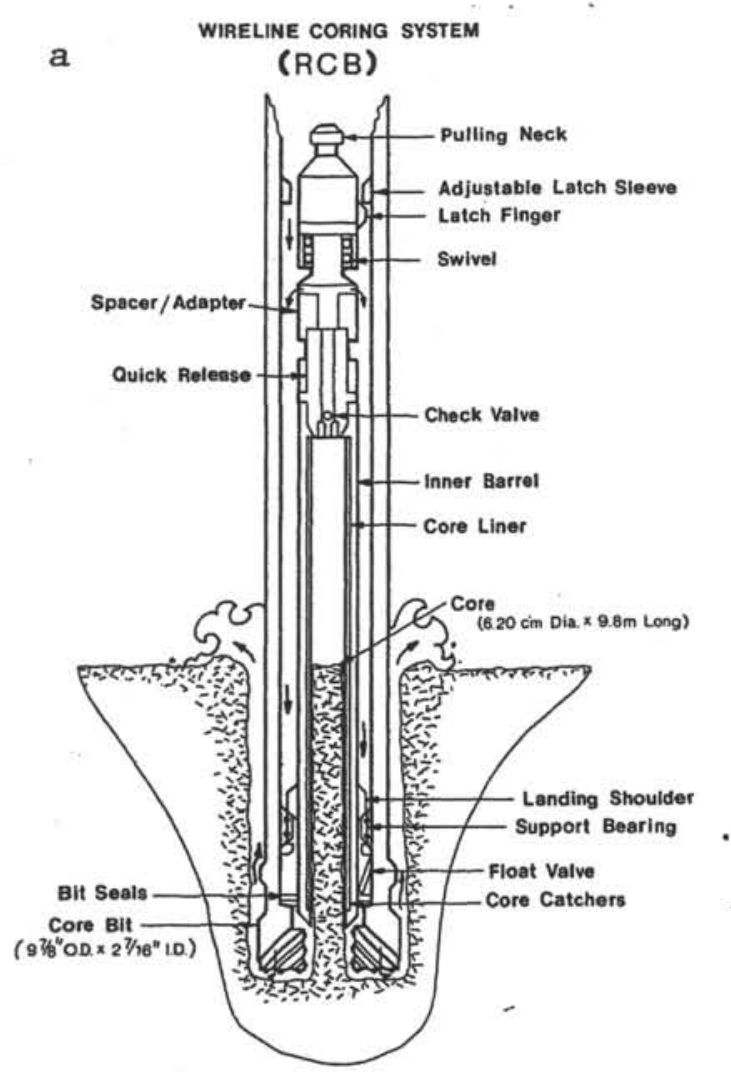
ADVANCED PISTON CORER
(APC)
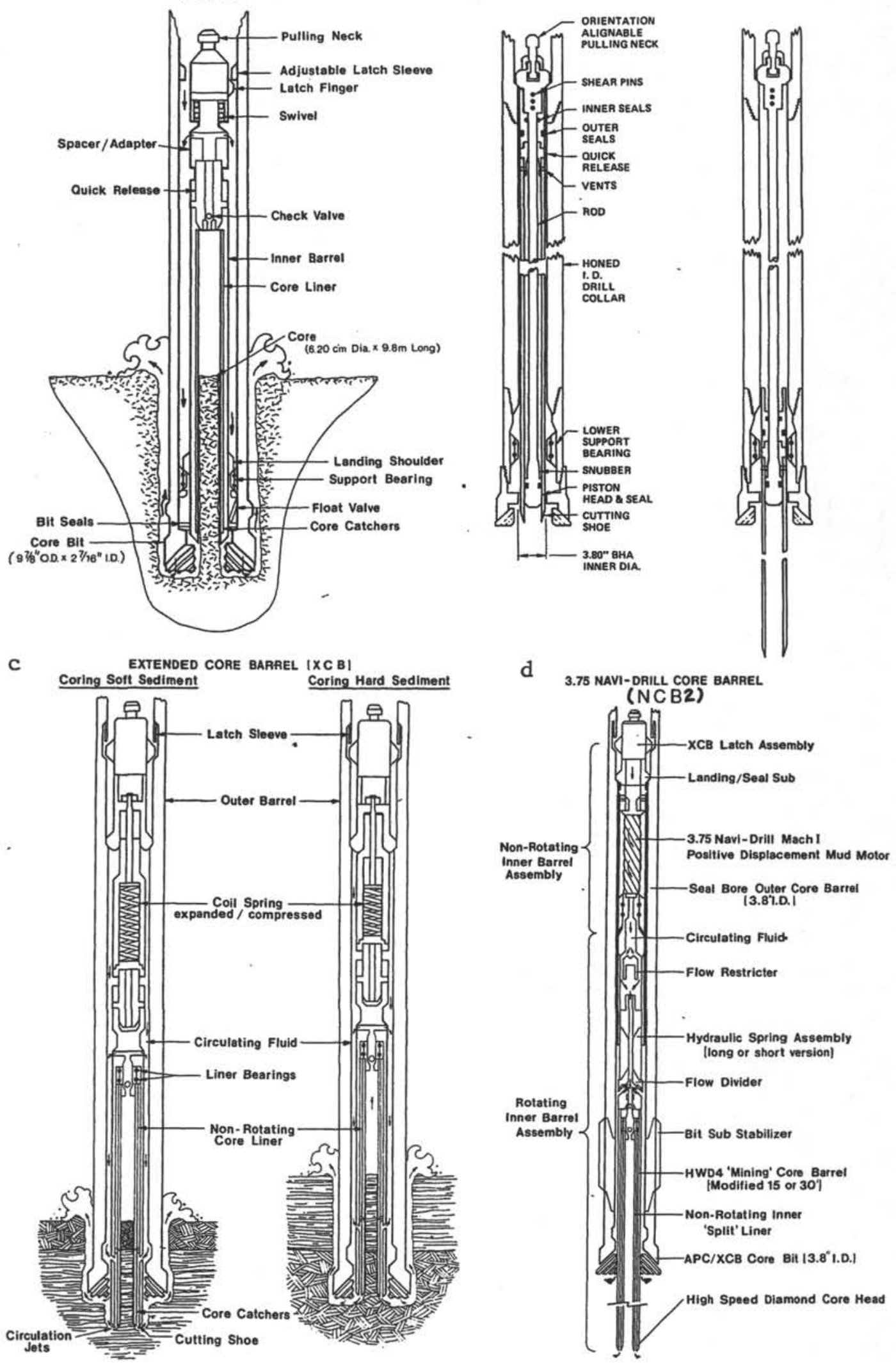

Figure 4. Coring systems used in shipboard drilling operations. 
When basalt or very hard sediments are encountered, a hard-formation core catcher assembly is installed on the inner core barrel. Much greater bit weights are required and the rate of penetration may fall to $1-2 \mathrm{~m} / \mathrm{hr}$. Circulation rates do not appear critical to core quality but must be sufficient for efficient removal of cuttings.

2. Advanced Hydraulic Piston Coring System (APC) - very soft to soft sediment A system combining the principles of oceanographic piston coring and stored drill string energy has been developed for coring soft marine sediments (Fig. 4b). The APC has become the second principal ODP coring system, as it produces virtually undisturbed cores at a very high recovery rate. The APC in current use is the fourth generation of ODP hydraulic piston corers. It has advantages over previous systems of increased strength and penetration power, fewer parts, and more efficient handling. Full cores may now be taken from depths as great as $300 \mathrm{mbsf}$, although $200 \mathrm{mbsf}$ or less is the normal limit. The APC requires a special seal bore drill collar as an outer core barrel, rendering the APC BHA incompatible with the standard RCB system. It is, however, compatible with the more recently developed extended core barrel (XCB) system described below.

In piston coring operations, the corer is locked together by shear pins until it has been lowered into place at the bit by sand line. Upon landing, the seals of the corer seal off the bore of the drill string. Pressure is then applied to the drill pipe with mud pumps until forces resulting from differential pressure cause the shear pins to fail. The inner core barrel is thus forcibly ejected through the bit while moving past a fixed internal piston. A sliding seal against the bore of the outer core barrel maintains downward fluid pressure on the inner barrel until it reaches the end of its stroke. The extended assembly and the full inner barrel are then recovered with the sand line.

The hydraulic piston core system was designed primarily for coring the soft material usually found in the upper $100-300 \mathrm{~m}$ of the sediment column. Reduced penetrations and recovery are possible to a fairly high degree of induration before damage to the APC's cutting shoe occurs. Sand, especially in the fine- to medium-grain size range, is extremely difficult to penetrate owing to its incompressibility. Fairly good recovery of sand cores has been achieved, however, through the combined use of flapper, sock, and standard core catchers.

The pressure required to extend the piston core barrel (and therefore, the force with which it penetrates the sediment) may be varied by using from one to three shear pins in a choice of two strengths. The APC now in use also has a provision for varying the penetration velocity for any given shoot-off pressure. There is some indication that excessive penetrating force results in core disturbance in soft sediment and an effort is made to use only the amount of pressure necessary to achieve full penetration. As coring continues into more compacted material, cores are monitored closely for incomplete recovery or indications of flow-in disturbance (caused when the piston is pulled to the top of the barrel following an incomplete stroke). More or larger shear pins are then employed on subsequent cores to increase penetrating force.

Experience has shown that APC "refusal depth" is usually determined not by the inability of the APC to penetrate, but by the amount of force required to withdraw it from the sediment. 
Using the Eastman-Whipstock Multishot orientation tool (see Section IX.O.2) in conjunction with the APC system, cores may be oriented geographically in situ with respect to the downhole ambient field. Also, von Herzen-type heat flow shoes can be used with the APC to recover measurments of in-situ temperature.

\section{Extended Core Barrel System (XCB)}

The extended core barrel (XCB), developed initially by DSDP and modified by ODP, has a spring-loaded cutter shoe that extends beyond the bit to core soft material ahead of the disturbing influences of the fluid jets and roller cones (Fig. 4c). The resistance of harder material causes the BHA weight to force the inner barrel upward, with the cutter shoe retracting to a position above the roller cones. This automatically restores full circulation to the point at which core is being formed. The inner core barrel (with cutter shoe) is driven by the drill string, but the plastic core liner is rotationally decoupled from the inner barrel.

The primary advantage of the XCB system is that it permits coring operations to proceed uninterrupted for as much as several hundred meters beyond the APC refusal point. As both the APC and XCB systems require a large-diameter bit throat, an outer core barrel assembly has been designed that permits the corers to be deployed interchangeably. This provides the option of changing between hydraulic piston coring (APC) and rotary (XCB) coring without a time-consuming round trip of the drill string.

In some sediment types, the XCB has outperformed the RCB in terms of core quality and recovery. The system was redesigned in 1987-88 to address problems with mechanical failures and drilling hydraulics. Development will continue with the aim of extending the $\mathrm{XCB}$ 's range into harder material.

\section{Motor-Driven Core Barrel (MDCB)}

Another type of coring system, currently under development by ODP, is the motordriven core barrel (Fig. 4d). The MDCB is a downhole, slimline mud motor married to a core barrel with an outside diameter of $3.75 \mathrm{in}$. The version used formerly aboard ship (the Navi-drill core barrel; NCB) was borrowed from the mining industry.

The entire coring assembly is wireline retrievable and fully compatible with the APC/XCB system. The positive-displacement mud motor uses seawater pumped down the drill string to produce high rotational speeds at the core barrel (up to $850 \mathrm{rpm}$ ) independent of rotation of the drill string and core bit. This allows optimum utilization of different types of narrow-kerf diamond core heads that are capable of coring in lithified formations beyond the capabilities of the XCB.

The latest phase of this new technology is designed to cut and recover a 2.4-in. (61 $\mathrm{mm}$ ) diameter core up to $15 \mathrm{ft}(4.5 \mathrm{~m})$ long. The MDCB penetrates ahead of the main core bit so that the entire core is cut from material undisturbed by the borehole. The core is captured in a metal core liner or an optional polycarbonate liner.

One potential advantage of the MDCB system is the 3.75-in. "pilot hole" left below the drill string after the MDCB core barrel is retrieved. This pilot hole could be used for slimline packer work or other in-situ experiments with retrievable samplers. 
The MDCB system is a natural extension of the APC/XCB system, allowing the XCB to operate in semilithified formations and give way to the MDCB system as more indurated lithologies are encountered. The ultimate goal is to recover high-quality cores from a single hole extending from piston-coreable soft sediment into basement that must be penetrated with diamond core heads, all without the necessity of a pipe round trip for a different BHA.

Different versions of the NCB were field-tested on Legs 104, 114, 118, and 124E. The first operational use was during Leg 121. Development, testing, and improvement of the MDCB will continue until it becomes a routine tool for ODP operations.

\section{Diamond Coring System (DCS)}

ODP is developing a Diamond Coring System (DCS) for deep-water applications. The system being developed will be able to both drill and core in sedimentary and crystalline rock formations in up to $4500 \mathrm{~m}$ of water. A prototype version of the DCS was tested in January 1989 near the Philippines in $1700 \mathrm{~m}$ of water to evaluate the potential for using a top-driven high speed diamond coring system deployed from a floating vessel.

The DCS proposed for Phase II involves running a 3-1/2-in. diameter, high-strength tubing string inside the standard 5- and 5-1/2-in. drill pipe. A high speed, thin kerf impregnated, diamond coring bit is attached to the outer core barrel assembly on the end of the tubing string. The core barrel allows for a 10.0-ft X 2.20-in. core to be taken (5-ft cores are optional). The core is retrieved in standard acetate butyrate core liners. Split or whole steel liners are optional for high temperature applications.

An open swivel electric top drive rotates the tubing string. It operates at speeds varying between 60 and $540 \mathrm{rpm}$ and is capable of producing a maximum torque of $11,000 \mathrm{ft}-1 \mathrm{~b}$ but will be limited to a $8300 \mathrm{ft}-\mathrm{lb}$ during coring operations. The open swivel concept allows for the core barrel to be retrieved without having to disconnect from the tubing string.

Both weight on bit and mud flow must be controlled in a precise manner. Weight-on-bit control is accomplished by introduction of a secondary heave compensator, which removes load fluctuations resulting from the mechanical inefficiencies of the primary 400-ton passive heave compensator. Controlled mud flow is accomplished using an independent mud pump with low volume flow but with a high pressure capability.

All of the diamond coring operations and drilling functions will be performed from a manned platform suspended in the drill ship's derrick. A driller's console will be situated on this platform to allow overall control of the DCS.

In addition to the vessel mounted DCS hardware, several other pieces of hardware and concepts have been developed or refined to be used with this system. Specifically these include the Mini Hard Rock Guide Base, modified reentry cone, use of the 5 and 5-1/2 inch drill pipe as a mini riser, mechanical attachment tensioning tool, tapered stress joint, mechanical attachment receptacle and multiple back-off devices. All of this equipment is necessary to deploy the DCS in up to 4500 meters of water and conduct coring operations.

\section{Pressure Core Sampler (PCS)}

The Pressure Core Sampler is a coring system currently under development by ODP that is capable of retrieving core samples at near in-situ pressures. The pressurized core 
samples can be taken from the mud line down to indurated formations and/or basement rock. The PCS uses both oilfield pressure coring technology and deep-ocean coring technology developed by DSDP. The current Phase I tool provides for recovery of fluid and/or gas samples and constant monitoring of the sample chamber pressure.

The ability to transfer and directly access the core sample while maintaining near in-situ pressure will be provided for by the Phase II PCS in the near future. The Phase II PCS will also produce a thermal history of the core sample during the coring operations.

The PCS is a free-fall-deployable, hydraulically actuated, wireline retrievable, pressure coring system completely compatible with the BHA used for the APC, XCB, and MDCB. The PCS is not compatible with the BHA used for RCB coring or the DCS. The PCS is made up of a modified XCB latch, hydraulic actuator, accumulator, ball valve, and detachable sample chamber. When the PCS is deployed, it lands and latches into the BHA and is rotated with the BHA during coring operations. The core sample is contained in a nonrotating metal core tube with integral core catchers. The PCS recovers a nominal 42$\mathrm{mm}(1.65$-in.) diameter core sample, $0.86 \mathrm{~m}$ (34 in.) long, at pressures up to $689.7 \mathrm{~atm}$ $(10,000 \mathrm{psi})$.

\section{Vibra-Percussive Corer (VPC)}

ODP's prototype development of a VPC is an attempt to introduce the capability of downhole vibration into the coring of unconsolidated sediments in formations where APC refusal is prematurely reached or where incompressible, sandy formations restrict penetration of the piston corer. The VPC tool is being designed for deployment in the $\mathrm{XCB} / \mathrm{APC}$ bottom hole assembly. The VPC will be a wireline retrievable system which may be deployed at any point during a coring operation and is intended to be fully interchangeable with the APC and XCB, allowing the choice of coring tool/technique to be optimized for any formation (other than hard rock) without a drill string round trip.

The VPC system will use many existing ODP core barrel components. The lower end will be an APC cutting shoe and core tube containing conventional core catchers and butyrate core liner.

It is to be powered by an all-new, seawater-driven percussion unit. This unit will superimpose a high frequency force on the normal downward thrust resulting from the pressure developed in the drillstring by the mud pumps.

Prototype development and land testing of the VPC is scheduled to continue during the first half of 1990 with initial sea trials anticipated in the fall of 1990.

\section{Selected Other Equipment}

\section{a. Core Catchers}

Two basic versions of the DSDP dog-type core catcher are used in rotary coring operations. The soft formation version features ten dogs that operate to maximize closure of the inner core barrel bore. The hard formation configuration has eight dogs and stronger construction at the expense of gaps in the closure. Normally, both versions of dog-type catchers are run in tandem.

The "flapper" type core catcher consists of a full opening and closing cylindrical trapdoor arrangement. This is the most commonly used core catcher with the APC and is sometimes used in rotary-coring soft sediments. 


\section{b. Core Bits}

The primary core bit now in use is the four-cone roller cutter type with sealed journal bearings and tungsten carbide inserts (teeth). Inserts are rounded for the hardest rocks, or chisel-shaped and extended for softer formations. Bits currently in use include several variations of three common types distinguished by their inserts. There are also special bits with a narrower bit throat and bits for use with the APC/XCB systems that require a bit with a larger throat. The large throat diameter also permits logging operations through the bit. Drag-type APC/XCB bits with polycrystalline diamond cutters are being developed to combine large throat and smaller hole diameter.

\section{c. Bit Releases}

The requirement to pass logging and other instruments through the drill pipe and into the open hole led to the development of bit release mechanisms. The core bit, float valve, lower support bearing, and a modified bit sub are disconnected and left at the bottom of the hole. This leaves the pipe open-ended with a minimum inside clearance of $3-15 / 16$ in. The original (mechanical) bit release (MBR) is still used in certain operational situations. A special shifting tool is lowered to the bit on the wire line. In the hydraulic model (HBR), differential pressure is used to shift an annular piston and actuate the release mechanism after a special plug, or "go-devil," has been pumped into place at the bit.

\section{d. Heave Compensator}

The drill string heave compensator is used routinely in rotary coring operations to decouple the vessel's vertical motion from the drill string. This greatly reduces shock loading on the bit bearings, thereby increasing bit life. The heave compensator also permits temperature probe readings with reduced bit weight in soft sediments and improves hole verticality by allowing better control of weight on the bit.

The heave compensator system maintains relatively constant weight on the core bit by acting as a pneumatic spring. The entire drill string is supported by the pistons of large cylinders that are incorporated into the traveling block in the derrick. The amount of drill string weight supported by the heave compensator can be varied simply by adjusting pressure.

e. Sonic Core Monitor (SCM)

This device uses a sonic transducer mounted at the top of a core barrel to make continuous measurements of changing core height inside the core barrel as the coring process progresses. The measurements are stored in downhole, solid-state, electronic memory for later examination when the core barrel and memory unit are recovered. The data collected are used to identify lost core intervals and clarify the placement of cores in the stratigraphic column.

The first attempt to demonstrate feasibility was established using the SCM as a modification of the XCB system. Development plans include incorporating the SCM into the RCB system in such a way that the SCM can be used on the RCB without expending additional rig time. Successful incorporation of the SCM into the RCB, and addition of the magnetic multishot system (Section IX.O.2), will allow for magnetic orientation of scribed RCB hard rock cores. Testing is scheduled for Leg 134. 


\section{E. Unstable Holes}

Pelagic sediments (clays, oozes, chalks) of the deep ocean areas have been found to be quite stable. The major exception in the pelagic environment occurs when thin strata of chert intercalated in soft ooze are encountered. Fragments of chert apparently become dislodged from the side of the hole, fall down, and wedge the bit. Similar problems may be encountered when penetrating basalt. Zones of basalt rubble are sometimes found at basalt/sediment interfaces, especially in areas of high basement relief and in young basalts. Basalt flows are often composed of shattered volcanic glass and pillow lava zones, which may be subject to sloughing and wedging behavior. When sediments of continental influence are encountered, such as unstructured, poorly indurated coarse turbidites and unconsolidated sand strata, severe sloughing and fill-up problems may occur. Caution must be exercised in all these situations.

Penetration of overpressured/underconsolidated zones may result in severe holecleaning problems when sloughing or flowing sediment "packs off" around the drill collars. The resultant rise in annulus pressure from the mud pumps then forces circulation into the weak zone and cuttings cannot be removed. Such conditions have been encountered in areas of high sedimentation rate and in thrust fault zones.

Drilling proceeds as long as the Operations Superintendent, in consultation with the CoChief Scientists and Drilling. Superintendent, determines that there is a reasonably good chance of achieving important scientific goals and that steps are being taken to minimize the risk of losing drilling tools. If the drill pipe becomes stuck temporarily or if severe torque conditions exist, drilling in the hole is usually terminated.

If unstable hole conditions are encountered, the following actions are considered: (1) circulate slugs of mud to clean the hole of cuttings and slough, and (2) pull above the mudline, offset the ship about $1000 \mathrm{ft}(305 \mathrm{~m})$, and re-drill.

If the pipe becomes stuck and cannot be freed in a reasonable period of time, it becomes necessary to disengage the pipe with the drill pipe severing system above the sticking point and to abandon the hole. The drilling history of the hole must be considered and a severing point in the free drill pipe is chosen. The severing tool is run on the logging wireline. Positive depth control is by means of a casing collar indicator, and is correlated with the driller's pipe tally for location of tool joints, drill collars, etc. The severing system is critical to the ODP operation as it provides the only means of recovering the majority of the drill string if drilling tools become irretrievably stuck.

\section{F. Reentry Procedures}

Approaching a reentry site, an acoustic beacon is deployed as usual to provide a geographical reference for the ship's position, and the streamed gear is retrieved as the ship comes about to position over the beacon.

A single-bit exploratory hole is drilled at the reentry site to core the sediment section in which the cone and casing will be set. Coring is necessary to determine that there is sufficient soft sediment to support the conductor casing but that the sediment is not too stiff to allow the assembly to be "jetted" in. The exploratory hole must be deep enough to 
identify setting points for additional casing strings and to identify any potential hole problems within reach of a single bit. Often the sedimentary section cored in the exploratory hole is drilled without coring in the reentry hole so that the deep objectives can be reached more quickly.

The reentry cone, $16 \mathrm{ft}(4.9 \mathrm{~m})$ in diameter by $12 \mathrm{ft}(3.7 \mathrm{~m})$ high, with four acoustic reflectors spaced around the circumference, is temporarily positioned in the moonpool. Joints of 16-in. casing, usually totaling $50-60 \mathrm{~m}$ in length, are picked up, with a casing hanger made up on the top joint. The casing string is then lowered through and latched into the cone. The BHA is run inside the casing and a running tool positioned so that the bit is approximately 6 in. above the shoe in the casing. With the running tool engaged, the whole assembly is an integral unit. After a check to make sure all the latches are securely locked, the casing, cone, and BHA are lowered to the bottom and jetted in with circulating water until the cone is positioned at the seafloor with the casing supporting the weight. The BHA is then unlatched from the casing/cone and coring begins.

When it becomes necessary to change the bit, the drill string is tripped out of the hole and the bit replaced. The drill string is then run to within $10 \mathrm{~m}$ of the bottom and a television/sonar combination on a frame is run down outside the pipe on the coaxial TV umbilical wireline. The sonar tool locates the reflectors atop the cone, and the TV camera allows visual reentry (Figure 5). The vessel is then maneuvered to bring the pipe directly over the cone. The drill string is "stabbed" into the reentry cone, and coring resumes.

This brief description of reentry procedures does not convey the amount of time necessary for these operations. Days of constant activity on the rig floor may intervene between periods of core recovery.

\section{G. Free-Fall Funnel}

Although not strictly a reentry cone, the free-fall funnel (FFF or "mini-cone") affords an option for attempting to salvage a hole in which operations must be terminated short of reaching the objective owing to operations or equipment problems (e.g., stuck core barrel, unanticipated low rate of penetration necessitating bit change). The FFF is latched around the drill pipe and allowed to free-fall to the seafloor while the drill pipe is still in the hole. A drill pipe round trip is made and the funnel is located and reentered using the TV/ sonar assembly. It is recommended that the FFF be used only where a considerable time savings is expected, rather than redrilling the section. The FFF is not a substitute for a reentry cone, as it does not case off upper sediments and it does not stand clear of the seafloor.

\section{H. Bare-Rock Coring and Drilling Systems}

In areas where adequate sediment cover exists (70-120 m), single-bit and multi-bit reentry crustal holes have been established (e.g., DSDP Sites 395, 417, and 504), utilizing the sediment cover to provide bit confinement and BHA support. However, a means of providing bit confinement, lateral BHA support, and drill string stability was required to effectively spud a hole in minimal sediment cover or into bare rock. Techniques for improving hole stability, minimizing hole disturbance, and freeing the BHA if it became 


\section{DYNAMIC POSITIONING SYSTEM AND REENTRY JOIDES RESOLUTION (SEDCO/BP 471)}

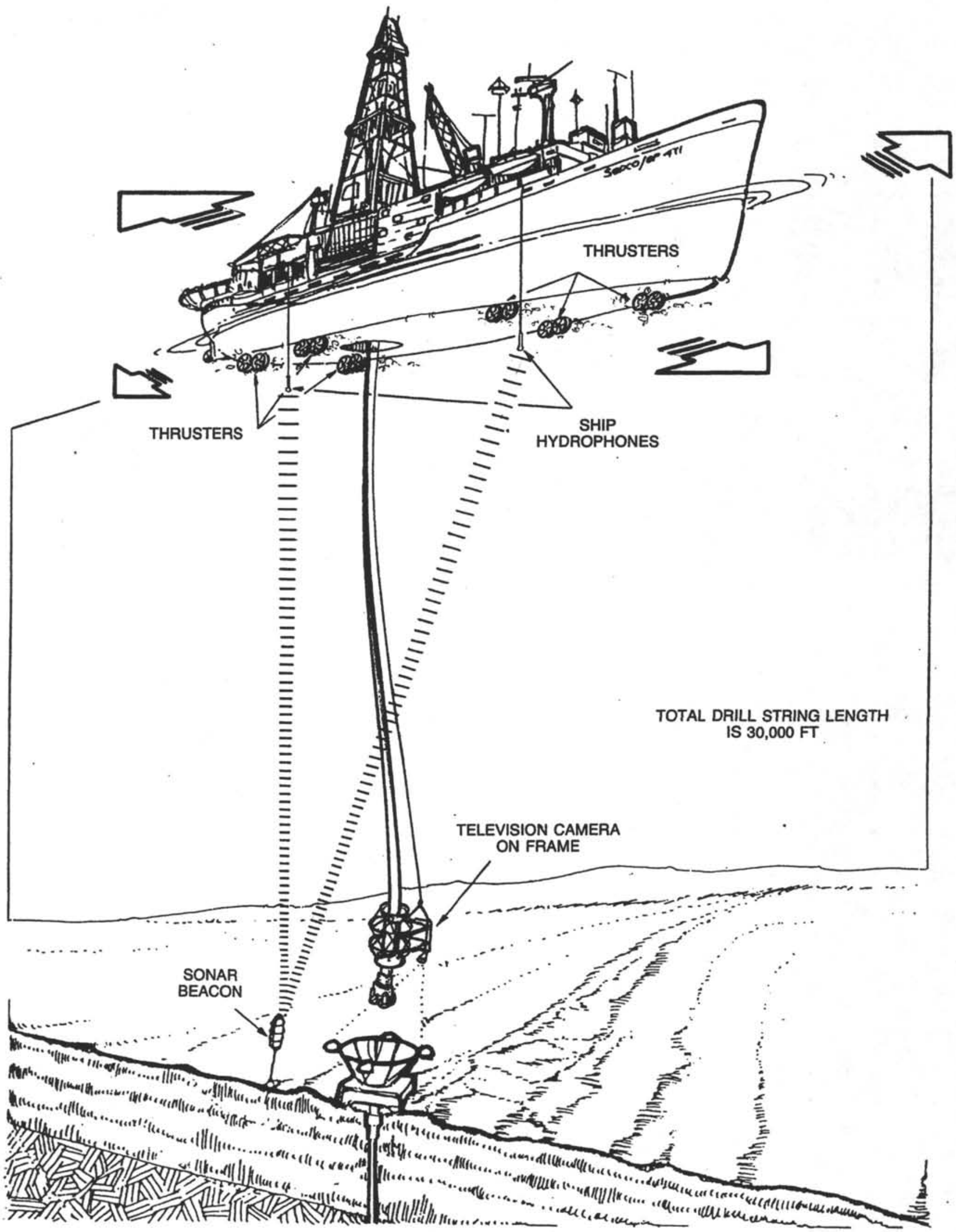

Figure 5. Dynamic positioning system and reentry--JOIDES Resolution. 
stuck were considered essential. It was also necessary to develop drilling and coring bits that can penetrate the highly abrasive and fractured formations with minimal bit weight. A deep-water television system was required for selecting actual drill sites, setting the reentry system, and monitoring the BHA while spudding a hole.

To address these technical problems, a number of engineering hard-rock drilling systems and techniques have been developed, including (a) a hard-rock guide base and deployment system; (b) positive-displacement drilling and coring motors; (c) a television system; and (d) hard-formation drilling and coring bits.

At present, the limiting factor in drilling young fractured basalt formations is hole instability, resulting in low penetration rates and poor core recovery. Long-term engineering development and short-term equipment modifications are being made to overcome this problem, so that future hard-rock coring legs can be increasingly successful.

\section{Hard-Rock Guide Base and Deployment System}

The Hard-rock Guide Base (HRB) was designed to stand on solid seafloor, providing limited BHA support and constraint for the bit to spud a hole in bare rock (Fig. 6). The HRB is a box-shaped structure with a reentry cone fixed inside. It is deployed by being lowered through the ship's moonpool vertically on cables. Once below the ship's keel, it is rotated into the horizontal running position and lowered to the seafloor. On the bottom, the HRB is filled with cement to provide additional mass. The HRB can be deployed in up to $18,000 \mathrm{ft}(5500 \mathrm{~m})$ of water and is designed to land on up to a $20^{\circ}$ sloping seafloor with up to $3-\mathrm{ft}(1-\mathrm{m})$ diameter boulders present.

The first HRB was set successfully during Leg 106 in $3341 \mathrm{~m}$ of water on the MidAtlantic Ridge (Site 648). The HRB provided the lateral support and bit confinement necessary to establish a hole at this bare-rock site, and to permit reentry and continued operations during Leg 109. During Leg 118, assembly and deployment of another HRB was accomplished in 1.5 days, vs. the 3.0 days required during Leg 106 . Continuing development has made HRB deployment both quicker and safer. ODP is developing a new "mini-HRB" that is a standard reentry cone converted to an HRB by assembling four corner boxed segments. Future operations at hard-rock sites will probably make use of these newer mini-HRB's and the DCS system.

\section{Positive-Displacement Drilling and Coring Motors}

In an effort to provide as much stability as possible to the BHA while spudding a hole in bare rock, a positive-displacement drilling motor (PDM) is used to provide torque to the drill bit. The use of downhole motor technology allows the entire drill string to remain stationary from a rotational standpoint. Fluid is pumped through the downhole motor, producing torque to drive the bit.

A positive-displacement coring motor ( $\mathrm{PDCM}$ ) was developed for use in the upper portion of a hole where only minimal BHA support is available. The coring motor is designed to allow continuous coring with a special slimline, wireline-retrievable core barrel system. As with drilling motors, coring motors allow the drill string to remain stationary, providing considerable stability to the BHA while coring. 


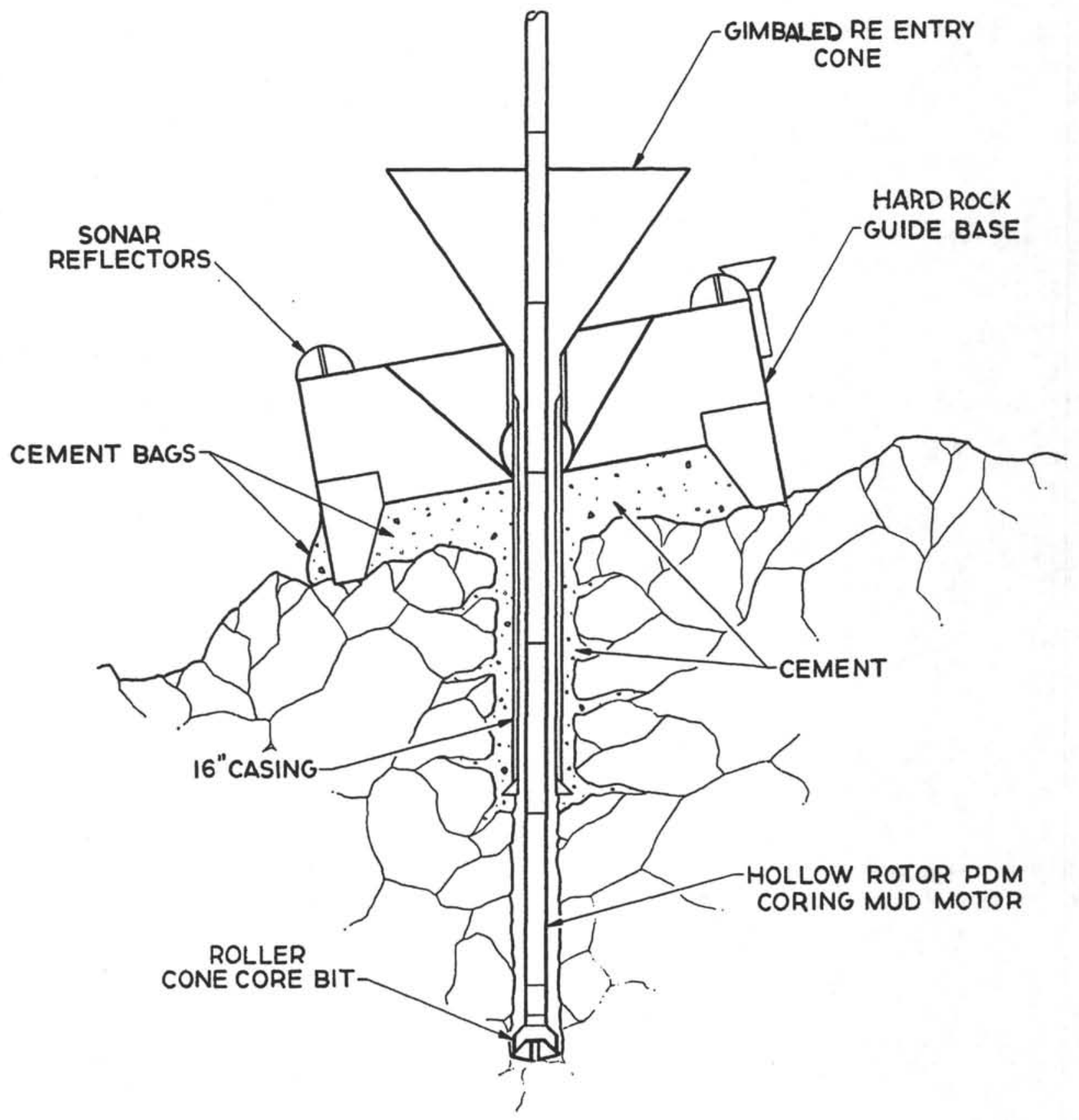

Figure 6. Hard-rock guidebase with reentry cone and casing. 
In practice, positive-displacement drilling and coring motors have provided significant drill string and BHA stability. Boreholes have been established in fractured basalt, hydrothermal sediment, and serpentinized peridotite with and without use of a guide base.

\section{Television system}

The real-time video system includes a TV camera, lights, a winch, coaxial cable, and a vibration-isolated TV (VIT) frame that attaches around the drill string, allowing the TV system to be raised and lowered by wireline on the outside of the drill pipe. The system is designed for operations in water depths of up to $20,000 \mathrm{ft}(6100 \mathrm{~m})$. The TV system has been effective for carrying out detailed local site surveys, for selecting hard-rock drilling sites, for monitoring placement of sub-sea structures (guide bases, reentry cones, casing, etc.), and for monitoring hard-rock spudding operations with an unsupported BHA.

\section{Pollution Prevention and Safety}

The possibility of an uncontrolled flow of formation fluids from core holes into the ocean is a recognized hazard that must be prevented by use of appropriate precautions. JOIDES Resolution is not equipped with a closed circulation system for primary control nor with preventers for secondary control of blowouts. Therefore, fundamental control is provided through careful use of geological and geophysical data to avoid closed structures of permeable formations.

\section{Review of Sites}

All proposed sites are reviewed during the planning phase of a leg by the JOIDES Panel on Pollution Prevention and Safety. The regional geology and available seismic profile records are examined to assure that the proposed sites will not be drilled on a closed structure. In addition, the JOIDES Safety Panel advises ODP on precautions to follow during coring operations and on proper abandonment procedures.

Additional review of proposed sites and the JOIDES Safety Panel's recommendations is made by a panel of scientists selected by the Ocean Drilling Program.

\section{Safety Manual}

The JOIDES Pollution Prevention and Safety Panel has prepared a manual for shipboard use that details guidelines to be followed under various circumstances (JOIDES Journal Volume XII, Special Issue No. 5, March 1986). It is ODP policy to follow the recommendations in the manual in conjunction with individual site recommendations.

\section{Abandonment}

JOIDES Resolution is equipped to fill boreholes with cement or weighted drilling mud. Plugging is standard procedure for holes in which hydrocarbon shows are encountered and for holes drilled into consolidated sediments of continental margins.

An oilfield-type cementing pump and a continuous jet mixer are on board for mixing and emplacing a cement slurry. Weighted mud is kept in a liquid mud storage tank and is emplaced with the rig mud pumps. 


\title{
VI. PRE-CRUISE PREPARATION
}

\author{
A. Pre-Cruise
}

\section{Physical Examination}

It is the responsibility of each shipboard scientist to obtain a physical examination by a duly licensed physician. All pertinent forms along with instructions are mailed by ODP to participants well in advance of each leg. The completed physical examination form must be returned to ODP well in advance of the cruise departure date, to allow sufficient time for review by the ship's physician. In order to board the ship, each participant must have a completed physical examination form on file at ODP.

\section{Travel Arrangements}

Before the cruise, each shipboard scientist must obtain a passport and the necessary visas and inoculations required by countries to be visited. Since JOIDES Resolution (SEDCOIBP 471) is a Liberian registered vessel, it is necessary for all U.S. personnel to have valid U.S. passports in their possession upon joining or leaving the vessel at American ports as well as during international travel to and from the ship. Scientists from countries other than the U.S. must make their own travel arrangements, both for the cruise and for the post-cruise meetings. Travel costs for non-U.S. scientists are paid by funding sources within their own countries.. For U.S. scientists at academic institutions and government agencies, travel to and from the cruise and post-cruise meetings is arranged by ODP/TAMU and paid for by funds available through United States Science Advisory Committee (USSAC). Questions about travel arrangements may be addressed to the ODP/TAMU Travel Supervisor, Ocean Drilling Program, 1000 Discovery Drive, College Station, Texas 77845-9547.

\section{Personal Clothing and Equipment}

Each person must take into account the anticipated weather based on season and geography of the cruise, and bring appropriate clothing and footwear. Steel-toed safety shoes are required on the rig floor (Co-Chief Scientists please note). Footwear worn outside on catwalks, deck, or rig floor is not to be worn in accommodations areas; it is important to bring a pair of "indoor shoes" or slippers. Because of the ship's free daily laundry service, it is not necessary to bring very many changes of sea clothes. Scientists are responsible for providing their own rain and cold-weather gear. It is suggested that plain, light-colored t-shirts be brought along to be stenciled with the cruise logo. The logo will usually fit on childrens' t-shirts if desired. Hard hats, required outside aft of the accommodations area and at all lifeboat drills, are available aboard ship, on loan.

U.S. participants may send one "personal box" to or from the ship with the regular ODP freight. The box can contain only work clothes, boots, books, toiletries, or similar low-value, non-vital items. The maximum size box allowed is $12 " \mathrm{x} 18$ " $\mathrm{x} 6$ ". In order to guarantee delivery to the ship this box must be received by the ODP Logistics and Technical Support Office (1000 Discovery Drive, College Station, Texas 77845-9547 USA) no later than 21 days prior to the first day of the scheduled port call. Deadlines for 
personal boxes sent back from the ship are determined during the cruise by the Lab Officer and Storekeeper. Every personal box sent from the ship to the U.S. must be supplied with a completed U.S. Customs form 3299 (available on board); the form requires, among other information, exact return flight information of the sender. If changes in return scheduling occur, it is the responsibility of the owner to notify the ODP Logistics and Technical Support Office and supply the correct information immediately upon return to the U.S.

For those scientists who, at or before the Co-Chief Scientists' pre-cruise meeting, have indicated a need to send equipment to the ship for approved special experiments, arrangements can be made to send these items to the port call along with the regular ODP freight. Information on the equipment must be provided to the ODP Logistics and Technical Support Office as soon as possible after the pre-cruise meeting and should include a description of the equipment, value(s), serial number(s), owner(s), place(s) of manufacture, and dimension(s)/weight(s). Normally, all such equipment is sent via ocean freight, which requires several weeks, if not months, of transit time to the port. Therefore, it is imperative that the equipment arrive at ODP/TAMU in ample time to be assured delivery. The Logistics office will supply cut-off dates as to when equipment must be available at ODP/TAMU.

Alternatively, the Logistics office will supply applicable address and labeling requirements so that scientists can send their equipment prepaid directly to the port. In such a case, the sender must inform the Logistics office of the Air Way Bill Number (or Bill of Lading), routing, number of pieces, estimated time of arrival, and whether any special handling is required for the equipment. When returning the equipment from the vessel, it can be sent via the next scheduled ODP ocean freight shipment back to ODP/TAMU and then sent on to the recipient, or sent via collect air freight directly to the recipient. Boxes, crates, and other containers should be saved for shipping the equipment back home, owing to limited materials on board.

Scientists who expect to take closeup photographs of cores for their own research must bring their own cameras and film. Everyone is welcome to use the core lab space, lighting fixtures, and copy stand. The following equipment is what a scientist must bring in order to do his own closeup photography: (1) a 35-mm camera with a lens capable of closeup photography (a macro-lens), and (2) daylight balanced 35-mm film with an ASA of 25 or 64 (Kodachrome is recommended). Faster films cannot be used in the copy area because of the lighting fixtures provided, but it is suggested that 400 ASA film be brought also, for general shipboard photography. ODP will not provide film, camera, or film processing.

If expensive, foreign-made personal items such as cameras are to be taken on board by U.S. citizens, they must be pre-registered (U.S. Customs Form 4457) to avoid paying duties when reentering the United States. It is advisable to save sales receipts or other evidence that prove the item was purchased in the United States. Non-U.S. scientists should refer to their own countries' Customs laws to avoid problems with their equipment.

All luggage, including official ODP hand-carried items and personal effects, is subject to inspection by Customs. 


\section{B. Port Call}

Scientists are usually scheduled to arrive at the departure port on the second day of the port call prior to the start of the cruise. Co-Chief Scientists are usually scheduled to meet the ship when it first docks. Scientists will be provided information on how to contact the ODP Logistics Representative at his hotel, or the port agent's office, to learn the ship's location. If any major delays are encountered when traveling to the port call, scientists should promptly notify the ODP Logistics and Technical Support Office (409-845-8482) or the designated port agent by telephone or telex.

Cabin assignments are made by the Laboratory Officer, Staff Scientist, and Operations Superintendent, and are posted aboard ship. Scientists normally move into their cabins immediately upon arrival at the ship. Changes in berthing must be cleared through the Laboratory Officer.

A pre-cruise meeting of the shipboard scientific staff is held on board before the ship sails. This meeting serves as a general orientation to the ship and a pre-cruise scientific discussion concerning leg objectives, shipboard sampling programs, and arrangement of shipboard work schedules (including scientists' shifts at the sampling table).

\section{Under Way}

While in transit from the departure port to the first site, scientists will have time to familiarize themselves with lab equipment and with standard ODP data collection policies. The ODP Staff Scientist and ODP technical personnel devote much of their effort during the transit to helping scientists with this task.

As the shipboard VAX computer is used in almost every aspect of shipboard data collection, a considerable amount of time should be spent in familiarization with this system. Training offered en route to the first site consists of an overview of the computer system, an introduction to the major software packages, and instruction on how to use the system documentation and computer-aided courses.

If the transit time to the first site is long (more than a couple of days), there is often time to set up an informal seminar series, during which shipboard scientists can present talks on their research interests to other members of the shipboard staff. A 35-mm carousel slide projector, transparency projector, and a microphone are available in the science lounge.

\section{UNDERWAY GEOPHYSICS}

\section{A. Introduction}

The underway geophysics laboratory aboard JOIDES Resolution is located aft on the poop deck, under the helicopter platform (Figs. 2 and 7). Shipboard personnel use this laboratory to

- collect navigational and positioning data,

- collect and display bathymetric data (12-kHz and $3.5-\mathrm{kHz}$ echo sounder data), 
1. RACK

2. SEISMIC RECORDER

3. $3.5 \mathrm{KhZPDR}$

4. $12 \mathrm{KhZ}$ PDR

5. VERSATEK PLOTTER

6. SEISMIC SYSTEM TERMINAL

7. CHART TABLE

8. WATCHSTANDERS BENCH

9. WORK BENCH

10. STORAGE CABINET

11. BOOKSHELVES

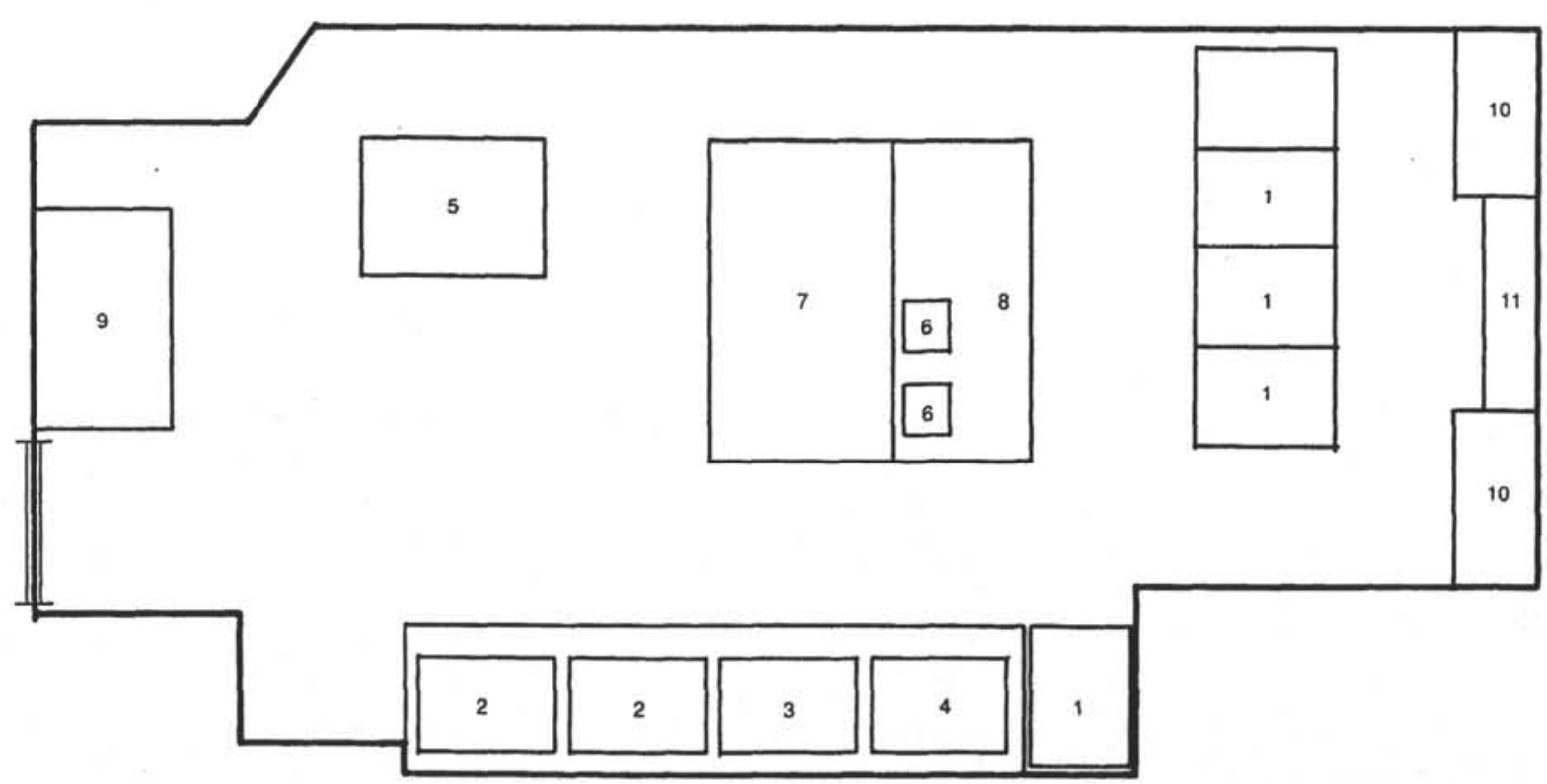

Figure 7. Schematic layout of the underway geophysics laboratory. 
- collect and display magnetics data,

- collect, process, and display in real time both single-channel digital and unprocessed analog seismic data,

- produce standard (SEG-Y) format seismic data tapes for further processing and postcruise archiving.

A number of shipboard personnel are involved in its operation (Co-Chief Scientists, Lab Officer, Electronics Technicians, Technicians). Because it is located on the fantail, individuals visiting the lab must wear a hardhat.

\section{B. Description of the Equipment}

\section{Navigation Data Recording}

A Magnavox 1107-GPS combination Transit and Global Positioning Satellite Navigator, equipped with a Rubidium frequency standard, allows navigation during selected time intervals using a minimum of two GPS satellites. A Magnavox MX 4400 GPS receiver is on the ship's bridge. Other navigational equipment on the bridge includes a Magnavox MX702A Transit Receiver, and Decca and Loran C positioning systems.

Complete GPS and Transit position and status data are stored on a disk file at an operator-selected interval, independent of the shot interval. The operator can switch to a new file at any time, allowing the old file to be archived on floppy disk or tape, or to be sent to the main computer (VAX) where it is stored and later sent to a pen plotter to generate navigation plots.

The "SMOOTH" program was developed by the ODP Computer Group to plot navigation tracks on board. SMOOTH accepts GPS, Transit Satellite, course, and speed changes, and produces a sorted file of updated fixes. These fixes are plotted with respect to time; the operator can delete bad fixes from the file or manually input fixes obtained from any other positioning system. Fixes collected while on site are averaged and a single point is plotted for the site. The edited file then passes through a smoothing fit algorithm that produces coordinates for drawing a ship's track. Finally the "smooth" track is plotted in a device-independent format. The user can choose the scale of the plotting and a wide variety of projection systems.

Navigation plots are produced after each transit and each site survey by the Technician in charge of the underway geophysics lab, if so directed by the Laboratory Officer and CoChief Scientists.

\section{Bathymetric Data Recording}

For collecting bathymetric data, both $3.5-\mathrm{kHz}$ and $12-\mathrm{kHz}$ Precision Depth Recorder (PDR) systems are available. An EDO transceiver and one multi-element 10-kw transducer are used to gather 3.5-kHz data; a PTR105B transceiver and an EDO 323B transducer are used to gather $12-\mathrm{kHz}$ data. Two Raytheon LSR1807M recorders are used for display. The $3.5-\mathrm{kHz}$ and $12-\mathrm{kHz}$ systems normally operate with CESP-III Correlators that give a 20-db signal-to-noise improvement over the standard system.

In early 1989 a sonar dome was added to the ship's hull, in order to obtain a better bathymetric signal at speeds greater than $8 \mathrm{kt}$. The sonar dome contains two $12-\mathrm{kHz}$ 
transducers and a $3.5-\mathrm{kHz}$ transducer. The sonar dome is designed to extend far enough below the hull to escape noise created by air bubbles along the hull/seawater interface.

\section{Magnetics Data Recording}

Magnetics data at a density of one reading per seismic shot are recorded in the header of seismic tapes. These data are collected using a Geometrics 801 proton precession magnetometer and displayed on a strip chart recorder.

\section{Single-Channel Seismic System}

a. Sources: The standard seismic sources used aboard JOIDES Resolution are two 80in. ${ }^{3}$ Seismic Systems, Inc. (SSI) water guns. One 400-in. ${ }^{3}$ SSI water gun is also available. The following air guns are available on board: one Bolt $1500-\mathrm{C}$ with chambers of 120 or 300 in..$^{3}$ and three Bolt 600 -A air guns with firing chambers that can be varied from 5 to 80 in. ${ }^{3}$.

b. Streamer-hydrophones: Two Teledyne streamers are mounted on winches on the fantail. They each contain 60 hydrophones, are $100 \mathrm{~m}$ long and can be towed up to 500 $\mathrm{m}$ behind the ship; the towing depth can be maintained by external depth depressors (birds) if desired. Streamer output is transformer coupled to the ship via the tow cable. The hydrophone elements are combined to produce a single signal. A $10-\mathrm{Hz}$ low cut filter is inserted between the streamer and the rest of the electronics to reduce highamplitude low-frequency noise that might overload the amplifier.

c. Data Recording: The seismic system operates independently from the main computer system (VAX). A Masscomp 561 super-micro computer is used as the central unit to record, process, and display data. Data are processed and displayed in real time on a 15-in.-wide Printronix high-resolution graphic printer (160 dots per inch). Raw data are recorded on tape; processed data can also be displayed on a 22-in.wide Versatec plotter that gives a higher resolution display (200 dots/in.).

Raw seismic data are also displayed in real time in analog format on two Raytheon LSR1807M recorders, using only a streamer, Ithaco amplifier and Khron-Hite filter. This analog mode would be the primary recording mode should irreparable equipment failure preclude digitizing.

The data acquisition software and interfaces of the various components of the ODP shipboard seismic system were developed at the University of Texas at Austin in cooperation with ODP staff. This software package, called HIGHRES/DEFINEPROCESS, includes the following processing/ reprocessing modules: Input Data (Trace Edit), Output Data (disk file or SEG-Y format tape), Display (Printronix or Versatec), Bandpass Filter, Automatic Gain Control (AGC), Trace Autocorrelation, Mutes (seafloor), T-Gain, Trace Equalization, and Time Window.

Post-acquisition processing can also be accomplished using SIOSEIS. SIOSEIS capabilities include the following: seismic section annotation in time, time-varying bandpass filter, F-K filtering, F-K migration, predictive deconvolution, and various other seismic data processing features.

The seismic system was designed to accommodate other scientific experiments such as vertical and oblique seismic profiling. 


\section{Underway Geophysics Procedures}

\section{Data Collection Policy}

ODP collects navigation data at all times while under way, even when no geophysical data are collected. Navigation data are automatically collected from various sources (heading, speed, wind, Transit and GPS satellites) and are stored on magnetic tape for reduction into a smooth cruise track. Geophysical data (bathymetry, seismics, magnetics) are collected whenever possible while under way and systematically during site surveys. When necessary, ODP is responsible for obtaining permission to collect underway geophysical data from the appropriate coastal states. The decision to collect geophysical data while under way is made during the Co-Chief Scientists' pre-cruise meeting, and is based on the need to collect geophysical data in under-explored or key areas. During the cruise, collection of geophysical data can be vetoed by the Captain for safety considerations.

A bridge log for ODP use is maintained by SEDCO personnel on the bridge at all times while under way (except during pilotage, etc.). This log includes entries for all intentional heading, course, and speed (shaft RPM) changes. The underway geophysics lab watch-stander is notified immediately of such changes whenever geophysical data are being collected so that the analog records can be annotated. Track charts for ODP use are maintained by SEDCO bridge personnel at all times while under way, on standard Defense Mapping Agency position plotting sheets (920-936 series). These track charts are sequentially numbered for each leg (e.g., Leg 112 \#1: Callao to Site 671; Leg 112 \#2: Site 671 to Site 672, and so on). Completed geophysical log sheets, bridge log sheets, and plotting sheets are given to the Yeoperson prior to the end of the cruise and are archived as ODP prime data (see Section X.A).

Powering up the system includes more than 22 operations, and is supervised by the Laboratory Officer. Electronics Technicians "boot" the computer at the beginning of each leg, install software updates, repair hardware malfunctions, and familiarize new users with the system as time permits. Regular watches are performed by Technicians, who are responsible for maintaining the geophysical log.

The decision of which seismic source to use is made by the Co-Chief Scientists in consultation with the Lab Officer.

\section{Site Survey Protocol}

During site surveys, the final location of the site is usually dependent on real-time geophysical data recording. As a consequence, the $\mathrm{Co}$-Chief Scientists have responsibility for directing the Captain of the vessel along the desired trackline (within safety limitations). This involves pre-site consultation as well as close communication between both parties as the ship is locating the site. The site approach is usually done at 5-6 kt over a period of a few hours. Site approaches and site survey tracks are plotted on the bridge at an expanded scale for ODP use.

Final selection of the site to be drilled is the responsibility of the Co-Chief Scientists. The Operations Superintendent must concur on where to drill in the event that a change is made to the location of a drill site (from the position previously established by ODP). Exact site selection is usually made in the underway geophysics laboratory, based 
on real-time JOIDES Resolution seismic records. The Co-Chief Scientists are responsible for communicating to the bridge the exact time to drop the beacon.

\section{Seismic Line Acquisition and Processing}

Because of the Masscomp configuration, the bandpass filter recorded on tape cannot be different from the bandpass filter used for real-time display. In order to protect seismic data for later reprocessing, it is ODP policy to use a $20-250 \mathrm{~Hz}$ bandpass filter during real time acquisition. More undigitized filtered data are displayed on Raytheon flatbed recorders. The Co-Chiefs are responsible for the choice of Khron-Hite bandpass filter parameters. Digitized seismic data are recorded on tapes using SEG-Y Format; each tape is approximately 6 hours long. While on site, every tape is copied by the System Manager. Every site survey line should be reprocessed using the parameters and Masscomp modules requested by the Co-Chief Scientists or other interested scientists, while the ship is on site.

Enhancement processing can be done by members of the scientific party under the guidance of ODP staff (Electronics Technicians and/or the Technician assigned to the lab). Reprocessing is done only after the data tapes are copied and the originals stored; all reprocessing is done using the copied tapes. Reprocessing must be discussed at the precruise meeting in order for the Laboratory Officer to organize the team of technicians. A set of reprocessing options is available with suggestions for applications in different geologic settings. The choice of parameters and options is the responsibility of the Co-Chiefs.

\section{Data Distribution}

Hard copies and photographs of analog seismic lines are given to the CoChief Scientists and are filed with the Yeoperson at the end of each transit. Photocopies of seismic lines are made for the shipboard participants who request them, either during or after the cruise depending upon the time available to the Technicians and Photographer.

The underway geophysics data are then edited to be published in the Initial Reports volume of the ODP Proceedings for each cruise. To this end, ODP established a contract with the Geological Data Center (GDC) at Scripps Institution of Oceanography. GDC runs ODP navigation data through a smoothing program that linearly interpolates positions of course/speed points between adjacent fix pairs. GDC generates time-vs.-depth profiles with ODP data (usually a 5-min interval log of the bathymetry). These digitized data are checked against echograms of seismic profiler records. The magnetics data are read from the headers of the seismic tapes provided by ODP. GDC produces profiles of digitized magnetics vs. ship time, which are compared to the original paper recording. Navigation, bathymetric, and magnetic data are merged to produce MGD77 Exchange formatted tapes. Twelve- and $3.5-\mathrm{kHz}$ echograms, analog seismic reflection records, and magnetometer records are microfilmed on 35-mm microfilm. GDC produces a report containing small-scale plots that summarize the navigation, bathymetric, and magnetic data.

The following underway geophysics data are sent to the ODP Data Bank at LDGO, and to the NGDC/World Data Bank: a computer tape of merged data in MGD77 Exchange format; microfilms of the roll records from seismic, bathymetric, and magnetometer recorders; and a copy of the informal report produced by GDC. 


\section{SHIPBOARD SCIENTIFIC PROCEDURES}

\section{A. Numbering of Sites, Holes, Cores, and Samples}

ODP and DSDP drill sites are numbered consecutively from the first site drilled by Glomar Challenger in 1968. Site numbers are slightly different from hole numbers. A site number refers to one or more holes drilled while the ship is positioned over a single acoustic beacon. Several holes may be drilled at a single site by pulling the drill pipe above the seafloor (out of one hole), moving the ship some distance from the previous hole, and then drilling another hole.

For all ODP drill sites, a letter suffix distinguishes each hole drilled at the same site. For example, the first hole takes the site number with suffix $\mathrm{A}$, a second hole takes the site number with suffix B, and so on.

\section{B. Conventions (and Exceptions)}

Many conventions regarding measurements, recovery, depths, etc., are followed by ODP for curatorial purposes. In certain cases, the scientific party may have evidence that calls for a departure from these conventions (e.g., involving treatment of voids or placement of core-catcher material). Such exceptions may be made for purposes of scientific discussion, provided they are reached by consensus, approved by the Staff Scientist, and thoroughly documented or explained in the cruise "Explanatory Notes" and/or Initial Reports Site Chapters. Please note, however, that the original curated lengths, depths, ID numbers, etc., will be retained in all ODP databases.

\section{Cored Intervals}

The cored interval is measured in meters below seafloor (mbsf). Mbsf depths are calculated by subtracting the drill-pipe measurement (DPM) water depth from the total DPM depth (see Section V.B for a discussion of depth measurement).

The depth interval of a core is the depth below seafloor that the coring operation began to the depth that the coring operation ended for that core. For rotary coring (RCB and $\mathrm{XCB}$ ), each coring interval is equal to the length of the joint of drill pipe added for that cored interval (although a shorter core may be attempted, if desired). The drill pipe in use varies in length from about $9.4 \mathrm{~m}$ to $9.8 \mathrm{~m}$. The pipe is measured as it is added to the drill string, and the cored interval is recorded as the length of the pipe joint to the nearest $0.1 \mathrm{~m}$. For hydraulic piston coring (APC) operations, the drill string is advanced $9.5 \mathrm{~m}$ (the maximum length of the piston stroke) or by the length of recovered material in the previous core if less than $9.5 \mathrm{~m}$ was recovered. The Operations Superintendent can provide further information regarding these procedures.

\section{Recovery}

Recovery of material equal in length to the cored interval is considered full, or $100 \%$, recovery. However, the length of the recovered material may differ from the length of the cored interval. Recovery less than the cored interval may occur for a variety of 
reasons, often involving difficult-to-recover lithologies such as sand, chert-ooze alternations, or fractured basalt; equipment problems such as incomplete APC strokeout may also be responsible. Apparent recovery greater than the cored interval may also occur, typically a result of gaseous expansion of the sediment.

Although $9.5 \mathrm{~m}$ is often cited as the standard value for full core recovery, please note that this practice is erroneous because full recovery for a given core depends upon the coring technique in use and other factors that may vary from core to core. The Operations Superintendent can clarify how lengths and depths of recovered materials are determined in each case, and scientists are encouraged to approach him with specific concerns regarding these values.

The sediment or rock from the cored interval is recovered in a plastic liner $(6.6 \mathrm{~cm}$ internal diameter). Additional material (up to $0.2 \mathrm{~m}$ in length) may be recovered in the core catcher, which has no plastic liner. The core catcher is a device at the bottom of the inner core barrel, which prevents the core from sliding out as the barrel is being retrieved from the hole.

Cores taken from a hole are numbered serially from the top of the hole downward. When full recovery is obtained, the core sections are numbered 1 through 7 (Fig. 8), the last section being shorter than $1.5 \mathrm{~m}$. For sediments, the core catcher sample is extruded into a short piece of plastic liner and is treated as a separate section below the last core section. For hard rocks, material recovered in the core catcher is included at the bottom of the last section.

\section{Recovery Less Than $100 \%$}

When sediment recovery is less than $100 \%$, whether or not the recovered material is contiguous, the recovered sediment is placed at the top of the cored interval, and then 1.5 -m sections are numbered serially, starting with Section 1 at the top. There will be as many sections as needed to accommodate the length of core recovered (Figure 8). For example, $3 \mathrm{~m}$ of core sample in a plastic liner will be divided into two $1.5 \mathrm{~m}$-long sections. Sections are cut starting at the top of the recovered sediment, and the last section may be shorter than the normal $1.5 \mathrm{~m}$ length; for example, $7 \mathrm{~m}$ of core will be divided into four 1.5 $\mathrm{m}$-long sections (Sections 1-4) and a fifth section $1 \mathrm{~m}$ long (Section 5).

The convention of placing recovered material at the top of the cored interval exists because in most cases of incomplete recovery, material enters the core barrel until the core "jams off" at some point, preventing additional material from entering the core barrel. This convention extends to core-catcher material in cases where the core liner is retrieved empty. However, the scientific party may choose to make an exception to this convention if evidence suggests that the material is from part of the cored interval other than the top.

\section{Voids}

There are two types of voids. Voids of known origin are those that grow visibly owing to gas expansion or from handling the core sections. These voids may be eliminated or collapsed, while maintaining the integrity of the core. Intervals where expansion occurred but were collapsed by hand are recorded. For voids of unknown origin, the void is not eliminated but instead is marked with a plastic spacer and the void is maintained. 

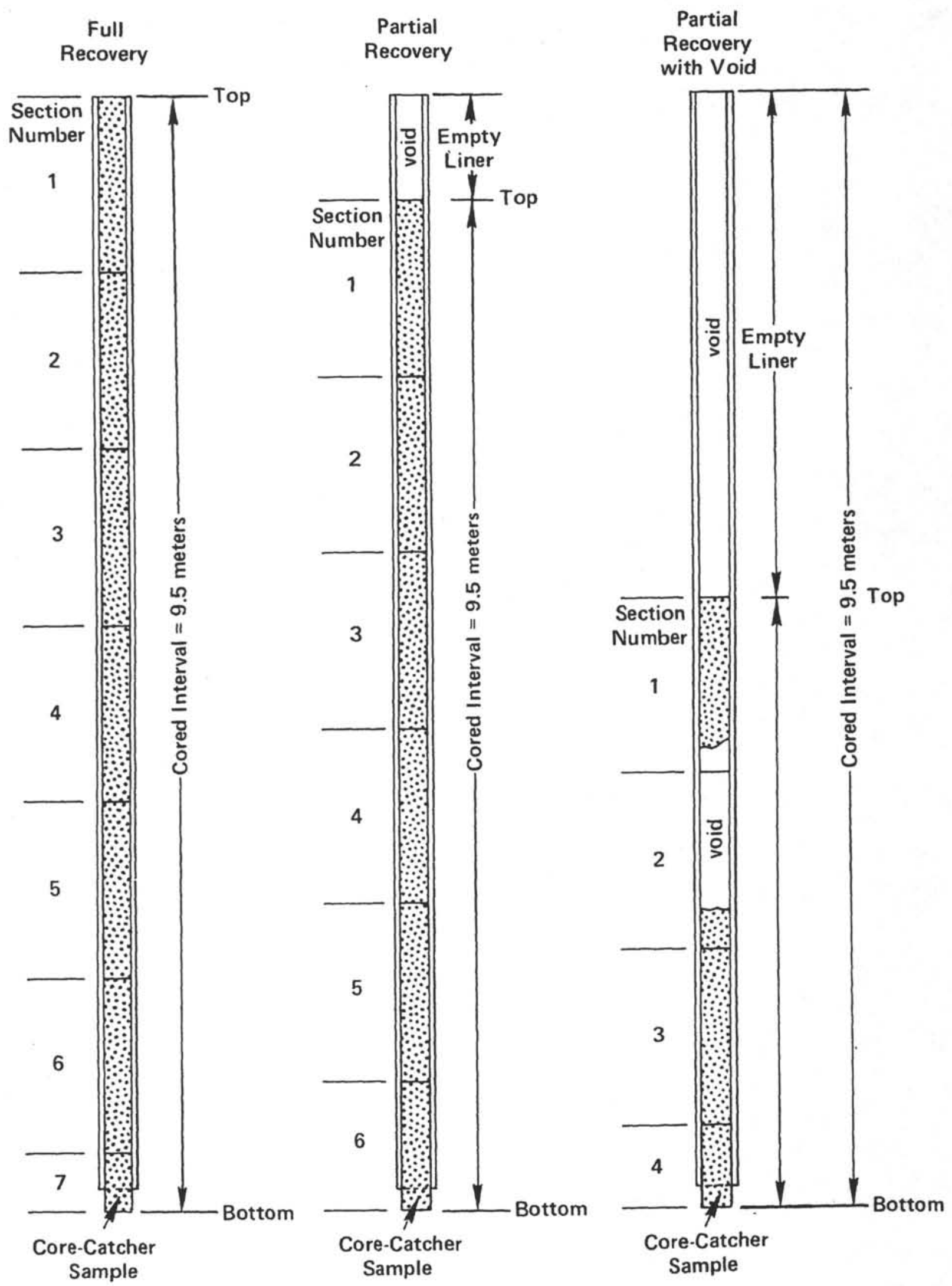

Figure 8. Diagram of procedures for numbering core sections. 


\section{Special Cases - Core Handling}

If sediment oozes out of the top of a core before it is cut into sections on the catwalk (as may occur in gassy cores), Section 1 should begin at the top of this overflow material. The fact that the section starts with overflow material and how much there is must be clearly noted. Likewise, if sediment oozes from a cut section before capping is possible, the sediment should be replaced in its original liner. This also must be noted clearly for that section. Core material from accidents such as shattered core liner should be reassembled as accurately as possible, producing no more than nine sections, and appropriate comments must be recorded as to the source of disturbance. At present, all comments that describe core handling are recorded in the "comments" section of CORELOG (see Section VIII.C.5) for that core.

\section{Core Identification}

An identification number for a core section consists of the following information: (1) Leg (and Subleg where applicable), (2) Site number + Hole letter, (3) Core Number and Type (see below), and (4) Section. For example, the identification number "101-627B-6H-3" means Section 3 of APC-cored Core 6, from the second hole drilled at Site 627 during Leg 101. The core catcher of this core is designated "101-627B$6 \mathrm{H}, \mathrm{CC} . "$

\section{Core Type}

There is a space on all core and sample identifiers for "Type" of core. The following abbreviations are used to specify core type: $R=$ rotary core barrel (RCB), $H=$ advanced hydraulic piston core (APC), $\mathrm{X}=$ extended core barrel (XCB), $\mathrm{B}=$ drill bit recovery, $\mathrm{C}=$ center bit recovery, $\mathrm{S}=$ sidewall sample, $\mathrm{W}=$ wash core recovery, $\mathrm{N}=$ positive displacement mud motor (NCB), $\mathrm{D}=$ positive displacement coring motor ( $\mathrm{PDCM}$ ), $\mathrm{Z}=$ diamond coring system (DCS), and $\mathrm{M}=$ miscellaneous.

\section{Wash Cores}

Cored intervals may be separated by drilled intervals. In soft sediment, the drill string can be "washed ahead" with the core barrel in place (but not recovering sediment) by pumping water down the pipe at high pressure to wash the sediment out of the way of the bit and up the space (annulus) between the drill pipe and the wall of the hole. However, it is possible to get "spotty" sampling of resistant layers within the washed interval. It is the scientific party's option to keep and number a wash core or not, depending on individual circumstances; when kept, this material carries a core identifier (type "W") using the next number in the coring sequence (e.g., 120-750B-11W). By convention, recovered material is placed at the top of the washed interval for illustration purposes, unless in the judgment of the scientific party there is evidence to place it elsewhere in the washed interval.

\section{Downhole Water Samples}

Downhole water samplers fall into two categories, and so have different identifiers. The first refers to water samples taken in the sediment at the bottom of the existing hole. 
In this case, the next consecutive core number is given, so that the water sampler identifier consists of leg-site-hole, the next consecutive core number, section one, $0-1 \mathrm{~cm}$ interval, and the code for that sampling device. Thus, the water sample will have the same core number and core type as the next sediment/rock core drilled immediately below the water sampling. In the second category are tools that are lowered down a previously drilled hole. In this case, the water samples taken at any depth in open borehole have no established relationship to consecutive cores. These samples are labeled with a sample ID consisting of leg-site-hole, depth in the hole, and the code for that sampling device numbered consecutively downhole.

\section{Sample Identification}

Every sample distributed from the ship or from a repository is labeled with a standard identifier: sample code, leg number (and subleg where applicable), site/hole number and letter, core number and type, section number, and interval within the section from which the sample came. It is imperative that this standard identifier be associated with all related data reported in the literature, and that residues of the sample remain labeled throughout their lives.

- Sample codes (observer codes) are assigned by the Curatorial Representative for that leg. In the case of samples taken for shipboard or shore-based scientists, the first three letters of the scientist's surname become that scientist's sample code. Samples taken for shipboard analyses and/or that are archived, such as interstitial or downhole water samples, have standard sample codes used every cruise.

Samples are referenced in publications by distance in centimeters from the top of a section to the top and bottom of the sample interval in that section. A full identification number for a sample consists of the following information: (1) Leg number (and subleg where applicable), (2) Site number + Hole letter, (3) Core Number and Type, (4) Section, and (5) Interval in centimeters. For example, the sample identification number "101-627B-6H-3, 98-100 cm" means that a sample was taken between 98 and $100 \mathrm{~cm}$ from the top of Section 3 of APC-cored Core 6, from the second hole drilled at Site 627 during Leg 101. A sample from the core catcher of this core might be designated "Sample 101-627B-6H, CC (8-9 cm);" core-catcher samples obtained for routine shipboard paleontological analysis will not have an interval designation assigned (e.g., "Sample 101-627B-6H, CC").

\section{Sample Sub-bottom Depth}

The depth below the seafloor for a sample numbered "101-627B-6H-3, 98-100 $\mathrm{cm}^{\prime \prime}$ is the sum of the depth to the top of the cored interval for Core 6 (in this example, 44.2 mbsf) plus the $3 \mathrm{~m}$ included in Sections 1 and 2 (each $1.5 \mathrm{~m}$ long) plus the $98 \mathrm{~cm}$ below the top of Section 3. The sample in question is therefore located at $48.18 \mathrm{mbsf}$, which in principle is the sample sub-seafloor depth. In reality, however, the precision implied by this value is misleading, as uncertainty surrounds all depth measurements made in drilling operations (see Section III.I.2).

In cases where precise interhole correlation is of scientific importance, the scientific party may choose to implement adjusted or normalized core depths, particularly to account 
for cores with apparent recovery greater than $100 \%$ or discrepancies in the position of marker horizons between holes (see discussion of composite depth determination in site chapters of the Leg 108 Initial Reports; Ruddiman, W., Sarnthein, M., Baldauf, J., et al., 1988. Proc., Init. Repts., ODP, 108).

Post-cruise sample requests should refer to a specific interval within a core section (using the correct core identifier, as explained above in Section VIII.B.10), rather than subbottom depths in meters.

\section{Core Laboratory Procedures - Sediments and Sedimentary Rocks}

This section and the flow diagram shown in Figure 9 outline the general procedure for handling sediments and most sedimentary rocks from the time the core arrives on deck until it is placed in D-tubes, boxed, and stored in the shipboard refrigerated core storage to await shipment home. Handling and sampling igneous and metamorphic rocks is discussed in the following section (Section VIII.D).

All scientific measurements made on cored material are recorded in metric units.

\section{Core Deck Routine (Sediments and Sedimentary Rocks)}

When a core arrives on the rig floor, Technicians assist SEDCO personnel in retrieving the plastic liner from inside the core barrel. The liner is set outside the core entry lab on aluminum brackets attached to the catwalk railing.

Disturbance of core material occurs in three ways: first simply by removing sediments from their in situ environment, second in the coring and recovery process, and third in splitting and sampling the cores. The methods used in deep ocean drilling usually permit recovery of relatively undisturbed cores. In some cases, however, distortion is evidenced by color variations, contorted bedding, fragmentation or brecciation, or anomalous physical properties values. Materials may become sorted or compacted, and may be contaminated with drilling fluid (commonly seawater), previously drilled material, or rust/grease from the drill string. Interaction of the core material with air can produce evaporation, hydration, oxidation, and other chemical alterations. It is important, therefore, to handle each piece of core material with utmost care so as to not compound disturbance or contamination.

While on the catwalk, the outside of the 9.5-m core liner is wiped and the top of the recovered material is located. The core is measured from the top of the material down, marked into $1.5-\mathrm{m}$ sections, and labeled temporarily with a core section identifier and an uporientation arrow.

Material stuck in the core catcher is put into a separate short piece of liner and is labeled "Core Catcher" (CC). The orientation of core-catcher material is preserved. A sample is selected from the core catcher for immediate study by the Paleontologists on duty. Note that this "paleo" core-catcher sample has no specific centimeter interval recorded as part of its sample identifier. 


\section{CORE LAB FLOW DIAGRAM}

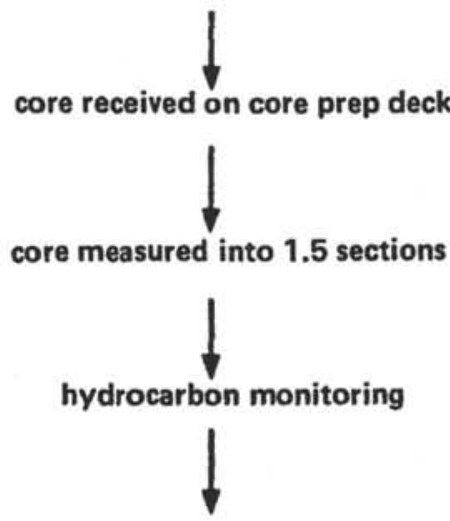

core cut into $1.5-\mathrm{m}$ sections

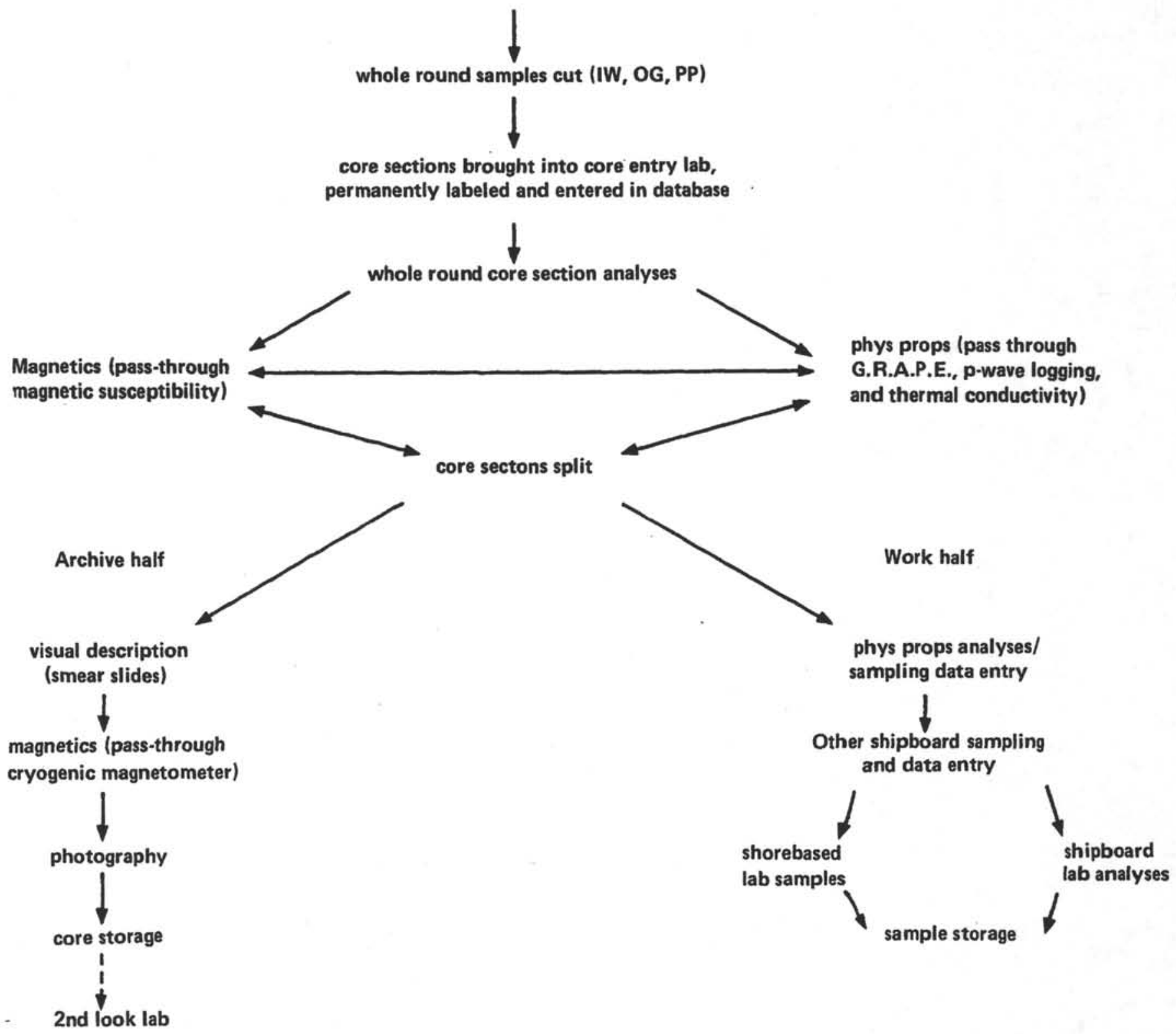

Figure 9. Core lab flow diagram. 


\section{Monitoring for Hydrocarbons (Sediments and Sedimentary Rocks)}

Sampling for the presence of hydrocarbon gases must be performed at all sites where there is any chance of encountering hydrocarbons. As the core barrel is brought on deck and the core liner removed, a Chemist or Technician checks for gas pockets, bubbles, or frothing within the liner. Any evidence of suspected hydrocarbons is reported immediately to the Operations Superintendent. The need to monitor for such traces is urgent in terrigenous sediments, although shows may be anticipated in other sediments, particularly carbonate deposits.

The Chemist is notified if hydrocarbons are suspected so that samples can be taken immediately for analysis. Ideally, samples for gas chromatographic analysis are taken prior to cutting/capping to prevent contamination from glues and other materials used in these processes. However, the presence of gas is also marked by bulging end caps on sealed core liners. As the sediments degas with the change in pressure and temperature, sections of core material are pushed apart by gas expansion. The Chemist uses a liner penetrator with syringe attachment and evacuated container to sample these gas pockets, then takes the sample to the chemistry lab and extracts a 5-ml sample to inject into the gas chromatograph.

Gas-related frothing may appear in the cut core sections or on split halves (although frothiness may also develop when the Driller is pumping water through the drill bit during coring operations). If the presence of gas is not noticed until the cores are split, a chunk of sediment may be taken by the Chemist and the gas sampled by headspace collection.

The presence of oil occurs as a tan or brown staining on sand grains or carbonate particles. Higher gravity crudes may not show staining, with only a petroliferous odor present. In either event, a small sediment sample or a split section of core is monitored for fluorescence under ultraviolet light. An additional test is to disaggregate some of the sediment in a beaker of trichloroethane or another organic solvent and check for a play of rainbow colors upon the surface of the liquid.

Even where no hydrocarbon shows are noted, the JOIDES Panel on Pollution Prevention and Safety requires that the fluids of all cores be examined routinely. A wafer of sediment is taken from the core where each whole round core sample is removed, and analyzed for organic carbon content. Moreover, drilling rates are monitored continually for changes that may indicate the presence of undercompacted shales, and bulk density is measured routinely for evidence of such shales.

\section{Core Cutting and Capping (Sediments and Sedimentary Rocks)}

After measuring, preliminary labeling, and monitoring for hydrocarbons, the core and liner are cut into 1.5-meter sections and the liner ends are capped. Material needed for whole-core sampling as specified in the approved sampling program is removed from the bottom of chosen sections before the liners are capped (see following Section VIII.C.4)). The tops and bottoms of each section are marked by colored end caps with blue for the top and clear for the bottom. A yellow cap is placed on a section end from which a whole-round core sample has been removed--usually but not always the bottom end of a section. The caps are attached to the liner by coating the end of the liner and the inside rim of the end cap with acetone. 
The Physical Properties Specialist may request that a removable endcap be placed at the top end of a section so that vane shear measurements can be performed parallel to bedding in the end of a core section after the core is run through the multisensor track (MST; see Section VIII.C.3). After these whole-core analyses are completed by the Physical Properties Specialist, a cap is glued in place prior to splitting the section.

\section{Whole-Round Core Sampling (Sediments and Sedimentary Rocks)}

The Ocean Drilling Program carries out several whole-round core sampling programs for geochemistry and physical properties analyses. At the time of core cutting, Paleontologists or Co-Chief Scientists present on the catwalk may decide to move the routine whole-round interval to a different location, based on preliminary identification of potentially important stratigraphic information at the routine location. On the other hand, if later stratigraphic data show that an important interval or boundary has been recovered within a whole-round section, this sample must be returned to the Curatorial Representative for normal core processing.

\section{a. Geochemistry Whole-Rounds}

ODP is continuing the routine whole-round core sampling of soft sediments for two major analytical programs begun during the Deep Sea Drilling Project: Interstitial (Pore) Water and Organic Geochemistry. The intent of the routine shipboard geochemical sampling program is to obtain a systematic set of data describing geochemical processes in sediments, particularly in those shallow sediments where epigenetic/ diagenetic changes are occurring actively. The routine whole-round sampling program provides adjacent samples for gas, interstitial water, and particulate organic matter analyses. It is desirable to maximize the information gained from each whole-round sample removed from the core and to obtain each of the routine analytical measurements on every sample, when possible, in order to assemble the most useful data set.

Routine $25-\mathrm{cm}$ whole-rounds designated for shore-based organic geochemical (OG) work are sealed with plastic wrap, caps, and electrical tape; labeled; and frozen. These samples are stored until a frozen shipment can be sent from a port call to the Gulf Coast Repository. No shipboard samples are taken from this $25-\mathrm{cm}$ whole round.

The interstitial water (IW) sample consists of a segment of core 5-10 cm long, length depending on the amount of pore water in the sediments. Each IW sample is cleaned and squeezed in a Carver hydraulic press in the chemistry lab (Section IX.D.4). Once routine shipboard analyses have been completed, the remaining water is used to fulfill approved shipboard sample requests. If necessary, residual waters may be consumed by shipboard scientists' requests. If any water remains, it is put into glass vials or plastic tubes, sealed, and returned to the ODP Gulf Coast Repository. The pressed cake of sediment is bagged and refrigerated for eventual storage at a repository, but may be subsampled on board for individual sample programs.

The following is the routine shipboard sampling program for IW and OG, as approved by the JOIDES Information Handling Panel:

Core 1: A 5-cm whole-round is taken from Section 3 or 4 for IW $(5 \mathrm{~cm})$ with $10 \mathrm{~cm}^{3}$ removed for analyses with the natural gas analyzer (headspace technique). Vacutainer samples are taken if gas pockets are observed. 
Core 2: $50 \mathrm{~cm}^{3}$ of the working half are taken for IW, and the adjacent $10 \mathrm{~cm}^{3}$ are taken for gas analysis. Paleontologists must designate the region to be sampled. The sample is to be removed immediately after splitting the core sections.

Core 3: A 30-cm whole-round is taken for shore-based OG ( $25 \mathrm{~cm}$ to be frozen), IW (5 $\mathrm{cm})$, and headspace gas analysis $\left(10 \mathrm{~cm}^{3}\right.$ are taken from the IW sample).

Cores 4 and 5: Repeat program for Core 2.

Cores $6,9,12,15, \ldots$ to total depth: Repeat program for Core 3.

When the 5-cm whole-round for IW does not produce a sufficient volume of water to conduct the shipboard geochemical analyses, a $35-\mathrm{cm}$ whole-round is taken, for shore-based OG ( $25 \mathrm{~cm}$ sediment to be frozen), IW $(10 \mathrm{~cm})$, and headspace gas analyses ( $10 \mathrm{~cm}^{3}$ taken from the IW sample).

\section{b. Physical Properties Whole-Rounds}

Routine whole-round samples may be requested for consolidation testing. These consist of a maximum of one $8-10 \mathrm{~cm}$ section per lithologic unit of unlithified sediment from core sections expected to have experienced no coring disturbance. If the Co-Chief Scientists determine that this frequency of sampling will excessively deplete the core, then sampling must be restricted to a duplicate core at the site (i.e., a dedicated hole). More frequent sampling requires submission of a formal sample request.

Sampling of whole-round cores for triaxial testing is an exception to the wholeround sampling policy and must be proposed through the JOIDES panel structure. Or, if time and resources permit, Co-Chief Scientists may authorize a dedicated additional hole for this purpose. That is, sampling is restricted to the third (or higher-numbered) "copy" of the interval to be sampled. At least two copies of the cored interval should be preserved intact.

All whole-round samples must be retained intact until the shipboard scientists have determined that stratigraphically critical intervals will not be destroyed.

\section{Permanent Labeling and Core Log Entry (Sediments and Sedimentary Rocks)}

The capped sections are brought into the core entry lab for permanent labeling. The core section identifier is engraved into the liner and double printed labels are mounted on the top end of the liner. By convention, the top of each core section is kept oriented toward the aft end of the ship to avoid confusion.

Information about each permanently labeled core section is entered into the core log database (CORELOG) by a Technician. CORELOG runs on the central shipboard VAX computer and is accessed by way of a video terminal in the core lab. The information is distributed via the VAX to video monitors in other shipboard labs for cross-checking and correlation of related data.

\section{Whole Core Laboratory Analyses (Sediments and Sedimentary Rocks) a. Magnetics Program}

Measurements of the magnetic susceptibility of whole-round core sections are made using a Bartington susceptibility meter, part of the multisensor track (MST) described in Section IX.C. 3 and below. 


\section{b. Physical Properties Programs}

The Physical Properties Specialist runs four analytical programs on whole-round core sections: bulk density (GRAPE) and compressional-wave ( $P$-wave) velocity using scanning devices on the MST, vane shear strength, and thermal conductivity. These analyses are run only on unlithified sediment. As thermal conductivity measurements require stabilization of the core sections' temperature to ambient temperature, this results in a 2- to 4-hour delay in core processing before splitting, sampling, and describing.

The MST, equipped with sensors for GRAPE and $P$-wave velocity as well as for magnetic susceptibility, is used to obtain a continuous record of these properties on undisturbed APC core sections. Data are collected directly by dedicated microcomputers and uploaded to the VAX (Section X.A). The task of running this equipment is generally handled by Technicians, but it is the obligation of the Physical Properties Specialist(s) to ensure proper data collection and documentation.

The Gamma Ray Attenuation Porosity Evaluator (GRAPE) is the sensor used to measure bulk density and porosity of cored material based on the attenuation of a gamma-ray source passing through the sample. The initial core processing aboard ship involves a GRAPE scan of all recovered APC core sections in order to obtain a continuous record of changes in bulk density downhole. The gamma ray source (Ba135 ) and detector pass the length of the core section, with the beam oriented perpendicular to the length of the section. Total gamma counts accumulated for 2 seconds are written to a computer file, and a computer bulk density is displayed on a monitor in real time (Section X.A).

During the core scan, two $500-\mathrm{kHz}$ transducers mounted alongside the GRAPE sensor collect $\boldsymbol{P}$-wave velocity measurements. A water contact between spring-loaded transducers and the core liner is used to ensure acoustic coupling. Two displacement transducers attached to the $P$-wave transducers provide a distance measure across the core. Delay time of the acoustic signal, distance between transducers, and amplitude of the received signal are recorded and plotted in real time. As with the GRAPE scan, the $P$-wave scan should be limited to high-quality APC cores.

Vane shear analyses are done in two directions (both parallel and perpendicular to the core axis) to provide an understanding of strength anisotropy. The parallel direction is performed by inserting the blade into the end of an unsplit section, adjacent to zones sampled for consolidation/triaxial testing and, ideally, also in alternating sections for the entire core (usually Sections 2, 4, and 6, avoiding Section 1). The vane test consists of inserting a blade into the sediment, initializing an X-Y plotter, and starting vane blade rotation. A standard rotation rate of $60 \%$ min is used, although this can be changed for special experimental purposes. Torque vs. rotation is plotted and the maximum torque value obtained is used to calculate shear strength.

Thermal conductivity measurements, necessary for studies of heat flow through the oceanic crust, are made on whole-round sections after the core temperature has stabilized to ambient lab temperature (usually 2-4 hours). This method involves drilling a small hole into the core liner and inserting a needle probe. A heater current is then initiated; up to five simultaneous measurements can be made over a period of five to ten 
minutes. These data are reduced to values of thermal conductivity on the lab computer (Section X.A). Thermal conductivity data, together with downhole temperature measurements, provide the parameters for computing heat flow.

\section{Splitting the Core (Sediments and Sedimentary Rocks)}

After all whole-round measurements are made, each section is taken to the core splitting room and placed in the core-cutting jig so that the core liner can be split longitudinally. Soft sediment cores are halved using a liner-cutting assembly with two razor-type blades, followed by a stainless steel spring wire attached to the end of the assembly. The splitting saw, a 9-in.-diameter diamond blade powered by a 3-H.P. motor, is used to longitudinally split core sections of hard rock or indurated sediments. The sections are then designated as working and archive halves, having been split such that a reference double line on the core liner is on the working half and a reference single line is on the archive half. On some APC cores, orientation relative to the Earth's magnetic north was determined during coring operations using the multi-shot survey instrument (see Sec. IX.0.2). The working and archive halves must be curated (by the Curatorial Representative or his alternate) so that they are mirror images of each other. If necessary, sediments along void boundaries must be supported by dividers to minimize movement in the liner.

\section{Core Description - Archive Half (Sediments and Sedimentary Rocks)}

This is the singular most important step in the entire scientific operation, since shipboard core descriptions become the basis of all subsequent sample studies and cores are rarely redescribed. If done with care, shipboard descriptions will need only minor modification before they are suitable for publication in post-cruise reports.

ODP Technical Note 8, "Shipboard Sedimentologists' Handbook," provides an excellent guide to all phases of core description for sediments and sedimentary rocks. In addition, the Staff Scientist will explain and demonstrate forms and shipboard procedures for core description.

For the sake of continuity and completeness, shipboard scientists are required to follow certain ODP conventions in describing cores, but are free to make whatever additional descriptions and interpretations they desire. Conventional description for sedimentary sections involves classifying sediment type; describing features such as color,

'texture, mineral composition, sedimentary structures, and evidence of bioturbation; and noting degree of coring disturbance (see Appendix B). Both megascopic and microscopic core data are used to construct "barrel sheets."

For megascopic core description of sedimentary sections, it is recommended that the entire core be split and laid out before beginning the description process. Color codes used are from the Munsell Soil Color Chart. Textural analyses to determine the sand-siltclay ratio can be made by hand lens or microscope. Keys are posted in the core lab to help estimate coring disturbance and common sedimentary structures. Megascopic data are recorded on visual core description (VCD) forms (see Section X.A).

For microscopic examination of sedimentary sections, smear slides should be prepared often enough to get a good general idea of the dominant lithology and any lithologic variations. Smear slide data serve to quantify the sediment constituents (using the 
COMPONENTS list posted in the core lab), which is essential to determining sediment type. All percentage values are based on an areal scan of the smear slide. These data are recorded in the SLIDES database (alternatively on sediment smear slide/thin section forms). Descriptions of thin sections of sediments and sedimentary rocks are recorded in SLIDES also. Note that descriptions of all thin sections must be completed during the cruise.

After the archive halves of core sections are described, they are photographed with both black-and-white and color film. The Photographer or Technician on watch in the core lab will take closeup photographs intended for Hole Summaries and ODP publications, at the request of any shipboard scientist. A black-and-white print of the closeup will be made for the requesting scientist. Scientists who want to take closeups not intended for Hole Summaries are encouraged to do their own closeup photography using the space, lighting, and copy stand set up in the core lab. The photographer will hold a short training session in the use of the core lab equipment at the beginning of the leg. ODP does not provide film, camera or film processing (see Section IX.L). After the archive halves have been photographed, they are boxed in D-tubes and stored on a core lab D-tube rack.

\section{Magnetics Analyses on Archive Halves (Sediments and Sedimentary Rocks)}

Magnetics analyses are performed on the archive halves of sedimentary core sections using the three-axis pass-through cryogenic rock magnetometer. A microcomputer moves core sections through the magnetometer for a complete record of the natural remanent magnetization (NRM). The data are written to files by the microcomputer, then uploaded to the VAX and stored as prime data (Section X.A).

The core sections may be subjected to low-field, partial alternating-field (AF) demagnetization and brought back through the sensing region of the cryogenic magnetometer. Archive sections may be demagnetized up to $15 \mathrm{mT}$ or the median destructive field, whichever is lower. The AF coils in the cryogenic magnetometer can be used to demagnetize discrete samples up to $20.0 \mathrm{mT}$, although damage to the instrument will occur if demagnetizing fields of this intensity are used extensively. Fields greater than $20.0 \mathrm{mT}$ may produce anhysteretic remanences.

Paleomagnetists are permitted to take shipboard samples (not counted against their personal sample total) from the working half to augment analyses of the split cores for shipboard studies. These discrete samples may then be thermally demagnetized or AFdemagnetized up to $100.0 \mathrm{mT}$ using the Schonstedt $\mathrm{AF}$ demagnetizer.

Smooth core flow is of the utmost importance. Paleomagnetic analyses of core sections must fit within the time constraints imposed by other scientific programs, including physical properties, sedimentology and petrology. The strategies required to ensure collection of high-quality data while facilitating core flow are at the discretion of the CoChief Scientists and the shipboard party.

\section{Core Sampling - Working Half (Sediments and Sedimentary Rocks)}

a. Shipboard Sampling Responsibilities

Requests for shipboard samples must be received by the ODP Curator at least two months prior to cruise departure. A Cruise Sampling Plan is 
assembled by the Co-Chief Scientists, and approved by the Curator during the transit to the first site of the leg. The approved Cruise Sampling Plan is the official guide for sampling activities during the cruise. Once the plan has been formulated and approved, exceptions and additions that would infringe upon the limitations discussed below (Section VIII.C.10.b) or the ODP Sample Distribution Policy (see Appendix A), can be authorized only by the Curator. All cruise participants and shore-based scientists are urged to meet the deadline for submission of sample requests in order to avoid delay in receiving their samples. Investigators (both shipboard and shore-based) who receive shipboard samples incur certain obligations that are detailed in both the ODP Sample Distribution Policy and on the ODP Sample Request Form (see Appendix A).

Shipboard scientists participate in taking samples for themselves and others, under the guidance of the Curatorial Representative, as described by the Cruise Sampling Plan. Working halves of sedimentary core sections (usually one core at a time) are sampled using plastic tubes pushed into the core, usually taking $3 \mathrm{~cm}^{3}$ or 10 $\mathrm{cm}^{3}$ samples, depending upon the sample request. Samples from lithified materials may be removed using a mallet to insert the plastic tube, or by chiseling or sawing. Samples are then inserted into heavy plastic bags, sealed, and labeled with a computer-generated sample label containing sample identifier and requestor's sample code. The labels are generated at the same time sample information is typed into the computer database (SAM) for all samples removed from cores. Sampling can become quite routine; the Curatorial Representative may post a template for sampling repeating programs (e.g., a request for two samples per core will receive samples evenly spaced across core sections), and the shipboard party usually institutes a watchstanding schedule at the sampling table.

Shipboard sampling is undertaken only in order to provide data for $O D P$ Proceedings volumes, not for detailed subsequent analyses. Therefore, it is inappropriate to request more material than can reasonably be analyzed within the eighteen months immediately following the cruise. Additional samples for more detailed studies may be requested from the Curator 12 months after termination of the cruise.

b. Limitations on Shipboard Sampling

The number and size of samples taken during the cruise is strictly controlled by NSF/ODP policy. Limitations on the freedom of shipboard scientists to sample the cores arise from two sources:

i) The cores are considered valuable resources for future researchers, so the shipboard participants are permitted to sample not more than one-half of any interval in the working half. The archive half is never to be sampled. Also, no individual may have more than $50 \mathrm{cc}$ of sample per meter of core recovered without prior express approval of the Curator.

In the event that intervals are recovered that are of great interest to scientists in general and are in limited supply (e.g., stratigraphic boundaries), sampling of critical intervals is deferred entirely until the cores reach the repository, so that careful planning can maximize scientific return from those samples.

ii) Space, facilities, manpower, and rate of core recovery necessarily influence the number of samples that can reasonably be taken during the cruise. If the total 
number of cruise-related sample requests is greater than the system can readily accommodate, fulfillment of some sample requests is deferred until the cores reach the repository. The guidelines for cruises of normal length are that (1) the maximum number of soft mud samples is 20,000 ; (2) the maximum number of igneous, metamorphic, or indurated samples to be allocated among cruise participants is the number of hours spent drilling hard rock multiplied by 20; and (3) the maximum number of igneous and metamorphic samples per individual is $\mathbf{1 0 0}$.

\section{Storage of Core Sections (Sediments and Sedimentary Rocks)}

Both halves of each core are prepared for storage by inserting the split sections into labelled D-tubes, with wetted sponges. Working halves are stored in the core rack at the end of the sampling table to facilitate further sampling. Archive halves are kept temporarily on racks beside the core photography table. Core sections are boxed either as time permits at the end of each site or when additional space is needed on racks.

\section{Core Laboratory Procedures - Igneous and Metamorphic Rocks}

The following procedures are used for handling and sampling igneous and metamorphic rock cores aboard JOIDES Resolution. Lithified sediment cores may be handled in a similar manner if desired. Adherence to these procedures ensures that proper orientation and sequence of rock pieces are maintained.

\section{First Arrival of a Core on Deck (Igneous and Metamorphic Rocks)}

Before the core catcher is removed from the core barrel, a Technician uses wax pencil to mark the bottom of each rock piece in the core catcher with a cylindrical (drilled) outer surface. Rounded pieces (rollers) are not marked. When the core catcher is removed, the bottom of the core in the core liner is marked with wax pencil. The rock(s) from the core catcher are placed in the bottom end of the core liner in correct stratigraphic order and orientation; for hard rock cores, there is no "core catcher" section.

The liner is brought to the catwalk core rack. If hard rock pieces are scattered along the length of the liner, the upper end of the liner is raised slightly to shunt all the pieces to the lower end. Since hard rock cores do not always break at neat 1.5 -m intervals, the liner is marked temporarily into $1.5-\mathrm{m}$ sections, but cut into sections of approximately $1.5 \mathrm{~m}$ where there are fractures in the core. Sections are numbered from the top down, as with sediment cores. End caps are put on but not glued in place.

\section{Core Entry Lab Procedure (Igneous and Metamorphic Rocks)}

Technicians carry the core sections into the core entry lab and enter core information in the computer database (CORELOG), carefully noting the actual lengths of the rocks in the liner to give the true core length. Empty 1.5-m sections of capped core liner are split in half and permanently labeled with the core section identifiers. Starting with the top of 
Section 1, pieces of rock are carefully shaken out of the uncut liner into the corresponding liner half, maintaining order and orientation. The bottom of each piece that can be oriented (i.e., with a length greater than the width of the liner) is marked with a wax pencil.

Next, the Physical Properties Specialist, in consultation with the duty Petrologist, Geochemist, and Paleomagnetist, selects a sample or samples for physical properties measurements (sonic velocity and 2-minute GRAPE). These samples are taken before the cores begin to dry out, and are stored in sea water for an hour to stabilize at room temperature. These samples are used also for paleomagnetics measurements, and a thin section is made before the sample is powdered for X-ray fluorescence analysis.

Pieces of whole core chosen for physical properties sampling are marked on opposite sides with orientation arrows that point to the top of the section. Temporary place holders are set in the liners wherever pieces are removed. Both the removed pieces and the place holders are given temporary labels indicating their position in the section. The pieces chosen for sampling are split lengthwise and marked with orientation arrows before being slabbed or mini-cored. Samples are taken only from the halves designated as working halves of the core. It is important that wherever such samples are from pieces that fit together with adjacent pieces, the plane of splitting through all the adjoining pieces is predetermined. Then, when the sampled pieces are returned to the split liners, textures and features will fit together correctly.

Measurements of physical-property anisotropy may require a sample larger than can be obtained from the working half alone. Prior to splitting the rocks, the Physical

Properties Specialist may select representative whole-round pieces, which are stored separately in seawater. If the measurements are to be made aboard ship, the minicorer or rock saws are used on the full-diameter pieces to obtain samples; sample destruction is minimized. Once the measurements are taken, the pieces can be kept in seawater storage for shore-based work or returned to the liners, in which case they are split into archive and working halves.

\section{Placing of Spacers, Numbering, and Splitting (Igneous and Metamorphic Rocks)}

The duty Petrologist attempts to reconstruct the core, and marks lightly on the core the plane of the saw cut to split all features equally between working and archive halves. Broken or beveled rock pieces with features that can be aligned from piece to piece are fitted together. Spacers go between all pieces that cannot be fitted together. Each continuously cored piece or group of pieces is distinguished by a number, starting with " 1 " at the top of each section. Pieces that fit together have the same number with letter suffixes; for example, three pieces of the third rock (counting from the top of the section) that fit together are numbered 3a, 3b, 3c (Fig. 10). If two pieces occupy a single interval, each half is numbered (and lettered, if necessary) identically. Placement of spacers automatically "numbers" the pieces, but they are not numbered by label until after they are split. 
NUMBERING SYSTEM FOR

HARD ROCK PIECES

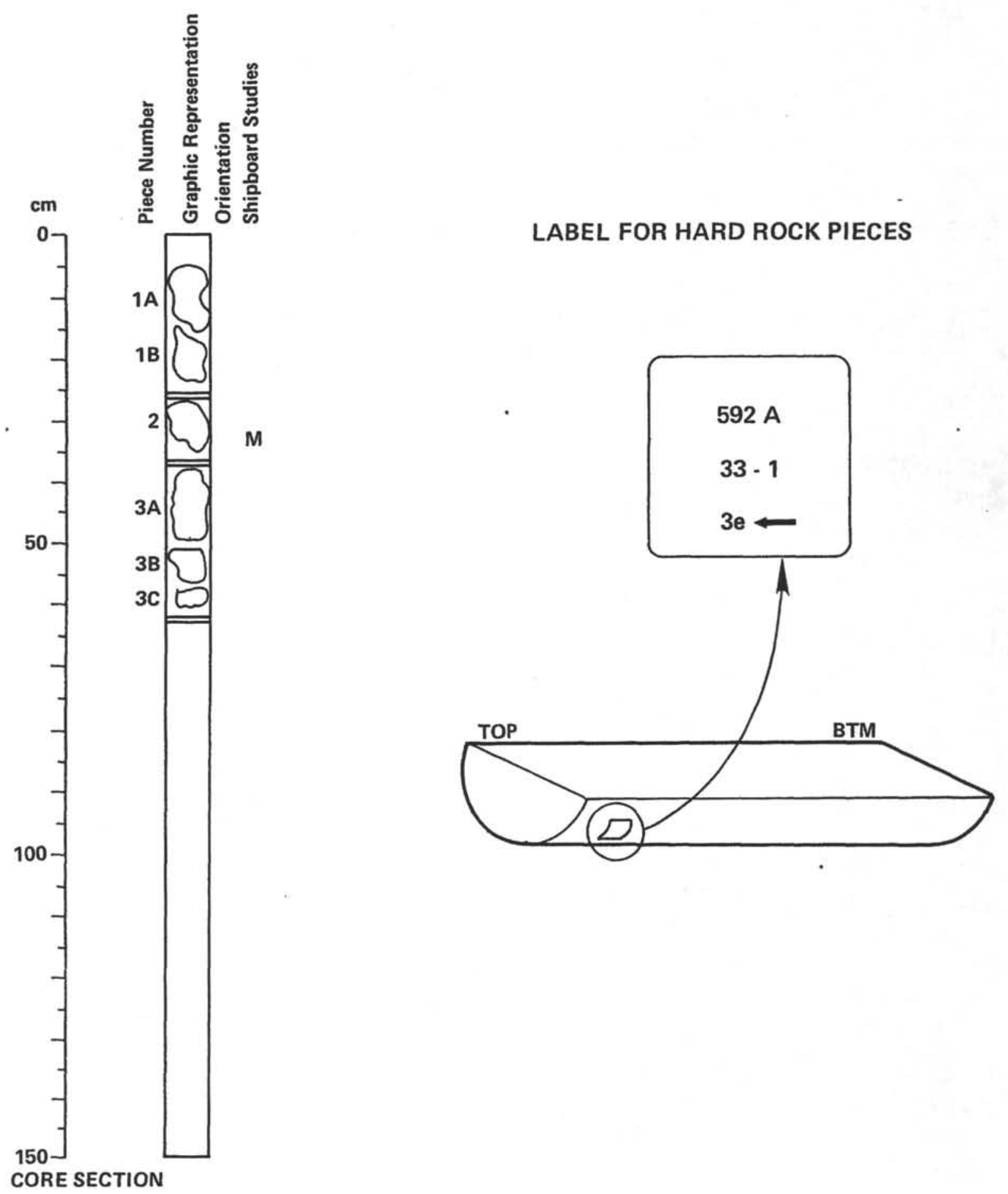

Figure 10. Numbering system for hard-rock pieces. 
All hard rock cores are split by hand on a Felker saw in the core lab or core splitting room. The bottom of each oriented piece is marked clearly before being split to ensure that the piece is not reversed during splitting or when returned to the liner. Pieces are split symmetrically with regard to contacts or special features. Pieces that fit together or that have contiguous features (identified by one number with letter suffixes) are split along a single line drawn on all the pieces fitted together. The line is drawn with a wax pencil held against the edge of the liner or along the top of the pieces, whichever conveniently divides special features into both archive and working halves.

When shattered rock is recovered that is too fragmented to piece together by hand if removed from the liner, the fragments are held together with masking tape or shrink tubing and cut as one unit.

Glassy margins, intensely altered areas, clays, and other mineral coatings may be accidentally broken off during handling. These chips are collected and placed in plastic bags marked with the appropriate piece number. The bags are put with the working half of the core.

\section{Labeling (Igneous and Metamorphic Rocks)}

Technicians and scientists number the core fragments as divided by spacers. Pieces are turned over in the liners, flat side down for drying. Pieces that were removed for physical properties analyses are returned to the liner for labeling. If the analyses haven't been completed, temporary labels are applied to the place holder. Labels are as small, neat, and clear as possible, but large enough to contain leg number, hole number and letter, core number and type, section number, and piece number (Fig. 10).

Labels are computer generated, with hand-written piece numbers, and orientation arrows on each oriented piece. The labels are attached to the bottom (rounded) side of each piece of core, with a small amount of epoxy resin to completely seal the label, so that the labels read parallel to the length of oriented pieces with the arrow showing the way upcore. When the epoxy is set, the pieces are returned to their liners.

\section{Photography and Description (Igneous and Metamorphic Rocks)}

Following labeling, all archive halves of each core are moved to the description table to be described by Petrologists, using the HARVI data entry program. Visual Core Description (VCD) forms for igneous and metamorphic rocks are available as backups to the HARVI data base. Once descriptions are completed, the archive cores are photographed (dry). Then the archive halves are covered in shrink tubing and placed in D-tubes for storage.

\section{Preliminary Shipboard Sampling (Igneous and Metamorphic Rocks)}

Three types of samples are taken from the working halves of each core for shipboard analysis. Mini-cores (used for paleomagnetics and several other measurements) are given an interim code "SBA" (for shipboard analysis) in the core sampling database. X-ray fluorescence samples are given the code "XRF." Thin section billets are coded "TS." Samples taken in any of these categories are logged into the sampling database by the Curatorial Representative, who notes on the completed listing whether properties of the 
samples are modified in any way and who keeps track of all SBA, XRF, and TS samples as analytical work is completed.

SBA mini-core samples are used for a number of measurements. A flow procedure is set up to maximize information from such samples. Some of the uses for mini-cores are paleomagnetics measurement, density, porosity (non-GRAPE), sonic velocity, geochemistry, and thin-section billets.

Scientists select samples for shipboard thin-section preparation, according to the approved Cruise Sampling Plan, while the archive halves are being described. Instructions for orientation, impregnation, or other special procedures are written on the sample bag. Unless otherwise requested, thin sections are polished and cover slips are not applied. All thin sections produced aboard ship are the property of ODP and must be described during the cruise using the HRTHIN data entry program (with paper forms available as backups). A major objective of this procedure is to have a complete collection of thin sections described for ODP reports and ready for microprobe analysis ashore. Thin sections are returned to a repository at the end of the cruise, but are available on loan for microprobe and petrographic work. Billets are returned to the working half and may be reassigned as $\mathrm{XRF}$ or personal samples.

\section{Personal Samples (Igneous and Metamorphic Rocks)}

After the cores are described and sampled for shipboard analyses, the working halves are stored in D-tubes on the core lab core rack. Personal sampling usually awaits chemical and magnetic characterization of the cores. The Co-Chief Scientists, Staff Scientist, and Curatorial Representative schedule a time when all hard-rock sample requestors may sample as a group (these are known as sampling parties). Materials available for personal samples are working halves of cores, SBA samples that have been returned to the liners, and TS billets.

Samples are designated by piece number and interval. No more than half of a given interval and/or piece can be sampled. Critical intervals with limited material of unusual interest (such as glassy zones) are marked before sampling begins with labels reading "Special Sample--Requires Sample Plan." Where the critical interval is very small or is one that many scientists may wish to sample, a suitable plan is devised but sampling is not undertaken aboard ship. The plan is transmitted to the repository at the end of the cruise and sampling is completed there. The delay in receipt of samples is a small price to pay for conservation of as much of the critical intervals as possible.

Each scientist may take no more than 100 hard rock samples during the cruise. Samples taken only for the purpose of obtaining data in the shore laboratories of the shipboard party to complete shipboard analyses are not counted against the 100 sample limit of any scientist. It is understood in such situations that the data will go into the site chapters of the Initial Reports and are communicated to all shipboard scientists as soon as they are obtained. Scientists wishing to take home samples that were originally collected as SBA, XRF, or TS samples must have the sample relabeled and reentered in the sample database with the code of that scientist. These samples are counted against the 100 -sample limit. Shipboard scientists who have arranged to take samples for one or more collaborators can still take only 100 samples, to be distributed among the collaborators at their discretion. 
The Curatorial Representative and the ODP Staff Scientist must be given a final distribution list of these samples.

Each scientist selects his samples by putting a small piece of masking tape containing his personal sample code on the core liner next to the area to be sampled. Scientists who request samples from the same location are given the opportunity to come to a mutually acceptable agreement before samples are cut. Technicians and the Curatorial Representative cut the sample with either the mini-corer or Felker saw and return the unused portion of the rock piece to the core. The sample is placed in its bag, labeled, and sealed. Bagged samples are inventoried by the Curatorial Representative. Each scientist receives lists of the samples he has taken.

\section{SCIENTIFIC LABORATORY AND DATA COLLECTION FACILITIES}

This section includes brief descriptions of the scientific systems and equipment presently aboard JOIDES Resolution. The labs (Fig. 2) are set up for continuing routine studies and some of the equipment is adaptable to more detailed programs by individual scientists. Questions concerning the availability of specific scientific systems can be addressed to the Supervisor of Technical Support, Ocean Drilling Program, 1000 Discovery Drive, College Station, Texas 77845-9547. Procurement of items of considerable expense or in limited demand, other than those normally aboard JOIDES Resolution, is the responsibility of those wanting to use them.

All proposals for special shipboard experiments must be formulated in writing and are then delegated to the appropriate personnel at ODP. Large-scale experiments that may pervade more than one cruise; involve coordinated activities with other ships, countries, or institutions; or clearly require a major commitment of all ODP departments, should be referred to the ODP Deputy Director. Most requests involve smaller-scale, legspecific shipboard scientific experiments, and should be referred to the ODP Manager of Science Operations.

\section{A. Core Laboratory}

The core lab is divided into the core entry lab, core splitting room, sampling area, and description area (sedimentology lab) (Fig. 11). The core entry lab is adjacent to the catwalk, where cores are laid out after having been retrieved from the hole. The core splitting room, beside the core entry lab, is isolated from the rest of the core lab. After whole-round core measurements are completed, the cores are cut longitudinally into working and archive halves, and core description and sampling are begun.

The sedimentology lab contains separate description and photography tables, as well as bench space and microscope stations. Smear slides are prepared using Isotemp ovens and hot plates under benchtop fume adsorbers. Diverse mounting media are available: Norland Optical Adhesive (ultraviolet light setup in the lab), Hyrax, Piccolite, Permount, gum tragacanth, clove oil, Canada Balsam, and a German synthetic Canada Balsam (Eukitt). Most standard lab chemicals and equipment are available, as well as the following stains and dyes: Methylene blue, Malachite green, Rose bengal, Alizarin red "S," and Safranin "O." 
Figure 11. Layout of core lab, paleomagnetics lab, and physical properties lab.
1. SAFETY SHOWER \& EYE BATH
2. ELECTRONICS RACK
3. FAXITRON (X-RAY)
4. COMPUTER TERMINAL
5. THERMAL CONDUCTIVITY
6. MST (MULTISENSORTRACK)
7. LASERPRINTER
8. MINI-SPIN MAGNETOMETER
9. AVC DEMAGNETIZER
10. PENTA-PYCNOMETER
11. THERMAL DEMAGNETIZER
12. BALANCE
13. CRYOGENIC MAGNETOMETER
14. TRIM SAW
15. VANE SHEAR
16. VELOCIMETERS
17. OVEN
18. HEAT SEALER
19. CAPSTAN MOTOR \& CORE SPLITTER
20. TOOL BOX
21. MINI-CORERS
22. FELKER SAW
23. MICROSCOPE STATION
24. CLOSE-UP PHOTO TABLE
25. DATA BOARD ("WHITE BOARD")
26. RIG FLOOR MONITORS
27. FREEZE DRYER

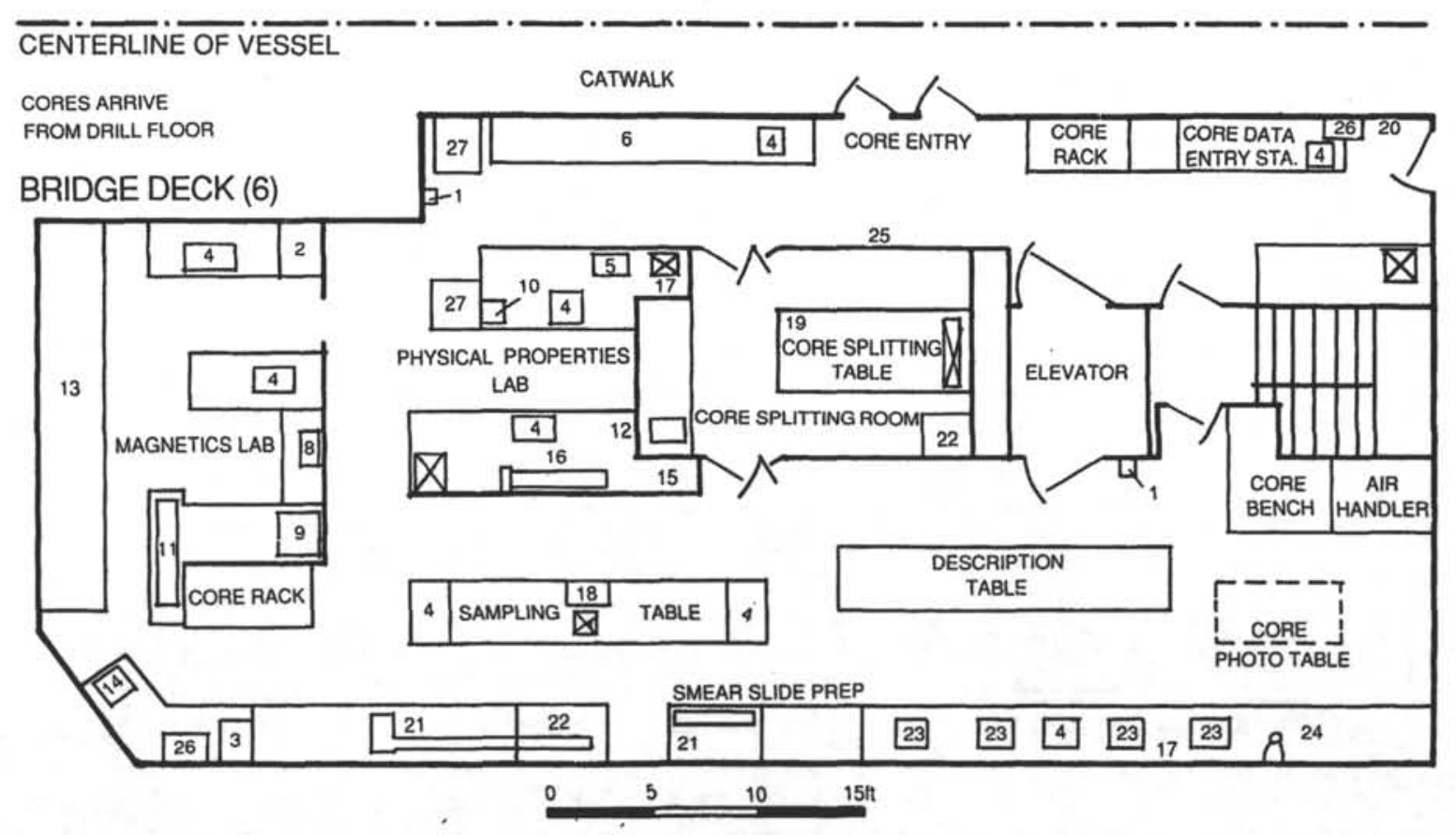


Standard testing sieves in a variety of mesh sizes and a Labtec laser particle-size analyzer (PSA) are available for grain-size studies. The PSA provides rapid percentage measurements of silt- and clay-sized particles using a focused laser diode light source $(0.8 \mu \times 2.0 \mu)$ to measure the sizes of individual particles in solution. The PSA can be operated in either of two size ranges: $250 \mu-<4 \mu$ and $125 \mu-<2 \mu$, with eight size intervals measured for each range.

The optical equipment in the sedimentology lab is similar to that available in the microscope lab (see Section IX.F), and includes two Zeiss standard WL microscopes and two Zeiss SR stereomicroscopes. Oculars, objectives, micrometers, filters, and camera attachments for these microscopes are interchangeable among all the Zeiss microscopes on board. The microscopes are each supported by a vibration isolation system. Although ODP attempts to maintain adequate supplies aboard ship, all shipboard scientists are encouraged to bring their own hand lenses.

Core sampling equipment includes Felker radial arm saws, a drill press with diamond coring bit ("minicorer"), various hand tools, and sample-bag sealers. Computer terminals are conveniently located for direct input of sampling data, printing sample labels, entering SLIDES data (from smear-slide and thin-section descriptions), or for word processing.

(Further information about shipboard sedimentologic procedures is available in ODP technical note 8: "Handbook for Shipboard Sedimentologists.")

\section{B. Paleomagnetics Laboratory}

\section{Introduction}

The shipboard paleomagnetics lab is located at the aft end of the core lab on the lab structure's bridge deck (Fig. 11). The paleomagnetics lab is equipped for measurement of magnetic remanence (using spinner and cryogenic magnetometers) and volume magnetic susceptibility, using split and whole cores of sediment and discrete samples of sediment and rock. Discrete samples may be demagnetized with the alternating magnetic field or thermal demagnetizers. Split archive halves may be AF-demagnetized (using in-line demagnetization coils built into the cryogenic magnetometer) to an intensity limit of $15 \mathrm{mT}$. APC cores may be oriented geographically as they are taken, using the Multishot core orientation tool (Section IX.B.4 below). Results from these analyses are thus available for immediate integration with other shipboard data (Section X.A). Shipboard measurements help reduce the effects on data of alterations caused by oxidation, mechanical disturbances, and exposure to high magnetic fields that may occur between coring and shore-based sampling.

A Technician assigned to the paleomagnetics lab is responsible for the lab equipment and database. In addition to performing maintenance and/or repairs on the lab equipment, the technician will train shipboard paleomagnetists in use of the equipment and the PALEOMAG account on the shipboard VAX computer. As with all members of the technical staff, however, his/her primary responsibility is to core processing; the Laboratory Officer, with guidance from the $\mathrm{Co}$-Chief Scientists, will assign technical support to laboratories as required to meet the overall scientific goals of the cruise. 


\section{Paleomagnetics Sampling}

Hard rock samples are taken with either the mini-coring drill press, producing a cylinder of $2.54 \mathrm{~cm}$ ( $1 \mathrm{in}$.) diameter, or with the rock saws (including a double-bladed saw), to convenient dimensions. The minicore cylinders may be cut to prescribed length with parallel ends. Shipboard supplies for sediment sampling are limited to clear plastic cubes with outside dimensions of 1 in. $x 1$ in. $x 3 / 4$ in. and an interior volume of $7 \mathrm{~cm}^{3}$. There are various devices available for assisting in sampling with these cubes. Other sampling containers (such as U-channels or cubes of a different size) must be provided by the scientist who wishes to use them. All sampling schemes must be authorized by the ODP Curator prior to the cruise.

\section{Paleomagnetics Equipment}

The Molspin Minispin spinner magnetometer is a basic field unit interfaced with a microcomputer for control and data acquisition. The BASIC program for the Minispin executes spin sequences and from the data from each spin calculates declination, inclination, and intensity in $\mathrm{mA} / \mathrm{m}$ corrected for the volume of the sample. A series of measurements is made on each sample as it is run through a demagnetization sequence. The Minispin can measure both rock and sediment samples up to $2.54 \mathrm{~cm}$ ( $1 \mathrm{in}$.) cubed in size, with intensities ranging from 0.05 to $105 \mathrm{~mA} / \mathrm{m}$. Ordinarily, six separate spin orientations are required to produce an accurate measurement. In general, the processing rate will vary with the NRM intensity and response to demagnetization of the samples from a particular lithologic unit.

The Schonstedt Alternating Field Demagnetizer is used for demagnetization of discrete samples of rock or sediment. The user can select a range of peak fields from 0 to $100 \mathrm{mT}$.

The Schonstedt Thermal Demagnetizer is used for thermal demagnetization of dry rock samples with a temperature range of $0-800^{\circ} \mathrm{C}$.

The lab's Molspin Pulse Magnetizer is capable of magnetizing samples to 9000 gauss.

A Schonstedt Portable Three-Axis Fluxgate Magnetometer is available to measure ambient fields, with a range of \pm 2000 milligauss and a sensitivity of 0.01 milligauss ( 1 gamma). The sensor is small enough ( $1.3 \times 7 \mathrm{~cm}$ cylinder) to fit into small spaces such as the sample access tube of the cryogenic magnetometer.

The Bartington Magnetic Susceptibility Meter has two sensors: one for discrete samples and a loop (mounted on the MST) for whole-core pass-through measurements. The meter has two measurement modes for different sensitivities. An accuracy of $1.0 \times 10^{-6}$ cgs can be obtained with a 1-second measurement cycle and one of $0.1 \times 10^{-6} \mathrm{cgs}$ with the 10-second cycle using either sensor. This instrument is part of the multi-sensor track (see Section VIII.C.4), using an $80-\mathrm{mm}$ dual frequency loop $(0.47$ and $4.70 \mathrm{kHz}$.)

The 2G 760-R superconducting rock (cryogenic) magnetometer is used primarily for continuous NRM measurements on archive halves of cores, though these cores may be uniformly demagnetized inside the cryomag's mu-metal shielding and remeasured. It is calibrated in units of magnetic flux, $\mathrm{phi}_{0}$, and measures in units of $\mathrm{mA} / \mathrm{m}$. The cryomag may also be used to measure and demagnetize discrete samples; a control program written in QuickBASIC and run on an IBM PCAT-clone facilitates these measurements. 
The best-shielded instrument is the cryogenic magnetometer, which resides inside three concentric mu-metal cylinders. Its AF coil assembly is also contained within these shields. A superconducting lead shield surrounds the sensing region and maintains an absolutely stable field within. The two Schonstedt demagnetizers and the fluxgate unit in the Minispin are each housed in three nested cylinders. The sample storage cans are cylinders $12 \mathrm{in}$. in diameter and $24 \mathrm{in}$. in length.

\section{Core Orientation}

Using the Eastman-Whipstock Multishot orientation tool (see Section IX.O.2), cores may be oriented in situ with respect to the downhole ambient field. This tool requires a special nonmagnetic drill collar (the Monel collar) as part of the bottom-hole assembly, as well as a variety of expendable items (film, batteries, etc.) and additional setup time on the part of the Technicians. Thus, it is imperative to develop a coring plan that can be discussed at the Co-Chief Scientists' pre-cruise meeting (usually held about four months pre-cruise). The decision to orient cores at a given site must be made well in advance of the cruise. It is also important to provide the technical/logistics staff, well before the cruise, with an estimate of the number of cores to be oriented.

\section{Data Processing}

Initial data acquisition is done by various computers and data are stored temporarily on diskettes. These diskettes are uploaded to the central VAX computer where further processing can take place (Section X.A). Some processing routines have been developed to concatenate files into convenient units (such as files by core rather than files by section) and to assign a preliminary sub-bottom depth value to each data point. The VAX is well-suited to data manipulation. There are a number of programs available for plotting data, and plots can be generated on a laser printer in the magnetics lab.

\section{Physical Properties Laboratory}

\section{Introduction}

The physical properties lab is located near the core entry doors to the core lab (Fig. 11). The shipboard physical properties program is aimed at monitoring values and variations of physical and mechanical properties of recovered lithologies. Since the properties of sediments and rock change with time after they are recovered, a complete shipboard physical properties program represents the best opportunity to obtain reliable physical properties data from the cores. In addition to providing results for specific physicalproperties studies, results from this lab are valuable for correlating drilled sequences to seismic reflection and refraction profiles and downhole logging results, and for defining the nature of lithologies derived from distinct geologic settings.

\section{Sampling for Physical Properties}

The Physical Properties Specialists are responsible for obtaining representative coverage of the recovered lithologies. In sediments, for instance the physical properties can vary on a scale of centimeters. Consequently, the data are likely to be of little use if too few 
are collected. The recommended sampling frequency is at least every other section; more frequent sampling is, of course, highly desirable. One sample per core is the absolute minimum unless disturbance and/or poor recovery preclude making useful measurements.

A coordinated sampling program is vitally important if statistically valid conclusions regarding variations of physical properties and their relationships to lithology, depositional and/or tectonic setting, and geologic history are to be drawn. The best data sets are those in which velocity, density, porosity, strength, mechanical characteristics, and other properties can be cross-correlated with carbonate content, X-ray diffraction, X-ray fluorescence, grain size analyses, paleontology studies, and logging results. To achieve this, the Physical Properties Specialists should coordinate sampling strategy with other shipboard participants.

Samples taken should be representative of the general lithology; the properties of unusual materials are also of interest and may provide key ties in correlations. The Physical Properties Specialist is expected to note the sample material tested and relative abundances of unusual materials. Even very brief sample descriptions, for example "finely laminated limestone," "nannofossil chalk with a thin (1-mm) layer of foraminifers," or "serpentinized gabbro," are critical in later interpretation of the data.

\section{Whole Core Section Analyses}

A number of physical properties tests require whole-round 1.5 -m lengths of core sections and therefore must be performed prior to having the core sections split (see Section VIII.C.7). These tests include whole-section logging for density, porosity, and velocity, thermal conductivity, and vane shear measurements made parallel to bedding. Density, porosity, velocity, and magnetic susceptibility of a core section are measured on the multi-sensor track (MST). A computer controlled stepping motor drives a fiberglass core boat through the sensing devices. Bulk density and porosity are determined by measuring the attenuation of a gamma-ray beam through the sample. Compressionalwave ( $P$-wave) velocity is measured while the core section passes between two $500-\mathrm{kHz}$ transducers (see Section VIII.C.6.b). Magnetic susceptibility is measured as the core stops in a sensing loop (see Section IX.B.3).

The MST was designed to accommodate up to eight sensors, each controlled by its own microcomputer. A master microcomputer controls track movement and coordinates data acquisition of the individual sensor computers and data transfer to the main shipboard VAX computer complex (Section X.A).

\section{Whole Round Samples for Consolidation/Triaxial Testing}

The GDS Consolidation Testing System measures dynamic properties such as compressibility of nonlithified, undisturbed sediment samples. The system also measures permeability to yield information regarding pore pressure conditions, state of consolidation, and hydrothermal flow rates. These tests are performed on an 8-10-cm sample cut from a whole round core section (see Section VIII.C.4).The GDS system normally resides at ODP shore-based facilities at Texas A\&M University, available to visiting scientists. With early notification, the system can be made available for shipboard work.

Present JOIDES guidelines approve one $8-10-\mathrm{cm}$ sample per major 
lithologic unit for consolidation testing. Additional samples may be requested by investigators for consolidation and/or shore-based triaxial testing, but requests must be made well in advance of the cruise. One constant rate of strain consolidation test can be performed in a 24-hour period, so several tests can be completed during a cruise.

The whole-round samples used in these tests can be reused for other studies. As it is important to get the range of physical properties data from as close an interval of sediment section as possible, the shipboard Physical Properties Scientist uses the consolidation sample to run tests of all index properties and carbonate content. X-radiographs of these samples can be made prior to trimming the material for testing, thus providing information for descriptions of structure. Remains of the test sample can be sub-sampled for shipboard micropaleontological analysis and shore-based studies.

\section{Working Half Sample Analyses}

\section{a. Compressional Wave Velocities}

The shipboard laboratory is equipped with a Hamilton frame velocimeter to measure velocities parallel and perpendicular to bedding. Velocities of very soft sediments, in high-quality APC cores, can be obtained from continuous $P$-wave scans. If the sediment is firm enough to trim, sample chunks are measured in the compressional-wave frame. The trimmed faces of the sediment/rock chunk must be flat and parallel, or the measured velocities are inaccurate. A dual-blade trim saw is used for cutting parallel faces of firm to hard rocks. "Biscuits" of hard sediment are probably representative of the sediment in situ and are easy to sample, but they must be examined carefully and trimmed before measurements are made.

\section{b. Index Properties}

The index properties that are attainable with shipboard equipment include bulk density, water content, grain density, porosity, and void ratio. All measurements are made by noting gravimetric-volumetric relationships on wet and dry samples using a programmed, dual-pan Scientech system (weight), automatic Quantachrome Pentapycnometer (volume), and freeze-drier. Wet samples are weighed and measured for volume as quickly as possible to avoid desiccation. Then the samples are freeze-dried for $\sim 24$ hours, re-weighed, and the volume determined. All index properties are calculated from these raw data. The dried material is then used for carbonate analysis and for XRD analysis if requested. Bulk density and porosity of porous, hard lithologies can also be obtained from relationships of sample weights in air and submerged, using an Ohaus triple-beam balance. In basalts, this latter method has proven to yield better results for the wet-stage volumetric measurement relative to the pycnometer.

Another measure of bulk density and porosity can be made using 2-minute GRAPE counts. Although the GRAPE does not give a direct measurement of density, it has the significant advantage of insensitivity to ship motion. For this analysis, samples initially used for velocity analyses are plastic-wrapped to prevent moisture loss and placed in the scanning GRAPE. Measurements are made parallel and perpendicular to bedding. c. Vane Shear Strength

Shear strength measurements are made both parallel and perpendicular to bedding. 
Measurements parallel to bedding require inserting the blade into the end of a wholeround core section or sample (see Section VIII.C.6.b). Measurements perpendicular to bedding are performed on the working half on unlithified sediments in areas of minimum disturbance. A Wykeham-Farrance spring-type device and a torque transducer/X-Y plotter system are the two motorized vane-shear apparatuses available on board. Generally, once a sediment becomes "biscuited" the vane tests are not meaningful.

Hand-held torvanes are also available for vane shear strength determinations. Adapter heads are used with the torvanes to obtain a wider range of sensitivity.

\section{d. Thermal Conductivity}

Thermal conductivity measurements are made using a Thermcon-87 electronics unit (from WHOI) equipped with five heater-wire/thermistor sensors. These measurements require temperature drift rates less than $0.4 \% \mathrm{~min}$; thus, most cores need $\sim 2-4$ hours to reach laboratory temperature equilibrium.

This measurement is performed in whole-round sections using a needle probe for soft lithologies. A half-space needle probe and water bath are used for hard lithologies. Since good contact between the sample and half-space probe is necessary for valid thermal conductivity measurements, the sample face may be polished prior to testing. e. Resistivity

Sediment and pore fluid resistivity measurements are attainable for unconsolidated materials. A four-electrode probe inserted into split cores is used to obtain resistivity using a Wayne-Kerr Precision Component Analyzer (Model 6425). Normal operating conditions are $0.5 \mathrm{Vac}$ at $1 \mathrm{kHz}$. Pore fluid resistivities are measured using another resistivity unit in conjunction with a $0.5 \mathrm{ml}$ teflon cell.

\section{f. Other Measurements}

The Physical Properties Specialist is encouraged to expand upon the conventional tests listed above. A liquid limit device and a plate for plastic limits are available for determining Atterberg limits. Hand penetrometers are available for another measure of sediment strength.

\section{Data Processing}

Data from velocity, shear strength, and index properties measurements are entered into the computer data base via the "PHYSPROPS" program. Thermal conductivity measurements are written to computer files and paper forms for data collection (see Section X.A).

\section{Chemistry Laboratory}

\section{Introduction}

The chemistry lab is located on the lab structure's fo'c'sle deck (Fig. 12). Two ODP Chemists sail on most cruises, providing 24-hour coverage in the chemistry lab, providing dedicated technical support for routine analyses and assisting shipboard Inorganic and Organic Geochemists.

(Further information about chemistry facilities aboard ship can be found in ODP technical notes 5 (inorganic geochemistry), 6 and 7 (organic geochemistry). 
Figure 12. Layout of chemistry, XRF/XRD, thin section, SEM, and paleontology labs.

1. BALANCE

2. AUTOMATED C-H-N-S ANALYSER

3. ROCKEVALUATION SYSTEM

4. CANOPY HOOD

5. FUME HOOD

6. PRESSES

7. ION CHROMATOGRAPH

8. AUTOMATIC TITRATION

9. FREEZE DRYER

10. FREEZER BELOW

11. WATER PURIFICATION SYSTEM

12. GRINDERS

13. ATOMIC ABSORPTION

14. STORAGE CABINET
15. GAS STORAGE \& CENTRAL REGULATOR

16. SAFETY SHOWER \& EYE BATH

17. HP 1000 COMPUTER FOR CHEMISTRY LAB

18. GAS CHROMATOGRAPH

19. SPECTRO PHOTOMETER

20. ELECTRONICS/COMPUTER CABINET

21. XRFMONITOR

22. XRF X-RAY GENERATOR

23. GAS BOTTLE STORAGE

24. DEC. MINICOMPUTER AND XRD CONTROLLER

25. HEAT EXCHANGER

26: X-RAY SPECTROMETER

27. XRD GENERATOR

28. COLOR PLOTTER

\author{
29. COLOR TERMINAL \\ 30. OVENS \\ 31. COMPUTER TERMINAL \\ 32. SAW GS-10 \\ 33. PETRO-THIN GRINDER \\ 34. LOGI TECH LP . 30 GRINDER POLISHER \\ 35. BUEHLER LAP WHEEL \\ 36. W-2O VAC INPREGNATOR \\ 37. FINE POLISHER \\ 38. SLIDE PREP \\ 39. MICROSCOPE \\ 40. FURNACE \\ 41. STEAM WASHER BELOW \\ 42. $\mathrm{CACO}_{3}$ COULOMETER \\ 43. TOC COULOMETER
}

CENTERLINE OF VESSEL

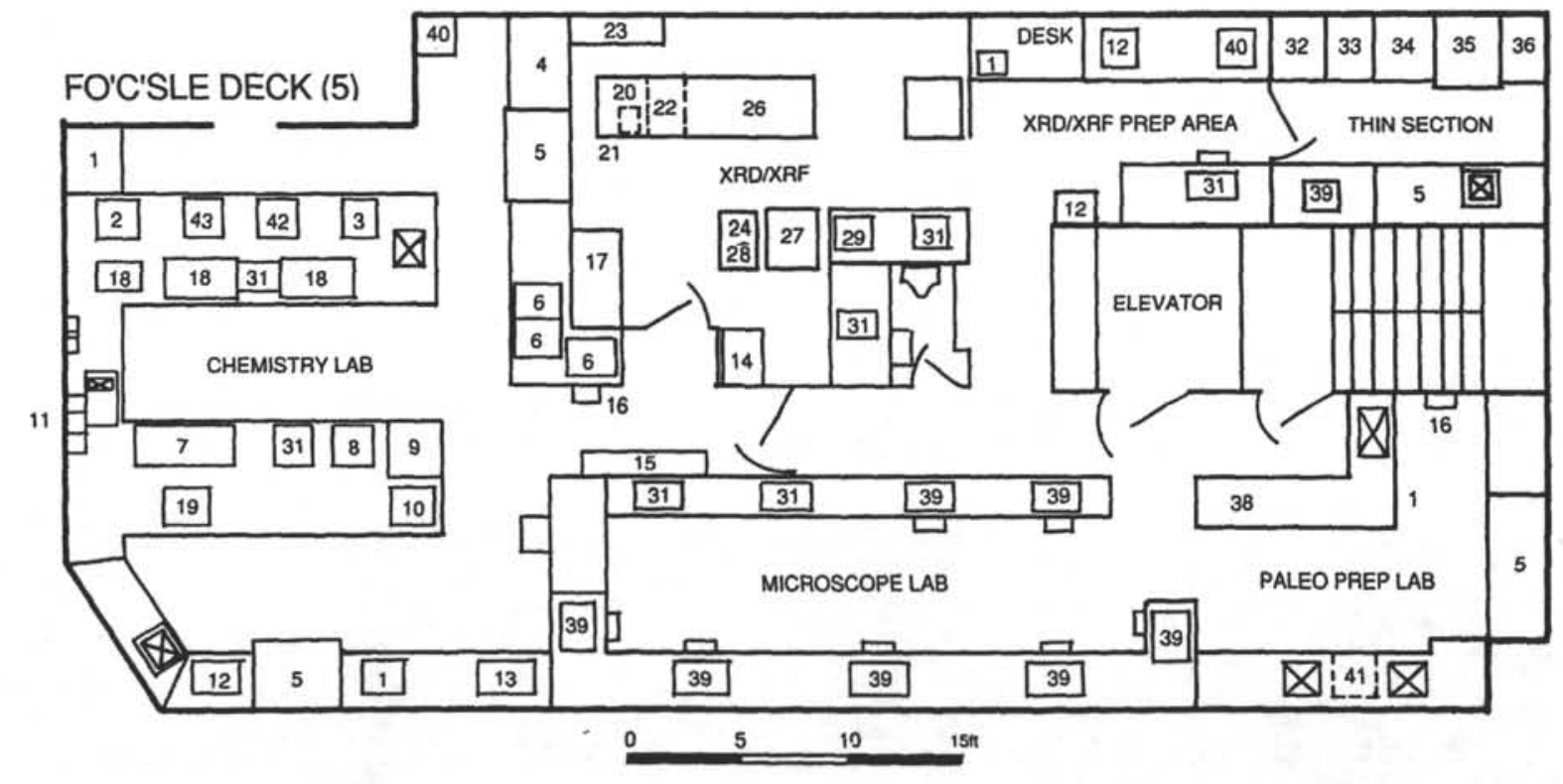


The ODP Chemists' first responsibility is hydrocarbon monitoring. Routinely, a 5-10- $\mathrm{cm}^{3}$ sediment head-space sample is taken in the section adjacent to the IW sample. This sample is heated to $70^{\circ} \mathrm{C}$ for $20-30$ minutes. The evolved gases are analyzed on the Carle gas chromatograph (GC) or Hewlett-Packard GC's natural gas analyzer. When gas pockets are detected in the core liner, a vacutainer-type gas sample is taken and analyzed immediately. If no gas is suspected and no gas pockets are identified through the core liner, the only routine sample taken is the head-space sample.

Occasionally coring will continue only after gas analysis results come back from the chemistry lab. If the levels are critical, this information goes directly to the Operations Superintendent so that he, in consultation with the Co-Chief Scientists and Organic Geochemists, may make the final decision on whether to continue drilling.

The ODP Chemists' second area of responsibility is maintenance of the chemistry lab and equipment, and collection of routine chemistry data. Scientists may bring along their own equipment and/or analytical programs to be run in conjunction with the ongoing shipboard analyses, but a 2-3 month lead time is essential to guarantee the availability of necessary space and supplies. Shipboard scientists may request assistance from the ODP Chemists with these special programs, but collection of routine chemistry data may take priority.

Some analyses use microcomputers to collect data (Section X.A). This facilitates data transfer to the VAX computer system. Other analyses require that data be entered manually into the VAX computer system for data archiving and ODP formatted plots. Many graphics programs are available for sample data reduction and plotting.

\section{Gas Monitoring Equipment}

Gas monitoring equipment in the chemistry lab includes two Hewlett Packard 5890 Gas Chromatographs (GC) and a Carle model 101 GC. The Carle is used for the rapid analysis (less than 5 minutes) of methane/ethane ratios. One of the $5890 \mathrm{GCs}$ is configured as a natural gas analyzer (NGA) with three chromatographic columns, which allow hydrocarbon separations as well as stationary gas separations. These gases include oxygen, nitrogen, carbon dioxide, hydrogen sulfide, and hydrocarbons through $\mathrm{C}_{14}$. The second $5890 \mathrm{GC}$ is a dedicated research GC, but is used for gas analysis in the event of failure of both the NGA and the Carle. The research GC is fitted with a split/splitless 50-m fused quartz small-bore column. This GC is used primarily for hydrocarbon analysis of liquid extracts. If necessary, it can be fitted with a single Poropak column for separation of light hydrocarbons. Both $5890 \mathrm{GCs}$ are equipped with a thermal conductivity detector (TCD) and a flame ionization detector (FID) in series. The Carle operates only with an FID.

The GCs are connected to the Lab Automation System (LAS) via an HPIB loop. The LAS stores, converts, and integrates data input, and generates a customized report for each analysis. Three HP3393 Integrators are also used to calculate results of each analysis. The LAS runs on an HP1000 minicomputer consisting of a $600+$ CPU and a 60-megabyte Winchester disk drive. The HP1000 is available for programming using the RTE-A operating system. 


\section{Carbon Analyzers}

The Delsi Nermag Rock-Eval II Plus TOC is a microprocessor-based instrument for whole-rock pyrolysis. It is used to evaluate type and maturity of organic carbon, calculate petroleum potential, and detect oil shows. It has a printing recorder and an automatic sampler that holds 24 samples.

Two Coulometrics analyzers are available, which produce accurate colorimetric measurements of carbonate-carbon and total carbon in sediments. At present, only the "inorganic" coulometer is set up in the lab. It uses hydrochloric acid to convert carbonate to carbon dioxide, which is then back-titrated to a colorimetric endpoint. The total carbon part of the coulometer is a backup to the CNS (see below). In total carbon analysis, the sample is heated to $\sim 1000^{\circ} \mathrm{C}$ and the resulting $\mathrm{CO}_{2}$ is back-titrated to a colorimetric endpoint.

In the Carlo Erba Nitrogen-Carbon-Sulfur (CNS) Analyzer 1500, samples are introduced into a vertical combustion column where injection of ultrapure oxygen "flash combusts" the sample. As the flow of $\mathrm{He}$, the carrier gas, carries the combustion products through the combustion column, the gases are reduced and oxygen is removed. $\mathrm{CO}_{2}, \mathrm{~N}_{2}$, and SO are then carried into the chromatographic column where they are separated. Finally, these gases are detected by a thermal conductivity detector. The chromatogram as well as the area counts of each peak and the calibrated concentration are processed by EAGER software. An autosampler allows 50 samples to be set up for analysis in one batch.

\section{Interstitial Water Program}

Interstitial water core samples are placed in a Manheim squeezer. The squeezer is then placed in one of two Carver hydraulic presses that are capable of 25 tons constant pressure, and squeezed until a sufficient quantity of water is extracted, usually $\sim 30 \mathrm{~mL}$ from a 500 $\mathrm{cm}^{3}$ sample. The resultant pore water is filtered through a $0.45 \mu \mathrm{m}$ filter.

First the water is titrated for a $\mathbf{p H} /$ alkalinity determination. This analysis is automated by interfacing a Metrohm 665 Dosimat autotitrator, Metrohm $605 \mathrm{pH}$ meter, and an IBM PCAT-clone.

Titrations of calcium, magnesium, and chlorinity are performed using a Metrohm 655 Dosimat, which is capable of dispensing titrant in microliter amounts.

Colorimetric measurements of ionic concentrations in pore water samples are conducted on the Bausch \& Lomb Model 1001 Spectrophotometer. In a wavelength range from 190 to $950 \mathrm{~nm}$, analyses can be made of concentrations of nitrate, silica, ammonia, nitrite, phosphate, bromide, and other common pore-water constituents. The spectrophotometer can accommodate a variety of cell types and sizes, facilitating precise analysis of small (microliter) sample volumes. A sipper is installed, eliminating the need for cuvets.

The atomic absorption unit on board is a microprocessor-based double-beam Varian SpectraAA/20 BQ. The monochromator has a wavelength range of $190-900 \mathrm{~nm}$. Three slit widths are available: $0.2,0.5$, and $1.0 \mathrm{~nm}$. Hollow cathode tubes and AA grade standard solutions are available for $\mathrm{K}, \mathrm{Na}, \mathrm{Sr}, \mathrm{Li}, \mathrm{Mg}, \mathrm{Ca}$, and $\mathrm{Fe}$ analysis. The instrument is equipped with a deuterium lamp for background correction. Nitrous oxide is available for use as an oxidant. 
A Dionex Ion Chromatograph (IC) is used primarily for sulfate analyses of pore water. The IC uses the patented Dionex system of two-column chemical suppression. It is microprocessor-controlled and attached to the LAS. Its autosampler can hold 56 samples.

\section{Associated Lab Instruments}

Two balance systems are available in the chemistry lab. A Cahn 29 balance mounted on a gimbaled table is used to measure samples from micrograms to $1250 \mathrm{mg}$ in weight. Twin Scientech balances are available for measuring samples from $1 \mathrm{mg}$ to $20 \mathrm{~g}$ in weight. By employing a method of differential counterbalancing with computer averaging, these balance systems compensate for all but the roughest sea state.

Two Labconco 39-port freeze driers are available for removing water from sediment samples. Each can hold 39 individual samples of up to $15 \mathrm{~cm}^{3}$ each, one at each port, or larger sample(s) in the central manifold.

The ship's potable water can be passed through a Barnstead Ropure ultra-pure water deionizer, to produce both lab and reagent $(>18 \mathrm{ohm} / \mathrm{cm})$ grade waters by osmotic pressure. There is a 100-liter reservoir. This water can then be deionized in the Barnstead Nanopure system.

Electric agate mortar/grinders and hardened steel ball Spex mill grinders for homogenizing dried sediment samples and a shatterbox for pulverizing basalt or hard-rock samples are all available. Various drying and ashing ovens are available, as are refrigerators and freezers. There are two fume hoods: one is for solvents, the other for chemical reactions.

\section{Chemicals and Gases}

There are two hydrogen generators in the chemistry lab, which supply the GC FIDs. Bottled helium (GC carrier gas) and oxygen are kept aboard the ship. The ship's pressurized air system is available throughout the lab structure and is filtered appropriately.

The chemistry lab contains a complete set of standard lab chemicals: acids, bases, solvents, etc. An ample supply of laboratory glassware and support equipment is maintained aboard ship for use during the cruise. Since the ODP Logistics and Technical Support Office maintains an up-to-date inventory and can supply additional information about the availability of specific chemicals and supplies, it is suggested that scientists contact this office if questions arise about procedures or supplies. Even though a complete set of standard lab chemicals and supplies is kept aboard ship, it is advisable to check well in advance of a cruise to assure that specific requirements can be met.

\section{E. Paleontology Preparation Laboratory}

The paleontology preparation laboratory is located on the fo'c'sle deck (Figure 12). The paleo prep lab contains equipment and supplies needed to process micropaleontological samples and make slides. Detailed information regarding shipboard paleontological facilities and procedures appears in ODP Technical Note 12: "Handbook for Shipboard Paleontologists." Items required by shipboard participants but not listed below or in Technical Note 12 must be brought to the attention of the ODP 
Logistics and Technical Support Office well in advance of the cruise departure date. A reasonable effort will be made to obtain such materials, or Paleontologists may be advised to bring specially required items to the ship themselves, provided no item will constitute a hazard in the shipboard environment.

\section{Lab Equipment}

-2 ovens

-3 infrared lamps

-3 hotplates

- 2 U/V light set-ups

-2 sonic baths

-1 sonic probe

-2 slide warmers

-2 benchtop fume adsorbers

- 3 filtration systems

- 1 lab glassware washer

- 1 sample splitter

- 1 microsplitter

-1 centrifuge

- assortment of U.S. standard testing sieves $(44-1000 \mu)$
- sieve cleaning brushes

- beakers, funnels, filters, evaporating dishes, etc.

- glass microslides and coverslips, cardboard micropaleo slides and metal slide holders, slide storage boxes.

- slide labels, sample vials, sieve cleaning brushes, stage and eyepiece micrometers, drawing tubes for microscopes.

- sable hair brushes, picking trays, England Finder slides, photo supplies, and manual point counters are available from the Lab Officer.

\section{Chemicals, Mounting Media, Stains and Dyes}

- acetic acid, acetone, bromoform, Calgon, formaldehyde, glycerin, hydrochloric acid, hydrogen peroxide, Quaternary "O", sodium hydroxide, sodium pyro-phosphate, toluene, xylene, numerous other types.

- Norland Optical Adhesive, Canada Balsam, Hyrax, Piccolite, Permount, clove oil, gum tragacanth, and Eukitt, a German synthetic Canada Balsam.

- Methylene Blue, Malachite Green, Rose Bengal, Alizarin Red "S," Safranin "O"

\section{F. Microscope Laboratory}

\section{General Information}

The microscope laboratory (Fig. 12) is for use by paleontologists and petrologists. It is equipped with vibration-isolated Zeiss stereo and binocular microscopes and accessories (see below for details). At the start of each cruise, the microscopes are set up with color-coded parts as specified in the following list. Parts can be interchanged with other microscopes if necessary; the technician responsible for microscopes will modify the set-ups as requested. The list of additional equipment below details specific objectives, oculars, etc. that are available. Problems with the microscopes should be referred to the Lab Officer.

There is one Zeiss Photomicroscope III, two Zeiss Standard WL microscopes, and three Zeiss stereomicroscopes intended for use by shipboard paleontologists. Also in the microscope lab are one Zeiss Photomicroscope (type III 
POL) and two standard Zeiss WL petrographic microscopes, with polarizing lenses and accessories for reflected light and optical figure analysis intended for use by shipboard petrologists. All of these microscopes also have interchangeable accessories that are compatible with other Zeiss models, and accept still photographic and video camera attachments.

Black-and-white print film is available for taking photomicrographs of interest to the shipboard scientific party as a whole; scientists wishing to take photomicrographs for their own research must bring the necessary film supplies with them. Photomicrographs taken for general shipboard party use are identified on a standard form (one sheet per roll of film), and contact prints are made by the photographer. No personal photomicrographs will be developed or printed, and no enlargements of the negatives are made aboard ship, except for inclusion in the Hole Summaries. Enlargements can be requested from the ODP Data Librarian after the cruise.

Two video screen printers are available in the microscope lab: a Mitsubishi blackand-white printer and a Hitachi color printer. These instruments are intended to provide "photodocumentation" of specimens more rapidly and inexpensively than possible with regular photographic techniques. The resulting images are not of publication quality but they are valuable for study and interpretation. On request, the Technicians will set up these printers on microscopes with video camera attachments, and will demonstrate their use.

A shipboard paleontology library is kept in the microscope lab. This collection of texts, journals, and reprints is cataloged in a separate paleontology library catalog and crossindexed in the main shipboard science library catalog. Although considerable effort has gone into assembling as complete a set of references as possible for biostratigraphic age determination, some important references may be missing. In particular, paleontologists are advised to bring along their own copies of reprints critical to their shipboard work. Efforts to expand the paleontology library holdings are ongoing, and the assistance of shipboard Paleontologists in suggesting or contributing additional reference materials greatly benefits future shipboard parties. The Yeoperson can catalog, bind, and add donated materials directly to the shipboard library.

Checklist II for IBM P/C-compatibles, a program for paleontology data analysis and graphics, is available on computers in the microscope lab and computer users' room.

\section{List of Shipboard Optical Equipment (with color code)}

a. Optical Equipment for Paleontology

Zeiss Standard WL microscope (LIGHT GREEN): Standard, phase contrast, or Nomarski differential interference contrast microscopy with the following objectives (all with DIC adapter ring): PH2 25X Neofluar, PH\# 63X Neofluar, PH3 63X Planapo, 63X Planapo, 100X Planapo.

Zeiss Standard WL microscope (GRAY): Standard, phase contrast, or Nomarski differential interference contrast microscopy with the following objectives (all with DIC adapter ring): 10X Neofluar, PH2 16X Plan, 25X Plan, PH2 40X Neofluar, PH3 63X Neofluar.

Zeiss Photomicroscope III (GOLD): Standard, phase contrast, or Nomarski differential interference contrast microscopy with the following objectives (all with DIC 
adapter ring): 40X Planapo objective, PH2 40X Neofluar, PH3 63X Neofluar, 63X Planapo, 100X Planapo.

Zeiss SR Stereomicroscopes (GOLD/RED, BLUE/WHITE, LT GREEN/YELLOW): Reflected light microscopy with the following features: $10 \mathrm{X}$ wide oculars, standard and $\mathrm{F}=50$ objectives, black and white stage, glass stage, fiber light illuminator.

b. Optical Equipment for Petrography

Zeiss Photomicroscope III (YELLOW)

Zeiss Standard WL Microscope (BLUE): Transmitted or reflected light microscopy with the following features: rotary polarizer and rotary analyzer, 2.5 Plan, 10X Pol, 25X Neofluar, 40X Pol, and 63X Neofluar objectives; epi-condenser (incident light attachment); 4X Epiplan, 8X Epiplan, 16X Epiplan, and 40X Epiplan objectives.

Zeiss Standard WL Microscope (WHITE): Transmitted light microscopy with the following features: rotary polarizer and rotary analyzer, 2.5 Plan, 10X Pol, 25X Neofluar, 40X Pol, and 63X Neofluar objectives.

c. Additional Equipment

Accessories: Stereoscope and microscope drawing tubes, England finder slides, and micrometers

Oculars and Objectives: S-KPL 10X/20, KPL 10X wide, and KPL 16X/12 oculars; KPL 16X and KPL 25X focusing stereo eyepieces; 3.2X Plan (Pol), 10X Pol (Achromat), 16X Epiplan (dry), 16X Neofluar, 25X Neofluar (Pol;dry), Ph2 25X Neofluar, 40X Pol (Achromat), 63X Achromat (Pol;dry), and 100X Pol objectives.

\section{G. Thin Section Laboratory}

The thin section laboratory (Fig. 12) has been outfitted to make thin sections from lithified and non-lithified materials. When only one or two thin sections are required, they are made "by hand" using a Buehler Petro-Thin thin-sectioning system and thin-section grinder. When many thin sections are requested, the Logitech LP-30 lapping machine can be used to produce $\sim 100$ high-quality thin sections a week (although since there is no dedicated technician in this lab, that number is higher than would normally be possible aboard ship), in batches of up to 40 at a time. The sections are polished on a Logitech WG-2 polishing system. Special support equipment in the thin section lab includes a Logitech CS-10 thin section cut-off saw and IU-20 impregnation unit used to impregnate porous or friable specimens with synthetic resins. Delicate or critical samples can be cut on a Leco VC-50 Vari-speed diamond saw. A Zeiss standard WL binocular microscope is available in this lab for monitoring slide preparation.

Scientists working in the core lab should request thin sections as they describe the split cores. After completion of a thin section, the remaining billet is returned to its original interval in the working half of the core, and may be subsampled for other shipboard analyses or as a personal sample.

Note: All thin sections made aboard ship are the property of ODP and are curated as a reference collection. An initial microscopic description must be completed aboard ship for each slide. Scientists 
wishing to continue post-cruise studies on thin sections can borrow slides with the understanding that the slides will be returned to the Curator, via the ODP Staff Scientist, at the post-cruise meeting. Slides can be borrowed again as needed.

A Technician is assigned to the lab as needed to produce thin sections, in addition to that Technician's other duties; the Lab Officer, with guidance from the Co-Chief Scientists, assigns technical support to the thin-section and other laboratories as required to meet the scientific goals of the cruise.

\section{H. XRF and XRD Laboratory}

\section{Introduction}

The X-ray laboratory, on the lab structure's fo'c'sle deck (Fig. 12), contains state-ofthe-art equipment chosen for its stability in a shipboard environment. Use of the lab is planned at the Co-Chief Scientists' pre-cruise meeting; the Lab Officer, with guidance from the $\mathrm{Co}$-Chief Scientists, assigns technical support to this lab as required to meet the scientific goals of the cruise.

\section{X-ray Fluorescence}

An Applied Research Laboratory 8400 hybrid spectrometer is used for X-ray fluorescence analyses. This instrument is fully microprocessor-controlled with auto-sample loading. It has an end-window Rhodium X-ray tube, a $60 \mathrm{kV}$ generator, and two independent goniometers with scintillation, flow proportional (P-10), and sealed $\mathrm{Kr}$ detectors. The following analytical crystals are available: $\mathrm{LiF} 200, \mathrm{LiF} 220, \mathrm{LiF} 420, \mathrm{PET}$, TLAP, and GE111. A DEC Micro-11 computer with a 28-megabyte Winchester disk drive supports the ARL-8400. Software includes quantitative, qualitative, statistical analysis, and fundamental parameters (XRF-11) programs.

\section{X-ray Diffraction}

A Philips ADP 3520 is used for X-ray diffraction analysis. It is fully microprocessorcontrolled with auto-sampler loading, and is configured with a $\mathrm{Cu} \mathrm{X}$-ray tube and monochromator. A second DEC Micro-11 computer with 28-megabyte Winchester disk drive supports this system. Software support includes quantitative, qualitative, searchmatch of JCPDS and user data bases, line profile analysis, and statistical analysis programs.

\section{Sample Preparation Equipment and Supplies}

a. Grinders

- Shatter box (tungsten-carbide)

- auto-mortar and pestle (agate)

- mixer-mill (steel)

b. Fusion Devices

- Claisse fluxer-bis (Au-Pt crucibles)

- ashing furnace 


\section{c. Chemicals}

- flux: $80 \%$-lithium tetraborate, $20 \%$ lanthanum oxide

- boric acid (powder)

$-\mathrm{NaNO}_{3}$ (powder)

- NaI

- Organic liquid binder

\section{Shipboard Computer System}

\section{Introduction}

JOIDES Resolution is equipped with a research-oriented computer system designed to perform routine clerical and arithmetical tasks in order to free scientists and technicians for more creative research activities. The super-mini VAX and peripheral equipment, the Computer System Manager's office, and a computer user's area with computer terminals, printers, and work tables are all housed on the lab structure's new main deck (Fig. 13). Further information is provided in the "User's Guide to the JOIDES Resolution Computer System," a brochure sent to all shipboard scientists prior to the cruise.

The central VAX computer system assists in performing such diverse functions as core-log entry, core sampling, data analysis, drill string engineering, presentation graphics, chemistry, inventory control, office automation, and manuscript preparation. This is accomplished through conveniently located microcomputer workstations arranged in a distributed processing architecture. A central theme in the design of the shipboard system was the offloading of common tasks onto workstations for more efficient use of the central system. This type of computer system architecture minimizes the possibility that shipboard operations will be delayed by a central system failure. All major system components are backed up with redundant twins or a complete complement of spare parts. The result of this approach is a system that fails gently, with a gradual degradation of performance when individual components fail, in contrast to a system where the demise of any one piece of equipment creates a catastrophic failure.

The central VAX system is configured as a combination of four computers, two VAX 11/750s and two VAX 3500s, to meet the changing requirements of each cruise. These systems are connected in a clustered environment allowing them to share data and peripheral devices. The $11 / 750$ s serve as disk and print servers, offloading these timeconsuming tasks from the 3500 s. The VAX 3500 s provide high-speed computational power and serve shipboard users directly.

The system offers archival storage of shipboard data on 3.5 gigabytes (almost one million typed pages) of rapid access mass storage. Among the disk drives providing this storage are both fixed and removable magnetic disks as well as high-density optical disks. In addition, magnetic tape drives are available, which are capable of reading and writing 1600 bpi nine-track tapes.

Most of the daily workload is accomplished directly on microcomputer workstations. Several workstation configurations are available, including IBM-PCAT-compatible, Apple Macintosh, and DEC PRO-350. Each of the workstations is configured for a specific set of tasks. Word-processing stations, for example, are connected to a local 
COMPUTER

1. POWER CO'NDITIONER

2. VIDEO SYSTEMS CONTROL

3. TAPE STORAGE

4. DISC DRIVES

5. STORAGE CABINET

6. VAX-CPU

\section{COMPUTER OFFICE}

7. VAXSYSTEM CONSOL

8. TAPES \& STORAGE

\section{COMPUTER USER}

9. DAISY PRINTER

10. TERMINALS

11. PLOTTER

12. LASER PRINTER

13. LINE PRINTER

14. TAPE STORAGE RACKS
SCIENCELOUNGE

15. VIDEO RECEIVER/AMP STEREO,

VCR-STEREOS, VHS

LASER DISC PLAYER

TAPE \& VIDEO DISC LIBRARY

STEREO CASSETTE PLAYER

16. LARGE SCREEN COLOR T.V.

17. WALL OF REMOVABLE ACCESS PANELS

18. SMALL WALL-MOUNT SPEAKERS

19. RIG VIDEO MONITOR

20. GAMES \& PUZZLES

MAGAZINES

VIDEO GAMES

21. COFFEE TABLE

22. FOLDING CURTAIN

23. SCREEN \& DEMO BOARD

24. MOVIE PROJECTOR

SLIDE PROJECTOR

OVERHEAD PROJECTOR

25. SHELVES

26 COPY MACHINE

27. FILE CABINET

28. READING LIBRARY

CENTERLINE OF VESSEL

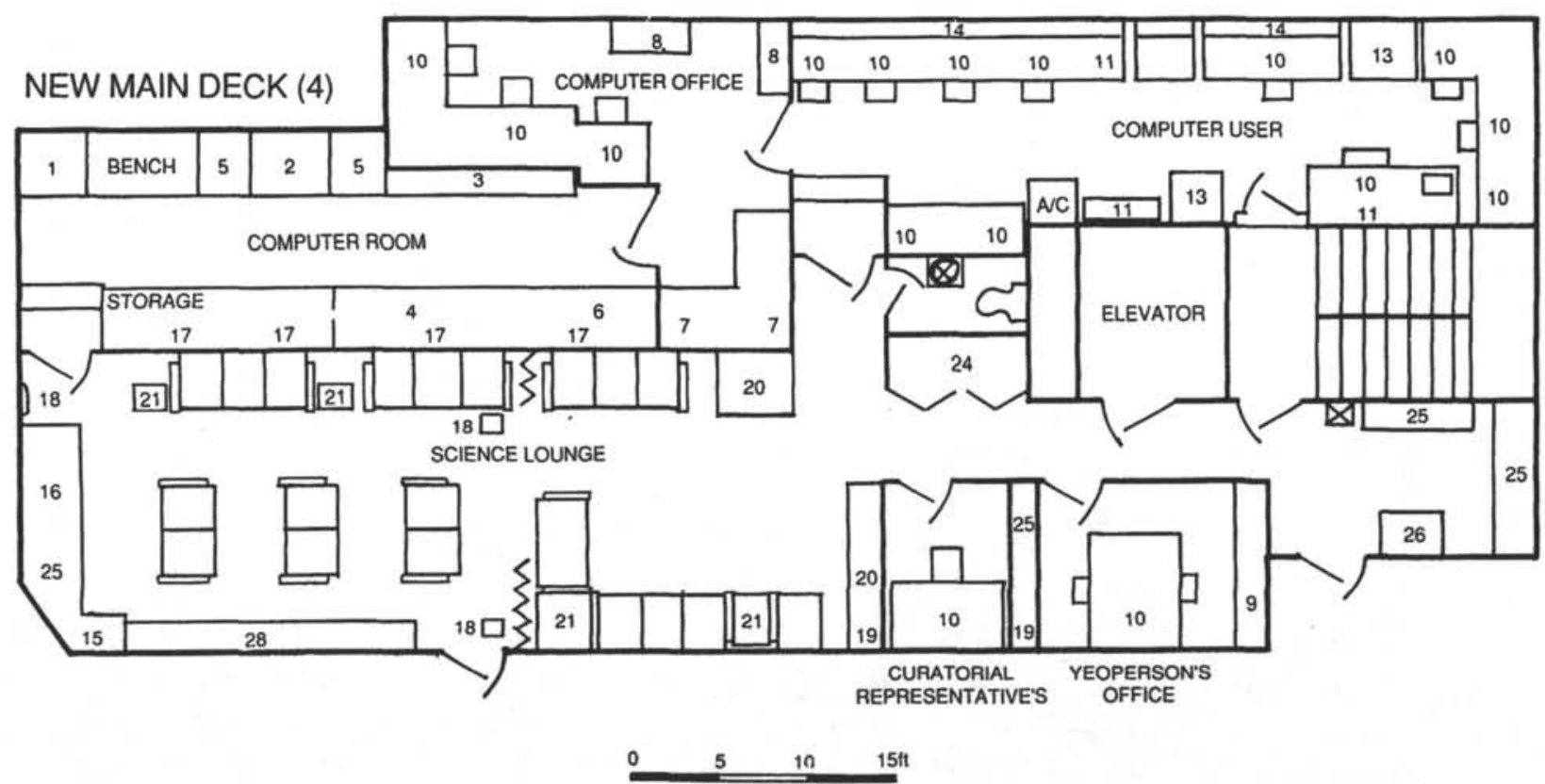

Figure 13. Layout of computer rooms, science lounge, and offices. 
printer and have word-processing software installed on the system's hard disk. Other specialized workstation component lists are included in the Shipboard System Description below. All workstations are connected to the central VAX system for easy transfer of documents and data files.

The VAXcluster, PC, and Macintosh workstations share peripheral devices and data over an AppleTalk Local Area Network. The Network allows an easy transfer of data between systems through the use of a common fileserver disk on the VAXcluster. In addition, output from a workstation may be routed to a variety of hard-copy devices based on the type and quality of output desired.

A networked satellite communications capability allows the shipboard host computer system to access a similar VAX system at ODP headquarters in College Station, Texas. This communications link operates at 2400 bits per second through the Marisat satellite communications system. Capabilities of the system include access to scientific data from past cruises, shipboard inventory control, and electronic mail.

\section{Shipboard System Description}

\section{a. Host system}

- VAX 3500 CPU with 16 meg RAM memory

- VAX $11 / 750$ CPU with 4 meg RAM memory

- 3.5 gigabyte mass storage ( 1 million typed pages)

- Magnetic tape drives (1600 bpi)

- 48 port asynchronous communications capability

- 2400 baud asynchronous satellite communications link

- 64 line terminal server (ethernet)

- Local area VAXcluster environment

- AppleShare compatible fileserver

- Redundancy in all major system components

b. Workstations

- Wordprocessing stations (28)

- PCAT-compatible microcomputer

- 40-Mb hard disk

- DSDD internal floppy

- HD internal floppy

- Monochrome monitor

- Dot matrix printer

- Core sampling stations (3)

- PRO-350 microcomputer

- Dot matrix printer

- Sample bag printer

- Sampling station interface

- Data acquisition station (5)

- PRO-350 microcomputer

- Real time interface

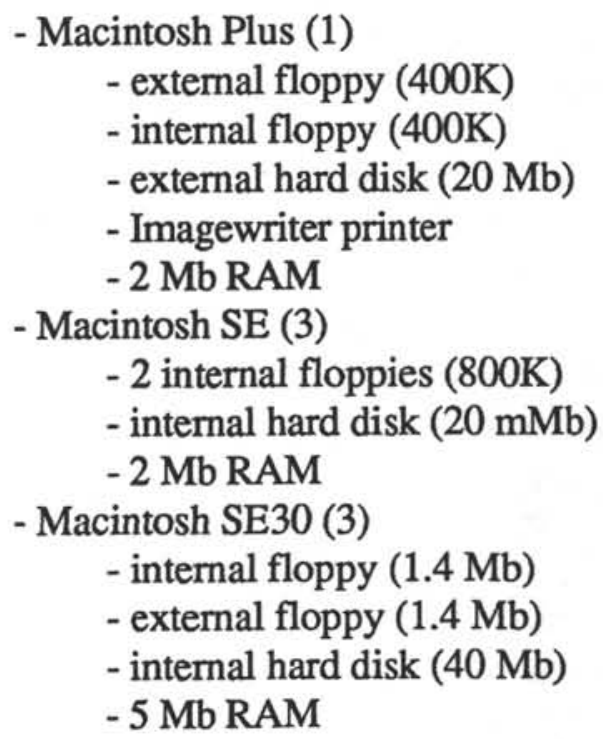


- Macintosh II (2)

- Color monitor

- 2 internal floppies $(800 \mathrm{~K})$

- internal hard disk $(40 \mathrm{Mb})$

- $5 \mathrm{Mb}$ RAM

c. System peripherals

- QMS Laser printer (2)

- 36" drum plotter (1)

- Apple LaserWriter IINT (4)

- Apple LaserWriter IINTX (2)

d. Software

- VAX VMS operating system

- P/OS operating system (PRO-350)

- BASIC

- COBOL

- FORTRAN

- PASCAL

- DATATRIEVE (relational database)

- System 1032 (relational database)

- VAX WordPerfect (wordprocessing)

- RS/1 (data analysis and graphics)

- IMSL (statistics)

- Minitab (statistics)

- 20/20 (spreadsheet)

- BLAST (communications)

- SMOOTH (navigation plotting)

- SAS (statistics)

- DI-3000 (graphics)

- Picsure (presentation graphics)

- CORELOG (coring inventory)

- SAM (core sampling)

- SLIDES (smear slide description)

e. Computer subsystems

- Underway Seismic

- Masscomp UNIX system

- Underway interface

- Gas Chromatography

- HP Lab Automation System

- A/D interfaces
- Macintosh IIX (12)

- Color monitor

- 2 internal floppies (1.4 Mb)

- internal hard disk $(40 \mathrm{Mb})$

- $5 \mathrm{Mb}$ RAM

- High speed printer/plotter (2)

- Letter quality printer (2)

- 8-bit optical scanner

- Digitizing tablet

- CHEMDB (chemistry database)

- PHYSPROPS (database)

- MATMAN (inventory control)

- Data Acquisition (MST, etc.)

- Cruise Logistics

- Macintosh operating system

- MacDraw

- Adobe Illustrator

- PixelPaint

- AudoCAD

- Cricket Graph

- Data Desk Professional

- Mac WorkPerfect

- Excel

- MS DOS 3.2

- Checklist II (paleontology data analysis and graphics)

- Lotus 1-2-3

- PC WordPerfect

$-2020$

- Grapher

- X-ray Lab

- XRF Micro-11 system

- XRD Micro-11 system

\section{f. DSDP data available aboard JOIDES Resolution}

All computerized data generated from Legs 1-96 of the Deep Sea Drilling Project are available for use aboard JOIDES Resolution. DSDP data are stored in System 1032 (S1032), a database management system used by ODP. The data are organized into datafiles, called datasets in \$1032, which reflect the type of analyses or descriptions 
resulting in the data. For a complete explanation of the DSDP datasets, see ODP Technical Note 9, Deep Sea Drilling Project Data File Documents, in the ship's library. This document lists and explains briefly the data items in each dataset.

The System Manager assists scientists in accessing DSDP data aboard ship.

\section{Shipboard Documentation}

Documentation for the shipboard system is available in a variety of forms. A step-bystep "new user's guide" to accessing the system may be obtained from the Computer System Manager when a user account is first issued. For the more experienced user, copies of the User's Handbook provide an in-depth description of the computer and applications programs. A set of the Digital Equipment Corporation VAX system manuals is kept in the computer user room and covers the entire system in great detail.

In addition to hardcopy documentation the system provides on-line documentation and computer-aided instruction. The on-line documentation provides a way for users to find out how a command or utility program works without exiting the system, using the system-wide HELP command. Computer-aided instruction courses are available on the system for several system topics.

\section{Shipboard Computer System Policies and Procedures}

The computer system operates under the authority of the Computer System Manager, who is responsible for ensuring the operational integrity of the prime data collection processes. Data collection priorities are clearly established in existing ODP policies and are interpreted, when necessary, by the ODP Staff Scientist.

Access to the computer system is controlled by an ACCOUNT/PASSWORD scheme. Personal accounts and files last for the duration of the cruise only. User access to the system is limited to the use of interactive terminals in the labs and user areas; only the System Manager may operate the main system controls.

The System Manager is responsible for training shipboard participants to use the data acquisition programs. Training in computer services not critical to the scientific effort is available as time permits.

\section{Shipboard System Daily Routines}

Prior to the start of the cruise, the System Manager attends the pre-cruise Co-Chief Scientists' meeting to discuss system policy and procedures and to arrange to accommodate any special computing needs that may arise. The System Manager is usually busy testing the system and installing modifications before the ship sails; the system is not available for user access during this period except by special arrangement.

Introductory classes on the computer system are provided to all interested scientists by the Yeoperson and Computer System Manager while the ship is en route to the first site (training may begin in port if the transit time to the first site is very short). This training consists of an overview of the system, an introduction to the major software packages, and instructions on how to use the system documentation and computer-aided courses.

As operations on site begin, the focus of computer system activities shifts towards core-related data collection programs. The CORELOG program provides a rapid and 
convenient method of entering data on core depths, recovery, and coring status. The SAM software package provides an automated and highly efficient method of entering large volumes of sediment and hard-rock sample data into the shipboard computer database. A complete guide to using these programs is provided in the User's Handbook aboard ship.

After the last site is finished and the ship is en route to port, the System Manager is very busy making final archives of cruise data, preparing reports of system activities, and installing the port-call system environment. The system is taken off line for these final activities and is unavailable to users during the last $\sim 15$ hours of each cruise.

\section{J. Science Offices}

Work areas for ODP personnel reflect the limited space available aboard ship. Each lab contains desks and tables for use when working directly with core material and analytical equipment. In addition, the science library on the ship's fo'c'sle deck, and the computer user's area and science lounge on the lab structure's new main deck contain tables, easy chairs, computer terminals, and study carrels for data compilation, writing, study, and reading (Fig. 13; Fig. 14). A portable light table is set up in the science library, and a conference room with large table adjoins the library. Basic drafting supplies are stored in a supply cabinet in the library. Drafting pens are kept in the Yeoperson's office. Scientists must provide their own specialized drafting equipment.

The Yeoperson's and Curatorial Representative's offices are located in the lab stack on the new main deck. Prime data files are kept in these offices. On the ship's bridge deck are the Co-Chief Scientists', Staff Scientist's, Laboratory Officer's, and Operations Superintendent's offices.

\section{K. Science Library}

The shipboard library is located on the fo'c'sle deck in the forward part of the ship (Figure 14). This collection of more than 800 volumes contains basic reference works, ODP Proceedings volumes, a set of DSDP Initial Reports, geologic and bathymetric maps, and selected monographs covering various aspects of geology and oceanography. In addition, at the beginning of each cruise, collected reprints relating to cruise objectives are added to the library. These materials are intended to provide the necessary resources for shipboard analysis of drilling results.

All scientific library materials are cataloged and shelved according to Library of Congress call number. Scientific books and other research items are primarily for use in the library. A simple checkout system is provided for materials that must be removed to other parts of the ship. Materials returned to the library are reshelved by the Yeoperson.

A separate paleontology library housed in the microscope laboratory is crossindexed in the main shipboard science library card catalog.

Other library facilities include ten study carrels, a large map/chart table, microfiche and microfilm readers, computer terminals, a copying machine, and a portable light table. 


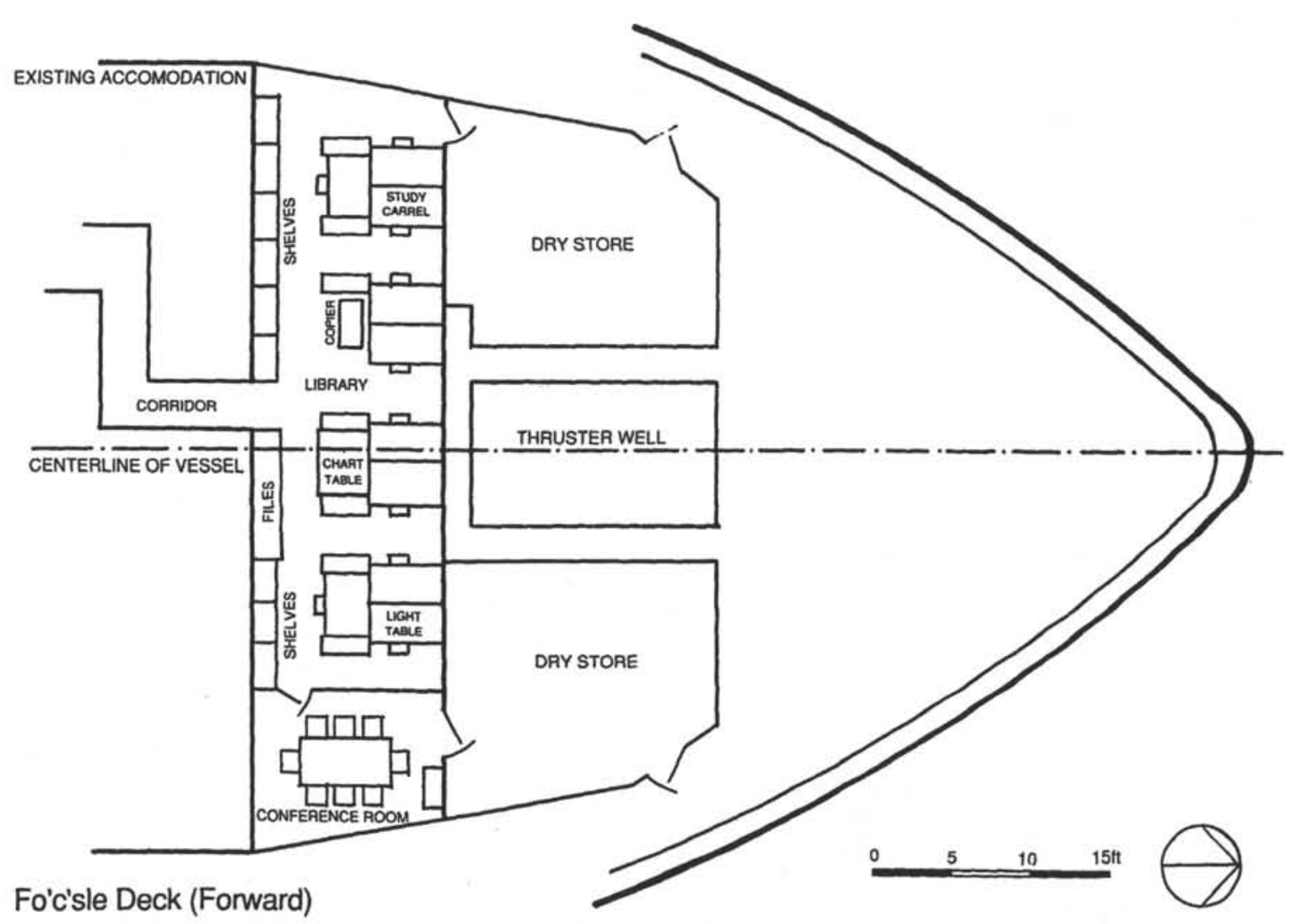

Figure 14. Layout of shipboard science library. 


\section{Photography Laboratory}

\section{Introduction}

The primary function of the shipboard photography lab is to document the cores while they are fresh. In addition, the Photographic Technician is responsible for core closeups meant for publication in hole summaries, seismic profile copywork, documentation of equipment, and public relations photography. Processing of photomicrographs, $\mathrm{X}$-radiographs, and cruise-related personal copywork is accomplished on a time-available basis.

Requests for non-routine photographic work are cleared through the ODP Logistics and Technical Support Office prior to the cruise so that special preparations and scheduling can be pre-planned. If a request made during the cruise is within the constraints of available time and supplies, the Photographer may fill it. Problems with requests are referred to the Lab Officer.

\section{Labs and Equipment}

A comprehensively equipped darkroom is on the upper 'tween deck (Fig. 15). The Photography Technician is in charge of this lab, and no other personnel are allowed to use its equipment. The darkroom has facilities for black-and-white developing and printing (both manually and with a Kreonite Print Processor) and for E-6 Ektachrome color film developing using a Wing-Lynch Film Processor. There is an MP4 copystand for seismic profile and document copying. Public relations photographs and other special photographic projects are performed with still camera systems and a video camera.

A specially designed table in the core lab is used for photographing the archive halves of each core. This table is equipped with a $4 \times 5$ overhead-mounted view camera for black-and-white and color sheet film. On a bench near the photography table is an MP4 copystand with $4 \times 5$ and $35 \mathrm{~mm}$ cameras for core closeups.

Binocular microscopes in the core lab and microscope lab have Polaroid and 35-mm camera attachments. Black-and-white film is supplied by the Photographer and 35-mm film development is done on a time-available basis. X-radiographs of core sections may be developed in the darkroom also.

Ship film is not available for personal use at any time. It is imperative that scientists bring along their own camera systems and adequate film for anticipated use on the cruise, both for pleasure photography and for non-routine photography projects (see Section VI.A.3).

\section{Policies and Procedures}

Both black-and-white and color core photos are produced of every core recovered during a cruise. One black-and-white print of every core goes to each CoChief Scientist, to the ODP Staff Scientist, and to the Yeoperson (ship copy). Core photos are not made available to shipboard participants during the cruise because of limited time and supplies, but may be requested from the shore-based ODP photo lab after the cruise.

Closeup photos of designated core intervals (intended for use in the Hole Summaries and eventual publication in the ODP Proceedings volumes) may be taken at the 


\section{PHOTO DARKROOM}

1. NITROGEN BOTTLES \& REGULATORS

2. FINISHING AREA

3. TRAY PROCESSING SINK

4. LIGHT TIGHT DRAWERS \& VIEW LIGHT

5. ENLARGING STATION

6. FILM PROCESSOR

7. AIR TEMPERED FILM PROCESSOR

8. FILM DRYING CABINET

9. FILM REFRIGERATOR

\section{PHOTO FINISHING DARKROOM}

10. WASH UP SINK

11. THERMOSTATIC WATER MIXING

12. AUTOMATIC PRINT PROCESSOR

13. PORTABLE CHEMICAL MIXERS

14. COPY STUDIO

15. FINISHING DESK

16. LIGHT TIGHT DOORS

\section{ELECTRONICS SHOP}

17. FILE CABINETS

18. STORAGE CABINETS

19. WORK BENCHES

20. COMPUTER TERMINAL

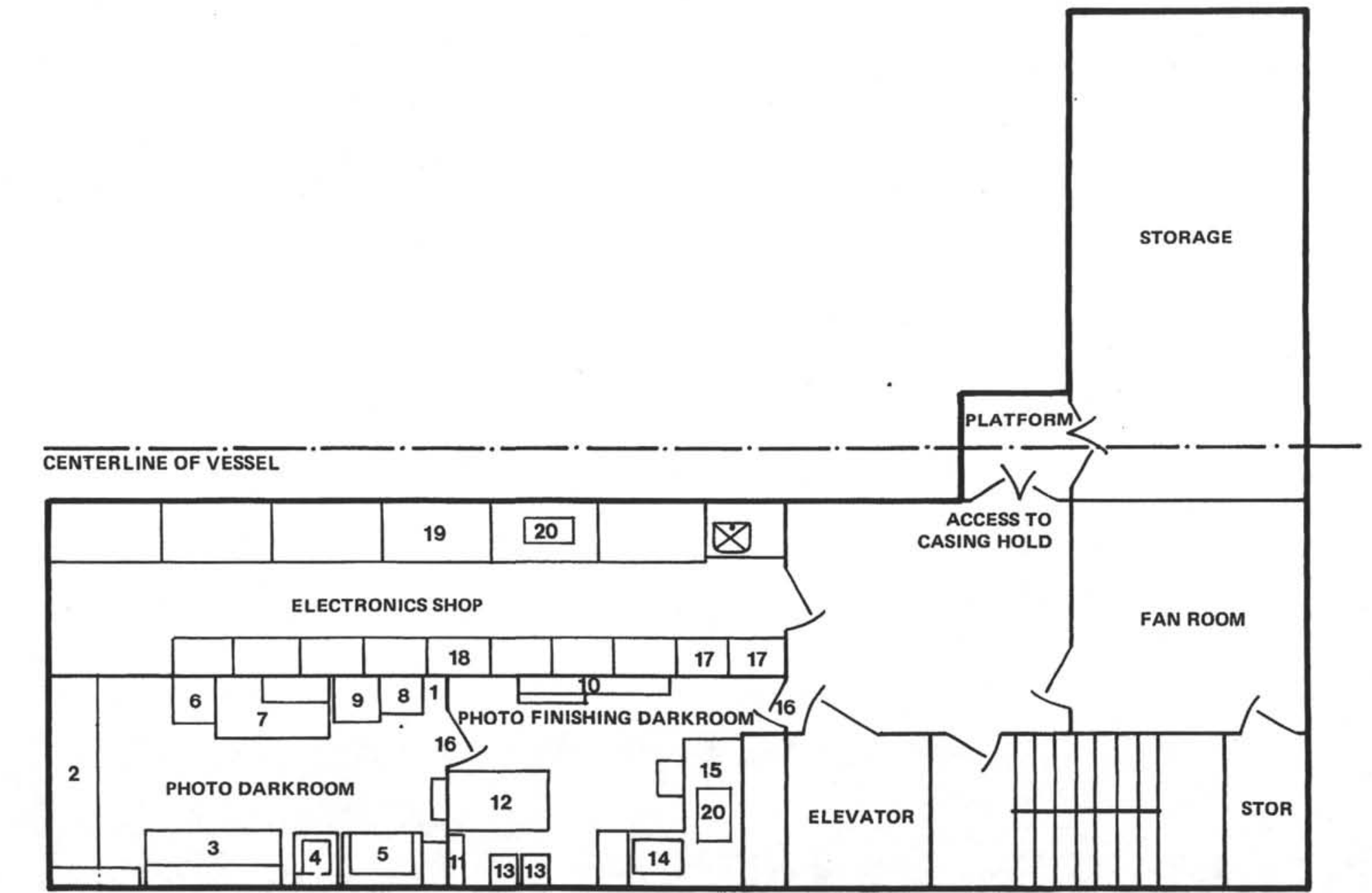

Figure 15. Layout of photography laboratory and electronics shop. 
request of individual scientists; a request form for this purpose is available in the core lab or from the Photographer. Core closeups are taken in the core lab on the MP4 copystand using black-and-white film. One copy of the $4 \times 5$ black-and-white closeup is given to the requesting scientist, and one is kept in shipboard files. Rarely, 35-mm color transparencies may be made if color is a vital factor. In this case, the closeup is shot twice: one is given to the requesting scientist and the other is returned to ODP Science Services.

All underway seismic charts are copied to black-and-white film during the cruise; $8 \times 10$ prints are given to each $\mathrm{Co}-$ Chief Scientist.

The Photographer develops and prints photomicrographs and X-radiographs intended for the Hole Summaries. Since most of the film for the microscopes is Polaroid, this job should be minor part of the Photographer's daily routine. These materials are returned to the scientist who originated them.

Copywork for individual scientists of cruise-related graphs, drawings, or other scientific materials can be done as time is available to the Photographer. This service is provided mainly for scientists who must have slides or prints during or immediately after the cruise for lectures and presentations.

On a less scientific note, the Photographer is in charge of making a silkscreen for the cruise t-shirt logo. The design may be drawn by anyone in the ship's complement, is agreed upon by consensus, and then is made up by the Photographer. Screen-printing of tshirts usually takes place near the end of the cruise, and everyone available is invited to help.

A photograph of the entire ship's complement (or as many as can be roused at the time) is taken and distributed to everyone in the picture. Equator crossing ceremonies are captured in collage and presented to each person who survives the festivities.

\section{Electronics Shop}

The electronics shop, located on the upper 'tween deck (Fig. 15), is operated by ODP Electronics Technicians (ETs) who are responsible for maintaining and repairing all shipboard ODP electrical equipment. All equipment problems and malfunctions are to be reported immediately to the Lab Officer or ETs; no one is to attempt repairs or adjustments without their direct supervision.

Equipment may not be borrowed nor are the electronics shop facilities to be used without the permission of an ET.

\section{N. Second Look Lab}

The second look lab is located on the lower 'tween deck outside the core locker (Fig. 16); scientists can use this lab to carry out further descriptive work after cores have been removed from the core lab and stored in the refrigerated locker.

Archive halves of cores cannot be retrieved from the core locker without prior permission of the Lab Officer and the assistance of a Technician. Additional sampling of working halves can be done only after obtaining approval from the Curatorial Representative or ODP Staff Scientist. 


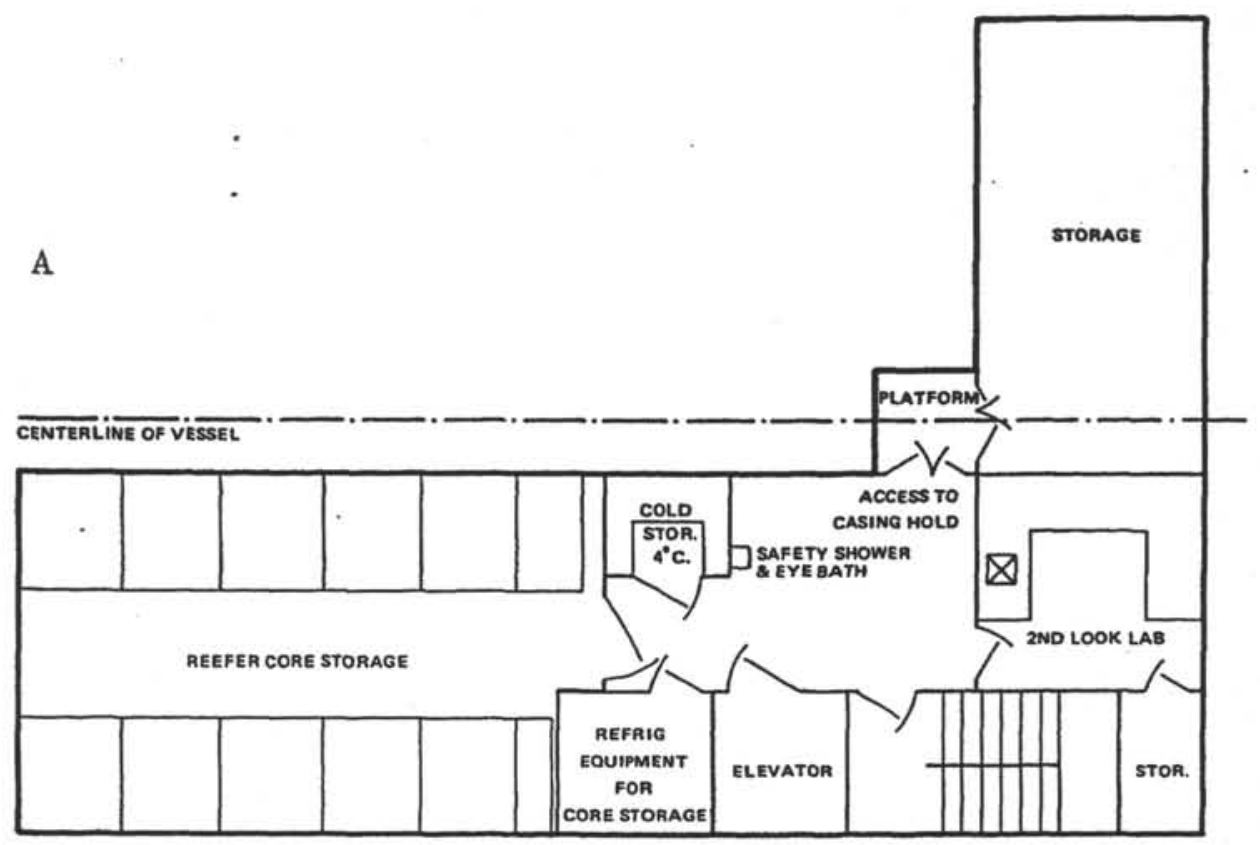

LOWER 'TWEEN DECK (2)

B

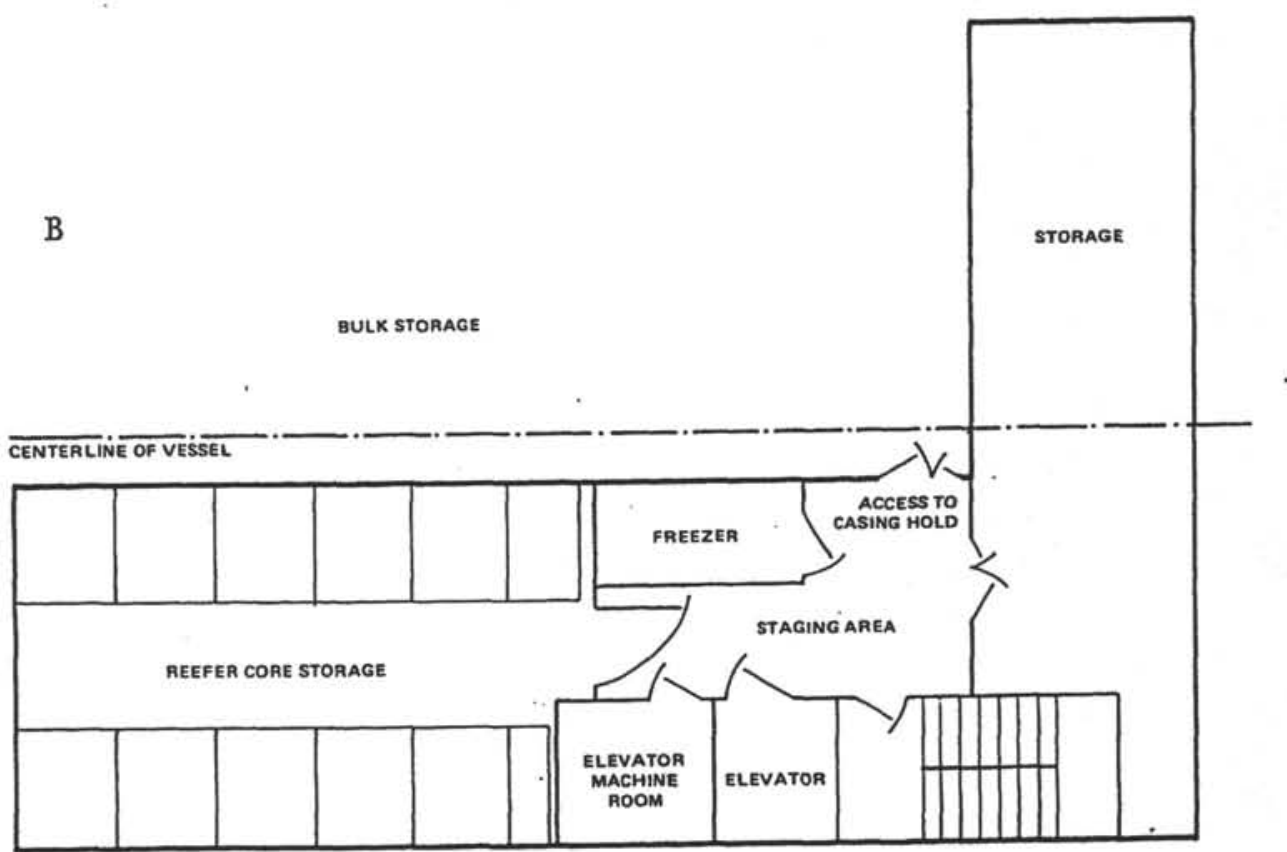

HOLD DECK (1)

Figure 16. Layout of second look lab and refrigerated core storage areas. 


\section{O. Downhole Measurements Laboratory}

The downhole measurements lab is located atop the laboratory structure (Fig. 2). It contains the LDGO-operated logging control room and lab, and space for ODP downhole instrumentation (Fig. 17).

\section{LDGO Wireline Logging Program}

According to JOIDES policy, all holes deeper than $400 \mathrm{mbsf}$ penetration and all holes that penetrate into basement rocks are logged with a standard suite of wireline logs. Logging facilities aboard JOIDES Resolution are provided by the Borehole Research Group (BRG) at Lamont-Doherty Geological Observatory, with a prime subcontract to Schlumberger. Geophysical log data are recorded using probes that are lowered on the end of the wireline through the drill pipe and into the previously drilled borehole. The depth at which measurements are made is determined by measuring the length of cable run into the hole. The Schlumberger logging tools can be stacked in certain combinations so that several types of measurement can be made on each lowering. Because much of the analysis of wireline logs depends on the ability to compare at each depth the results from different lowering of the various tool combinations, each combination includes some form of gamma-ray detector, in general, different logging runs can be depth-shifted using this common measurement. Each specialty log is recorded during a separate lowering. Log data are usually recorded whenever the logging sonde is moving in the open hole, both descending and ascending. Data are usually recorded at half-foot $(0.15-\mathrm{m})$ intervals in the borehole.

The Schlumberger logging tools, run in ODP boreholes by a Schlumberger field engineer, are combined into multiple-tool strings for efficient operations. At present, three standard tool strings are in operation: the seismic stratigraphic, the litho-porosity, and the geochemical combinations. Some of the more sophisticated post-processing and analysis cannot be accomplished without data from all three lowerings.

Following are descriptions of the most commonly run logging tools and tool combinations:

a. Seismic Stratigraphic combination includes the digital sonic (SDT), phasor induction (DIT), natural gamma spectrometry (NGT), and caliper (MCD) tools. Its value to seismic stratigraphy is that it directly measures compressional wave sound velocity and indirectly measures the two variables that most often affect velocity: porosity and clay mineral percentage.

b. Litho-porosity combination includes natural gamma spectrometry (NGT), lithodensity (LDT), and compensated neutron (CNT) tools. This combination provides measurements of formation porosity and density as well as an estimate of the proportions of the primary radioactive elements (U, K, and $\mathrm{Th}$ ).

c. Geochemical combination includes natural gamma spectrometry (NGT), induced gamma ray spectrometry (GST), and the aluminum clay tool (ACT: a second NGT paired with a Californium-source CNT neutron tool). Its value to geochemistry comes from its ability to measure relative concentrations of 11 elements: silicon, calcium, iron, sulfur, aluminum, manganese, hydrogen, chlorine, potassium, thorium, and uranium. 
CONTROL ROOM

1. ELECTRONICS RACK

2. FOLD DOWN COUNTER

ELECTRONICS

6. WORKBENCH

3. CONTROL DESK WITH COMPUTER

\& INTERCOM TO LOGGING WINCH OPERATION

4. OPERATION VIEWING PORT HOLE

5. AIRTIGHT DOOR

\section{WET WORKSHOP}

7. HEAVY DUTY WOOD WORK BENCH DOWNHOLE TOOL RACKS BELOW

8. HEAVY DUTY WOOD WORKBENCH

RE-ENTRY TOOL RACKS BELOW

9. HOOK-ON WORKBENCH EXTENSIONS

10. FOLD DOWN TABLE

11. MONORAIL ABOVE

12. WATERTIGHT DOOR

13. COMPUTER TERMINAL

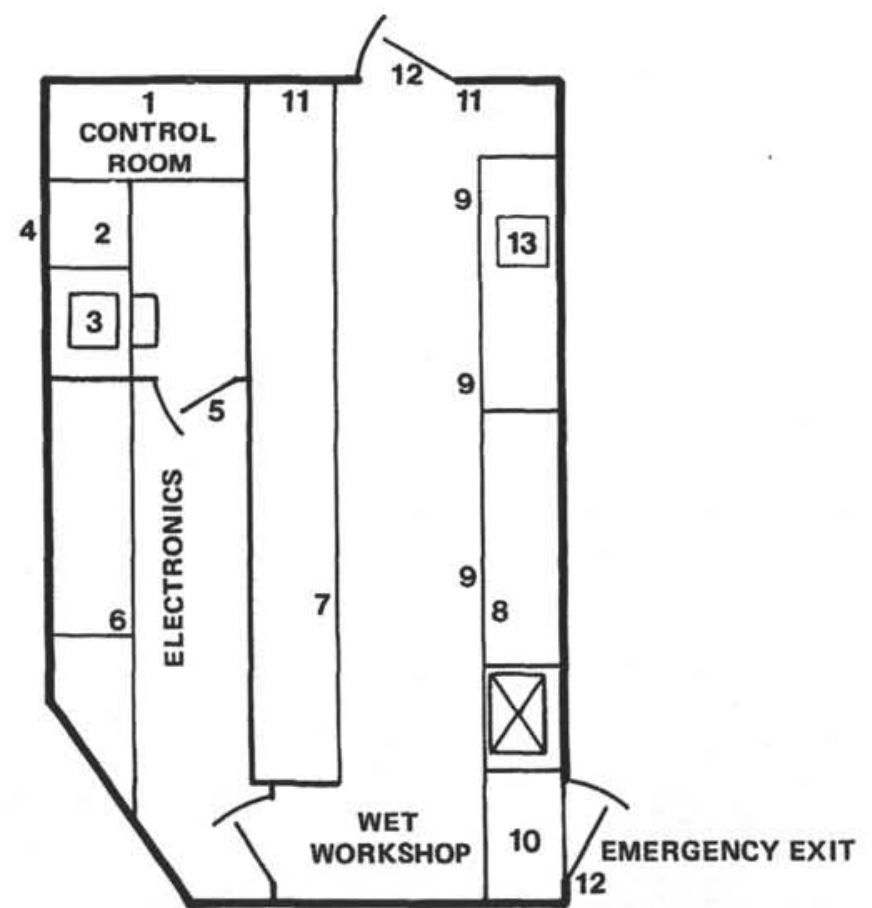

Figure 17. Downhole measurements laboratory. 
d. Dual Laterolog: Induction logging probes do not produce reliable results in highly resistive formations such as oceanic basalts. The Schlumberger Dual Laterolog (DLL) provides the deeper measurement of resistivity into the rock with high precision at high resistivities. This tool is also used for determination of the relative abundance of horizontal and vertical fractures.

e. Magnetometer/Hole Orientation: An additional measurement cartridge (the GPIT) can be included in the litho-porosity or geochemical strings, to determine hole azimuth and deviation and the vector components of the magnetic field. Although this device is not oriented gyroscopically, magnetic field inclination can be measured accurately. The device also monitors vertical and horizontal accelerations applied to the logging probe and thus can be used to determine the effects of ship heave on the logging run.

f. Well Seismic Tool (WST) is a wellbore clamped single-component geophone used to record vertical seismic profiles in a borehole. It provides a measure of formation velocity at seismic frequencies by measuring the traveltime between a surface seismic shot and the wellbore geophone, useful in depth correlating reflectors on nearby seismic lines. The WST in not used routinely aboard ship.

.g. Formation Microscanner: The Formation Micro-Scanner (FMS) produces highresolution borehole images from electrical conductivity measurements, allowing continuous recording of detailed vertical and lateral variations in formation properties. Four imaging pads contain sets of microelectrodes that come in direct contact with the borehole walls during the logging run. Processing the electrical currents recorded by the microelectrodes provides images that look like core photographs. The FMS has a vertical resolution of $\sim 1 \mathrm{~cm}$, but a detection threshold for conductive features on the order of microns. This fine-scale detection ability (raw data points are recorded every $2.5 \mathrm{~mm}$ ) allows for detailed study of subsurface structures. In contrast, typical conventional downhole measurements are averaged over $150 \mathrm{~mm}$; thus, the sampling rate of the FMS is 60 times greater than most other logging devices.

Possible applications of FMS-derived images include detailed correlation of coring and logging depths; orientation of cores; mapping of fractures, faults, foliations, and formation structures; and analysis of depositional environments (with information on transport direction, structure of the pore space, nature of contacts, and depositional sequences). The FMS also provides precise measurements of borehole diameter in two orthogonal directions. In an isotropic, linearly elastic rock subjected to an anisotropic stress field, breakouts form along the borehole wall as a result of compressive stress concentrations exceeding the strength of the rock. Under these conditions, the breakout orientation develops in the direction of the least principal horizontal stress, and is visible in FMS images.

The LDGO Borehole Research Group owns three specialty logging tools that are run by the LDGO Logging Scientist:

h. Borehole Acoustic Televiewer (BHTV) is employed to detect and evaluate fractures and bedding intersecting the borehole wall. An acoustic beam scans horizontally around the circumference of the borehole wall as the tool is moved vertically. Televiewers are very sensitive and can outline quite small features such as 
fractures, vugs, or other large size porosity and bedding planes.

i. Multichannel Sonic Log: The complete waveform of the acoustic or sonic signal is recorded by the MCS $\log$ at each of 12 receivers spaced $15 \mathrm{~cm}$ apart. Subsequent waveform analysis allows determination of velocities of shear waves, compressional waves, Stoneley and normal modes, as well as compressional wave energy and frequency content. Thus, various elastic properties of the formation can be estimated. j. Lamont Temperature Tool: The TLT is self-contained and can be attached to any of the combination tool strings. Data from two thermistors and a pressure transducer are collected every 0.5 to $5.0 \mathrm{~s}$ and stored within the tool. Once the in-situ measurement is completed, the data are transferred to a shipboard computer for analysis. The fastresponse thermistor, though low in accuracy, is able to detect small abrupt temperature excursions caused by fluid flow from the formation. The slow-response thermistor has a high accuracy and can be used to estimate the temperature gradient. Data are recorded as a function of time, with conversion to depth based on the pressure transducer or, preferably, on simultaneous recording by Schlumberger of both depth and time.

Many other measurements that have been made in boreholes on land have been obtained in ODP boreholes for use by members of the scientific party of various legs. These include long-spaced resistivity, precision temperature, magnetic susceptibility, and gyroscopically oriented vector magnetic field.

Shipboard scientists sometimes bring specialty logging equipment on board to run experiments at particular sites. Software is available to permit data acquisition on the LDGO logging computer. There are several restrictions on specialty logging equipment that should be noted by prospective logging investigators. These include the TAMU weight restriction (minimum weight of $100 \mathrm{lb}$ floating for uncentralized tools and $200 \mathrm{lb}$ floating for tools with centralizers), the limitations in cable speed $(100 \mathrm{~m} / \mathrm{hr}$ lower limit), the specifications of the cable (7 conductors, 170-ohm line resistance, Gearhart-Owens cablehead or your own pigtail), the determination of depth (500 ppf quadrature signal), and the amount of space available for staging the log and recording the data (severely limited).

Planning for specialty logging by individual shipboard scientists must begin as early as possible, but not later than the Co-Chief Scientists' pre-cruise meeting, held at ODP about four months before the cruise departure data. Both the ODP Engineering and Drilling Operations Office and the LDGO Borehole Research Group must be notified of the particulars of such planning during or prior to this pre-cruise meeting.

LDGO has established two logging interpretation centers to collect and analyze ODP well log data, one on the ship and one at LDGO. The shipboard logging facility is a rapid analysis combination of uphole recording, playback, and cross-correlation software designed for real-time assistance in geological interpretation while still on the drill site. The logging facility at LDGO is a more elaborate facility where interested scientists can work on seismic spectra, degree of alteration, lithologic variation, fracture distribution, porosity changes, etc.: in sum, an entire array of scientific cross-correlation software designed to return maximum science from the ODP logging program.

A Schlumberger field engineer and an LDGO Logging Scientist sail on every cruise to oversee the collection of logging data. Most shipboard scientific parties also include a "Shipboard Logging Scientist" selected by ODP/TAMU (advice on this 
selection is usually sought from either the BRG or the JOIDES Downhole Measurements Panel). Whenever possible, this scientist is brought to LDGO for a week of intensive precruise training. The scientist has full access to the LDGO shore-based facility to work up the logging data after the cruise.

Scientists desiring more information about log analysis facilities aboard ship or at LDGO may contact Dr. Roger N. Anderson, Borehole Research Group, LamontDoherty Geological Observatory, Palisades, New York 10964, U.S.A. [Telephone: (914) 359-2900, ext. 335.] The Borehole Research Group has prepared a detailed Wireline Logging Manual, available on request.

\section{ODP Downhole Tools}

While LDGO manages and supervises routine downhole instruments using the logging wireline that is connected to either the Schlumberger computer or the LDGO computer, ODP is in charge of other downhole instrumentation, that is, equipment on the sandline, core lines, hydraulic piston corer, etc. The downhole tools that ODP/TAMU provides are described in detail in ODP Technical Note 10, A Guide to ODP Tools for Downhole Measurements.

The ODP equipment consists of the following instruments:

a. Magnetic Azimuth Core Orientation System Using the Advanced Hydraulic Piston Corer (APC)

The magnetic orientation system used with the APC was developed to take advantage of the non-rotary nature of piston coring in soft sediments (see Section IX.B.4). The core orientation system provides a magnetic reference azimuth for each core as well as a measurement of deviation from vertical and the azimuth direction of the nonverticality, that is, the angle of the hole at the specific location of the core in question and which way it is pointing.

The decision to obtain oriented piston cores must be made before the bottom-hole assembly (BHA) is made up and the pipe run in the hole at a given site. The $30-\mathrm{ft}$ nonmagnetic (Monel) drill collar must be included in the BHA just above the bottommost drill collar (also known as the outer core barrel). Planning for oriented piston coring must also take into account the fact that Multishot handling and delay time add 510 minutes per core to normal operating time while piston coring.

A non-magnetic pressure case housing an Eastman-Whipstock Magnetic Multishot camera is installed in the sinker bar assembly used to connect the sandline to the APC core barrel, between two sections of non-magnetic sinker bars, so that the entire nonmagnetic assembly is at least $30 \mathrm{ft}$ long. The Multishot instrument takes pictures of its compass/pendulum "angle unit" continuously at pre-selected intervals and records the images on $10 \mathrm{~mm}$ movie film. A Technician acts as Multishot operator and handles the duties of preparing the Multishot tool for each core run, removing and developing the film, interpreting the film, and recording the relative azimuth angle, deviation from vertical, and direction of deviation on special envelopes in which the individual film strips are stored. The azimuth orientation angle determined for each piston core is the angle $\left(0-360^{\circ}\right)$ between Magnetic North and the double lines on the core liner measured clockwise from North (looking down on the top of the core). Physical alignment 
between the double line on the side of the core liner and the reference "lubber" line that appears superimposed over the compass image on the pictures from the Multishot camera is accomplished through a series of mechanical devices built into the equipment. The total error to the orientation azimuth reading introduced by the purely mechanical elements of the system should not exceed $3^{\circ}$.

Routine hole drift measurements (deviation from vertical) can be taken with the Multishot tool even if the non-magnetic drill collar is not installed in the bottom-hole assembly. The Multishot angle unit measures verticality with a pendulum suspended over a bulls-eye. The amount of drift is read from the developed film, although the direction of drift is meaningless without the non-magnetic drill collar.

\section{b. Formation Packers}

The TAM drill-string straddle packer is designed for use in reentry holes that penetrate stable formations. It is designed to be a weight-bearing part of the drill string, and has two hydraulic seals with which the zone between or below the seals can be tested. The original TAM straddle design was modified in consultation with ODP engineers to allow maximum flexibility for ODP use. By assembling it in the drill string with or without certain parts, it can be used in four possible modes, all of which are resettable: (1) as a single-element packer, (2) as a double-element double-strength single packer, (3) as a straddle packer and (4) as a straddle packer with the option to separately test the straddled interval or the interval below the lower element (to total depth).

The TAM rotatable packer is a single-element drill-string packer with rotational capability, which means that it can be included as part of a rotating, coring BHA. It differs from the straddle packer in that the rotatable packer has a much stronger, thickerwalled internal mandrel to withstand both the torque and compressive loads of drilling, a plumbing system that will permit cuttings to be circulated away without inadvertently inflating the packer element, and a more complicated go-devil and control sub. Both packers are compatible with the same set of downhole pressure recorders, and both are fully compatible with logging.

Several formation properties can be determined using drill-string packers. The critical parameter is fluid pressure in the isolated borehole section, which is actually measured and from which formation properties are derived. There are several kinds of downhole pressure recorders. ODP has available four self-contained mechanical recorders manufactured by Kuster Co. Each is calibrated for a different maximum pressure $(9950,11,900,12,400,15,275 \mathrm{psi})$, and all can be set to record for 3,6 , or 12 hours. The Kuster recorders are housed in special carriers that attach to the packer go-devils; when the go-devil is properly seated in the packer, the pressure recorders monitor pressures in the section of borehole isolated by the packer.

Three pressure values are measured in the isolated borehole section: hydrostatic pressure, in-situ pore pressure, and test pressure. The testing procedure in each tested zone is thus: (1) hydrostatic pressure measured first, both to check the recorder calibration and to provide a reference baseline for the in-situ and test pressures; (2) fluid pressure measured when the packer is inflated and the formation isolated; and (3) active testing, so that permeability can be estimated from the transient behavior of pressure in 
the borehole in response to controlled pumping from the surface through the go-devil and into the formation; both pulse (or "slug") tests and constant flow tests are made.

The ODP packers are not kept aboard ship, and planning for their use must be developed in the early stages of planning for cruise objectives.

\section{c. In-Situ Pore Water Sampler and Temperature/Pressure Measurement Instrument}

A new version of the "Barnes" in-situ pore water sampler has been developed and is now in use. The prototype of the original sampler was first used on DSDP Leg 47B and was carried over for use on early ODP legs. The new instrument integrates water sampling, temperature or pressure measurements. It has been adapted for open hole fluid sampling as well as in-situ filtration from sediments at the bottom of the hole. The tool is lowered down the drill pipe on the sandline, and the filter probe extends more than one meter beyond the end of the drill bit.

\section{d. Probeless Pore Water Sampler}

The probeless pore water sampler (PWS) comprises a WSTP tool modified to be used in conjunction with the inflated ODP rotatable drill-string packer. Development of this mode of sampling has been suspended until the rotatable packer is proven, but it may also be feasible with the reliable drill-string straddle packer.

\section{e. Other Engineering Tools}

A series of tools is used by ODP Engineering and Drilling Operations to monitor and improve drilling capabilities on the ship. These tools are deployed when they can be fit into normal operations, in order to increase the quantity and quality of baseline data. These data provide information on actual accelerations at the bit during coring or other selected operations, and drill pipe stresses including binding, tension, and torque. The shipboard-mounted Ship Motion Data System, a vertically stabilized gyro sensor package, gives continuous data on roll, pitch, and heave of the ship. This information correlates with data from the downhole tools. Dedicated shipboard programs using these tools may impact scientific time allotments, but information gained is used to verify analytical computer model predictions of fatigue and stress and provides ODP with guidelines on safe drill string operating limits.

\section{SHIPBOARD SCIENTIFIC DATA AND REPORTS}

The scientific laboratories aboard JOIDES Resolution permit both a wide variety and a large quantity of scientific data to be generated during each cruise. Two informal (unpublished) reports and three formal (published) reports are prepared during the cruise by the shipboard scientific party, based primarily on prime data gathered at each site. Hard copies of prime data, including computer printouts and handwritten paper forms, are collected by the Yeoperson on a regular basis during the cruise, and computer data files are transferred regularly to the VAX, to be stored for end-of-leg transmission to ODP's Data Base Group.

The informal reports (Hole Summaries and Preliminary Report) are distributed by ODP to a limited number of recipients immediately following completion of the cruise. The 
formal reports (Nature and Geotimes articles and the press release) are submitted to their respective publishers and major news services as quickly as possible after the cruise. Each of the five shipboard reports must be completed before the ship docks. The Co-Chief Scientists have final responsibility for ensuring that all data are collected and reports written, but the entire shipboard scientific party participates in the process. The Staff Scientist is familiar with expected format and content of data collection and scientific reports, and guides the scientific party in the compilation of them. Guidelines for preparation of Hole Summary reports, including format and ODP conventions, are distributed to all shipboard scientists at the beginning of the cruise. Guidelines for preparation of articles for Geotimes and Nature are on file in the shipboard library. Following these guidelines will help to minimize editing by the Staff Scientist and Yeoperson.

\section{A. Data Collection Aboard Ship}

Below is a table listing prime data generated during a cruise, and the primary and backup methods for collecting prime data. Data collection is performed in one or more of the following ways: (1) data are key punched by shipboard personnel into a computerized data entry program; (2) data are hand written onto paper forms; and (3) data are captured directly by a computer connected to a lab instrument, and are then uploaded for storage on the central VAX computer.

Scientists who pursue shipboard scientific programs generating data other than that collected routinely, including scientists who bring their own analytical equipment to the ship, must make available to ODP copies of their prime data before the end of the cruise, along with details of analytical, data-collection, and data-processing procedures.

The ODP Data Base Group relies on each shipboard participant to correctly, completely, and legibly enter data into data entry programs or onto paper forms.

Prime data from each leg are brought back to ODP and merged with all data from previous ODP and DSDP Legs. The ODP database is used by the entire scientific community--thus the importance of initially correct, complete, and legible work. No individual may take home paper prime-data forms or prime-data computer printouts. Although shipboard supplies are limited, it is possible to photocopy on the ship the forms needed for personal use during and immediately after the cruise.

The ODP database is available to everyone in the scientific community; however, data are restricted in distribution to members of that leg's scientific party for a period of twelve months following the completion of the cruise. Thereafter all data are open to the public. Most requests can be answered quickly and free of charge. If a charge is made to recover expenses, an invoice will be sent and must be paid before the request is processed.

Members of the ODP Database Group are available for consultation with reference to data needs, and consultation is encouraged. Questions and requests may be addressed to: Data Librarian, Database Group

Ocean Drilling Program

TAMU Research Park 1000 Discovery Drive College Station, TX 77845-9547 U.S.A.
(409) $845-8495$ or $845-2673$

Easylink (Telex): 62760290 Bitnet: DATABASE@TAMODP 


\begin{tabular}{|c|c|c|c|}
\hline DATA TYPE & $\begin{array}{l}\text { IMARY COLLECTION } \\
\text { METHOD }\end{array}$ & $\begin{array}{l}\text { COMPUTER APPLICATION/ } \\
\text { INSTRUMENT NAME }\end{array}$ & $\begin{array}{l}\text { BACKUP } \\
\text { METHOD }\end{array}$ \\
\hline \multicolumn{4}{|l|}{ U/W GEOPHYSICS } \\
\hline Bridge log & Paper form (\#2002) & & \\
\hline Geophysical log & Paper form (\#2001) & & \\
\hline LEG-SITE-HOLE & Computer form & LEGS & Paper forms \\
\hline CORELOG & Computer form & CORELOG & Paper form (\#7006) \\
\hline \multicolumn{4}{|l|}{ SEDIMENTOLOGY } \\
\hline Smear slide/thin section & Computer form & SLIDES & Paper form (\#7001) \\
\hline Visual core description & Paper form (\#7000) & & \\
\hline \multicolumn{4}{|l|}{ PALEOMAGNETICS } \\
\hline Intensity/direction & Direct capture & & Paper form (\#8000) \\
\hline Susceptibility & Direct capture & MST & \\
\hline \multicolumn{4}{|l|}{ PHYSICAL PROPERTIES } \\
\hline Index properties & Computer form & PHYSPROPS & Paper form (\#4005) \\
\hline GRAPE 2-minute & Computer form & PHYSPROPS & Paper form (\#4000) \\
\hline Shear Strength & Computer form & PHYSPROPS & Paper form (\#4001) \\
\hline $\begin{array}{l}\text { Compressional/shear wave } \\
\text { velocity }\end{array}$ & Computer form & PHYSPROPS & Paper form (\#4002) \\
\hline Thermal conductivity & $\begin{array}{l}\text { Direct capture and } \\
\text { paper form (\#4004) }\end{array}$ & & \\
\hline GRAPE & Direct capture & MST & \\
\hline P-wave logger & Direct capture & MST & \\
\hline \multicolumn{4}{|l|}{ CHEMISTRY } \\
\hline Rock evaluation & Computer form & CHEMDB & Paper form (\#3005) \\
\hline $\mathrm{CaCO}_{3}$ and carbon & Computer form & CHEMDB & Paper form (\#3009) \\
\hline Interstitial water & Computer form & CHEMDB & Paper form (\#3001) \\
\hline Gas chromatography & Computer form & CHEMDB & $\begin{array}{l}\text { Paper forms (\#3002 } \\
\& \# 3008)\end{array}$ \\
\hline \multicolumn{4}{|l|}{ PETROLOGY } \\
\hline Thin section description & Computer form & HRTHIN & Paper form (\#7003) \\
\hline Visual core description & Computer form & HARVI & Paper form (\#7005) \\
\hline PALEONTOLOGY & Paper form (\#6000) & & \\
\hline X-RAY FLUORESCENCE & Computer printout & & $\begin{array}{l}\text { Paper form (\#3007) } \\
\text { for majors }\end{array}$ \\
\hline X-RAY DIFFRACTION & Computer printout & & \\
\hline DOWNHOLE LOGGING & $\begin{array}{l}\text { Direct capture and } \\
\text { paper forms (\#5000-\#5002) }\end{array}$ & & \\
\hline
\end{tabular}

Table listing ODP prime data generated during a cruise, and the primary and backup methods for collecting prime data. 


\section{B. Hole Summaries}

Upon completion of drilling at each site, the shipboard scientists individually and as a group prepare a report of the results from that site. At the end of the cruise, these site reports together with the barrel sheets are assembled into one summary report. One copy of this Hole Summary is retained aboard JOIDES Resolution. A second copy is returned to ODP where it is photocopied and distributed to shipboard scientists and others who intend to contribute to the Proceedings of the Ocean Drilling Program for that leg. This report, which has the status of an unreferenceable personal communication, is distributed approximately four weeks after the end of the cruise. Copies of the report include a cover letter which states explicitly that the contents are background information and not intended for publication. Distribution is limited to those who have a real "need to know."

At the initial post-cruise meeting (generally 4-5 months after the end of the cruise), the Hole Summaries are revised by the Co-Chief Scientists and representatives from the shipboard party, and go directly into production as the Initial Reports volume of the Proceedings of the Ocean Drilling Program. The volume is published approximately 12 months post-cruise.

\section{Preliminary Report}

This report consists of a general and condensed discussion of the scientific results of the cruise. It is returned to ODP Science Operations at the end of the cruise, for distribution to JOIDES panel members and to others which special involvement in ODP activities. Usually, the Preliminary Report (or a compilation of the site summaries) is reprinted in the JOIDES Journal.

\section{Press Release}

A press release is prepared briefly outlining the essence of cruise objectives, accomplishments, and results in lay language. This release is written by the $\mathrm{Co}-\mathrm{Chief}$ Scientists and transmitted to ODP before the ship docks. Contents and wording of the release are subject to approval by ODP, JOI, and NSF. This press release is supplied to local area news media before the ship docks, if time permits, and is released by ODP soon after the cruise ends. Cruise-related press conferences are held when a cruise produces information of outstanding public interest.

\section{E. Geotimes and Nature Articles}

One obligation shared by all members of the scientific party is to make a prompt report of their preliminary results to the international community of scientists. Nature and Geotimes have agreed to publish appropriately written reports following each cruise. Guidelines for preparation of articles for Geotimes and Nature are on file in the shipboard library. 
These articles must be completed prior to the end of the cruise so that they can be returned to ODP immediately for final editing and preparation of artwork. They are published within two to three months after the end of the cruise.

The Nature article is published in its "News and Views" column. It should be shorter than 800 words and may include one figure. Nature's readers should be addressed as intelligent, well-informed generalists, not as specialists in the field of deep ocean drilling or even as geologist; jargon and undefined technical terminology are unacceptable. The Geotimes article may be five double-spaced pages in length and may contain two or three figures or photographs. The reader is usually an earth scientist but probably not a specialist in the field of deep ocean drilling.

Other journals such as Geo-Marine Letters appreciate receiving short papers that discuss recent cruise results. Once the obligatory Nature and Geotimes articles have been completed, shipboard parties are welcome to submit articles to any publication. Please send copies of such articles to the Curator, Ocean Drilling Program, 1000 Discovery Drive, College Station, Texas 77845-9547, at the same time they are submitted for publication.

\section{F. ODP Publications Policy}

Shipboard and shore-based cruise participants are granted specific privileges. They have immediate, unlimited access to all cruise data, and are not subject to the 12 -month moratorium period for distribution of samples and data from their cruise. In return, all cruise participants agree to adhere to the following restrictions and to contribute to ODP's publications in a timely manner. The following publications policy has been recommended by the JOIDES Information Handling Panel and approved by the JOIDES Planning Committee for implementation:

\section{Initial Reports Volume}

Initial Reports volumes are scheduled to appear within one year of the end of a leg. A small meeting of the Co-Chief Scientists and key personnel, about 4-5 months post-cruise (the initial post-cruise meeting), will refine, edit, and complete the Initial Reports volume for that cruise.

\section{Scientific Results Volume}

Scientific Results volumes are scheduled to appear 30 months from the end of a leg. All shipboard and shore-based cruise participants who receive samples and/or data prior to 12 months post-cruise are required to submit a substantive formal report to this volume. The precise nature of this report will be negotiated between the participant and the Co-Chief Scientists prior to the initial post-cruise meeting. Acceptance of this report to the Scientific Results volume by the deadline will fulfill the participant's obligation to ODP, although additional papers are welcome. The Scientific Results volume may consist of direct contributions, as well as reprints of papers submitted to non-ODP publications under the following guidelines: 


\section{a. Prior to the science post-cruise meeting:}

Any submission to a non-ODP publication prior to the science post-cruise meeting (10-12 months post-cruise) must have had its authorship and theme agreed to by a consensus of the scientific party before the end of the cruise. The Co-Chief Scientists will examine the manuscript to ensure that the agreement about theme and authorship has been fulfilled. Authors are responsible for (1) alerting the editor(s) of the non-ODP publication of the fact that the paper also may be reprinted in the Scientific Results volume, (2) obtaining waivers of copyrights and/or permissions required, and (3) submitting camera-ready copy of the paper published by the non-ODP publication to the Scientific Results volume. Authors may, alternatively, expand and/or rewrite such papers for submission to the Scientific Results volume in the normal fashion.

b. Between the science post-cruise meeting and fulfillment of obligation:

Any submission to a non-ODP publication between the time of the science postcruise meeting and the fulfillment of the author's obligation for publication in the Scientific Results volume must have had its theme and authorship agreed to by the CoChief Scientists and a consensus of the scientific party. The Co-Chief Scientists will examine the manuscript to ensure that the agreement about theme and authorship has been fulfilled. The same paper or an expanded version must be submitted simultaneously to the Scientific Results volume. It will be subjected to the ODP peerreview process independently of the review conducted by the non-ODP publication. It is the author's responsibility to inform the editor(s) of the non-ODP publication of the submission, and that the paper may be accepted or rejected by ODP independently of the non-ODP publication's decision.

c. After fulfillment of obligation:

After the participant's promised contribution to the Scientific Results volume has been accepted by ODP, authors may published at will in the open literature. Authors who fail to contribute an acceptable manuscript to the Proceedings may not publish in any other medium until the Scientific Results volume has been published.

\section{POST-CRUISE ACTIVITIES}

\section{A. Post-Cruise Meetings}

In 1989, beginning with Leg 125 , a two-phase post-cruise meeting schedule was put into effect in order to streamline post-cruise publications. The new schedule incorporates an initial post-cruise meeting and a scientific post-cruise meeting.

The initial post-cruise meeting is usually held $4-5$ months post-cruise. Its primary purpose is to refine and complete the Site Chapters of the Initial Reports volume by revising the Hole Summaries. Normally, the meeting lasts about five days, and involves the Co-Chief Scientists, the ODP Staff Scientist, and a few key representatives from the shipboard scientific party. At the end of this first meeting, the Initial Reports manuscripts go directly in to publication, so that the volume may be published within one year of the end of the cruise. 
The scientific post-cruise meeting, for the entire science party, is held for the purpose of planning and reviewing the scientific content of the Scientific Results volume. This second meeting is held $10-12$ months post-cruise, and lasts about 3 days. Participants bring drafts of each of their Scientific Results manuscripts for discussion and preliminary review. The emphasis of this meeting is on discussing the scientific results of the cruise. Initial submission of manuscripts for the Scientific Results volume follows this meeting by some four to six months.

\section{B. Post-Cruise Reports}

\section{Proceedings of the Ocean Drilling Program}

The Proceedings of the Ocean Drilling Program is composed of an Initial Reports volume and a Scientific Results volume for each leg. The Proceedings volumes serve two purposes: first, they detail inventories of materials and data recovered by each cruise and provide the scientific community at large with a basis for selecting samples and data for detailed studies; and second, they provide the shipboard and shore-based scientists with an opportunity to publish an integrated report of their preliminary results.

Papers submitted to the Proceedings are expected to contain research of the same quality of those submitted to other major scientific journals. However, owing to its very specialized nature, the Proceedings can be sympathetic to papers that contain high-quality data not yet ready for final interpretation.

\section{a. Initial Reports}

The Initial Reports volume is published approximately 12 months after the cruise ends. Contents include an introduction, explanatory notes, site chapters, and the barrel sheets from the Hole Summaries revised at the post-cruise meeting (see Section X.A above). In addition, an underway geophysics chapter and chapters of precruise site-survey data and cruise data may be published if ready. Upon close of the initial post-cruise meeting, the Initial Reports goes directly into editing, production, and printing, with no further opportunity for revision.

\section{b. Scientific Results}

The Scientific Results is published approximately 30-32 months after the cruise, allowing time for shipboard and shore-based cruise participants to complete their preliminary post-cruise studies. Contributions to this publication consist of results of research conducted in the year to 18 months following the cruise, and may be authored by individual participants or by consortia. Initial submission of manuscripts for peer review can be expected to range between 16 and 18 months post-cruise.

An Editorial Review Board is established to handle peer review of Scientific Results manuscripts from each cruise; this board consists of the Co-Chief Scientists and ODP Staff Scientist for that cruise, an ODP editor, and one other scientist to be selected by the Manager of Science Operations in consultation with the Co-Chief Scientists. The board is responsible for obtaining manuscript reviews and for making decisions concerning acceptance or rejection of papers.

Please note that manuscripts can no longer be copyedited routinely at ODP, although authors whose primary language is not English can be provided with editorial 
assistance. Furthermore, authors are required to submit all artwork for figures and plates for their accepted papers in camera-ready form, ready for publication.

Authors should be aware that five free plates are allowed for each manuscript submitted for publication in the Scientific Results volume. Submission of more than five plates means that the authors agree to pay US $\$ 75$ for processing each additional plate.

The "Instructions to Contributors" booklet contains guidelines for preparing manuscript text, tables, and figures in ODP format. This booklet and further information may be obtained from the ODP Manager of Science Services, Ocean Drilling Program, 1000 Discovery Drive, College Station, Texas 77845-9547.

\section{General Geological Articles}

Publication of such an article is entirely at the discretion of the shipboard party. The party is encouraged to prepare a technical article discussing cruise scientific results for a major journal, such as Science or Bulletin of the Geological Society of America, as soon as possible after the cruise ends. Authorship is at the discretion of the complete scientific party. 


\section{APPENDIX A. SAMPLE DISTRIBUTION POLICY}

Distribution of Ocean Drilling Program and of Deep Sea Drilling Project samples is undertaken in order to (1) provide support to shipboard scientists in achieving the scientific objectives of their cruise and to support shorebased investigators who are preparing contributions to ODP reports; (2) provide individual investigators with materials to conduct detailed studies beyond the scope of ODP reports; (3) provide paleontological reference centers with samples for reference and comparison purposes; and (4) provide educators with samples for teaching purposes.

Funding for sample-related activities must be secured by the investigator independently of requesting the samples.

The Ocean Drilling Program Curator is responsible for distributing samples and for preserving and conserving core material. The Curator, who may accept advice from chairmen of the appropriate JOIDES advisory panels, is responsible for enforcing the provisions of this sample distribution policy. He is responsible for maintaining a record of all samples that have been distributed, both onboard ship and subsequently from the repositories, indicating the recipients and the nature of investigations proposed. This information is available to interested investigators on request.

Every sample distributed from the ship or from a repository is labeled with a standard identifier, which includes leg number, hole number, core and section numbers, and interval within the section from which the sample was removed. It is imperative that this standard identifier be associated with all data reported in the literature, and that residues of the sample remain labeled throughout their lives, so that later workers can relate the data to the cores.

Distribution of sample materials is made directly from the repositories (Lamont-Doherty Geological Observatory, Scripps Institution of Oceanography, or Texas A\&M University) by the Curator or his designated representative.

\section{Distribution of Samples for Research Leading to Contributions to ODP Reports.}

Any investigator who wishes to contribute to the reports of a scheduled cruise may write to the Curator, Ocean Drilling Program, P.O. Drawer GK, College Station, Texas 77841 , USA, in order to request samples from that cruise. Requests for a specific cruise must be received by the Curator at least TWO MONTHS in advance of the departure of that cruise, in order to allow time for review of the request in conjunction with other requests, so that a suitable shipboard sampling program can be assembled. The request should include a statement of the nature of the proposed research, size and approximate number of samples required to complete the study, and any particular sampling technique or equipment which may be required. Requests will be reviewed by the staff representative and co-chief scientists of the cruise and by the Curator. Approval/disapproval will be based upon the scientific requirements of the cruise as determined by the appropriate JOIDES advisory panel(s). The scope of a request must be such that samples can be processed, that proposed research can be completed, and that the paper can be written in time for submission to the relevant ODP cruise report. 
Except for rare, specific instances involving ephemeral properties, the total volume of samples removed during a cruise-related sampling program will not exceed one-quarter of the volume of core recovered, and no interval will be depleted. One-half of all recovered materials will be retained in the archives in as pristine a condition as is practicable.

Investigators requesting shipboard samples of igneous materials may receive a maximum of 100 igneous samples per cruise.

Because many sample requests are received for shipboard work and because the time of the shipboard party is at a premium, co-chief scientists are strongly urged to limit shipboard sampling to the minimum necessary to accomplish the cruise objectives. Shorebased investigators whose requests for cruise-related samples are approved should expect that they will receive the samples after the cores are returned to the repository, and should schedule research activities accordingly.

Co-chief scientists may invite investigators who are not cruise participants to perform special studies of selected core samples in direct support of shipboard activities. If this occurs, the names and addresses of these investigators and details of all samples loaned or distributed to them must be forwarded to the Curator, via the ODP Staff Representative to that cruise, immediately after the cruise. These investigators are expected to contribute to the cruise reports as though they had been cruise participants. All requirements of the Sample Distribution Policy apply.

Any publication of results other than in ODP reports within twelve (12) months of completion of the cruise must be approved and authored by the whole shipboard party and, where appropriate, shorebased investigators. After twelve months (12), individual investigators may submit related papers for open publication provided they have already submitted and had accepted their contributions to the ODP reports. Investigations which are not completed in time for inclusion in the ODP reports for a specific cruise may be published in a later edition of the ODP reports; however, they may not appear in another journal until the report for which they were intended has been published.

\section{Distribution of Samples for Research Leading to Publication Outside of the ODP Reports}

A. Researchers who wish to use samples for studies beyond the scope of the ODP reports should obtain sample request forms from the Curator, Ocean Drilling Program, P.O. Drawer GK, College Station, Texas 77841, USA. Requestors are required to specify the quantities and intervals of core required, to make a clear statement of the nature of the proposed research, to state the time which will be required to complete the work and to submit results for publication, and to specify funding status and the availability of equipment and space for the research.

Additionally, if the requestor has received samples from ODP or from DSDP previously, he/she will be required to account for the disposition of those samples by citing published works, four (4) copies of which must be sent to the Curator. If no report has been published, this requirement can be fulfilled by sending a brief (two or three page) report of the status of the research.

If the requestor has never before received samples from ODP or DSDP, he/she will be required to show that the samples will be used for responsible research. This 
requirement can be met by providing the Curator a copy of their resume and bibliography. If the requestor is a student working on a higher degree, he/she can meet this requirement by sending a copy of their dissertation or research proposal endorsed by the student's advisor.

Unused and residual samples should be returned and data should be sent to the Curator if the project has terminated. Paleontological materials may be returned either to the Curator at ODP or to one of the designated paleontological reference centers. If material is returned to a reference center, notify the Curator when it is sent.

Requests for samples from researchers in industrial laboratories will be honored in the same manner as those from academic organizations. Industrial investigators have the same obligations as other investigators to publish all results promptly in the open literature and to provide the Curator with copies of all reports published and of all data acquired in their research.

In order to insure that all requests for highly desirable but limited samples can be considered together, approval of requests and distribution of samples will be delayed until twelve (12) months after completion of the cruise or two (2) months after official publication of the core descriptions, whichever occurs earlier. The only exceptions to this policy will be made for specific requests involving ephemeral properties. Requests for samples may be based on core descriptions published in ODP reports produced by the shipboard party, copies of which are on file at various institutions throughout the world. Copies of original core logs and data are kept on open file at ODP, and at the repositories at Lamont-Doherty Geological Observatory and at Scripps Institution of Oceanography.

B. Most investigations can be accomplished handily with samplevolumes of $10 \mathrm{ml}$ or less. Investigators must provide explicit justification of requests for larger sample sizes or for frequent intervals within a core. Requests which exceed reasonable size or frequency limits will require more time to process, and are unlikely to be granted in their entirety.

Requests for samples from thin layers, from stratigraphically-important boundaries or from sections which are badly depleted or in unusually high demand may be delayed in order to coordinate requests from several investigators or while the Curator seeks advice from the community. Investigators who submit such requests may expect to receive suggestions for alternative sampling programs or that they join a research consortium which will share the samples. In any event, such exceptional requests will require more time for processing than will more routine requests.

Investigators who wish to study ephemeral properties may request a waiver of the twelve-month waiting period; however, such requests will be referred automatically to the relevant co-chiefs. If approved, the investigator will join the shorebased contributors to the shipboard science effort, and will incur the obligations thereof (section 1).

C. Samples will not be provided until the requestor assures the Curator that funding for the proposed research is available or unnecessary. If a sample request is dependent in any way upon proposed funding, the Curator is prepared to provide the proposed funding 
organization with information on the availability (or potential availability) of suitable samples.

D. Investigators who receive samples incur the following obligations:

(1) To publish significant results promptly; however, no contribution may be submitted for publication prior to twelve (12) months following the termination of the relevant leg unless it is approved and authored by the entire shipboard party.

(2) To acknowledge in all publications that the samples were supplied through the assistance of the international Ocean Drilling Program and others as appropriate. (3) To submit four (4) copies of reprints of all published works to the Curator, Ocean Drilling Program, 1000 Discovery Drive, College Station, Texas 77845-9547, USA. These reprints will be distributed to the repositories and to the ship. All reprints received will be logged in an on-line bibliographic data base.

(4) To submit all final analytical data obtained from the samples to Data Base Supervisor, Ocean Drilling Program, 1000 Discovery Drive, College Station, Texas 77845-9547, USA. Please consult announcements in the JOIDES Journal or call (409) 845-2673 for information on acceptable data formats. Investigators should be aware that they may have other data obligations under NSF's Ocean Science Data Policy or under relevant policies of other funding agencies which require submission of data to national data centers.

(5) To return all unused or residual samples, in good condition and with a detailed explanation of any processing they may have experienced, upon termination of the proposed research. In particular, all thin sections and smear slides manufactured onboard the vessel or in the repositories are to be returned to the Curator. Paleontological materials may be returned either to the Curator at ODP or to one of the designated paleontological reference centers.

Failure to honor these obligations will prejudice future applications for samples.

E. Cores are available for examination by interested parties at the repositories. Investigators are welcome to visit the repositories in order to inspect cores and to specify sample locations when that is required for their research; however, time and space in the workrooms are limited, so advance appointments are required.

Occasionally, the space may be fully booked several weeks in advance, so investigators are urged to call for appointments well ahead in order to avoid disappointment. Only the Curator or his delegate may actually remove samples from the cores.

F. A reference library of thin sections, smear slides and archive photographs is maintained in the repositories for the use of visiting investigators. All thin sections and smear slides produced onboard the ship or in the repositories belong to this library.

\section{Distribution of samples to Paleontological Reference Centers}

As a separate and special category of repository activity, selected samples are being 
distributed to paleontological reference centers, where the prepared material may be studied by visitors. Foraminifera and Calcareous Nannofossils and Diatoms can be viewed;

Radiolaria will be prepared in the future.

Location

U.S. East Coast

LDGO

Palisades, NY 10964

U.S. National Museum

Smithsonian Institution

Washington, DC 20560

U.S. Gulf Coast

Department of Oceanography

Texas A\&M University

College Station, TX 77843

U.S. West Coast

Scripps Institution of Oceanography

Univeristy of California, San Diego

La Jolla, CA 92093

Western Europe

Natural History Museum

CH-4001 Basel, Switzerland

USSR

Institute of the Lithosphere

Staromonet 22

Moscow 109180

Japan

Natural Science Museum

Department of Geology

3-23-1 Hyakunio-cho

Shinjuku-ku, Tokyo 160

New Zealand

New Zealand Geological Survey

P. O. Box 30368

Lower Hutt, New Zealand
Contact

Ms. Rusti Lotti

Dr. Martin Buzas

Dr. Stefan Gartner

Dr. William Riedel

Mr. J. B. Saunders

Dr. Ivan Basov

Dr. Y. Tanimura

033-364-2311

03-364-2316

264729

061-29-55-64

231-48-36
(914) $359-2900$

7105762653 LAMONTGEO

(202) $357-1390$

(409) $845-8479$

(619) $534-4386$

910337127 IUC-

WWDSIOSDG

Dr. Tony Edwards

(04) 699059

\section{9}


Further details concerning the paleontological reference centers are reported periodically in the JOIDES Journal.

\section{Distribution of Samples for Educational Purposes}

Samples may be available in limited quantities to college-level educators for teaching purposes. Interested educators should request application forms from the Curator, Ocean Drilling Program, P.O. Drawer GK, College Station, Texas 77841, USA. Requestors are required to specify preferred sample size and location, to make a very clear statement of the nature of the coursework in which the samples will be used, to explain how the samples will be prepared and how they will be used in the classroom, to explain in detail why they cannot use similar materials derived from outcrops or dredge hauls (it is NOT acceptable to argue that it requires less effort for the requestor to obtain samples from ODP than to assemble them from other sources!), and to clarify that funds are available to prepare the materials for classroom use. In general, only samples of materials which are abundant in the collection and which are in little demand for research purposes should be requested for educational purposes. The Curator will not approve requests for materials which are limited in supply or for which demand (real or potential) is great, including most paleontological materials.

\section{Distribution of Data}

The Deep Sea Drilling Project and the Ocean Drilling Program routinely capture much of the data generated onboard ship and published in Program reports. Additionally, data supplied by investigators who have received samples are incorporated into the data bases, so data sets which are larger than can be published are available to investigators. Magnetics, downhole logging, seismic reflection, bathymetric data, and other data collected by the drilling vessel become available for distribution to investigators at the same time as core samples.

Requests for ODP and DSDP data should be addressed to the Data Base Supervisor, Ocean Drilling Program, 1000 Discovery Drive, College Station, Texas 77845-9547, USA. Many varieties of DSDP data will be included in ODP data bases. Information on sources of DSDP data will be available from the ODP Data Base Supervisor.

A charge will be made to recover material expenses in excess of $\$ 25.00$ incurred in filling individual requests. If required, estimates of charges can be furnished before the work is performed. 


\section{OCEAN DRILLING PROGRAM SAMPLE REQUEST FOR SHIPBOARD AND SHOREBASED CRUISE PARTICIPANTS}

(Submit to the Curator at least two months before cruise departs.)

Please be aware of the current sample distribution policy which is published in recent issues of Initial Reports of the Deep Sea Drilling Project and in Proceedings of the Ocean Drilling Program.

1. Proposed leg name (include number if known):

2. Name(s), office address, telephone number, and telex number of investigator(s):

3. Purpose(s) of request. Please summarize the nature of the proposed research concisely in 5-7. This summary will be included in various official reports.] Provide a detailed description of the proposed research, including techniques of sample preparation and analysis, roles of individual investigators, etc., on an attached sheet. The detailed description of the project will be employed in reviewing the sample request. 
4. Please describe the proposed core sampling program in detail sufficient so that those who must carry it out onboard ship will understand your needs. Specify the size of samples (cubic centimeters); the number of samples to be taken from each section, core, and/or hole; particular stratigraphic or lithologic units to be sampled; special sampling techniques, equipment (for example, specialized tools which you are providing), storage or shipping requirements; or any other information that will be helpful in conducting your sampling program. Be aware that, if the number of samples which you are requesting is large, the taking of your samples is likely to be delayed until the cores reach the repository ( 4 to 6 months following the oruise), so it is to your advantage to keep the total number of samples small.

5. Are sufficient funds, space, and facilities now available to support the proposed research?

Source of Funds:

NSF:

Other (identify agency):

Space:

Facilities:

If funds, space, or facilities now available are inadequate, how do you anticipate remedying the situation? If a sample request is dependent, wholly or partially, upon propsed funding from the National Science Foundation, the sample request and funding proposal must be considered together; therefore, it is important that the funding proposal be submitted at the same time as this request.

If NSF funding is to be employed in the proposed research, please enter the relevant NSF Grant No. or NSF Proposal No.

devoted to research on DSDP or ODP samples: $\%$ , and percent of funding in that grant which would be

6. Please estimate the time it will require for you to obtain publishable results:

7. In what condition will the samples be once your research is complete? Will they be useful to others? If so, for what kinds of research? 
8. If you have ever before received samples from DSDP or ODP, please indicate the ODP sample request number (if known), and the number and the volumes of samples received. Were all of these samples analyzed? If not, were they returned to DSDP/ODP? If work is still in progress, please attach a brief (2-3 page) progress report. If the work has ended, please return the samples. Micropaleontologists may keep their processed residues until their professional use of the samples is completed, whereupon they must be returned to the Curator.

9. If you have ever before received samples from DSDP or from ODP, please attach a comprehensive list of the publications in journals, outside of the ODP reprints, which resulted from each sample request. If you reference publications which have not yet been forwarded to the Curator, please enclose four (4) reprints of each. If work is still in progress, please attach a brief (2-3 page) progress report. If the work has ended, please return the residues.

10. Please summarize any other information which you feel would be useful in reviewing your request on an attached sheet.

11. If your samples will require special storage or shipment (for example, frozen organic samples) please specify a destination airport which is near your institute. Specify the name, telephone number, and telex number of someone who can: re-ice the shipment at the destination airport, clear the shipment from customs, and provide transportation to final destination.

12. Would you prefer that we:

a) ship your samples to you,

b) give them to you at the end of the cruise so that you can put them in your suitcase, or

c) pack them in a box and give them to you at the end of the cruise?

Acceptance of samples implies willingness and responsibility on the part of the investigator to fulfill certain obligations:

(a) To publish significant results promptly; however, no contribution may be submitted for publication prior to twelve (12) months following the termination of the relevant leg unless it is approved and authored by the entire shipboard party.

(b) To acknowledge in all publications that the samples were supplied through the assistance of the international Ocean Drilling Program and others as appropriate.

(c) To submit (4) copies of reprints of all published works to the Curator, Ocean Drilling Program, Texas A\&M Research Park, 1000 Discovery Drive, College Station, Texas 77840, U.S.A. These reprints will be distributed to the repositories, and to the ship. The Bibliographies of all reprints received by the Ocean Drilling Program will be sent to the National Science Foundation.

(d) To submit all final analytical data obtained from the samples to the Data Base Supervisor, Ocean Drilling Program, Texas A\&M University Research Park, 1000 Discovery Drive, College Station, Texas 77840 , U.S.A. Please consult recent issues of the JOIDES Journal or call 409-845-2673 for information on acceptable data formats. Investigators should be aware that they may have other data obligations under NSF's Ocean Science Data Policy or under relevant policies of other funding agencies which require submission of data to national data centers.

(e) To return all unused or residual samples, in good condition and with a detailed explanation of any processing they may have experienced, upon termination of the proposed research. In particular, all thin sections and smear slides manufactured onboard the vessel or in the repositories are to be returned to the Curator. Thin sections and smear slides used to describe the cores are unique representatives of the materials and as such they are kept as members of the ODP reference collection. All unused or dry residua paleontological materials may be returned either to the Curator at ODP or to one of designed paleontological reference centers upon completion of the investigators' use of the materials.

It is understood that failure to honor these obligations will prejudice future applications for samples. 
All requests will be reviewed by the Assistant Curator, by the ODP staff science representative, and by the Co-chief Scientists for the cruise, who will prepare a science study plan which will be submitted to the Curator for approval.

Approval/disapproval will be based upon the scientific requirements of the cruise as determined by the appropriate JOIDES advisory panel(s). In the case of duplicate proposals, shipboard scientists will have priority over shorebased scientists. Requests for samples for post-cruise studies will be handled separately.

Completion of this form in no way implies acceptance of your proposed investigation.

Date:

Date:

Date:

Signatures of Investigators

Send this completed form to the Curator at least two months in advance of the cruise departure date. The Curator's address:

Curator

Ocean Drilling Program

Texas A\&M Unlversity Research Park

1000 Discovery Drive

College Station, Texas 77840

U.S.A. 
APPENDIX B. NEW SEDIMENT CLASSIFICATION SCHEME Jim Mazzu110 ${ }^{1,2}$, Audrey Meyer ${ }^{2,3}$, and Robert Kidd ${ }^{4}$.

\section{INTRODUCTION}

The Deep Sea Drilling Program (DSDP) employed a sediment classification scheme that was devised by the JOIDES Panel on Sedimentary Petrology and Physical Properties and adopted for use by the JOIDES Planning Committee in March of 1974. That JOIDES classification scheme was put into service on DSDP Leg 38, and was also used by the Ocean Drilling Program (ODP) through 1987; it is fully described in the various Initial Reports of the Deep Sea Drilling Program (see, for example, Ross et al., 1978).

The DSDP concentrated its early drilling effort in deep marine sedimentary environments for various scientific and technical reasons, and thus the JOIDES sediment classification scheme evolved with strong emphasis upon the proper classification of fine-grained calcareous and siliceous ("pelagic") sediments. However, the weakness of the JOIDES classification scheme--its lesser emphasis upon the classification of coarse-grained carbonate ("neritic"), clastic, and mixed sediments--became apparent as DSDP and ODP expanded the ocean-drilling effort to continental margins and marginal seas, and resulted in its modification in a variety of ways by the shipboard scientists on most DSDP and ODP legs to date. For example, the Leg 101 shipboard scientists found that the JOIDES classification scheme did not precisely classify coarse-grained carbonates, which were a major component in their cores; thus they amended the Dunham (1962) classification scheme for such sediments to the JOIDES classification scheme to meet their needs.

The purpose of this paper is to describe a more comprehensive sediment classification scheme for the Ocean Drilling Program which places equal emphasis upon pelagic, neritic, clastic, and mixed sediments, and thereby responds to the growing need for the precise description of sediments from continental-margin and marginal-sea environments. This sediment classification scheme is a revision of the original JOIDES sediment classification scheme, but also adopts some modifications to the same that were proposed by Dean et al. (1985). This new scheme was approved by the JOIDES Sediments and Ocean History Panel in 1987 for shipboard use.

This new classification scheme is a descriptive rather than genetic classification, for it classifies sediments on the basis of their textures and compositions rather than their assumed or postulated genesis. It provides a consistency of classification and nomenclature that will allow for easier communication between scientists and greater efficiency in the acquisition, storage, and retrieval of sedimentological data from the ODP computerized data-storage system.

1 Department of Geology, Texas A \& M University
2 Ocean Drilling Program, Texas A \& M University
3 Department of Oceanography, Texas A \& M University
${ }^{4}$ Department of Earth Sciences, University College of Swansea, U.K. 


\section{BASIC SEDIMENT TYPES}

The sediment classification scheme described here defines two basic sediment types: (1) granular sediment and (2) chemical sediment. Granular sediment is composed of discrete grains of organic (e.g., foram tests, mollusc shells) or inorganic (e.g., quartz grains, rock fragments, volcanic ash) origins that were deposited by physical or organic processes. Some examples of granular sediment are foraminiferal chalk, quartz sandstone, vitric ash, and oolitic grainstone. Chemical sediment is composed of minerals that formed by inorganic processes such as precipitation from solution or colloidal suspension, deposition of insoluble precipitates, or recrystallization of detrital evaporites and siliceous, calcareous, or carbonaceous (plant) biogenic debris, and generally has a crystalline (i.e., non-granular) texture. Some examples of chemical sediment are coal, halite, pyrite, and gypsum.

Separate sediment classification schemes have been devised for granular and chemical sediments, for there are great differences in the 1ithologies, fabrics and depositional histories of these two basic sediment types even when they are present together in the same sediment sample.

\section{CLASSIFICATION OF GRANULAR SEDIMENTS}

Classes of Granular Sediments

There are four types of grains that can be found in granular sediments: pelagic, neritic, siliciclastic, and volcaniclastic grains. Pelagic grains are composed of the fine-grained organic debris of open-marine siliceous and calcareous microfauna and microflora (e.g., radiolarians, nannofossils) and associated organisms. Neritic grains are composed of coarse-grained calcareous skeletal debris (e.g., shell fragments), coarse-grained calcareous non-skeletal debris (e.g., ooids, peloids), and fine-grained calcareous grains of non-pelagic origin (e.g., micrite). Siliciclastic grains are composed of mineral and rock fragments that were derived from plutonic, sedimentary, and metamorphic rocks. Volcaniclastic grains are composed of rock fragments and minerals that were derived from volcanic sources.

Variations in the relative proportions of these four grain types define five major classes of granular sediments: pelagic, neritic, siliciclastic, volcaniclastic, and mixed sediments (Figure 1).

Pelagic sediments are composed of more than $60 \%$ pelagic and neritic grains and less than $40 \%$ siliciclastic and volcaniclastic grains, and contain a higher proportion of pelagic than neritic grains (Appendix, Examples 1-9).

Neritic sediments are composed of more than $60 \%$ pelagic and neritic grains and less than $40 \%$ siliciclastic and volcaniclastic grains, and contain a higher proportion of neritic than pelagic grains (Appendix, Examples 10-13).

Siliciclastic sediments are composed of more than $60 \%$ siliciclastic and volcaniclastic grains and less than $40 \%$ pelagic and neritic grains, and 
RATIO OF SILICICLASTIC TO VOLCANICLASTIC GRAINS

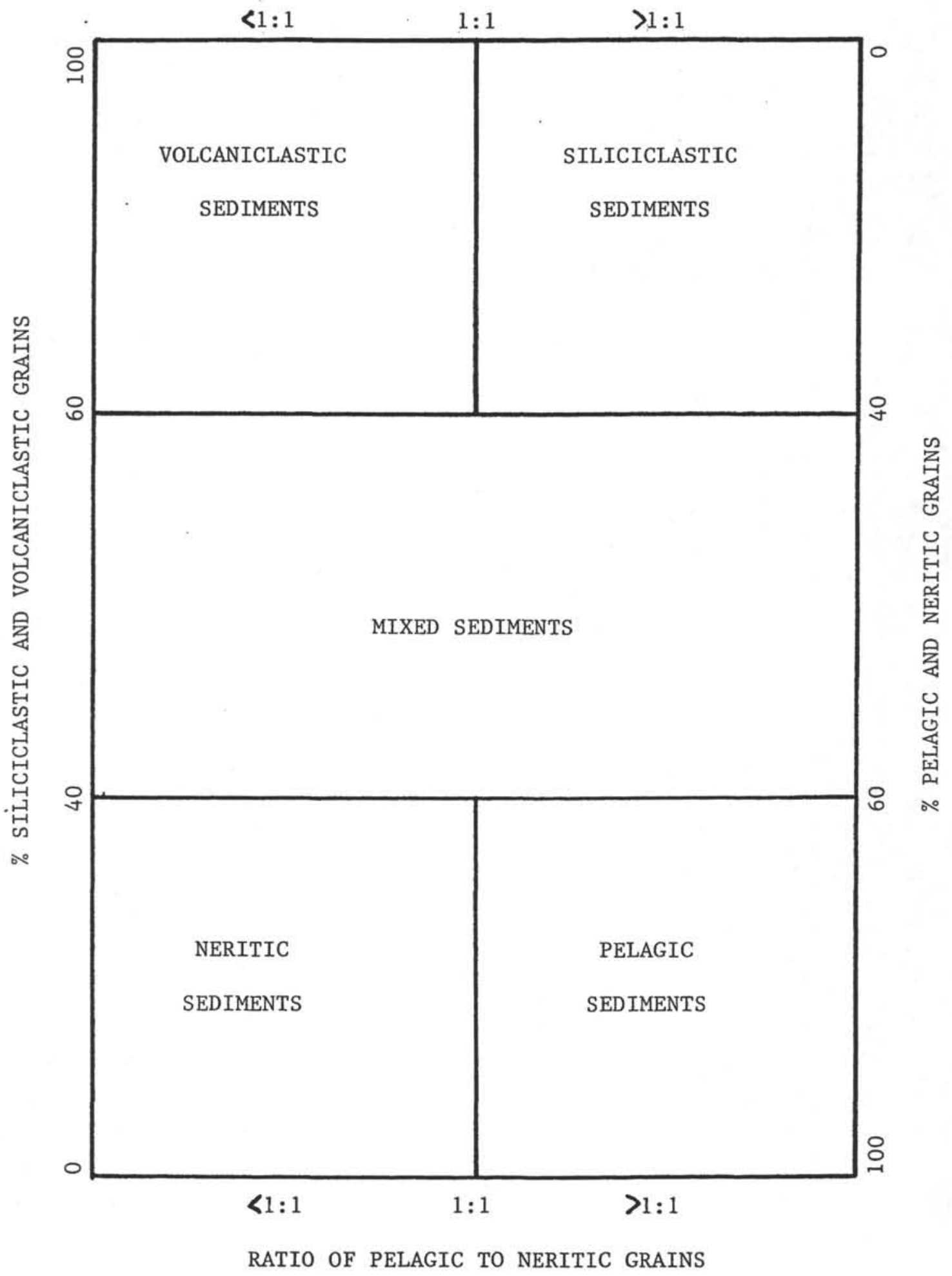

Figure B-1. Diagram showing classes of granular sediments. 
contain a higher proportion of siliciclastic than volcaniclastic grains (Appendix, Examples 14-19).

Volcaniclastic sediments are composed of more than $60 \%$ siliciclastic and volcaniclastic grains and less than $40 \%$ pelagic and neritic grains, and contain a higher proportion of volcaniclastic than siliciclastic grains (Appendix, Examples 20-22). This class includes epiclastic sediments (volcanic detritus that is produced by erosion of volcanic rocks by wind, water, and ice), pyroclastic sediments (the products of the degassing of magmas), and hydroclastic sediments (the products of the granulation of volcanic glass by steam explosions).

Lastly, mixed sediments are composed of 40 to $60 \%$ siliciclastic and volcaniclastic grains, and 40 to $60 \%$ pelagic and neritic grains (Appendix, Example 23).

\section{Classification of Granular Sediment}

A granular sediment can be classified by designating a principal name and major and minor modifiers. The principal name of a granular sediment defines its granular-sediment class; the major and minor modifiers describe the texture, composition, fabric and/or roundness of the grains themselves (Table 1).

Principal Names

Each granular-sediment class has a unique set of principal names:

For pelagic sediment...the principal name describes the composition and degree of consolidation using the following terms (Appendix, Exs. 1-9):

1. ooze: unconsolidated calcareous and/or siliceous pelagic sediments

2. chalk: firm pelagic sediment composed predominantly of calcareous pelagic grains

3. limestone: hard pelagic sediment composed predominantly of calcareous pelagic grains

4. radiolarite, diatomite, and spiculite: firm pelagic sediment composed predominantly of siliceous radiolarians, diatoms, and sponge spicules, respectively, and

5. chert: hard pelagic sediment composed predominantly of siliceous pelagic grains

For neritic sediment...the principal name describes the texture and fabric, using the following terms (from Dunham, 1962; Appendix, Exs. 10-13):

1. boundstone: components organically bound during deposition

2. grainstone: grain-supported fabric, no mud, grains $<2 \mathrm{~mm}$ in size

3. packstone: grain-supported fabric, with intergranular mud, grains $<2 \mathrm{~mm}$ in size

4. wackestone: mud-supported fabric, with greater than $10 \%$ grains, grains $<2 \mathrm{~mm}$ in size

5. mudstone: mud-supported fabric, with less than $10 \%$ grains

6. floatstone: matrix-supported fabric, grains $>2 \mathrm{~mm}$ in size

7. rudstone: grain-supported fabric, grains $>2 \mathrm{~mm}$ in size 
TABLE 1

OUTLINE OF GRANULAR-SEDIMENT CLASSIFICATION SCHEME

$\begin{array}{cccc}\text { SEDIMENT } & \text { MAJOR } & \text { PRINCIPAL } & \text { MINOR } \\ \text { CLASS } & \text { MODIFIERS } & \text { NAMES } & \text { MODIFIERS }\end{array}$

$\begin{array}{lllll}\text { P S } & \text { 1. composition of } & \text { 1. ooze } & \text { 1. composition of } \\ \text { E } & \text { E } & \text { pelagic and neritic } & \text { 2. chalk } & \text { pelagic and neritic } \\ \text { L } & \text { D } & \text { grains present in } & \text { 3. limestone } & \text { grains present in } \\ \text { A } & \text { I } & \text { major amounts } & \text { 4. radiolarite } & \text { minor amounts } \\ \text { G } & \text { M } & \text { 2. texture of clastic } & \text { 5. diatomite } & \text { 2. texture of clastic } \\ \text { I } & \text { E } & \text { grains present in } & \text { 6. spiculite } & \text { grains present in } \\ \text { C } & \text { N } & \text { major amounts } & \text { 7. chert } & \text { minor amounts } \\ \text { T } & & & \end{array}$

\begin{tabular}{|c|c|c|c|}
\hline $\begin{array}{ll}\text { N } & \text { S } \\
\text { E } & \text { E } \\
\text { R } & \text { D } \\
\text { I } & \text { I } \\
\text { T } & M \\
\text { I } & \text { E } \\
\text { C } & \text { N } \\
& \text { T }\end{array}$ & $\begin{array}{l}\text { 1. composition of } \\
\text { neritic and pelagic } \\
\text { grains present in } \\
\text { major amounts } \\
\text { 2. texture of clastic } \\
\text { grains present in } \\
\text { major amounts }\end{array}$ & $\begin{array}{l}\text { 1. boundstone } \\
\text { 2. grainstone } \\
\text { 3. packstone } \\
\text { 4. wackestone } \\
\text { 5. mudstone } \\
\text { 6. floatstone } \\
\text { 7. rudstone }\end{array}$ & $\begin{array}{l}\text { 1. composition of } \\
\text { neritic and pelagic } \\
\text { grains present in } \\
\text { minor amounts } \\
\text { 2. texture of clastic } \\
\text { grains present in } \\
\text { minor amounts }\end{array}$ \\
\hline $\begin{array}{l}\text { SILICI- } \\
\text { CLASTIC } \\
\text { SEDIMENT }\end{array}$ & $\begin{array}{l}\text { 1. composition of all } \\
\text { grains present in } \\
\text { major amounts } \\
\text { 2. grain fabric } \\
\text { (gravels only) } \\
\text { 3. grain shape } \\
\text { (optional) } \\
\text { 4. sediment color } \\
\text { (optional) }\end{array}$ & $\begin{array}{l}\text { 1. gravel } \\
\text { 2. sand } \\
\text { 3. silt } \\
\text { 4. clay } \\
\text { (etc.) }\end{array}$ & $\begin{array}{l}\text { 1. composition of all } \\
\text { grains present in } \\
\text { minor amounts } \\
\text { 2. texture and compo- } \\
\text { sition of silici- } \\
\text { clastic grains } \\
\text { present as matrix } \\
\text { (for coarse-grained } \\
\text { clastic sediments) }\end{array}$ \\
\hline $\begin{array}{l}\text { VOLCANI- } \\
\text { CLASTIC } \\
\text { SEDIMENT }\end{array}$ & $\begin{array}{l}\text { 1. composition of all } \\
\text { volcaniclasts present } \\
\text { in major amounts } \\
\text { 2. composition of all } \\
\text { pelagic and neritic } \\
\text { grains present in } \\
\text { major amounts } \\
\text { 3. texture of silici- } \\
\text { clastic grains } \\
\text { present in major } \\
\text { amounts }\end{array}$ & $\begin{array}{l}\text { 1. breccia } \\
\text { 2. lapilli } \\
\text { 3. ash/tuff }\end{array}$ & $\begin{array}{l}\text { 1. composition of all } \\
\text { volcaniclasts present } \\
\text { in minor amounts } \\
\text { 2. composition of all } \\
\text { neritic and pelagic } \\
\text { grains present in } \\
\text { minor amounts } \\
\text { 3. texture of silici- } \\
\text { clastic grains } \\
\text { present in minor } \\
\text { amounts }\end{array}$ \\
\hline $\begin{array}{l}\text { MIXED } \\
\text { SEDIMENTS }\end{array}$ & $\begin{array}{l}\text { 1. composition of } \\
\text { neritic and pelagic } \\
\text { grains present in } \\
\text { major amounts } \\
\text { 2. texture of clastic } \\
\text { grains present in } \\
\text { major amounts }\end{array}$ & $\begin{array}{l}\text { 1. mixed } \\
\text { sediments }\end{array}$ & $\begin{array}{l}\text { 1. composition of } \\
\text { neritic and pelagic } \\
\text { grains present in } \\
\text { minor amounts } \\
\text { 2. texture of clastic } \\
\text { grains present in } \\
\text { minor amounts }\end{array}$ \\
\hline
\end{tabular}


For siliciclastic sediment...the principal name describes the texture, and is assigned according to the following guidelines (Appendix, Exs. 14-19): 1. The Udden-Wentworth grain-size scale (Wentworth, 1922; Table 2) defines the grain-size ranges and the names of the textural groups (gravel, sand, silt and clay) and sub-groups (fine sand, coarse silt, etc.) that are used as the principal names of siliciclastic sediment.

2. When two or more textural groups or sub-groups are present in a siliciclastic sediment, they are listed as principal names in order of increasing abundance (Shepard, 1954; Figure 2).

3. The suffix -stone can be affixed to the principal names sand, silt, and clay when the sediment is lithified; shale can be used as a principal name for a lithified and fissile siltstone or claystone; and conglomerate and breccia are used as principal names of gravels with well-rounded and angular clasts, respectively.

4. The terms mud and mudstone should not be used to describe mixtures of silt and clay. The distinction between silt and clay-sized particles is an important part of determining their transport history (e.g., Dean et al., 1985 , p. 251), and thus the relative proportions of these two textural groups should be estimated as well as possible.

For volcaniclastic sediment...the principal name describes the texture. The names and ranges of three textural groups (from Fisher and Schmincke, 1984) are as follows:

1. volcanic breccia: pyroclasts greater than $64 \mathrm{~mm}$ in diameter

2. volcanic lapilli: pyroclasts between 2 and $64 \mathrm{~mm}$ in diameter

3. volcanic ash: pyroclasts less than $2 \mathrm{~mm}$ in diameter. When lithified, use the name tuff.

(Appendix, Examples 20-22)

For mixed sediment...the principal name describes the degree of consolidation, using the terms mixed sediments or mixed sedimentary rocks (Appendix, Example 23).

Major and Minor Modifiers

The principal name of a granular-sediment class is preceded by major modifiers and followed by minor modifiers (preceded by the suffix with) that describe the lithology of the granular sediment in greater detail (Table 1).

The most common uses of major and minor modifiers are to describe the composition and textures of grain types that are present in major (greater than 25\%) and minor (10-25\%) proportions. In addition, major modifiers can be used to describe grain fabric, grain shape, and sediment color. The nomenclature for the major and minor modifiers is outlined as follows:

The composition of pelagic grains can be described with the major and minor modifiers diatom(-aceous), radiolarian, spicules(-ar), siliceous, nannofossil, foraminifer $(-a 1)$, and calcareous. The terms siliceous and calcareous are used generally to describe sediments that are composed of siliceous or calcareous pelagic grains of uncertain origins. 


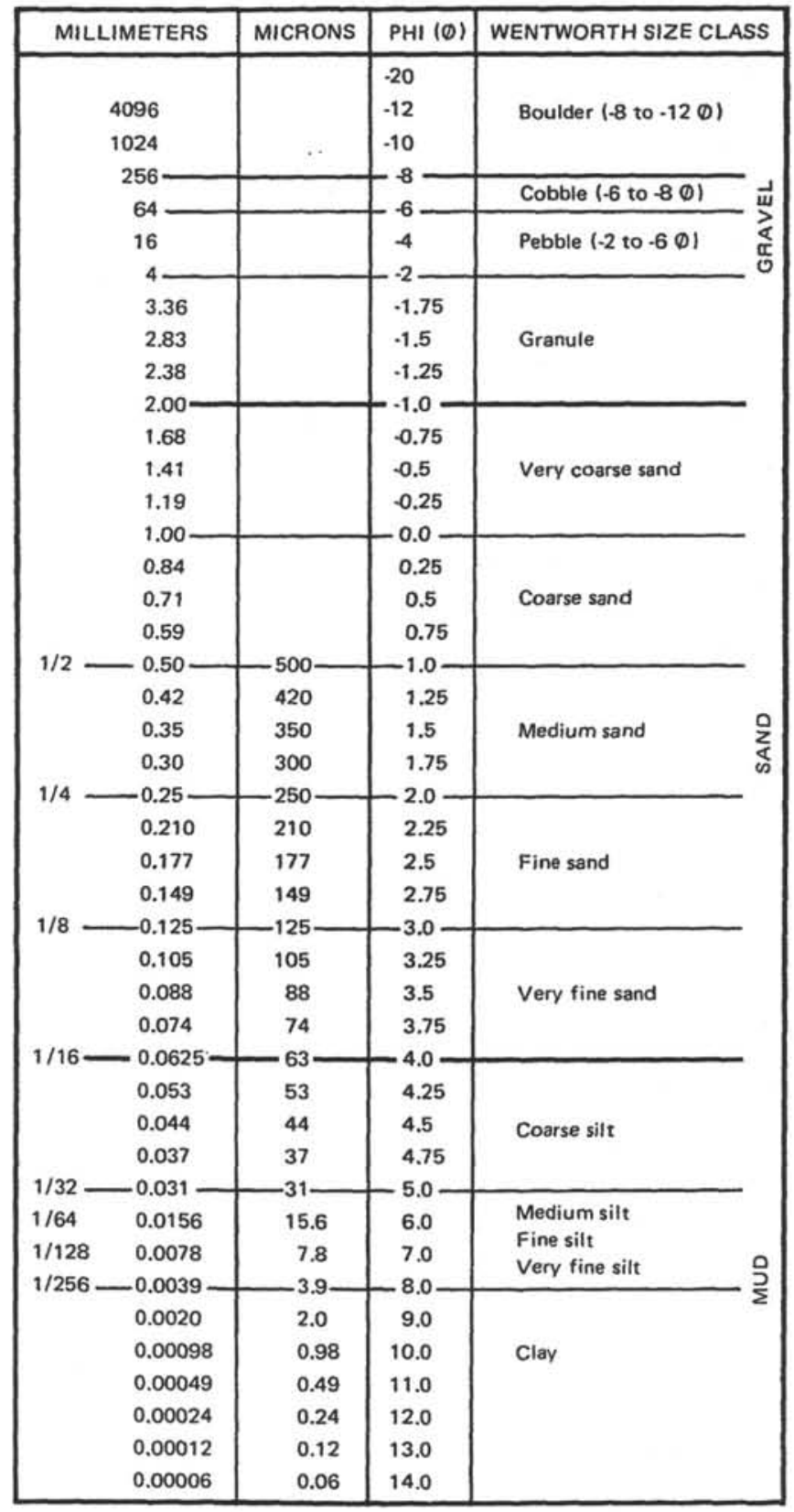

Table 2. Udden-Wentworth grain-size scale for siliciclastic sediments (Wentworth, 1922). 


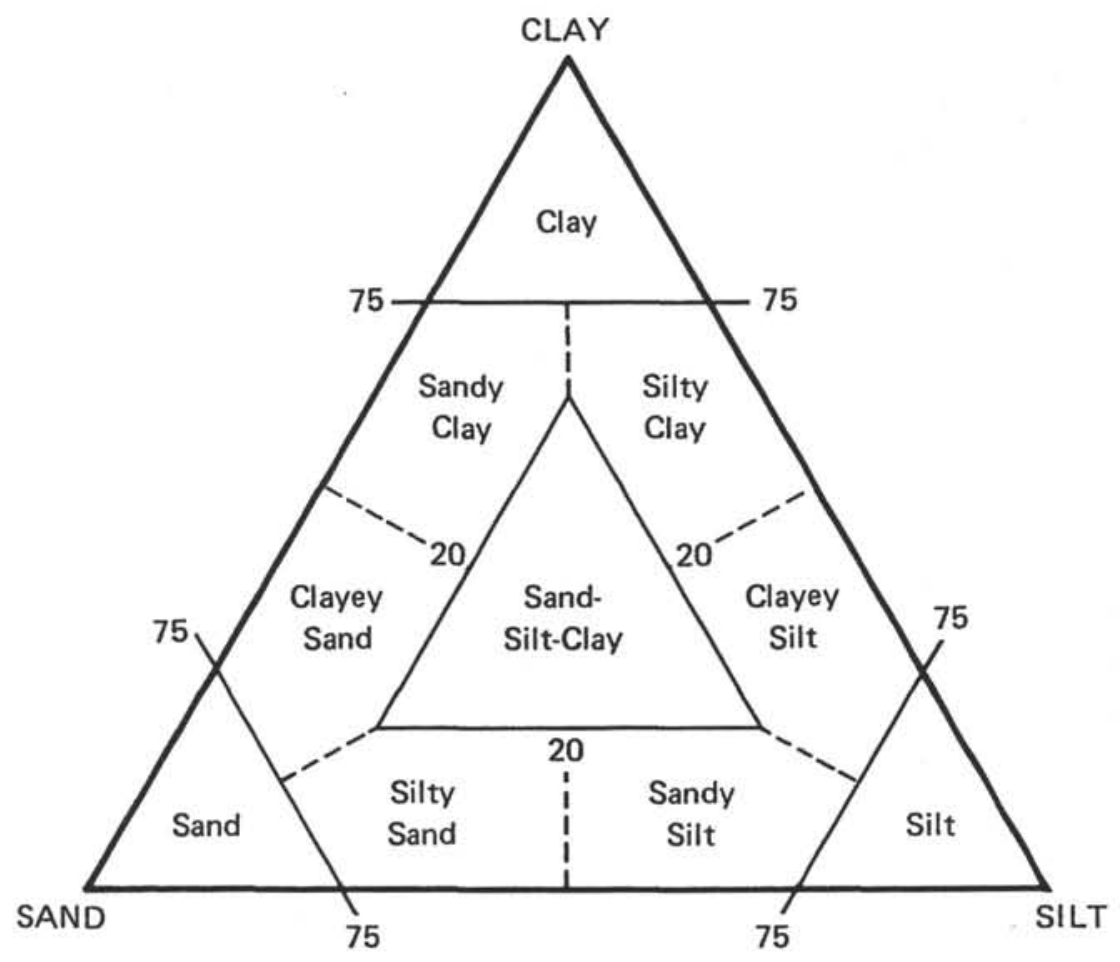

Figure B-2. Ternary diagram showing principal names for siliciclastic sediments (from Shepard, 1954). 
The composition of neritic grains can be described with the following major and minor modifiers:

1. ooid (or oolite): spherical or elliptical non-skeletal particles smaller than $2 \mathrm{~mm}$ in diameter, having a central nucleus surrounded by a rim with concentric or radial fabric;

2. bioclast (or bio): fragment of skeletal remains. Specific names such as molluscan or algal can also be used;

3. pellet (-al): fecal particles from deposit-feeding organisms;

4. intraclast: reworked carbonate-rock fragment or rip-up clast;

5. pisolite: spherical or ellipsoidal non-skeletal particle, commonly greater than $2 \mathrm{~mm}$ in diameter, with or without a central nucleus but displaying multiple concentric layers of carbonate;

6. peloid (pel): micritized carbonate particle of unknown origin; and

7. calcareous, dolomitic, aragonitic, sideritic: these modifiers should be used to describe the composition of carbonate muds or mudstones (micrite) of non-pelagic origins.

The texture of siliciclastic grains is described by the major and minor modifiers gravel, sand, silt, and clay.

The composition of siliciclastic grains can be described by:

1. mineralogy: using modifiers such as quartz, feldspar, glauconite, mica, kaolinite, zeolitic, lithic (for rock fragments), calcareous, gypsiferous, or sapropelic (for detrital clasts of calcium carbonate, gypsum, and organic matter, respectively); and

2. provenance: the source of rock fragments (particularly in gravels, conglomerates, and breccias) can be described by modifiers such as volcanic, sed-lithic, meta-lithic, gneissic, basaltic, etc.

The composition of volcaniclastic grains is described by the major and minor modifiers lithic (rock fragments), vitric (glass and pumice), and crystal (mineral crystals), or by modifiers that describe the compositions of the liths and crystals (e.g., feldspar or basaltic).

The fabric of the sediment can be described by the major modifiers grain-supported, matrix-supported, and imbricated. Generally, fabric descriptors are applied only to gravels, conglomerates, and breccias, for they provide useful information on their transport history. However, they must be used with extreme caution, for drilling and fluid-flow through a core barrel will often alter the sediment fabric.

The shapes of grains can be visually estimated with a comparitor (Figure 3 ) and described by the major modifiers rounded, sub-rounded, sub-angular, and angular. Generally, shape descriptors are applied only to sand, for they provide useful information on their transport history, and are used at the scientists' discretion.

The color of sediment can be determined with a standard colorcomparitor, such as the Munse11 Chart, and is employed as a major modifier. Generally, color descriptors are applied only to silt, clay, and shale, for they provide useful information on their depositional environment or organic content, and are also used at the scientists' discretion. 


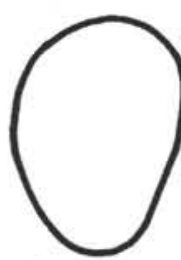

Rounded

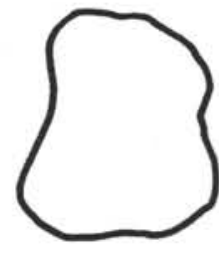

Sub-round

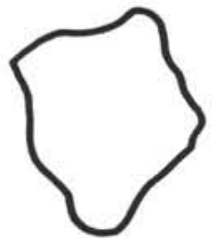

Sub-angular

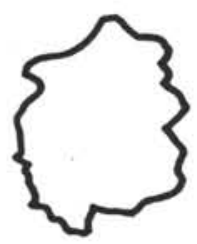

Angular

Figure B-3. Grain-shape comparitor

Steps in Using the Granular-Sediment Classification

The first step in the use of the granular-sediment classification scheme is to estimate the relative proportions of pelagic, neritic, siliciclastic, and volcaniclastic grains within a sample. This can be achieved by a variety of methods, most usually by visual examination of smear slides or thin sections, but also aided by "carbonate-bomb" analysis, $\mathrm{X}$-ray diffractometry, SEM imagery, and other available techniques. The relative proportions of the four grain-types should total $100 \%$, but may total to less than $100 \%$ if non-granular components (e.g., cements) have also been estimated. In the latter case, the relative proportions of the three grain-types should be normalized to $100 \%$.

The second step is to plot the relative proportions of pelagic, neritic, siliciclastic, and volcaniclastic grains on the diagram shown in Figure 1, and thereby determine the granular-sediment class of the sample and its appropriate principal name.

The third step is to attach major and minor modifiers before and after the principal name to describe the lithology of the sample in greater detail. Generally, different sets of major and minor modifiers are used for the five sediment classes, according to the following guidelines (Table 1):

For pelagic and neritic sediment, major and minor modifiers that describe the composition of pelagic and neritic grains are listed in order of increasing abundance. In addition, the texture (but not the composition) of associated clastic grains are also listed in order of increasing abundance (Appendix, Examples 1-13).

For siliciclastic and volcaniclastic sediment, major and minor modifiers that describe the composition of siliciclastic or volcaniclastic grains are listed in order of increasing abundance. In addition, the composition of associated neritic and pelagic grains are also listed in order of increasing abundance. Lastly, major modifiers that describe grain fabric, grain shape, and sediment color can also be listed before the compositional modifiers. Grain-fabric modifiers are commonly listed for gravels, while grain-shape modifiers are commonly listed for gravels and sand. Sediment-color modifiers are commonly listed for silt and clay (Appendix, Examples 14-22). 
For mixed sediment, major and minor modifiers that describe the composition of neritic and pelagic grains and the texture (but not the composition) of clastic grains are listed in order of increasing abundance (Appendix, Example 23).

Examples and Comparison with other Classification Schemes

Examples of the classification of granular sediments with this proposed scheme are shown in the Appendix. In this appendix, each sample is classified by means of the proposed classification scheme, the JOIDES classification scheme, and the classification scheme recently proposed by Dean et al. (1985) for deep-sea sediments.

The proposed classification is very similar to the JOIDES classification scheme, for (1) we classify the sediment with a principal name to describe its class and modifiers (qualifiers) to describe their petrographic characteristics in greater detail, (2) we employ the same terms for principal names and modifiers (for pelagic and clastic sediments) that were used in the JOIDES scheme, and (3) we also list the major and minor modifiers in order of increasing abundance.

Our sediment classification scheme differs from the JOIDES scheme in three minor ways. First, we distinguish major from minor modifiers, and place the former before the principal name and the latter after the principal name, while the JOIDES classification scheme places all modifiers (qualifiers) regardless of their proportions before the principal name in order of increasing abundance. Second, we do not allow the use of genetic terms such as pelagic clay, for our sediment classification is descriptive in nature. Third, we allow for the description of other characteristics of granular sediments, in particular grain shape, grain fabric, and sediment color.

The classification scheme proposed here is also very similar to the sediment classification scheme for deep-sea sediment proposed by Dean et al. (1985), for we use a principal name to describe the sediment class and major and minor modifiers to describe their petrographic characteristics. We differ from Dean et al. (1985) in one minor regard, the location relative to the principal name of the minor modifiers--we place them after the principal name (with the prefix with), but Dean et al. (1985) places them before the principal name (with the suffix -bearing).

Our sediment classification scheme does differ from both the JOIDES and the Dean classification scheme in one major way: the classification of neritic sediments. Neither the JOIDES nor the Dean classification scheme includes a formal classification scheme for coarse-grained carbonates. This has often led to confusion and disagreement among shipboard parties as they sought to improvise such a classification scheme when coarse-grained carbonate rocks were encountered, and resulted in variations in sediment classification between legs.

\section{CLASSIFICATION OF CHEMICAL SEDIMENTS}

Chemical sediment is composed of minerals that formed by inorganic processes such as precipitation from solution or colloidal suspension, 
deposition of insoluble precipitates, or recrystallization of detrital evaporites and siliceous, calcareous, or carbonaceous (plant) biogenic debris, and generally has a crystalline (i.e., non-granular) texture.

There are five classes of chemical sediments: carbonaceous sediments, evaporites, silicates, carbonates, and metalliferous sediments. Each class of chemical sediment has its own distinctive classification scheme.

\section{Carbonaceous Sediments}

Carbonaceous sediments are composed of greater than $50 \%$ organic remains, principally plant and algal remains, that has been altered by carbonization, bituminization, or putrification from its original form. The two most common varieties of carbonaceous sediments are the coal series and sapropels.

The coal series is classified according to rank. Four ranks are recognized and used as principal names:

1. peat: soft, earthy organic debris with recognizable plant fragments;

2. brown coal: few recognizable plant fragments, but coal is soft, dull and brown;

3. bituminous coal: black and hard, with bright layers, and breaks into cuboidal fragments, along cleats; and

4. anthracite coal: bright and lustrous, with conchoidal fractures.

Sapropel is a jelly-like ooze or sludge which is principally composed of algal remains and which accumulates in anaerobic environments; its lithified equivalent is sapropelitic coal. There is no formal classification for sapropels and sapropelitic coal in this classification scheme.

The principal name of the coal series and sapropels can be modified by terms that describe non-carbonaceous components such as clastic detritus (e.g., muddy peat, clayey sapropel).

Oil shales, asphalt sands, and tar sands are best classified as clastic sediments, for the oil, asphalt, and tar are cements (albeit poor ones).

\section{Evaporites}

Evaporites are composed of minerals produced from a saline solution that became concentrated by evaporation of the solvent. The evaporites are classified according to their mineralogy using terms such as halite, gypsum, and anhydrite. They may be modified by terms that describe their structure or fabric, such as massive, nodular, nodular-mosaic and chicken-wire.

\section{Silicates/Carbonates}

Silicates and carbonates are defined as sedimentary rocks that are non-granular and non-biogenic in appearance and composed of silicates and carbonate minerals. Silicates and carbonate may have formed from the recrystallization of siliceous and calcareous grains, but are distinguished by the absence of clearly identifiable granular and biogenic components. 
They may also form as primary precipitates, as in the case of dolomite or proto-dolomite, or as hydrothermal alteration products, such as in the case of zeolites. They are classified according to their mineralogy, using principal names such as chert (microcrystalline quartz) or porcellanite (a softer, less dense variety of chert), calcite, and dolomite. They should also be modified with terms which describe their crystalline (as opposed to granular) nature, such as crystalline, microcrystalline, massive, and amorphous.

\section{Metalliferous Sediments}

Metalliferous sediments are a broad category of non-granular non-biogenic sedimentary rocks that includes pyrite, goethite, manganese, chamosite, glauconite, and other metal-bearing minerals. They are classified according to their mineralogy.

\section{REFERENCES}

Dean, W. E., Leinen, M. and Stow, D.A.V., 1985. Classification of deep-sea fine-grained sediments. Jour. Sed. Petrology, 55(2):250-256.

Dunham, R., 1962. Classification of carbonate rocks according to depositional texture. In Ham, W.E. (Ed.), Classification of Carbonate Rocks. Tulsa, Amer. Assoc. Petrol. Geol., 108-121.

Fisher, R. V., and Schmincke, H.-U., 1984. Pyroclastic rocks. Berlin (Springer-Verlag), $472 \mathrm{p}$.

Ross, D. A., Neprochnov, Y. P., and Supko, P. R., 1978. Introduction and explanatory notes, Leg 42B, Deep Sea Drilling Project. In Ross, D. A., Neprochnov, Y. P., et al., Init. Repts. DSDP, 42(2): Washington (U.S. Govt Printing Office), 3-15.

Shepard, F., 1954. Nomenclature based on sand-silt-clay ratios. Jour. Sed. Petrology, 24:151-158.

Wentworth, C.K., 1922. A scale of grade and class terms for clastic sediments. Jour. Geology, 30:377-392.

\section{APPENDIX TO THE SEDIMENT CLASSIFICATION SCHEME EXAMPLES OF GRANULAR-SEDIMENT CLASSIFICATION}

PELAGIC SEDIMENTS

Example 1. Firm, fine-grained sediment composed of $100 \%$ nannofossils.

Proposed classification: nannofossil chalk

JOIDES classification: nannofossil chalk

Dean et al. (1985) classification: nannofossil chalk

Example 2. Firm, fine-grained sediment composed of $100 \%$ diatoms.

Proposed classification: diatomite

JOIDES classification: diatomite

Dean et al. (1985) classification: diatomite

Example 3. Soft, fine-grained sediment composed of $60 \%$ nannofossils and $40 \%$ diatoms.

Proposed classification: diatom nannofossil ooze

JOIDES classification: diatom nannofossil ooze

Dean et al. (1985) classification: diatom nannofossil ooze

$* * *$ Note that the composition of the pelagic grains are listed in

order of increasing abundance. 
Example 4. Firm, fine-grained sediment composed of $30 \%$ diatoms, $50 \%$ radiolarians, and $20 \%$ mollusc shells.

Proposed classification: diatom radiolarite $w /$ bioclasts JOIDES classification: bioclast diatom radiolarite

Dean et al. (1985) classification: bioclast-bearing diatom radiolarite

***Note that bioclasts are not clearly distinguished as a minor component in the JOIDES classification.

Example 5. Hard, fine-grained sediment composed of $60 \%$ forams, $5 \%$ diatoms, and $35 \%$ quartz-silt.

Proposed classification: silty foram limestone

JOIDES classification: silty foram limestone

Dean et al. (1985) classification: silty foram limestone

$* * *$ Note that diatoms, present in proportions of $5 \%$, are not noted in the proposed classification. Also, note that the texture but not the composition of the clastic grains is noted.

Example 6. Soft, fine-grained sediment composed of $100 \%$ unspecified carbonate grains.

Proposed classification: calcareous ooze

JOIDES classification: calcareous ooze

Dean et al. (1985) classification: calcareous ooze

Example 7. Soft, fine-grained sediment composed of $95 \%$ unspecified siliceous grains and $5 \%$ diatoms.

Proposed classification: siliceous ooze

JOIDES classification: siliceous ooze

Dean et al. (1985) classification: siliceous ooze

Example 8. Firm, fine-grained sediment composed of $65 \%$ forams, $20 \%$ ash, and $15 \%$ radiolarians.

Proposed classification: foram chalk w/radiolarians and ash JOIDES classification: ashy radiolarian foram chalk

Dean et al. (1985) classification: rad-bearing, ash-bearing foram chalk

***Note that ash and radiolarians are not clearly distinguished as

minor components in the JOIDES classification.

Example 9. Hard, fine-grained sediment composed of $65 \%$ diatoms and $35 \%$ clay. Proposed classification: clayey diatom chert

JOIDES classification: clayey diatom chert

Dean et al. (1985) classification: clayey diatom chert

NERITIC SEDIMENTS

Example 10. Grain-supported carbonate rock with intergranular mud; grains are composed of $60 \%$ ooids and $40 \%$ bioclasts.

Proposed classification: bioclast ooid packstone

JOIDES classification: no formal classification

Dean et al. (1985) classification: no formal classification

Example 11. Matrix-supported carbonate rock with $30 \%$ intraclasts.

Proposed classification: intraclast wackestone

JOIDES classification: no formal classification

Dean et al. (1985) classification: no formal classification

Example 12. Grain-supported carbonate rock with no mud; grains are composed of $40 \%$ peloids, $30 \%$ pellets, $20 \%$ bioclasts, and $10 \%$ quartz-sand. Proposed classification: pellet peloid grainstone w/sand and bioclasts JOIDES classification: no formal classification

Dean et al. (1985) classification: no formal classification $* * *$ Note that the composition of the sand grains is not noted. 
Example 13. Carbonate rock with $60 \%$ micrite (low-Mg calcite), $30 \%$ quartzsilt, and $10 \%$ forams.

Proposed classification: silty calcareous mudstone w/forams

JOIDES classification: no formal classification

Dean et al. (1985) classification: no formal classification

\section{SILICICLASTIC SEDIMENTS}

Example 14. Sediment with $100 \%$ sand, composed of well-rounded quartz-grains. Proposed classification: rounded quartz sand or quartz sand

JOIDES classification: quartz sand

Dean et al. (1985) classification: quartz sand

***The term rounded is optional to the new classification scheme.

Note also that the composition of clastic grains is only used as a modifier in the classification of siliciclastic sediments.

Example 15. Hard sediment with $70 \%$ medium and $30 \%$ fine sandstone, composed of quartz $(60 \%)$, feldspar $(30 \%)$ and mica $(10 \%)$.

Proposed classification: feldspar quartz fine-medium sandstone w/mica JOIDES classification: mica feldspar quartz sandstone

Dean et al. (1985) class: mica-bearing feldspar quartz sandstone

***Note that mica is not clearly distinguished as a minor component in the JOIDES classification.

Example 16. Sediment with $80 \%$ gravel composed of gneissic rock fragments, and $20 \%$ intergranular sand composed of quartz.

Proposed classification: grain-supported gneissic gravel w/quartz-sand JOIDES classification: sandy gneissic gravel

Dean et al. (1985) classification: sand-bearing gneissic gravel

$* * *$ Generally, both the composition and texture of the matrix in coarse-grained siliciclastic sediments are noted.

Example 17. Hard sediment with $50 \%$ clay, $35 \%$ quartz-silt, and $15 \%$ forams, red in color.

Proposed classification: red silty claystone w/forams

JOIDES classification: foram silty claystone

Dean et al. (1985) classification: foram-bearing silty claystone

$* * *$ Note that the term red is optional to the new classification scheme.

Example 18. Hard sediment with $60 \%$ sand-sized volcanic rock fragments (non-pyroclastic in origin) and $40 \%$ bioclasts.

Proposed classification: bioclast volcanic sandstone

JOIDES classification: bioclast volcanic sandstone

Dean et al. (1985) classification: bioclast volcanic sandstone

Example 19. Sediment with $60 \%$ quartz-silt and $40 \%$ ash.

Proposed classification: ashy quartz silt

JOIDES classification: ashy quartz silt

Dean et al. (1985) classification: ashy quartz silt

\section{VOLCANICLASTIC SEDIMENTS}

Example 20. Sediment with $100 \%$ basaltic rock fragments of volcaniclastic origin and greater than $64 \mathrm{~mm}$ in diameter.

Proposed classification: lithic breccia or basaltic breccia

JOIDES classification: lithic breccia

Dean et a1. (1985) classification: no formal classification

Example 21 . Sediment with $80 \%$ fine-grained volcanic glass and $20 \%$

nannofossils.

Proposed classification: vitric ash w/nannofossils

JOIDES classification: nannofossil vitric ash

Dean et al. (1985) classification: nannofossil-bearing vitric ash 
Example 22. Sediment with $40 \%$ fine-grained volcanic glass, $35 \%$ sand, and $25 \%$ smectite clay.

Proposed classification: sandy vitric ash w/smectite clay JOIDES classification: clayey sandy vitric ash

Dean et al. (1985) classification: no formal classification

$* * *$ Note that the total proportion of clastic grains is $75 \%$, but that volcaniclastic grains (glass) exceeds siliciclastic grains (sand) in abundance.

\section{MIXED SEDIMENTS}

Example 23. Soft sediment with $45 \%$ nannofossils, $35 \%$ quartz-sand, and $20 \%$ shell debris.

Proposed classification: sandy nannofossil mixed sediment w/bioclasts JOIDES classification: marly nannofossil ooze

Dean et al. (1985) classification: no formal classification

$* * *$ Note that the composition of the sand grains is not noted. 
APPENDIX C. DESCRIPTION OF IGNEOUS AND METAMORPHIC ROCKS

\section{A. Introduction}

Igneous rocks are classified mainly on the basis of mineralogy and texture. When describing the cores, a checklist of macroscopic features is followed to ensure consistent and complete descriptions. Two checklists, one for extrusive rocks and dikes and one for plutonic rocks, are presented below. These checklists have been used successfully on ODP Legs 106, 109, 111,115 , and 118 to date.

There are two forms used for the description of hard rocks: one for macroscopic description of cores and one for description of thin sections. A continuation sheet can be used with either form. The data on these forms go directly into a computerized database that is accessible to the entire scientific community. When scientists use abbreviations on these forms, it is necessary that the abbreviations be clearly identified the first time they are used on the barrel sheets.

Figures C-1 and C-2 are examples of completed Igneous/Metamorphic Visual Core Description forms. 
Pieces 1-3

CONTACTS: Azimuth 045. Dip $85^{\circ}$. Intruded by chill of lithologic Unit 152; Unit 151 not chilled.

PHENOCRYSTS: Random but fairly homogeneous distribution throughout unit. Occur as single crystals. Plagioclase - 1-2\%; 0.5-3.0 mm; euhedral, few subhedral; fresh(?). Clinopyroxene $-3 \% ; 1-2.5 \mathrm{~mm}$; euhedral-subhedral; fresh. Olivine $-3 \% ; 0.5-2.0 \mathrm{~mm}$; subhedral; altered either entirely or up to $60 \%$ to chlorite (+ oxide?). Olivines appear to alter margins inward.

GROUNDMASS: Uniformly fine grained.

COLOR: Light gray.

VESICLES: Non vesicular.

STRUCTURE: Massive.

ALTERATION: Relatively fresh (slightly altered), minor chloritization and minor $(<1 \%)$ pyrite in $0.5 \mathrm{~mm}$ patches. VEINS/FRACTURES: No marked alteration halos, veins comprise approximately $4 \%$ of unit. Pieces $1 \mathrm{~A}$ and $1 \mathrm{~B}-$ minor low-angle fractures, approximately $0.5 \mathrm{~mm}$ with chlorite/clays(?) plus possible laumontite or anhydrite(?) in Piece 1B. One small open fracture in Piece $1 \mathrm{~B}$.

\section{UNIT 152: HIGHLY OLIVINE-CLINOPYROXENE-PLAGIOCLASE PHYRIC BASALT}

Pieces 1-3

CONTACTS: Azimuth 045, runs through Pieces 1A-3.

Dip $85^{\circ}$.

Intrusive chilled against lithologic Unit 151 (hatched), extreme marginal $2 \mathrm{~mm}$ possibly glassy.

PHENOCRYSTS: Highly porphyritic, approximately $35 \%$ phenocrysts. Appear to be more concentrated towards chill margin. Occur generally singly but also in few glomerocrysts.

Plagioclase - 18-20\%; 0.5-3.0 mm; subhedral, larger ones possibly round; fresh.

Clinopyroxene - $13-15 \% ; 0.5-8.0 \mathrm{~mm}$; generally euhedral with some bladed; light green color; fresh.

Olivine $-2-4 \% ; 0.3-1.0 \mathrm{~mm}$; originally subhedral; altered to chlorite with associated oxide and pyrite.

GROUNDMASS: Uniformly very fine grained, extreme chill virtually glassy.

COLOR: Dark gray to black.

VESICLES: Nonvesicular.

STRUCTURE: Fairly massive.

ALTERATION: Fresh, 5-10\%(?) chloritized, slightly altered.

VEINS/FRACTURES: Low angle, short $2-3 \mathrm{~cm}, 1 \mathrm{~mm}$ fractures with chlorite/hematite filling. No halos.

\section{UNIT 153: SPARSELY TO HIGHLY OLIVINE-CLINOPYROXENE-PLAGIOCLASE PHYRIC BASALT}

Pieces 4-19

CONTACTS: Not seen. However, phenocryst content and proportion suggest unit may be continuation of Unit 152. See contact relations described in Unit 152.

PHENOCRYSTS: Diminish from about $15 \%$ in Pieces $4-7$ to $2-5 \%$ in Pieces $11-13$ to $1 \%$-virtually absent in Pieces 16-17B.

Generally occur singly with few plagioclase glomerocrysts (e.g., Piece 5).

Plagioclase $-0-8 \%$ (as in proportions above); $0.5-3.0 \mathrm{~mm}$, subhedral, fresh.

Clinopyroxene $-0-7 \%$ (as in proportions above); $0.5-3.0 \mathrm{~mm}$, euhedral-subhedral, some places good bladed prisms, fresh.

Olivine $-1-2 \%$ overall but apparently increasing with depth as other phenocryst assemblages decrease in quantity, $0.5 \mathrm{~mm}$ average but generally smaller towards bottom of unit; subhedral, totally altered to chlorite and pyrite.

GROUNDMASS: Very fine grained.

VESICLES: Nonvesicular.

COLOR: Light greenish gray.

STRUCTURE: Brecciated: Breccia fragments angular to rounded, vary in size from $\mathrm{mm}$ size to $5 \mathrm{~cm}$. Some fragments apparently originally glassy. Most very fine-grained (chilled margin?) material. Matrix: fine-grained chloritized material (possibly finely comminuted groundmass or possibly chilled basalt?). Piece 15 has definite chilled margin running vertically in core but might be portion of larger fragment.

ALTERATION: Moderately altered to mottled light greenish gray color throughout. All fragments have $0.25-5 \mathrm{~mm}$ alteration rims, light gray in color. Olivine replaced totally to chlorite \pm pyrite.

VEINS/FRACTURES: $15 \%$ filled veins. Virtually zero open fractures. Veins from $0.1-2 \mathrm{~mm}$ wide, filled with chlorite and traces of sulfides. 
1. Fine-grained and Medium-grained Extrusives and Dikes

Knter leg, site, hole, core number and type, and section information. Draw the graphic representation of the core; mumber the rock pieces; and record positions of shipboard samples.

Subdivide the core into lithologic units, using the criteria of changing grain size, occurrence of glassy margins, and changes in petrographic type and phenocryst abundances.

For each lithologic unit, answer the following:

A.1. Enter uNIT number (consecutive downhole), including piece numbers of top and bottom pieces in unit.

A.2. ROCX NAMB (to be filled in last).

A.3. CONTACT type (e.g., intrusive; discordant; depositional, etc.). Note the presence of glass and its alteration products (in\%), give the azimuth and dip of the contact.

A.4. PHINOCRYSIS: determine if homogeneous or heterogeneous distribution; if heterogeneous distribution, note variations.

For each phenocryst phase determine:

i. abundance (\%).

ii. average size in $\mathrm{mm}$.

iii. shape.

iv. percent degree of alteration and replacing phases and their relationships.

v. further comments

vi. fill in A.2. Rock name (see footnote naming basalts).

A.5. GROUNmass texture: glassy, microcrystalline, fine-grained ( $<1 \mathrm{~mm})$ or medium-grained $(1-5 \mathrm{~mm})$. Note the relative grain size changes within the unit (e.g., coarsening from Piece 1 to Piece 5).

A.6. COrOR (dry).

A.7. VESICLES: give percent, size, shape, fillings and their relationships (include $\%$ of vesicles that are filled by alteration minerals), and distribution.

Miaroles: give percent, size, shape, distribution.

A.8. SIRUCIURB: massive, pillow lava, thin flow, breccia, etc., and comments.

A.9. AITKRATION: fresh ( $2 \%$ altn); slightly ( $2-10 \%$ altn), moderately (10-40\% altn), highly (40-80\% altn), very highly (80-95\% altn) or completely (95-100\% altn) altered. Type, form, and distribution of alteration.

A. 10. VRTNS/FRACIURRS: percent present, width, orientation, fillings and relationships, halos.

Basalts are termed aphyric, sparsely phyric, moderately phyric, or highly phyric, depending upon the proportion of phenocrysts visible with the hand lens or binocular microscope (approximately xl0). Basalts are called aphyric if phenocrysts clearly amount to less than $1 \%$ of the rock, sparsely phyric if phenocryst content ranges from $1 \%-2 \%$, moderately phyric at 2\%-10\%, and highly phyric if phenocrysts amount to more than $10 \%$ of the rock. Basalts are further classified by phenocryst type (e.g., a moderately plagioclase-olivine phyric basalt contains $2 \%-10 \%$ phenocrysts, most of them plagioclase, but with some olivine). 


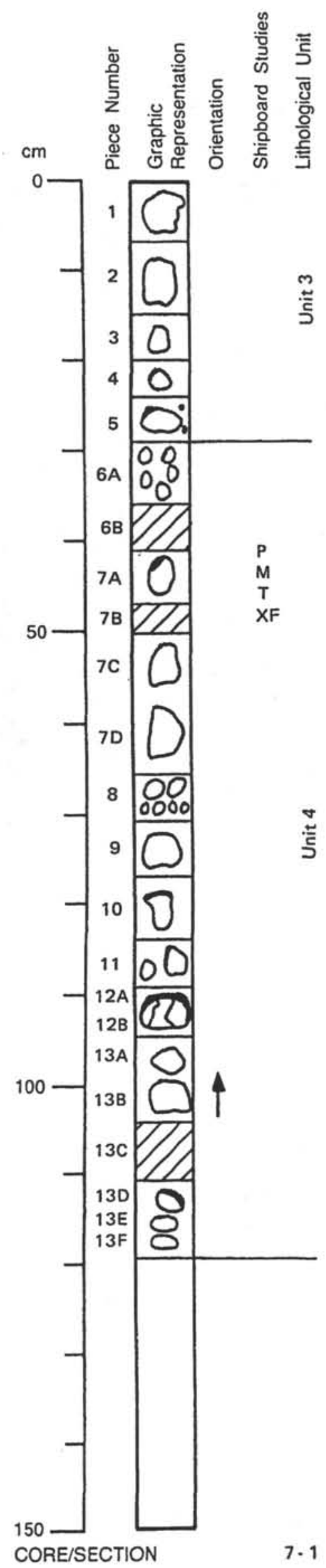

\section{$109-670 A-7 R-1$}

UNIT 4: serpentinite

PIECES 6-13: serpentinite

COLOR: black and white mottled

LAYERING: not apparent

DEFORMATION: possible shear zones between Pieces 7A and 7C and between 13B and 13D; parts of Piece 6 were embedded in sheared matrix material. Material was removed and placed with Pieces 7B, 13C, and 6B, respectively

Piece 6 - serpentine-rich material consisting of massive light green fibers surrounding pieces

Pieces $7 \mathrm{~A}$ and $7 \mathrm{C}$ - separated by a massive serpentine vein approximately $1.5 \mathrm{~cm}$ thick consisting of light green serpentine needles $>1 \mathrm{~cm}$ in length; both pieces contain talc + serpentine-rich layer on one side which defines the boundary of the shear zone

Piece 13 - massive serpentine-rich zones between Pieces 13A, 13B, and 13D similar to those found between $7 A$ and $7 C$

No apparent foliation defined by elongate minerals

PRIMARY MINERALOGY:

Olivine - mode: $95 \%$

crystal size: indeterminate in hand specimen

crystal shape: cannot be determined in hand specimen

preferred orientation: not apparent

percent replacement: $100 \%$ with serpentine, talc, and magnetite

Orthopyroxene - mode: $4-5 \%$

crystal size: $2-6 \mathrm{~mm}$

crystal shape: round

preferred orientation: not apparent

percent replacement: as much as $90 \%$ with serpentine + talc

Spinel - mode: $1-<1 \%$

crystal size: $<1 \mathrm{~mm}$

crystal shape: round to elliptical

preferred orientation: Piece 10 defined by long axes of elliptical spinel

grains

percent replacement: as much as $10 \%$, rimmed with magnetite

Clinopyroxene (Piece 9) - mode: $<1 \%$

crystal size: $4 \mathrm{~mm}$

crystal shape: round

preferred orientation: not apparent

percent replacement: $0 \%$, fresh

SECONDARY MINERALOGY:

Total percent - as much as $99 \%$

Texture - olivine replaced by alternating bands of dark and light secondary phases, orthopyroxene pseudomorphed by bastite and rimmed by talc, spinel rimmed by magnetite

Percent vein material - as much as $5 \%$ in rock pieces, $1 \mathrm{~mm}$ to $2 \mathrm{~cm}$ thick

Vein material - white talc veins as wide as $1 \mathrm{~mm}$, blue-green opaline

serpentine veins $2 \mathrm{~mm}$ wide, rich veins in Pieces $6-7$ and 13 (see

deformation section for description)

NOTE; Shading on graphic representation denotes freeze-dried vein material in correct stratigraphic position.

Figure C-2. 


\section{Coarse-grained Plutonics}

Knter leg, site, hole, core number and type, and section information. Draw the graphic representation of the core; mumber the rock pieces; and record positions of shipboard samples.

Subdivide the core into lithologic units.

For each lithologic unit, answer the following:

B.1. Enter unIr number (consecutive downhole), including piece numbers of top and bottom pieces in unit.

B.2. ROCX NAMB (to be filled in last).

B.3. COTOR (dry).

B.4. IAYRRTIG:

i. If massive, non-layered, or isotropic, skip to B.5.

ii. average thickmess of different layer types.

iii. azimuth and dip of layering.

iv. types of layering (modal, phase, grain size, graded, rhythmic, cyclic).

v. sequence of layers and relative abundance.

vi. layer contacts (sharp, abrupt, smooth, gradational, undulating, rough).

B.5. DEFORLAITIN; if rock is deformed, note:

i. nature and inclination of faults, folds, shear and/or brecciated zones.

ii. nature and inclination of foliations and lineations.

iii. features that define the foliation or lineation.

iv. grain size variations due to granulation and/or recrystallization.

B.6. PRTMARY MINKRAIOGY, includes intergranular and granular phases. Note

for each phase, in order of modal abundance:

i. modal percent.

ii. range of crystal sizes.

iii. crystal shapes.

iv. preferred orientations.

v. percent replacement with what?

B.7. SBCONDARY MTNKRAIOGY.

i. total percent secondary phases.

ii. textures of secondary phases.

iii. vein material: note total percent vein material, average vein thickness, types and textures of filling.

\section{B.8. Note additional features.}

Whenever possible, peridotites are classified according to their primary mineralogy. If no primary minerals can be identified because of extensive serpentinization, the serpentinized peridotites are called serpentinites. In the case of partially serpentinized samples, the term "serpentinized" is used to modify the rock name (e.g., "serpentinized harzburgite"). In some serpentinites, serpentine minerals closely pseudomorph primary minerals (e.g., lizardite replacing orthopyroxene in bastite). The primary mineralogy of these samples is estimated from the abundances of various pseudomorph types. 


\section{B. Instructions for Thin Section Description Form}

Figure C-3 shows an example of a completed Thin Section Description Form. This form accommodates both igneous (extrusive and intrusive) and metamorphic rocks. "Rock names" are derived using the I.U.G.S. classification system (I.U.G.S. Subcommission on the Systematics of Igneous Rocks, 1973). Rock "texture" and "grain size" descriptions are derived using terms defined at the end of this appendix. For porphyritic rocks, enter the grain size of the groundmass. The "Where Sampled" field is for indicating whether the sample was taken from a flow interior, chilled contact (intrusive, extrusive), pillow interior, massive unit, cumulate layer.

The "Phenocrysts" and "Groundmass" fields are divided into columns. "Groundmass" is used as the prime entry for equigranular rocks as well as for the groundmass of porphyritic rocks. If phenocrysts present in the rock are not listed, add them to the form; if phenocrysts named on the form are not present, cross them out.

The "Present \% Mineralogy" column refers to mineralogy that exists at the time of description, including vein, cavity, and vesicle fillings. The modal percentage of current minerals, including secondary mineralogy, must total 100\%. The "Original \% Mineralogy" column refers to percentages of minerals that were originally present (pre-alteration). Observations such as intergranular relationships and alteration can be written under

"Comments." If the rock is a cumulate, indicate which minerals make up the cumulus phases.

The "Secondary Mineralogy" section is for information on what mineral is being replaced or whether the secondary mineral fills a vein or vesicle. Information on mineral associations, distributions, size ranges, and morphology of secondary minerals can be written in this "Comments" field. The percentage, size range in $\mathrm{mm}$, location, filling, and shape of vesicles and/or cavities can be entered in the "Vesicles/Cavities" field.

\section{Iithologic Units - Basalts}

The following information is used in the "Structure" field of the Visual Core Description form.

1. Massive units: The core is commonly affected little by drilling and is recovered in long intact pieces.

2. Dikes: Units with one or two chilled intrusive margins.

3. Sheet flows: Units characterized by parallel, closely-spaced (under $0.5 \mathrm{~m}$ apart), mainly horizontal, flat glassy selvages, distinct from the rounded or inclined margins of pillow units.

4. Thin flows: Units recognized by homogeneous areas of core in excess of $1 \mathrm{~m}$ thick (i.e., thicker than the average pillow), formed by fine grained basalts.

5. Pillow basalts: all core remaining after the preceding lithologic types have been identified. These are characterized by chilled pillow margins (mostly curved or inclined), hyaloclastic breccias, and finegrained, often highly fractured rocks. 
ODP

THIN SECTION DESCRIPTION IGNEOUS / METAMORPHIC ROCKS

\begin{tabular}{|c|c|c|c|c|c|c|c|c|c|c|}
\hline \multirow[b]{2}{*}{ LEG } & \multirow{2}{*}{\begin{tabular}{|l|} 
\\
S \\
B
\end{tabular}} & \multirow[b]{2}{*}{ SITE } & \multirow{2}{*}{\begin{tabular}{|c|c} 
\\
0 \\
L \\
E
\end{tabular}} & \multirow[b]{2}{*}{ CORE } & \multirow{2}{*}{\begin{tabular}{|l|l|} 
\\
$y$ \\
$y$ \\
$p$
\end{tabular}} & \multirow[b]{2}{*}{ SEC } & \multicolumn{2}{|c|}{ INTERVAL } & \multirow{2}{*}{$\begin{array}{c}\text { PIECE } \\
\text { No. }\end{array}$} & \multirow[b]{2}{*}{ OBSERVER } \\
\hline & & & & & & & TOP & воттом & & \\
\hline 16 & & 50 & A & 20 & $\mathrm{R}$ & 4 & 220 & 25 & $15 \mid \mathrm{C}$ & J. Smith \\
\hline
\end{tabular}

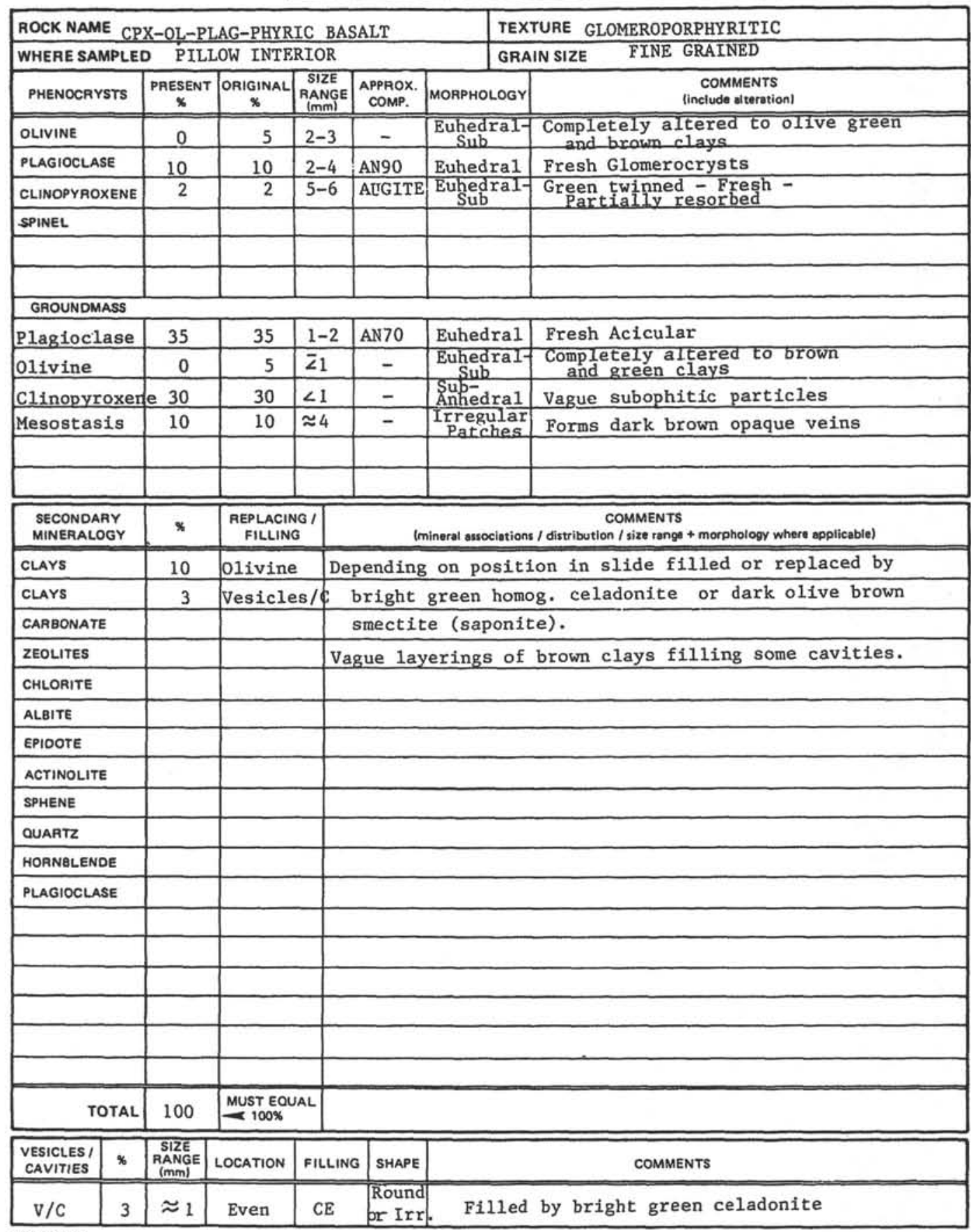

COMMENTS

Vein disects slide, but contents lost during slide preparation. Brown clays can be seen against wall in some areas.

These data are to be processed into a computerized dato base along with existing standardized data from other legs and will be accessible to the scientific community at larpe. RECORD ALL MEASUREMENTS CAREFULLY, COMPLETELY, and LEGIBLY. 
Additional lithologic types can be defined, or the definitions above modified. In either case, it is extremely important to record the characteristics of each lithologic type, so that lithologies from different holes and different legs can be compared.

D. Terminology and Definitions (Jackson, 1970; AGI, 1980; Dictionary of Petrology, 1983)

1. IGNEOUS TERMS

Aphanitic:

Microcrystalline:

Cryptocrystalline:

Glassy or Hyaline:

Phaneritic:

Coarse-grained:

Medium-grained:

Fine-grained:

\section{a. GRATN SIZE}

A uniform texture in which individual crystals are invisible to the unaided eye.

The texture of a rock having crystals that are small enough to be visible under a microscope. The texture of a rock having crystals too small to be resolved optically, although an aggregate birefringence may be evident. The material is glass, in practice seldom completely free of crystalitites and/or microlites.

A texture in which individual crystals are readily visible to the unaided eye. Crystals are larger than $5 \mathrm{~mm}$ in diameter. Crystals range from 1 to $5 \mathrm{~mm}$ in diameter. Crystals are visible but less than $1 \mathrm{~mm}$ in diameter.

\section{b. DEGREE OF CRYSTALITNITY}

Holohyaline:

Rocks which are completely glassy and lack megascopic crystals.

Hypohyaline/hypocrystalline: Rocks composed of crystals and glass; hypohyaline is dominantly glass, hypocrystalline is dominantly crystal.

Holocrystalline: Rocks composed entirely of crystals.

\section{c. SHAPE OF INDIVIDUAL CRYSTAIS}

Euhedral:

Subhedral:

Anhedral:
A crystal completely bounded by its own faces. A crystal bounded in part by its own faces and in part by surfaces developed through mutual interference of adjacent crystals.

A crystal not bounded by its own crystal faces but whose form is impressed on it by adjacent crystals.

\section{d. ROCK TEXIURES DEFTNED BY STNGIE-CRYSTAL SHAPES}

Panidiomorphic-granular:

Hypidiomorphic-granular:
The texture of a rock composed essentially of euhedral crystals.

The texture of a rock composed of a mixture of anhedral and either subhedral or euhedral crystals or both. 
Allotriomorphic-granular: The texture of a rock composed entirely of anhedral crystals. Aplitic texture usually implies fine grain size and sugary texture.

\section{e. INCIPIENT CRYSTALS}

Crystallites:

Microlites:

Skeletal crystals:
The most rudimentary form of crystals, as yet too small to have distinct mineral properties. They are seen microscopically as gramules, rods, hairs, and dendritic or feathery objects. Globulites are spherical crystallite commonly found in volcanic glass.

Incipient crystals large enough to have identifiable mineral properties, although still of microscopic size. The aphanitic groundmass of extrusives is usually composed of crystals of microlite size.

Incompletely formed crystals in which the faces of maximum growth rate have developed leaving hollow or hopper-shaped interiors.

\section{f. POSTSOIUIIFICATION FEATURES OF GLASSES}

Perlitic structure:

Devitrification:

Sphervilitic structure:

Variolitic:

Iithophysae:
Concentric shelly cracks that develop in some glasses.

The slow process of reorganization of a glass into crystals, usually of very small size. Spherical bodies from microscopic size to many feet in diameter which consist of radiating fibers and plates.

A texture found in basic rocks in which the spherulites consist of minute, radiating fibers of plagioclase with interstitial glass, augite, olivine, or magnetite. Rocks with a variolitic structure frequently have a pitted or spotted appearance.

Spherulites which consist of concentric shells with hollow interspaces. The cavities are often lined with minute crystals of quartz, tridymite, cristobalite, feldspars, or fayalite.

\section{g. PORPHYRITIC TEXITURES}

Glomeroporphyritic texture: Intersertai:

Microlitic:
Clumps of phenocrysts.

Said of the texture of a porphyritic igneous rock in which the groundmass, composed of a glassy or partly crystalline material other than augite, occupies the interstices between unoriented feldspar laths.

A texture found in porphyritic rocks having a microcrystalline groundmass which is composed mainly of more or less euhedral, tabular, or prismatic crystals. 


\section{h. VESICUIAR STRUCIURES}

Scoriaceous structure:

Pumaceous structure:

Amygdaloidal structure:

Miarolitic structure:

Orthocumulate:

Mesocumulate:

Adcumulate:
A highly vesicular structure similar to cinder. Gas cavities are numerous and roughly equidimensional, separated by thin walls of glass or aphanitic material.

A rock froth, excessively cellular and usually having very thin glass walls separating the gas bubbles.

Rocks in which gas cavities have subsequently been filled with introduced mineral material. Small angular gas cavities in phaneritic rocks into which crystals of the rock-forming minerals project.

\section{i. CUMUIATE TEXXIURES}

A cumulate composed chiefly of one or more cumulus minerals plus the crystallization products of the intercumulus liquid.

A cumulate containing a small amount of intercumulus material.

A cumulate containing less then 5\% intercumulus material. Formed by continuous growth of cumulus crystals from the interstitial liquid.

j. OTHER TEXIURAL FEATURES

Cataclastic textures:

Corona structure: =reaction rim

Dendritic:

Fluidal textures:

Fusiform:

Intergranular:

Mesostasis:

Ophitic:

Poikilitic:
Textures developed by the mechanical crushing of rock or mineral grains.

A zone of one mineral surrounding another. The rim may be complete or partial.

Said of a mineral that has crystallized in a branching pattern.

An alignment of elements of the rock as a result of liquid flow.

Shaped like a spindle, i.e., tapering toward each end from a swollen middle.

Said of the ophitic texture of an igneous rock in which the augite occurs as an aggregation of grains, not in optical continuity. The last formed interstitial material, either glassy or aphanitic, of an igneous rock.

Said of the holocrystalline, hypidiomorphicgranular texture of an igneous rock (esp. diabase) in which lath-shaped plagioclase crystals are partially or completely included in pyroxene crystals, typically augite. Subophitic implies partial inclusion. The texture of an igneous rock in which small grains of one mineral are irregularly scattered without common orientation in a typically anhedral larger crystal of another mineral. 
Protoclastic:

Symplectic:

Trachytic:

Diabase/dolerite:

Hypermelanic:

Mesotype:

2. METAMORPHIC TERMS

Idioblastic:

Xenoblastic:

Prismatic:

Acicular:

Bladed:

Tabular:

Lenticular:
Said of igneous rocks in which the earlier formed crystals have been broken or deformed due to differential flow of the magma before complete solidification.

Said of a rock texture produced by the intimate intergrowth of two different minerals.

A textural term applied to volcanic rocks in which feldspar microlites of the groundmass have a subparallel arrangement corresponding to the flow lines of the lava from which they were formed.

\section{k. MISCETIANEOUS}

An intrusive igneous rock whose main components are labradorite and pyroxene and which is characterized by ophitic texture. An igneous rock that contains 90 to $100 \%$ mafic minerals.

A group of zeolite minerals.

\section{a. MTNERAL FORM}

A crystal of metamorphic origin bounded by its own faces.

A crystal of metamorphic origin not bounded by its own faces.

b. MINERAL SHAPES

One dimension is markedly greater than the other two, forming a prism with or without terminations. Dimensions are on the order of $\mathrm{a}: \mathrm{b}: 3-5 \mathrm{c}$.

Slender needlelike crystals with or without visible crystal faces. Dimensions are usually $a: b: 10-20 c$, where $a$ and $b$ are $a$ fraction of $a$ millimeter.

Three distinctly different demensions, one of which is usually much larger than the other two. Dimensions are usually a:2-3b:5-10c. Two dimensions are markedly greater than the third; the crystal is usually bounded by two flat parallel faces and therefore has a uniform thickness. Dimensions are usually 3-10a:3-10b:c, with $a$ and $b$ either equal or nearly equal.

A lens-shaped crystal, thickest in the middle and tapering at the edges, often to a very thin edge. Dimensions are usually $2-5 a: 2-5 b: c$. 
Equant or equidimensional: All three dimensions are equal or subequal but

Blocky crystals:

the crystal has an irregular shape.

Spherical:

All three dimensions are equal or subequal but the crystal has roughly planar sides.

Equidimensional grains which have rounded

boundaries.

\section{c. METAMORPHIC TEXIURES}

Crystalloblastic textures:

Homeoblastic:

Granoblastic:

Nematoblastic:

Lepidoblastic:

Porphyroblastic:

Poikiloblastic:

Mosaic:

Sutured:

Cataclastic:

Mortar:

Mylonitic:

Porphyroclastic:

Blasto-porphyritic:
A crystalline texture produced by metamorphic recrystallization.

Essential mineral constituents are approximately the same size.

A non-schistose rock with equidimensional crystals.

Development during recrystallization of slender parallel prismatic crystals.

Foliated or schistose rock due to the parallel orientation during recrystallization of minerals with a flaky or scaly habit.

A crystalloblastic texture with two or more distinct grain sizes. The individual large crystals are called porphyroblasts.

A texture in which large porphyroblasts include numerous small crystal grains.

Crystals are equigranular and equidimensional and are generaily polygonal in shape, with simple straight-line or gently curved intergranular boundaries.

Crystals are generally equigranular and equidimensional, or they are lenticular and have highly irregular boundaries and much interpenetration of each grain into its neighbors.

Textures produced by mechanical crushing without essential recrystallization.

A texture consisting of larger mineral fragments set in a groundmass of crushed material derived from the same crystals. A very-fine-grained product of mechanical crushing without recrystallization of the primary minerals.

A cataclastic texture characterized by the presence of large relict mineral grains set in a matrix of smaller crushed grains.

Said of a relict texture in a metamorphic rock in which traces of an original porphyritic texture remain.

\section{d. FOLTATION}

Foliation is the general term used to include all planar textures and structures of metamorphic rocks which were developed during metamorphism. The foliation may be defined by layering of contrasting mineralogies 
(gneissosity), by planar preferred orientations of individual grains (schistosity), by planar fracture surfaces (cleavage), or by any combination of these three. In British terminology foliation is restricted to layering of contrasting mineral assemblages.
e. IINEATION

A general term for the parallel orientation of textural or structural features that are linear.

\section{REFFERENCES}

American Geological Institute, 1980. Glossary of Geology.

Jackson, K.C., 1970. Textbook of Lithology. New York: MoGraw Hill.

Tomkeieff, S.I., 1983. Dictionary of Petrology. New York: John Wiley \& Sons. 
Stone Soup

Acronyms and Abbreviations for the Ocean Drilling Program 
AABW [science] Antarctic Bottom Water AAPG American Association of Petroleum Geologists

ABM assigned board member (of the ERB)

ABS American Bureau of Shipping

ACAD computer-aided drafting (aka AUTOCAD, $\mathrm{CAD}, \mathrm{CADD})$

ACT [logging] neutron porosity (Cf source) logging tool (aluminum clay tool)

AD [drilling] assistant driller

AF [science] alternating field (demagnetization);

[logistics] air freight

AGU American Geophysical Union

AMS [logging] auxiliary logging measurements (temperature, tension)

APC [drilling] advanced hydraulic piston corer

API American Petroleum Institute

ARM [science] anhysteretic remanent magnetization ARP [JOIDES] Atlantic Regional Panel

ASCII [computers] American Standard Code for Information Interchange

ASK [ship] automatic station keeping (see DPS)

AWB [logistics] airway bill for air freight

shipments

AZ [science] acme zone (biostratigraphy)

B.A.S. British Antarctic Survey

bbl [drilling] barrel (unit of measure)

bec blind courtesy copy

BCOM [JOIDES] Budget Committee

BGR Bundesanstalt für Geowissenschaften und

Rohstoffe (Federal Republic of Germany)

BHA [drilling] bottom-hole assembly

BHC [logging] borehole compensated sonic logging tool

BHTV [logging] borehole televiewer downhole tool

B/L [logistics] bill of lading for surface (ocean) freight

BMR Bureau of Mineral Resources (Australia) bomb [curatorial] carbonate analysis (sample designation)

BOP [drilling] blowout preventer

BP British Petroleum

brf [drilling] below rig floor (as in mbrf: meters

below rig floor, by drill-pipe measurement)

BRG Borehole Research Group, Lamont-Doherty Geological Observatory

BRGM Bureau de Recherches Géologiques et Minières (France)

bsf [science] below seafloor (as in mbsf: meters below seafloor) bsl [science] below sea level (as in mbsl: meters below sea level; corrected--using ship's draft--from drill-pipe measurements

BSR [science] bottom-simulating reflector

BT [science] bathythermograph (as in XBT:

expendable bathythermograph)

BVA [drilling] ball-valve assembly

BW [drilling] borehole water

$\mathbf{C}_{\text {org }}$ [science] organic carbon

$\mathrm{C}_{1} / \mathbf{C}_{2}$ [science] methane/ethane ratio

$\mathbf{C}_{6+}$ [science] hexane and higher hydrocarbons

CAD computer-aided design and drafting (aka

AUTOCAD, ACAD, CADD)

CALI [logging] caliper logging tool

cc carbon copy (anachronistic term!)

CCD [science] carbonate compensation depth

CD-ROM [computers] compact disc--read-only

memory

CDS [drilling] colleted delivery system

CEPAC [JOIDES] Central and Eastern Pacific

Panel

CEPDPG [JOIDES] Central and Eastern Pacific

Detailed Planning Group

CFP Compagnie Français du Pétrole

CHECKLIST [science] Data base program used to enter paleontological data

CHEMDB [science] ODP data base program with entry applications for carbonate, interstitial water, gas chromatography, and rock-eval data CHN [science] carbon-hydrogen-nitrogen analyzer CMD [drilling] cable measuring device

CNRS Centre Nationale de Recherche Scientifique

(France)

CNS [science] carbon-nitrogen-sulfur analyzer

CNT-G [logging] neutron porosity ( $\mathrm{Am} / \mathrm{Be}$ source)

logging tool (Schlumberger version $\mathrm{G}$ )

COGLA Canadian Oil and Gas Lands

Administration

CORELOG [science] ODP database program

collecting core inventory data

COSOD [science] Conference on Scientific Ocean

Drilling

CPA [ship] closest point of approach, in nmi

CRC [science] concurrent range zone

(biostratigraphy)

CRM [science] chemical remanent magnetization

CSG [ODP] Computer Services Group

CT [drilling] coring technician

D5BC [ship] radio call sign of SEDCOIBP 471

DBMI [drilling] drill-bit motion indicator 
DC [drilling] drill collar, direct current

DCS [drilling] diamond coring system

DES [drilling] dual-elevator stool on the rig floor

(the top of the DES is the point from which drill-

pipe measurements are made)

DFD [science] data file documents

DIL [logging] dual induction log (resistivity)

DLL [logging] dual laterolog (resistivity)

DML [logging] downhole measurements laboratory aboard JOIDES Resolution (aka DHML and DHL)

DMP [JOIDES] Downhole Measurements Panel

DP [ship] dynamic positioning; [drilling] drill pipe

DPG [JOIDES] Detailed Planning Group

DPM [drilling] drill-pipe measurement

DPS [ship] dynamic positioning system

DR [ship] dead reckoning

DRM [science] depositional remanent magnetization

DS [drilling] drilling superintendent

DSDP Deep Sea Drilling Project

DW [drilling] draw works

ECOD European Science Foundation (ESF)

Consortium for the Ocean Drilling Program

ECR [ODP] East Coast Repository at LDGO; [ship] ship's engine control room

EDO [science] EDO-Western, manufacturer of reentry sonar system and seismic recorders EMD [ship] electromotive diesel (engines and electric motors)

EMR Department of Energy, Mines, and Resources (Canada)

ERB Editorial Review Board

ESF European Science Foundation (in terms of ODP, "the European Science Foundation

Consortium for the Ocean Drilling Program":

Belgium, Denmark, Finland, Greece, Iceland, Italy, the Netherlands, Norway, Spain, Sweden,

Switzerland, and Turkey)

ET electronics technician

ETA estimated time of arrival

ETD estimated time of departure

ETH Eidgenössiches Technische Hochschule (Switzerland)

EX [science] extinction

EXCOM [JOIDES] Executive Committee

FA or FAD [science] first-appearance datum

(biostratigraphy)

FAMOUS [science] Franco-American Mid-Ocean

Undersea Study

FCO [science] first common occurrence

(biostratigraphy)

FFF [drilling] free-fall funnel (aka minicone)
FID [science] flame ionization detector (gas chromatography)

FMS [logging] formation microscanner logging tool

FO [science] first occurrence (biostratigraphy)

FPAPWG [JOIDES] Fluid Processes in

Accretionary Prisms Working Group

FRG Federal Republic of Germany (West

Germany)

FUBAR fouled up beyond all recognition

FY fiscal year

FYF for your files

FYI for your information

GC [science] gas chromatograph; GLOMAR

Challenger

GCR [ODP] Gulf Coast Repository at TAMU

GEOMAR F.R.G. Research Center for Marine

Geosciences

GMT Greenwich Mean Time (replaced by UTC)

GPIT [logging] three-axis magnetometer-

inclinometer logging tool (also G-PIT)

GPS [ship] global positioning system (satellite

navigation)

GR [logging] natural gamma-ray logging tool

GRAPE [science] gamma-ray attenuation porosity

evaluator (bulk density analyzer)

GSA Geological Society of America

GST [logging] induced gamma-ray spectroscopy

logging tool

HARVI [science] ODP hard-rock visual description

data base

HBR [drilling] hydraulic bit release

$\mathrm{HC}$ [drilling] heave compensator

HEE [drilling] high energy engineering (pipe

severing system)

HF [science] heat flow; high frequency;

hydrofluoric acid

HIG Hawaii Institute of Geophysics (University of

Hawaii at Manoa)

HP Hewlett-Packard

HPC [drilling] hydraulic piston corer (current version: advanced hydraulic piston corer, APC)

HRGB [drilling] hard-rock guidebase

HRTHIN [science] ODP hard-rock thin-section

data base

HWDJ [drilling] heavy-wall drilling joint

IADC International Association of Drilling

Contractors

IAPSO International Association of Physical

Sciences Organizations (provides bottled standard

seawater for analytical calibrations) 
IBM International Business Machines (used generically as a term to describe personal computers)

IDSS [drilling] instrumented drill-string sub

IDW [drilling] integrated depth wheel

IFP Institut Français du Pétrole

IFREMER Institut Français de Recherche pour

l'Exploitation de la Mer

IGC International Geological Congress

IHP [JOIDES] Information Handling Panel

ILD [logging] deep induction resistivity logging tool

ILM [logging] medium induction resistivity logging tool

IOP [JOIDES] Indian Ocean Panel

IPG Institut de Physique du Globe

IPOD International Phase of Ocean Drilling

IR [drilling] iron roughneck

IRM [science] isothermal remanent magnetization

IW [curatorial] interstitial water (sample

designation)

JOI Joint Oceanographic Institutions, Inc.

JOIDES Joint Oceanographic Institutions for Deep

Earth Sampling

JPL Jet Propulsion Laboratory

JD Julian Day

KFZ [science] Kane Fracture Zone

K-WG [JOIDES] Kerguelen Working Group

LA or LAD [science] last-appearance datum

(biostratigraphy)

LANL Los Alamos National Laboratory

LAS [science] laboratory automation system

LD [drilling] lay down

LDGO Lamont-Doherty Geological Observatory

LDT [logging] lithodensity logging tool

LEGS [ODP] database program

LITHP [JOIDES] Lithosphere Panel

LLD [logging] deep laterolog

LLS [logging] shallow laterolog

LO laboratory officer; [biostratigraphy] last

occurrence (biostratigraphy)

LSS [logging] long-spaced sonic logging tool

Mac [computers] Apple Macintosh computer

MAR [science] Mid-Atlantic Ridge

MARK [science] Mid-Atlantic Ridge Kane Fracture

Zone

MATMAN [logistics] ODP (materials

management) inventory database system

MBR [drilling] mechanical bit release

mbrf [drilling] meters below rig floor mbsf [science] meters below seafloor mbsl [science] meters below sea level MCS [science] multichannel seismic; [logging] multichannel sonic (12-channel) logging tool

M-D [drilling] Martin-Decker rig-weight indicator

ML [logging] microlog

MOM [ship] SEDCO's Marine Operations Manual MORB [science] mid-ocean-ridge basalt

MOU Memorandum of Understanding

MRT [science] maximum-reading thermometer

MSDS [logistics] Marine Science and Development

Shop (SIO)

MSL mean sea level

MSP [curatorial] master sampling plan

MST [science] multi-sensor track

MT marine technician; eMpTy

MU [drilling] make up

NADW [science] North Atlantic Deep Water

NAMOC [science] Northwest Atlantic Mid-Ocean

Canyon

NCB [drilling] Navidrill core barrel coring system

NERC Natural Environment Research Council

(U.K.)

NFG not functioning good; useless

NGA [science] natural gas analyzer

NGDC National Geophysical Data Center

NGT [logging] natural-gamma spectrometry

logging tool

NRM [science] natural remanent magnetization

NSB National Science Board (U.S.)

NSF National Science Foundation (U.S.)

NSOW [science] Norwegian Sea Overflow Water

OBS [science] ocean-bottom seismometer

OCB [drilling] outer core barrel

OCR optical character reader

OCS [science] Outer Continental Shelf

ODP Ocean Drilling Program

OG [curatorial] organic geochemistry (sample

designation)

OHP [JOIDES] Ocean History Panel

OMD [JOIDES] Ocean Margin Drilling Program

ORI [science] Ocean Research Institute, University

of Tokyo (Japan)

OS [drilling] operations superintendent

OSE [logging] oblique seismic experiment

OSHA Occupational Safety and Health

Administration (not just a small town in upstate

Wisconsin)

OSU Oregon State University (rarely, Ohio State

University; hardly ever, Oklahoma State University)

OTC Offshore Technology Conference 
PC [computers] personal computer (as in IBM PC); photocopy

PCB [drilling] pressure core barrel

PCOM [JOIDES] Planning Committee

PDB [science] Pee Dee belemnite, a standard for

oxygen- and carbon-isotope analyses

PDC [drilling] polycrystalline diamond compact

drill bit

PDCM [drilling] positive displacement coring

motor

PDM [drilling] positive displacement (drilling)

motor

PDR [science] precision depth recorder

pDRM [science] post-depositional remanent

magnetization

PEC [JOIDES] Performance Evaluation Committee

PERC Preliminary Editorial Review Checklist

PI principal investigator

PMS [ship] power-management system; preventivemaintenance system

POOH [drilling] pull out of hole (in reality, lift the bit up off the bottom of the hole, not necessarily clear the mud line)

PP [science] physical properties (aka physprops)

PPSP [JOIDES] Pollution Prevention and Safety

Panel (aka Safety Panel)

PRO [computers] Digital Equipment Corporation

PRO-350 or PRO- 380 computer

$\mathrm{P} / \mathrm{U}$ [drilling] pick up

$\boldsymbol{P}$-wave [science] primary seismic or

compressional wave

PWS [science] pore-water sampler

RBI [drilling] Rock Bit Int'l. (drill bit

manufacturer)

RCB [drilling] rotary core barrel

$\mathbf{R} / \mathbf{D}$ [drilling] rig down

RDX [drilling] explosive used in pipe-severing system

$\mathrm{R} / \mathrm{E}$ [drilling] reentry

reefer [ship] shipboard refrigerated core/sample

storage

REPOSAM [curatorial] repository sampling

computer program

RFP request for proposals

RFQ request for quotes

RFT [drilling] retrievable formation tester (water sampler)

RIH [drilling] run in hole (actually, lower drill string below the rig floor, not necessarily below the mud line)

RKB [drilling] rotary kelly bushing
RMS [science] root mean square (e.g., in seismic velocities)

ROP [drilling] rate of penetration in drilling or coring

RSMAS Rosenstiel School of Marine and

Atmospheric Science (University of Miami)

RS-WG [JOIDES] Red Sea Working Group

RT [drilling] round trip of the drill string

(=POOH+bit change+RIH)

RU [drilling] rig up

RZ [science] range zone (biostratigraphy)

SAM [curatorial] shipboard sampling computer

program

S/B [drilling] set back

SBA [curatorial] shipboard analysis (sample

designation)

SBR [drilling] severing bit release

SCM [drilling] sonic core monitor

SCR [electronics] silicon control rectifier

SCS [science] single-channel seismic

SDP [curatorial] Sample Distribution Policy

SDT [logging] sonic digital logging tool

$S E D C O / B P 471$ [ship] registered name of drilling

vessel used by ODP; aka JOIDES Resolution

SEM [science] scanning electron microscope

SEM/EDA [science] scanning electron microscope energy dispersive analysis

SEPM Society of Economic Paleontologists and

Mineralogists

SES [drilling] sidewall-entry sub, inserted in the

drill string when logging

SF [logistics] surface freight; satellite fix

SFL [logging] spherically focused resistivity

logging tool

SGPP [JOIDES] Sedimentary and Geochemical

Processes Panel

SI [science] interational system of units

SID [curatorial] sample-investigations computer database

SIO Scripps Institution of Oceanography

SLIDES [computers] shipboard program for smear-

slide description data

SMOOTH [computers] shipboard navigation

plotting program

SMOW [science] standard mean ocean water

SMP [JOIDES] Shipboard Measurements Panel

SN [ship] satellite navigation

SOHP [JOIDES] Sediments and Ocean History

Panel

SOP [JOIDES] Southern Oceans Panel

SP [science] shot point (on seismic survey lines) 
SRDPG [JOIDES] Sedimented Ridges Detailed Planning Group

SSP [JOIDES] Site Survey Panel

TAG [science] Trans-Atlantic Geotraverse

TAMRF Texas A\&M Research Foundation

TAMU Texas A\&M University

TBG [drilling] tubing

TCD [science] thermal conductivity detector

TCPA [ship] time of closest point of approach

TD [drilling] total depth of a hole

T/D [drilling] top drive

TDK [drilling] tension device (Schlumberger)

TECP [JOIDES] Tectonics Panel

TEDCOM [JOIDES] Technology and Engineering

Development Committee

TGB [drilling] temporary guidebase

TIH [drilling] trip into hole (lower drill string

below the rig floor, not necessarily below the mud

line, by adding drill pipe)

TLT [logging] temperature logging tool

TOB thrown overboard (float test failure)

TOC [science] total organic carbon

TOH [drilling] trip out of hole (aka POOH)

TR [ship] transit satellite

TRM [science] thermoremanent magnetization

TS(B) [curatorial] thin section (billet) sample designation

TSV [ship] total support vessel

TWT [science] two-way traveltime

UBG used but good

UCSD University of California at San Diego

UDI Underseas Drilling, Inc.

UGH [drilling] upper guide horn

UMBRELLA [science] ODP data base containing descriptions of all ODP data bases

URI University of Rhode Island

USCG United States Coast Guard

USGS United States Geological Survey

USSAC United States Science Advisory

Committee

USSSP United States Science Support Program

UT University of Texas at Austin

UTC Universal Time Coordinated (used in place of

GMT or Z)

UTIG University of Texas Institute for Geophysics

U/W, UW [ship] under way (adverb); underway

(adjective)

UWG [ship] underway geophysics laboratory

VCD [science] visual core description form

VIT [drilling] vibration-isolated television (as in

VIT frame)
VLHPC [drilling] variable length hydraulic piston corer

VPC [drilling] vibra-percussive corer

VRM [science] viscous remanent magnetization

VSP [logging] vertical seismic profile downhole measurement

WCR [ODP] West Coast Repository at SIO

WD water depth

WHOI Woods Hole Oceanographic Institution

W/L, WL [drilling] wire line

WLR [drilling] wire-line reentry

WOB [drilling] weight on bit; waiting on berg (suspended operations in high latitudes)

WOC [drilling] waiting on cement (suspended operations)

WORM [computer] "write once, read many" laser disk drive

WOW [drilling] waiting on weather (suspended operations)

WPAC [JOIDES] Western Pacific Panel

WPDPG [JOIDES] Western Pacific Detailed

Planning Group

WST [logging] well seismic tool (used in VSP

experiments)

WSTP [science] downhole water sampler/

temperature/pressure probe

XBT [science] expendable bathythermograph

XCB [drilling] extended core barrel

XO [drilling] crossover (connecting pipe)

XRD [science] X-ray diffraction; [curatorial] sample designation (or XD)

XRF [science] X-ray fluorescence; [curatorial] sample designation (or XF)

Z "Zulu" or GMT, replaced by UTC 


\section{BIBLIOGRAPHY OF THE OCEAN DRILLING PROGRAM}

The following technical notes are available from the Manager of Science Operations, Ocean Drilling Program, 1000 Discovery Drive, College Station, Texas 77845-9547 USA.

Technical Note 1: Preliminary Time Estimates for Coring Operations (revised edition, December 1986)

Technical Note 3: $\quad$ Shipboard Scientists' Handbook (revised edition, March 1990)

Technical Note 5: Water Chemistry Procedures aboard JOIDES Resolution (September 1986)

Technical Note 6: Organic Geochemistry aboard JOIDES Resolution - An Assay (September 1986)

- Technical Note 7: Shipboard Organic Geochemistry on JOIDES Resolution (September 1986)

Technical Note 8: $\quad$ Shipboard Sedimentologists' Handbook (January 1988)

Technical Note 9: $\quad$ Deep Sea Drilling Project Data File Documents (January 1988)

Technical Note 10: A Guide to ODP Tools for Downhole Measurements (June 1988)

Technical Note 11: Introduction to the Ocean Drilling Program (February 1989)

Technical Note 12: Handbook for Shipboard Paleontologists (March 1989)

Also available from ODP Science Operations are the following pamphlets:

A User's Guide to the JOIDES Resolution Computer System (December 1988)

Instructions for Contributors to the Proceedings of the Ocean Drilling Program

Ocean Drilling Program Sample Distribution Policy

Ocean Drilling Program Guidelines for Pollution Prevention and Safety (JOIDES Journal Volume XII, Special Issue No. 5, March 1986)

Depth Control, Weight Indications, and Logging Cable Adaption for Third Party Tools aboard the JOIDES Resolution (June 1986) 